\title{
NARRATIVES OF STARTING, USING, AND STOPPING METHAMPHETAMINE USE
}

\author{
BY \\ JOHN DANCE
}

A thesis submitted to the Victoria University of Wellington in fulfilment of the requirements for the degree of Doctor of Philosophy

Victoria University of Wellington

(2018) 


\section{Table of Contents}

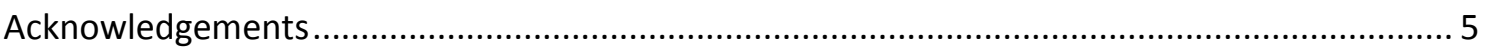

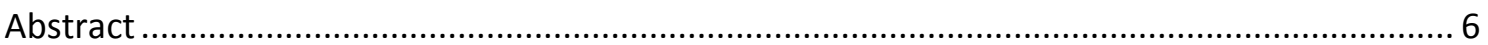

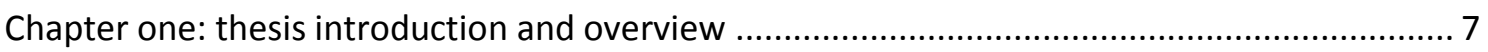

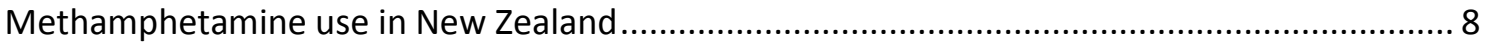

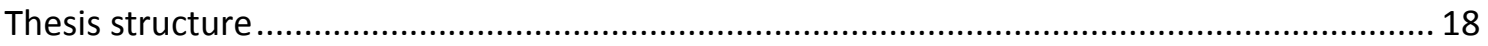

Chapter two: methamphetamine, drug panics and authoritative understandings of drug users

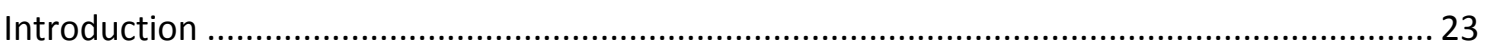

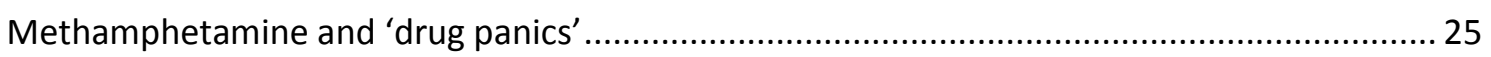

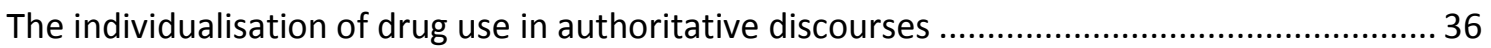

Theorising risk and decisions about starting, using and stopping drug use .............................. 55

Life course perspectives of desistance from drug use ........................................................... 73

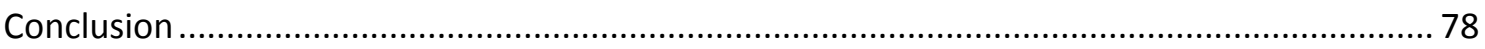

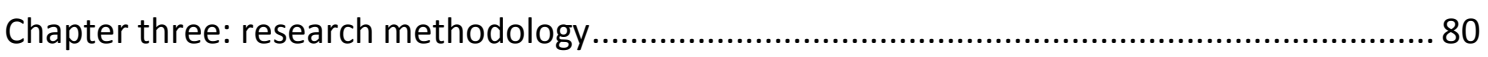

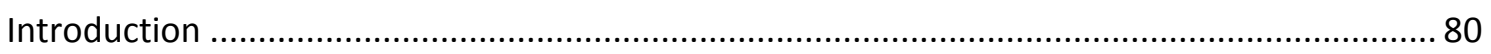

Social constructionism, interpretivism and qualitative approaches to researching drug-use ... 81

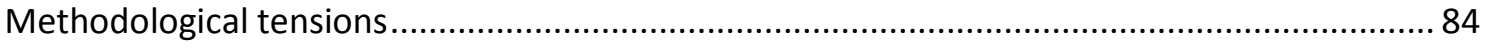

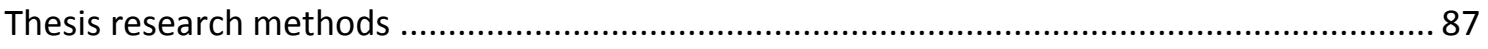

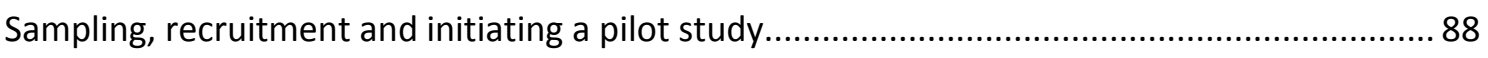

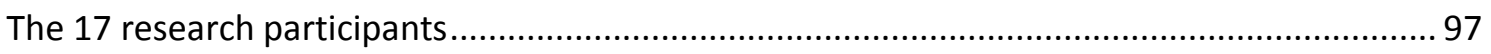

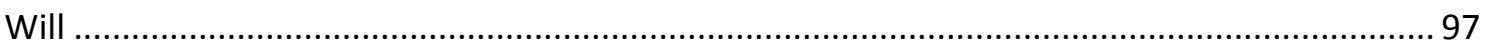

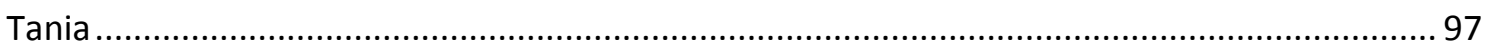

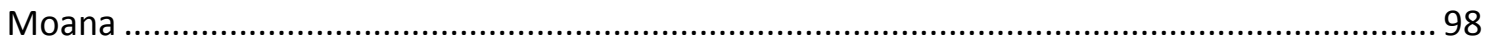

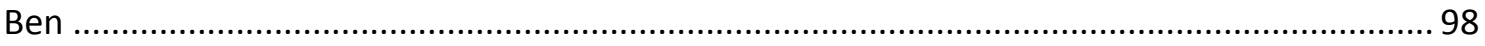

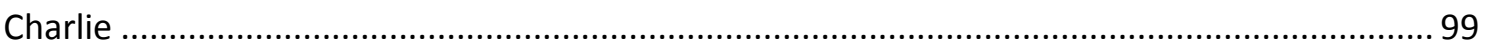

Steve 
Angus

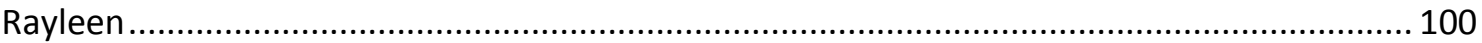

Amy

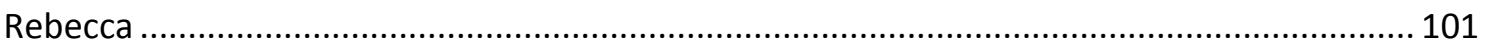

Sean

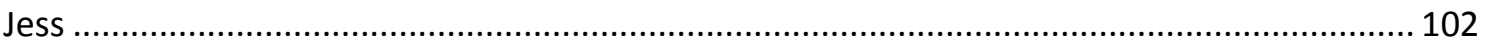

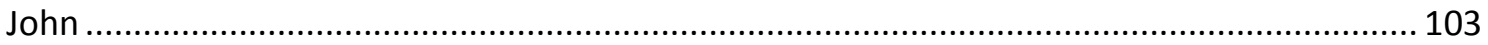

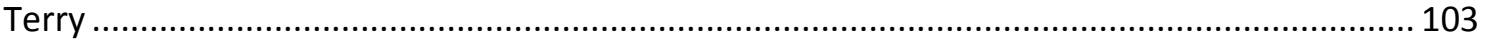

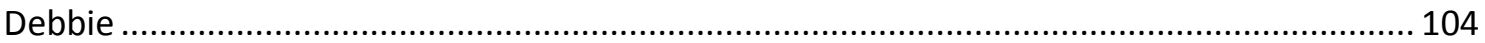

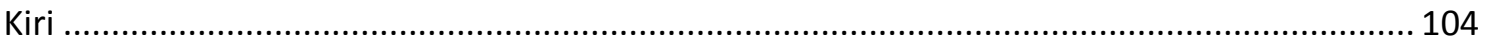

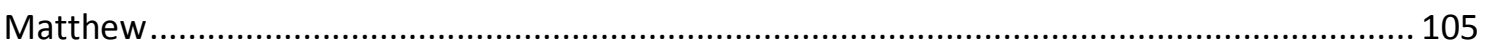

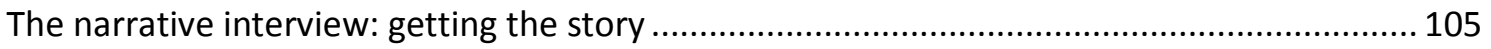

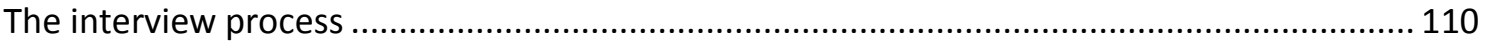

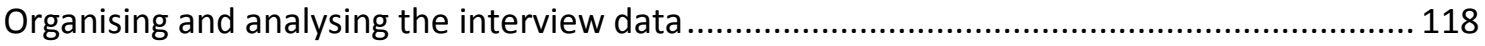

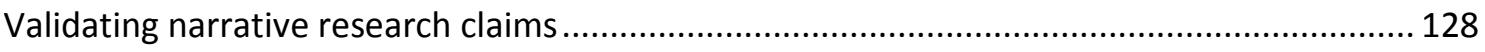

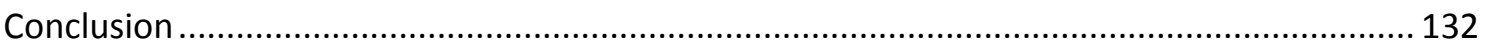

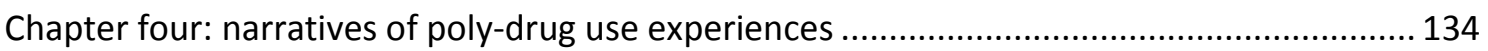

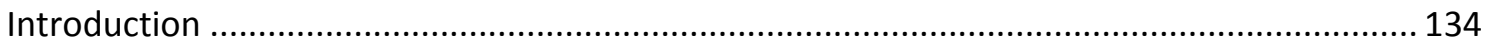

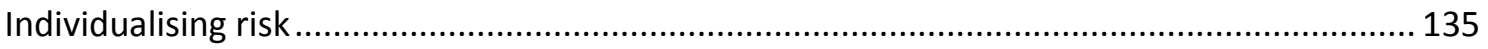

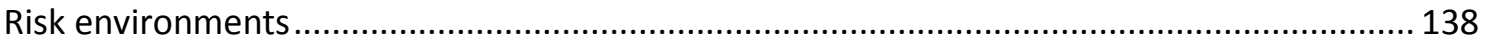

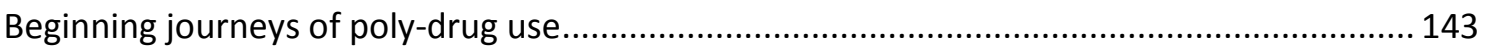

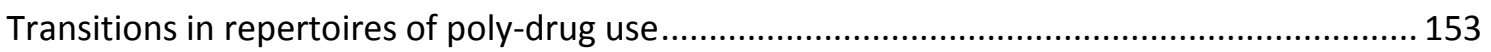

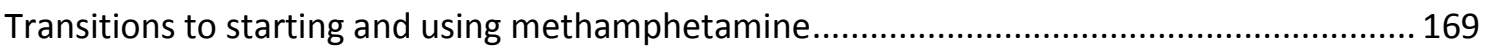

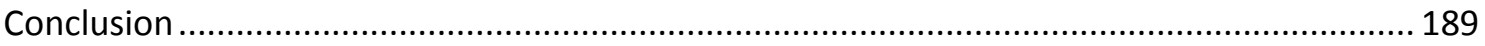

Chapter five: narratives of social relationships and drug use ................................................. 192

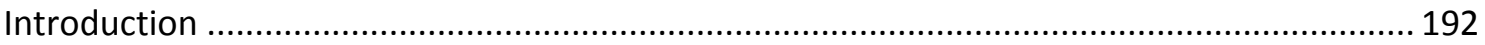

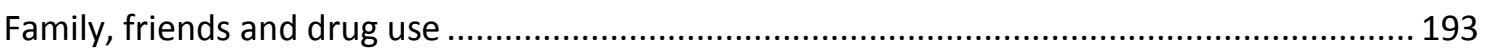




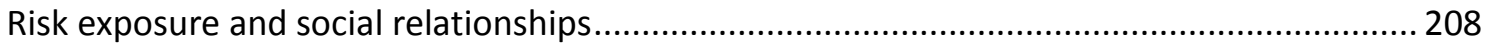

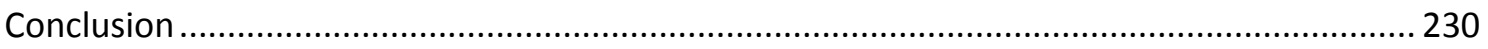

Chapter six: narratives of desistance from drug use............................................................. 233

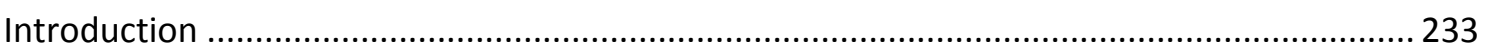

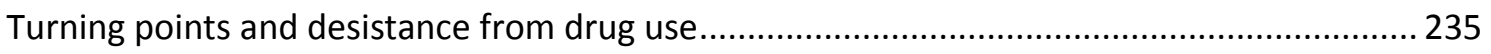

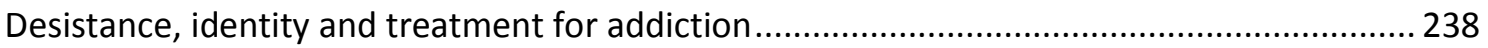

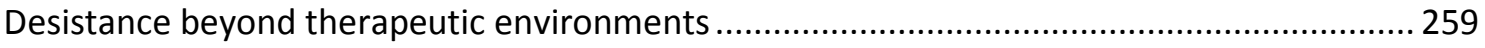

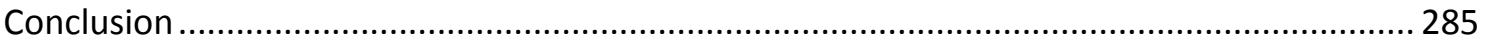

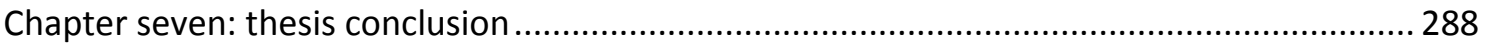

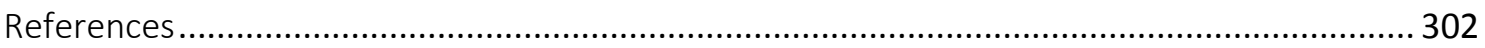

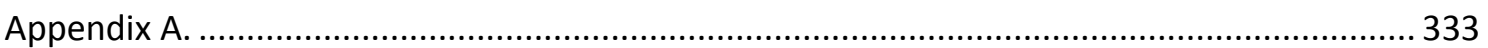

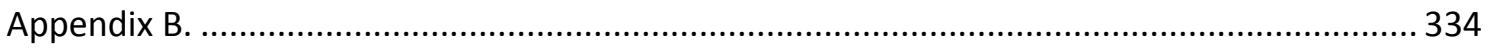

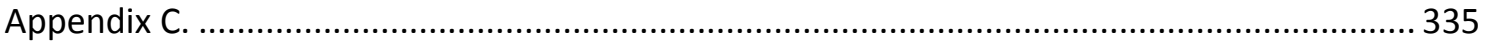

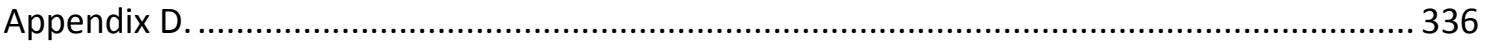

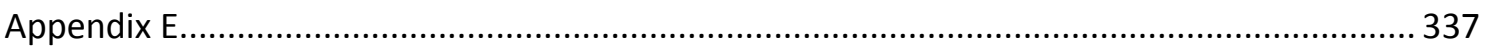




\section{Acknowledgements}

A huge thank you my AMAZING Mancunian supervisor, Fiona Hutton, and all the good people on the $11^{\text {th }}$ floor who have looked after me in preparation for submitting this thesis. And of course I must thank my amazing wife and my amazing family, who made this whole journey possible. The incredibly resilient people who shared their stories with me - I wish they were here to thank as well. But as anyone who knows me well will tell you, the real driving force deep within me requires a very simple acknowledgement:

To my beautiful daughter, Sophie. Thank you for giving me something that is so special that it is beyond description. I miss you so much.

Aloha oe' 


\begin{abstract}
Methamphetamine use has come to be seen as a significant policy issue in New Zealand and elsewhere. Panic about methamphetamine's effects, the increasing prevalence of its use and its alleged potential to cause more harm than other drugs has been fundamental in elevating public concern and initiating a raft of law and order responses. Using the familiar tropes of addiction and drug-induced criminality, authoritative discourses conveying the nature of the 'meth problem' have obfuscated the social, cultural and structural forces which intersect decisions about drug use. Instead, explanations of meth-use anchored to behavioural theories about risk have emphasised drug-use is as being the product of individualised cognitive decision making. In taking a narrative approach to analyse 17 drug-users' stories about starting, using and stopping methamphetamine use, this thesis sets out to theoretically engage with the experiential and contextual nuances of drug-taking decisions which continue to be excluded from authoritative accounts of problematic use. In doing so this thesis reveals how decisions about starting and using methamphetamine had occurred within established trajectories of problematic poly-drug taking behaviour. Collectively, the experiences of starting, using and stopping methamphetamine use storied by this sample of drug users help challenge pejorative constructions of problematic users of drugs as being wilfully self-destructive by highlighting that "risk actions are rarely the product of any one individuals' rational decisions"(Rhodes: 1997:216).
\end{abstract}




\section{Chapter one: thesis introduction and overview}

In New Zealand, as in many other parts of the world, the use of methamphetamine continues to attract significant media attention, where sensationalised coverage of crimes involving methamphetamine users has emphasised the drug's association with violence, psychosis and other pathological behaviours (Green and Moore: 2013). Unsurprisingly, lurid depictions of individuals subsumed by methamphetamine's unassailable effects in accounts of New Zealand's meth 'epidemic' have resulted in the enduring vilification of those who use the drug. The visibility of methamphetamine afforded by consistent media reporting has also evoked panicked reactions from community leaders, who have called upon policy makers to "fight" the "normalisation" of its use (The Nelson Mail. September $82017^{1}$ ). This has resulted in a raft of government enquiries, health summits, methamphetamine action plans ${ }^{2}$ and punitive law and order responses, targeting those involved in the manufacture, supply or use of methamphetamine.

However, despite the extensive corpus of government agency sponsored scholarship produced over the past decade, very little research attention has been given to the emic perspective of methamphetamine use in New Zealand. Instead, measurements of price, purity and availability have informed policy instruments which theorise drug use and its attendant economic harms as the outcome of 'choices' made by individuals, who participate in a marketplace of drug options. Those who use methamphetamine and other inherently dangerous drugs are thus posited as being rational consumers, who engage in agential risk assessments in order to determine the perceived costs and benefits associated with using particular drugs. Consequently, pejorative constructions

\footnotetext{
${ }^{1}$ https://www.stuff.co.nz/nelson-mail/news/96500088/community-battles-huge-meth-problem-in-nelson

${ }^{2}$ Introduced in 2009, the government's Methamphetamine Action Plan aims to provide "a cross agency plan of action to tackle the harms caused by methamphetamine", with 6 monthly reports completed to 2015 measuring outcomes against baseline supply and demand data. See https://www.dpmc.govt.nz/our-programmes/specialprogrammes/tackling-methamphetamine
} 
of the 'meth problem' have typically presented those affected by problematic meth use as being wilfully self-destructive.

This thesis argues that, by explaining drug use as the outcome of 'poor choices', authoritative understandings of the motivations which underpin the use of methamphetamine and other drugs have obfuscated the relational dynamics of drugtaking decisions. In order to redress the limitations of such understandings, this thesis sets out to capture and theoretically engage with the lived experience of problematic drug use as it was described by 17 current and previous methamphetamine users. By examining the socially situated processes which influenced their decisions about using methamphetamine, it is argued that drug use, like other behaviours deemed as inherently 'risky', is rarely the product of individualised risk assessment (Rhodes:1997). As the stories analysed throughout this thesis demonstrate, decisions about starting, using and stopping drug use are more usefully theorised as resulting from the inter-play between individual choices, and a constellation of social, institutional and other structural forces beyond the control of the individual (Farrell et al: 2011).

\section{Methamphetamine use in New Zealand}

Why methamphetamine users have been subject to public vilification is perhaps indicative of drug use in New Zealand having been largely confined throughout the $20^{\text {th }}$ century to a preference for cannabis, alcohol and various opiates (Newbold: 2004) ${ }^{3}$. The arrival of methamphetamine, referred to locally as ' $P$ ' or 'pure', in the late 1990s thus signalled a landmark change in New Zealand drug culture. A drug previously associated with rural drug economies in American states far away from New Zealand's boarders had now become popular among local drug users. Unlike cocaine, heroin or ecstasy, which faced the problems of supply inherent in cross border trafficking, methamphetamine could also be manufactured locally with relative ease, using

\footnotetext{
${ }^{3}$ Newbold (2004:54) notes in his historical review of drug control in New Zealand that these long standing drug preferences resulted in one of New Zealand's first drug control laws, the 1868 Distillation Act, "which forbade the common practice of potentiating beer with substances like opium, cannabis and tobacco".
} 
commonly available precursor chemicals (Nice: 2007). Meth's status as a 'homemade' product contributed to its appealing to local drug users, who had long since exemplified New Zealand's spirit of self-sufficiency in their efforts to perfect the art of growing cannabis, or produce 'home bake' heroin from prescription codeine (Reynolds, Lenton, Charlton and Caporn: 1997) ${ }^{4}$.

Methamphetamine also differed from other stimulant drugs in its route of administration, as users smoked ' $P$ ' in crystalline form. Unlike oral or intranasal administration of other stimulants, the inhalation of methamphetamine vapours resulted in higher concentrations of the neurotransmitter, dopamine, to be released, causing an intense 'rush', characterised by feelings of euphoria, energy and sexual arousal (McPherson et al: 2009, Meredith and Jaffe et al: 2005). Methamphetamine's euphoric effects lasted from six to twenty four hours, with users repeating the process of inhalation to re-experience the initial rush, often increasing the dosage as their tolerance to methamphetamine progressed. This pattern of repeating and increasing meth usage distinguished methamphetamine as being a highly addictive stimulant. ${ }^{5}$

In his evaluation of New Zealand drug control policy, Nice (2007:3) argues that geographical isolation and a small population (inferring market size), combined with the lack of illicit drug monitoring systems facilitated the rapid development of a local methamphetamine market long before government agencies were aware of its presence ${ }^{6}$. Aggressive meth production and supply, combined with methamphetamine's

\footnotetext{
${ }^{4}$ New Zealand is acknowledged as the first country in which home-bake heroin was manufactured. Home-bake production addressed the shortage of heroin supply resulting from the arrest of the Mr Asia syndicate. The first homebake laboratory was detected in Auckland in 1983. By 1986, ninety laboratories had been detected nationally. (Reynolds et al.1997)

${ }^{5}$ McPherson et al. (2009) note that smoking methamphetamine produces an immediate euphoria similar to that experienced with crack cocaine, but the effects may last much longer, as the half-life of amphetamines ranges from 12 to 36 hours, compared to cocaine's half-life of 90 minutes. (see also Albertson et al. 1999, Meredith et al. 2005, Kosten et al. 2012)

6 As Nice concludes, "the speed of methamphetamine's arrival was unimaginable": the first clandestine methamphetamine laboratory was detected by police in 1996, who did not fully understand the significance of their discovery. By 2000 nine labs had been detected nationally. By 2003 the number of detected labs had risen to $202-$ be a bit careful here - is this a real rise or the result of changing police priorities due to media coverage/government pressures? Just note this issue with official statistics here and fine to do this in a footnote. In 2006 ninety five kilograms
} 
addictive characteristics and cultural appeal, created New Zealand's first significant Class A drug market since the cessation of heroin importation following the apprehension of 'Mr Asia'7. The cultural illusion of New Zealand's immunity to the kind of social ills typically associated with sprawling cities in countries with much larger populations had also been compromised by the entrenchment of demand for methamphetamine. Methamphetamine users were thus emblematic of this unwanted cultural shift. Their association with "spikes in criminal activity (One News: February 9 2017,)"8, and "meth-fuelled violence" (Radio NZ: 25 November 2016) 9 signalled to 'ordinary' citizens that the presence of methamphetamine users threatened the 'New Zealand way of life'.

Although references to increasing levels of meth use are commonplace, since the peak of its use at a population level in 2001 (Wilkins et al. 2017), the prevalence of methamphetamine use has remained stable. Although its methodology does not specifically aggregate methamphetamine use as a response category ${ }^{10}$, the Ministry of Health (2016) household survey of amphetamine use (2015/2016) for example, provides a generalised indicator of current use. It's most recent findings estimate that, despite claims of epidemic use, only $1.1 \%$ of the population aged 16 to 64 - or approximately 34,000 New Zealanders - reported using amphetamines in the past year (Ministry of Health 2016). This measurement has remained largely unchanged when compared to household survey data collated by the Ministry of Health in 2011/2012 (ibid). The New Zealand Drug Foundation ${ }^{11}$ also reports that the overall numbers of methamphetamine

\footnotetext{
of imported methamphetamine hydrochloride (commonly referred to as 'ice' ${ }^{6}$ ) and a large volume of precursor chemicals were intercepted by Customs, signalling the involvement of transnational crime syndicates. (National Drug Intelligence Bureau, in Nice 2007

${ }^{7} \mathrm{Mr}$ Asia, better known as Terry Clark, headed NZ's largest drug importation syndicate along with Brian Fulcher up until their incarceration (and Clark's death) in the early 1980s (Newbold:2004).

${ }^{8}$ See https://www.tvnz.co.nz/one-news/new-zealand/new-figures-go-against-government-claims-suggest-nz-losingwar-p

9 See http://www.radionz.co.nz/news/national/318944/meth-fuelled-violence-strains-refuge-services-'all-bets-areoff'

10 The NZ Health Survey aggregates all amphetamine types in one response category: "Amphetamines, for example, P (pure methamphetamine), ice (crystal methamphetamine), speed” (MOH: 2016:1)

${ }^{11}$ https://www.drugfoundation.org.nz/policy-and-advocacy/meth-in-nz/
} 
users has decreased in New Zealand, noting that only $0.9 \%$ of the population $(26,4000$ people) reported using methamphetamine once or more from 2014 to 2015. This marked a decrease in national surveys of methamphetamine use recorded in 2009, which reported that $2.2 \%$ of the population had used methamphetamine on one or more occasions. It is therefore more likely that, although overall usage of methamphetamine is low, misuse of the drug has become a serious concern, particularly in some communities subject to experiences of social disadvantage, where harms associated with its use are often more visible.

Despite evidence that methamphetamine use has remained stable, the proliferation of measures used to monitor local drug behaviour has had the unintended consequence of elevating public anxieties about the nature of those who engage in problematic drug use. Through saturated media reporting on all things drug related, authoritative assessments of methamphetamine use infiltrate public understandings of drugs, those assumed as most likely to use them, and the risk they present to others. The most often cited measurements of methamphetamine use in New Zealand are provided by the Illicit Drug Monitoring System (IDMS) and New Zealand Arrestee Drug Monitoring (NZ ADUM) surveys conducted by Wilkins et al. (2006 - 2015). Although these are limited in determining prevalence, they highlight that methamphetamine is readily available and stable in price, despite government efforts to control supply and demand (Wilkins et al.: 2017). The most recent summary of the IDMS surveys for example indicates that, as of 2015 , accessing methamphetamine was reported by frequent drug users as easy to very easy, its strength reported as remaining high, and the price per gram decreasing from a high of $\$ 815$ in 2011, to a lower price of $\$ 668$ in 2015 (Wilkins et al.:2017:86).

NZ ADUM survey instruments add to snapshots of illicit drug use by making the correlation between criminality, addiction and meth use implicit: referencing the most recent NZ ADUM survey data, Wilkins et al. (2017) assert that "high levels of methamphetamine use have persisted among specific 'at risk' groups'”, notably among police arrestees (Wilkins et al. :2017:56). According to their measures, the number of 
police detainees who reported having used methamphetamine in the past 12 months increased from 28\% in 2012 to 36\% in 2015 (Wilkins et al., 2016, cited in Wilkins et al.:2017:56). The number of detainees who described feeling dependent on methamphetamine also increased, from 22\% in 2011 to 34\% in 2015 (Wilkins, et al., 2016, cited in Wilkins et al:2017:56). ${ }^{12}$

That meth is cheaper, stronger, easy to get and typically consumed by individuals subject to arrest forms the basis of a narrative imbued with drugs-war rhetoric, as evidenced in recent media announcements that "new figures go against government claims, suggest NZ losing war on P" (One News February 9 2017). New research technologies are then deployed which contribute to an ongoing process of threat assessment - and threat magnification. For example, Lai, Wilkins, Thai and Mueller (2017) recently conducted the first New Zealand based analysis of wastewater to determine patterns of drug use within two Auckland catchment areas, covering a population of approximately 1.23 million residents. Their analysis revealed that, along with codeine, morphine and methadone, methamphetamine was a commonly used drug, with levels of use detected daily.

It is of course inarguable that the problematic use of methamphetamine and other drugs causes an array of significant individual and social harms in New Zealand and globally. The 2017 UN World Drug Report estimates that 29.5 million or $0.6 \%$ of the global adult population suffer from drug use disorders, related to experiencing drug dependence and needing to access treatment (UNODC May 2017). The magnitude of harms caused by problematic drug use is also estimated as resulting in the loss of 28 million years of healthy life worldwide, primarily through drug-related disabilities, and premature deaths (ibid). Additionally, the 2016 New Zealand Drug Harm Index Research Report (McFadden: 2016) estimates the annual social cost of methamphetamine use as equating to $\$ 8300$ per 'casual' user and to $\$ 116,600$ per 'dependent user'. The total

\footnotetext{
12 There are significant methodological limitations in applying NZ ADUM data, and these issues are explored more comprehensively in chapter two.
} 
social cost of all amphetamine-type stimulants, which includes personal and community harm and intervention costs ${ }^{13}$, is estimated as equating to a value of $\$ 364.2$ million dollars per annum.

To date however, government responses to the use of methamphetamine and other drugs have largely resulted in a confusing and often contradictory landscape of drugpolicy. During the six year period this thesis was completed (2012 to 2017) alone, a mix of government initiatives were deployed to address social and economic harms linked to a variety of increasingly visible drug-taking behaviours. In many respects these shifting policy responses provided the impetus for undertaking this research, given that the lived experience of drug use seldom featured in debates about the efficacy of their intentions, notably where methamphetamine use was concerned. Instead, most of these simply intended to extend the reach of traditional prohibitionist efforts and reformulate new ways of coercing drug users to make the right choices.

For example, despite its own research correlating experiences of economic deprivation with welfare access (Ministry of Health 2010), in 2012 the National Government successfully implemented benefit sanctions for recipients who tested positive for drug use or who refused to be tested. In 2017 it pledged to increase these sanctions, by cutting benefits by half if recipients continued to engage in recreational drug use ${ }^{14}$. In response to the increasing visibility of problematic synthetic cannabis ${ }^{15}$ use, the National Government also introduced the Psychoactive Substances Act in 2013, lauded as an innovative response to the unregulated market of 'legal highs' ${ }^{16}$. Although the act

\footnotetext{
13 The cost of personal harms includes the impact of drug use on physical health, physiological wellbeing and personal wealth. Community harm includes the cost of crimes attributable to drug use, reductions in tax base, and harms to family, whanau and friends. Costs associated with interventions include attempts to address harmful drug use, including health, education and law enforcement (McFadden, 2016 p.11).

${ }^{14}$ See https://www.radionz.co.nz/news/national/338841/national-pledges-to-slash-benefits-for-drug-use

${ }^{15}$ Synthetic cannabis generally refers to a smokable plant material soaked in or sprayed with a synthetic cannabinoid.

${ }^{16}$ Piperazines, notably BZP - Benzylpiperazine and TMFPP - Trifluoromethylphenylpiperazine, are used in 'legal' or 'herbal' highs, which are often marketed as having similar qualities to MDMA - methylenedioxy- $N$ methamphetamine. Derivatives of Piperazines are also used in antidepressants and anti-psychotic medications (see Wilkins 2002, Johnstone et al. 2007).
} 
succeeded in reducing the number of outlets selling legal highs, as well as the number of products on offer, it criminalised those in possession of any unapproved substance. The removal of legally available synthetic cannabis also resulted in vulnerable populations reverting to inhaling glue and solvents (New Zealand Drug Foundation: 2014). More recently, in response to a natural cannabis drought, demand for homemade synthetic cannabis has increased, its use linked in media reports to the deaths of 20 drug users (The New Zealand Herald 15 September: 2017).

The absence of critical evaluation and reflection in the wake of politicised responses to drugs and drug users has excluded any forum to challenge policy makers' belief that they can have a negative impact on the availability, and in turn, the level of use, of illicit drugs, without ever producing suboptimal marketplace changes (Wilkins and Sweetsur:2009). However, as these policy shifts suggest, supply and demand interventions can reduce the availability of one substance while increasing the availability of another, or as is often the case, disproportionately problematize specific populations of drug users. Green (2008) makes this point when evaluating the reclassification of the previously legal high BZP ${ }^{17}$ in New Zealand, which resulted in drug users reporting being more likely to use ecstasy as a substitute drug. The New Zealand Drug Foundation (2014) also notes in reference to recent concerns about synthetic cannabis, that more benign forms of synthetic cannabis had been used extensively without causing significant harm throughout the 2000's. However, following an ESR (Institute of Environmental Science and Research) assessment that it was too chemically similar to natural cannabis it was prohibited using the analogue provisions in the Misuse of Drugs Act (ibid:4).

In keeping with other drug users, users of methamphetamine have also remained subject to relentlessly punitive law enforcement measures; the Ministry of Justice reports that, from June 2016 to June 2017 the number of convictions for dealing or trafficking in drugs has increased by $17 \%$, and for utensil related offences by $22 \%$, both

\footnotetext{
${ }^{17}$ Benzylpiperazine
} 
due to more convictions for meth-related offences (Ministry of Justice Trends in Conviction and Sentencing to June 2017). As of September 2017 investment in addressing methamphetamine addiction has been cited by the Government at totalling 82 million dollars, over half of which (42 million) will be spent on law enforcement (DAPANZ - Drug and Alcohol Practitioners' Association Aotearoa New Zealand Press Release 4 September 2017). This highlights the government's continued belief that it can "punish the problem away (ibid)", despite the National Drug Policy (2015 to 2020) document stating its intention "to be prepared to challenge traditional approaches and ways of thinking about" drug issues (Ministry of Health: 2015: iii).

Approaching drug use as a law and order problem has also ensured that harms resulting from licit drug use are excluded from drug-use debates, which typically equate all drug problems with illegal drug use. Yet government-sponsored assessments of drug related harms continue to highlight that legal drugs such as alcohol harm communities more extensively than methamphetamine or other illicit drugs. Wilkins et al.'s (2016:2014) summary of its arrestee monitoring surveys evidences this point: although $36 \%$ of detainees $(n=835)$ reported using methamphetamine in the past 12 months, they also reported consuming an average of 17 alcoholic drinks before their arrest (Wilkins et al: 2016:14). Additionally, detainees reported experiencing a range of drug-related harms, including damaging or stealing property, causing themselves or others physical harm, crashing their car, losing their job or overdosing as a result of their drug use. When asked to identify substances responsible for these problems, alcohol was identified as the most common contributing factor (78\%), with $34 \%$ identifying cannabis, $31 \%$ identifying methamphetamine and $11 \%$ identifying synthetic cannabis (ibid:2016:14). More broadly, estimates that $1.1 \%$ of the population aged 16 to 64 use amphetamine type stimulants can also be usefully contrast against estimates of hazardous drinking behaviour; comparatively, the most recent survey of alcohol use in New Zealand indicates that hazardous drinking rates have increased by $19 \%$, with approximately one in five, or 21\% of adults reporting a hazardous drinking pattern in 2015/16 (Ministry of Health: 2016: vii). 
Deemphasising the harm caused by licit drug use helps anchor public anxieties about drug problems to images of 'hard drugs', hardened criminals, and addicted users. Distinctions between legal and illegal drug use also help justifications for enhanced law enforcement, the outcome of which is often the disproportionate criminalisation of young people, a population more likely to engage in many forms of recreational drugtaking behaviour. This in turn diverts police attention away from policing organised criminal activities supporting the manufacturing, supply and widespread availability of illicit drugs (Weissennborn and Nutt 2011:214). Law and order responses initiated in response to public outcries about drug-related crime also discount the importance of needing to account for the lived experience of drug use, given that criminogenic drug users are rarely considered worthy of such humanistic assessments.

The origins of this research are thus embedded in my interest in authoritative understandings of drugs and how they inform debates about effectively governing those who use them. It is universally acknowledged that criminalising drug users has exacerbated the social, cultural and economic costs of harmful drug use (Buchanan and Young: 2000, Bourgeois: 2003). Criminalisation has succeeded in socially excluding vulnerable populations, undermined healthcare initiatives intended to reduce drugrelated harms, brought large numbers of young people into contact with the criminal justice system, and failed in its intention to eliminate black market demand for illicit drugs, notably methamphetamine (Morrison:2015). Given these realities, there is an ongoing need to represent in research the lives of those rendered invisible by the stigmatising effects of relentless law enforcement.

Scholarship examining the lived experience of using methamphetamine in New Zealand is also limited, with only three qualitative research efforts having examined methamphetamine use in a New Zealand context: these include Sheridan, Butler and Wheeler's (2009) evaluation of first time methamphetamine use; this provides valuable 
insights into users' experiences of meth initiation, but is limited in its focussing on patterns of use and perceived meth-related harms. Butler, Wheeler and Sheridan (2010) take a similar approach in another study when evaluating physical, psychological and other health related harms attributed to experiences of meth use. While this work also highlights important research themes, its focus is similarly confined to the impact of meth use on users' health and wellbeing. Hutton (2010) also provides a perspective of meth use in her exploration of recreational drug use within local nightclubs. However, although Hutton's work succeeds in identifying differing attitudes towards methamphetamine when compared to other 'club drugs', her work is primarily concerned with the normalisation of drug use in nightclub environments rather than the lived experience of meth use.

This research then, makes a unique contribution to existing findings on methamphetamine use in New Zealand. It shifts theoretical attention to the how's and whys of drug-taking decisions made by individuals who identified as using methamphetamine and other drugs. It addresses an important gap left in the wake of policy scholarship, which has done little in the way of accounting for the factors which influence, constrain and facilitate decisions about drug use. By providing an in-depth, account of the lived experience of starting, using and stopping methamphetamine use, the aims of this research are to explore how drug users negotiate socially situated risks associated with problematic drug using environments in conjunction with individualised risk assessment processes, to consider how self-identity is constructed and modified across experiential trajectories of drug use, and to provide an analysis which locates these processes and experiences within social, cultural and structural contexts constraining and facilitating problematic drug-taking behaviour (Mayock:2004). 


\section{Thesis structure}

This thesis consists of 7 chapters in total, starting with this introductory chapter. Chapter two reviews the literature which helps introduce the social and political drugslandscape foregrounding debates about drugs and how best to govern those who use them. This literature demonstrates how politically mediated 'drug-panic' discourses structure how we are permitted to think about the identities of those who use illicit drugs, and how these identities uphold particular ideologies about drug-problem causation. A focus on policy-based scholarship furthers this discussion by examining how authoritative understandings of drug use locate the root causes of problematic drugtaking behaviour in individual-level decision-making processes. Policy 'evidence' is acknowledged as fundamental to justifying draconian law and order policies which target 'dangerous' drug users, evidence which enables policy makers to hold individuals responsible for their actions and silence the role of structural forces in the lives of those experiencing the effects of problematic drug use. Consequently, given their absolute belief in the power of individual agency, policy discourses are identified as theorising problematic drug use and drug dependency as the outcome of individual failings and poor choices made by unfettered economic actors (Ritter:2003).

Having explored these issues, chapter two then introduces the key theoretical constructs used to foreground the analysis of participants' narratives throughout this thesis. It is argued that although drug-taking risks are often understood and negotiated at an individual, agential level, risk awareness and risk assessments invariably take place within social situations, structures and places, or, as Rhodes (2002) theorises, within risk environments (Rhodes:2002, Rhodes et al:2003, Fast, Small, Krusi, Wood and Kerr:2010, Mayock, Cronly and Clatts:2015). According to Rhodes (2002), it is within such environments that social, structural and physical environmental factors intersect in ways that constrain agency and make risk avoidance difficult, and where drug users are often less able to avoid transitioning into increasingly harmful drug using behaviour (Fast et al:2010:3). Examining life-course perspectives of offending, the process of desistance from drug use is also introduced here to conceptualise how exposure to environmental 
risks culminates in events which similarly influence transitions in drug-taking (Sampson and Laub: 2005). Life-course scholarship is identified as fundamental to theorising how environments alter the structural position of drug users, and intersect individual-level decisions about stopping drug use.

Chapter three sets out the qualitative methodology employed to theoretically engage with participants' narratives of starting, using and stopping methamphetamine use. This chapter highlights the methodological efficacy of taking a narrative approach to collate, interpret and thematically analyse their stories, and demonstrates how narrative research instruments revealed the meanings they ascribed to their drug-using behaviours, their relationships with others, and the ways in which they constructed and negotiate their drug using identities. When articulating this process the thematic groupings used in the proceeding analysis chapters are introduced, which are labelled as 'narratives of poly-drug use experiences', 'narratives of social relationships and drug use', and 'narratives of desistance from drug use'.

Chapter three then summarises an analysis of subthemes and inter-related experiences under the umbrella of these primary narrative groupings. It builds on the key theoretical assertions introduced in chapter two by revealing how participants' drug-taking decisions were subject to individualised understandings of drug use and risk accumulated through extensive poly-drug using histories, and the inter-play between the constraining and facilitating forces of socially situated risk environments. A reflexive account of the research experience is also provided throughout this chapter, in order to make myself visible in the research process, and distinguish where possible, my voice from the voice of the participants.

Chapter four begins by introducing the profiles of the 17 participants recruited and interviewed for this research initiative. Revisiting the imperatives of risk environment scholarship, this chapter then sets out the theoretical rationale which informs using a 
risk environment framework to analyse participants' risk assessment and decisionmaking processes in proceeding chapters. This analysis begins here with an exploration of poly-drug experiences, which reveals how participants' accumulated risk knowledge through the process of becoming 'drug experienced'. These experiences make visible the inter-play between individual-level decision making and socially situated understandings of risk. They help in explaining how these processes constrained or facilitated decisions which had pushed participants towards increasingly harmful drugtaking practices, demonstrating the theoretical utility of looking at psychoactive consumption holistically (Williams and Parker: 2001). In taking this approach, this chapter contextualises the environments which had influenced multiple experiential pathways to methamphetamine initiation and for some, ongoing experiences of problematic drug use.

Chapter five then further engages with the social relationships, connections and assemblages that participants had described when storying their trajectories of polydrug use. Drawing upon Rhodes' (2002) risk environment framework, this chapter explores how increasing exposure to drug-related risks in the context of the social relationships facilitated entry into, and confinement within, social environments populated by other problematic drug users. The divergence between male and female participants' risk experiences signposted throughout the previous chapter's analysis of poly-drug taking behaviour is also explored to illuminate gendered experiences of risk as well as variations in transitions towards more harmful forms of drug-taking behaviour. Collectively, the experiences of harms resulting from problematic drugtaking behaviour explored in this chapter contribute to theory building by illuminating how decisions about drug use result from "the inter-play between individual choices and a range of social forces, institutional and societal practices which are beyond the control of the individual" (Farrell et al: 2011:224). 
Utilising the life course perspectives of offending behaviour advanced in the work of Sampson and Laub (2005), chapter six focuses on the turning point experiences participants' identified as underpinning their decisions about stopping drug use. The stories analysed in this chapter reveal how prolonged periods of problematic drug use had exposed participants to unmanageable and unavoidable drug-related harms that culminated in significant life events - or turning points, which opened pathways towards desistance across the life course by disrupting social arrangements conducive to problematic drug-taking behaviour. This chapter also explores the identity transformations which intersected the process of desistance as it was storied in the context of participating in therapeutic communities. It demonstrates that decisions about stopping drug use also require individuals to disentangle themselves from past drug using identities, in order to build a renewed sense of self in the face of powerful countervailing social forces (Martin:2011).

The arguments developed throughout this thesis are then summarised in chapter seven by reflecting on the key theoretical assertions developed in each of the thematic analysis chapters. In sum, these narratives provide a comprehensive understanding of how the individuals who participated in the research had experienced starting, using, and for some, stopping methamphetamine use. Their experiences reveal how social relationships, group memberships and broader structural constraints converged in ways that determined how risk was assessed, and which choices could be made within the constraints of the social environments they occupied as problematic drug users. By storying the use of multiple drug types, of initiating methamphetamine use, and experiencing array of drug-related harms, participants rendered visible the complex nature of risk-taking shaping the lived experience of drug use. 


\section{Chapter two: methamphetamine, drug panics and authoritative understandings of drug users}

\section{Introduction}

This chapter begins by exploring the ontological politics of drug panic discourses, and identifies how these discourses have shaped ongoing concerns about methamphetamine use in New Zealand. Reviewing these discourses demonstrates that politically mediated representations of drug problems structure how we are permitted to think about the identities of those who use methamphetamine, as well as the root causes of harms associated with their drug use. It is argued that panic discourses individualise problematic drug use through the deployment of stigmatising tropes, which rationalise drug problem causation and inter-related experiences of social disadvantage by emphasising individual pathologies and failed 'choices'.

How these cultural understandings of dangerous drug users feed into broader political debates about governing drug use is then considered by examining the role of policybased scholarship in promoting ideologies which associate criminogenic behaviour with drug users. Reviewing this scholarship also emphasises how drug users are imagined as agential decision-makers, who must undertake prudent risk assessments in order to determine the perceived costs and benefits associated with their drug-taking decisions. The logic of neoliberal mores in contemporary drug policy is acknowledged as discounting the theoretical importance of complex social realities intersecting problematic drug use. Instead, causal explanations are favoured, which link the 'choice' of addiction to other self-induced afflictions, such as welfare dependency, incarceration, HIV infection and embeddedness in cultures of poverty (Hansen et al:2014).

Having signposted how these atheoretical explanations of drug use marginalise emic perspectives of lived experience, a corpus of ethnographic drug scholarship is reviewed which offers a context-rich perspective of how behaviours normatively defined as 'risky' 
are perceived, assessed, negotiated, and incorporated in the lives of problematic drug users (Williams:2013). The imperatives of risk environment and life course perspectives of drug use are then introduced as the primary heuristic devices this research uses to assert the theoretical importance of accounting for agency, culture and structure when exploring the decision-making processes which under-pin drug use. Synthesising these theoretical perspectives reveals how gendered, cultural and institutional power relations converge within social environments, which helps foreground the analysis of related experiential themes storied by participants in proceeding chapters ( $\mathrm{Hsr}$ et al: 2007).

As this scholarship has theorised, it is within these environments that social, structural and physical environmental factors intersect in ways that constrain agency and make risk avoidance difficult, and where drug users are less able to avoid transitioning towards increasingly harmful drug-using behaviour (Fast et al: 2010:3). Equally, desistance from drug use is subject to the same environmental constraints across life-course trajectories of drug use; because 'choice' is embedded within social structures, individuals motivated to transition away from drug use must exercise choice in concert with an array of structures, situations and networks offering support (Sampson and Laub:2003, cited in Williams:2013:36).

The theoretical debates explored in this chapter thus problematize the privileging of agency identified in authoritative accounts of drug use. Their application in evaluating the lived experiences of drug use affirms that decisions about drug use are not exclusively agential, nor are they solely determined by structural forces. As this thesis argues, drug taking is therefore more usefully theorised as resulting from the inter-play between structure and agency, where decisions about drug use are forms of structural action, which cannot be separated from the structural context of their occurrence (Measham and Shiner:2009). 


\section{Methamphetamine and 'drug panics'}

The lexicon of drug panics has been central to the stigmatising of methamphetamine users in public and political discussions about the root causes of drug problems, who is to blame, and why certain individuals 'choose' to use methamphetamine. What follows is a review of the cultural origins of the language, images and constructs used to discursively 'other' users of methamphetamine and other drugs. This discourse is identified as permeating social, cultural and institutional understandings of problematic drug use, which individualise drug problems by discounting experiences of structural disadvantage. The pervasiveness of this stigmatising discourse is referenced throughout the narratives of participants in this research, who negotiate the tensions between resisting and internalising the profoundly negative characteristics ascribed to them to identify nature of those who use drugs, and why they use them:

Prior to it being afforded the status of "the world's most dangerous drug" (National Geographic: 2006), understandings of methamphetamine were once confined to its medicinal value as a bronchial expectorant, weight loss aid and treatment for various mood disorders (Rasmussen: 2008). Its widespread use as a medication and later, as a substance to be used recreationally, resulted from iatrogenic practices established in post-war Britain, Japan and the United States (Kinsberg :2013, Sato: 2008, Rasmussen: 2008). Methamphetamine is therefore by no means a new drug as some media pundits have claimed, nor is it somehow pharmacologically distinct from other forms of amphetamine (save the absence of one carbon molecule as Rasmussen (2008) points out). It is more accurate to observe that methamphetamine shares much in common with the pharmaceutical properties and effects of Ecstasy (methylenedioxymethamphetamine or MDMA), and other amphetamine derivatives. It also continues to be legally available in the prescription form of the attention deficit hyperactivity 
disorder (ADHD) and weight loss medication, Desoxyn ${ }^{18}$ (Iversen:2006, Rasmussen: 2008).

Scholarship on trans-historical drug panics broadly locates the genesis of meth's enduring demonization in cultural reactions to increasingly visible use of misappropriated 'medicinal' methamphetamine in the $1960 \mathrm{~s}^{19}$. In his recent work exploring the history of methamphetamine, Parson's (2014) asserts that it was at this time authoritative anti-meth discourses would finalise the symbolic and legal recasting of methamphetamine from a valued therapeutic medicine to a dangerous illicit drug. Jenkins (1999) exploration of 'synthetic panics' suggests this resulted in part due to methamphetamine's association with the working class (notably 'biker' gangs linked to clandestine meth production), whose behaviour and aspirations clashed with middle class 'hippidom'. Educated counter-culture protagonists responded by framing methamphetamine and those using the drug as threats to harmless experimentation with culturally celebrated drugs like LSD and cannabis. By the end of the decade writes Jenkins, "methamphetamine had the distinction of being one of the very few drugs stigmatised within a drug culture of seemingly limitless tolerance" (1999:29). Further, this cultural divide facilitated the construction of an enduring stereotype, the 'speed freak', a negative drug using persona attributed to users of methamphetamine. 'Speed freaks' joined a myriad of other cultural identities assigned to allegedly dangerous drugusing populations. But unlike the profoundly racist identities attributed to Chinese users of opium ("the yellow peril") and Mexicans' as users of 'murder inducing' marijuana, the speed freak identity centred on a dangerously chaotic lifestyle, induced by psychosis and characterised by extreme paranoia, rather than racial attributes (www.druglibrary.org).

\footnotetext{
18 Desoxyn is the brand name for methamphetamine hydrochloride, which is sold in the form of 5 milligram tablets.

${ }^{19}$ Rasmussen (2008a:979) observes that, according to the Food and Drug Administration (FDA) at this time roughly eight to ten billion amphetamine tablets were being commercially manufactured each year by American drug companies, up to half of which were "diverted from medical channels altogether". FDA manufacturing surveys also estimated that in 1969 alone, 80,000 to 100,000kg of amphetamine salts were produced for a population of approximately 200 million, equating to up to fifty $10 \mathrm{mg}$ doses per person (FDA, cited in Rasmussen:2008a:979).
} 
Jenkins (1999) also notes that in contrast to the rise and decline of these panic-inducing stereotypes, the image of the psychotic meth user prevailed in proceeding decades, despite the waning popularity of methamphetamine, as drug-users turned to heroin, PCP and other new drugs, all of which received comparatively muted reactions to their use (Jenkins: 1999).

According to Parsons (2014), although short lived, the threat of methamphetamine gained new momentum in the wake of residual anti-drug hysteria, following the now extensively documented war against crack cocaine (see Reinarman: 1994). The popularisation of a smokable form of crystallised methamphetamine in Hawaii known locally as 'ice' prompted media warnings of an imminent threat "speeding its way across the Pacific" (Sager:1989:53, cited in Lauderback and Waldorf:1993:597). In 1992, USA Today reported the effects of ice were "not to be underestimated, as (could) be gleaned from 'the speed freaks' of the previous meth era" (Labianca: 1992:54). They reported that thirty five percent of all murders in San Diego could now be attributed to using ice, and that "no other drug could make that claim" (ibid: 56), Moreover, ice was "increasingly popular among teenage users" and "terrifying (was) the thought that people in positions of responsibility such as airline pilots and physicians, could take up smoking ice" (ibid: 56). Those hyperbolic warnings would establish in the media's methpanic lexicon an enduring phrase used to headline purported widespread use of meth in the early 90 s - the 'ice age' (ibid).

However, US claims that the use of 'ice' would degrade the nation even more than crack allegedly had, failed to materialise. Parson's (2014) notes that vested political interests capitalising on re-election through anti-meth campaigning were central to methamphetamine's comparatively brief resurgence as a 'new' drug epidemic. Further, in their aptly entitled article, "Whatever Happened to Ice? The Latest Drug Scare", Lauderback and Waldorf (1993) examined methamphetamine use in San Francisco, documenting 18 male sex workers' experiences with using 'ice'. Their findings challenged claims regarding the extent of geographical diffusion of ice use, as the drug 
was not reported as widely used by participants in San Francisco's 'speed' using culture (p599).

Short-lived as the second meth scare was, socio-political conditions would foster a third, and far more enduring, meth scare (Parsons:2014), confirming Jenkin's (1999?) observation that, unlike other drug users, users of meth have been the ongoing subjects of a 'panic renaissance'. Media commentators re-deployed the 'epidemic' metaphor once commonly associated with references to crack, citing evidence of 'new', stronger, forms of 'meth-ice' and 'crank' (Parsons:2014). Images of the psychotic meth user gripped by "criminal lunacy" remained emblematic of the speed freak persona popularised some 30 years earlier, with racial attributes remaining confined to an understanding of the meth user as exclusively white, poor and over-represented in rural areas (Brisman: 2007, Boeri, Harby and Gibson: 2009). Armstrong (2007:432) demonstrates this point in his review of methamphetamine reporting, in which he identifies language which links the 'problem of meth' with America's white, rural underclass. "Redneck Cocaine", "The Trailer Trash Drug" and other headlines he argues, created meth using imagery which distanced users from 'normal citizens' and placed them "outside the boundaries of middle class propriety". In contrast, Linnemann's (2010:96) evaluation of meth reporting from 1995 to 2007 points to other images of meth use, where meth was seen as transcending its rural underclass origins by reaching across the social spectrum, from "computer geeks in Silicon Valley", to "gay professionals in New York". Thus new victims were located, where even "one of the last bastions of white middle-class virtue, the soccer mom" was at risk of succumbing to meth's promise of weight loss, boundless energy and heightened sexual pleasure (97). 
Media images and the technologies of marketing also contributed to the pervasiveness of meth's alarmist narrative through aesthetic representations of methamphetamine use sharing much in common with the imagery of squalid heroin addicts used in antidrug campaigns of the 1980s. For example, Ayres and Jewkes (2012:323) reveal how print reporting on methamphetamine frequently employs lurid 'before and after' images of meth users, who are presented as toothless, skin pocked, prematurely aged and visually abhorrent. The visceral impact of meth user images which "exhume" a "deviant body" for "public dissection" (Giulianotti, 1997 cited in Ayres and Jewkes: 2012:323) are similarly deployed by anti-meth marketing campaigns. Billboards picturing the eroded "faces of meth" offer tagline warnings that "my friends and I share everything, now we share hepatitis and HIV", and "\$15 bucks for sex isn't normal, but on meth it is" (cited from Montana Meth Project.org, Hawaii Meth Project.org). As Penny (2012) has argued, it is through these aesthetic representations of meth users' "carnal pleasures and grotesque bodies" that the meanings attached to meth use have been immediately and powerfully conveyed, imposed in one stroke, without analysis or dilution. Their message is clear; meth users are dirty, self-defiling and dangerous; they "contaminate communities and in any decent sort of 'society' they constitute 'matter out of place' (Douglas: 1997:414, cited in Ayres and Jewkes: 2012:323)."

While there is a dearth of published scholarship on discursive representations of drug problems in New Zealand, the language and imagery employed in constructing narratives about New Zealand meth use is also characterised by similar tropes and discursive strategies to those documented extensively in US, UK and Canadian drugpanic scholarship (Linnemann: 2009, 2014, Boyd and Carter: 2010, Omori: 2010, Ayres and Jewkes: 2012).

For example, the familiar meth-epidemic motif has been deployed in a myriad of local headlines, with various media outlets warning of "the methamphetamine craze" and the "new street drug epidemic" threatening middle New Zealand (Zander:2002). The New Zealand Herald proclaimed that given the scale of local meth use, the nation was in fact 
"Chasing (a) US Sized Habit", with a hard drug problem "on track to be as bad as the United States" (NZ Herald, 23 September 2003). Newspaper coverage also reappropriated familiar drug using fallacies reminiscent of US reporting on crackcocaine $^{20}$, none more so than in the New Zealand Herald's headline article, "Alarm over Amphetamine Babies". The article described methamphetamine as "the drug of choice of women of child bearing age" (NZ Herald, 25 June 2003), evoking what Hartmann and Golub identify as the most insidious and mythical crack image of all, "...babies - addicted at birth, uncontrollable and without hope for the future" (1999:426).

Several isolated, yet dramatically violent events where offenders were reported as being meth users, helped cement methamphetamine's automatic association with violence and crime in a New Zealand context. These included William Bell's RSA murders, Antonie Dixon's sword attacks and Stephen William' ${ }^{21}$ admission to killing six year old Coral Burroughs while under the influence of methamphetamine (Nice 2007). Methamphetamine's association with these extreme acts of violence helped galvanise public condemnation of all methamphetamine users. Arguably, no one more so than Antonie Dixon, who's mediated persona again reimagined the longstanding psychotic speed freak stereotype. This point is illustrated by the New Zealand Herald, who recently reported that:

"Dixon was into methamphetamine and was a drug bully who would pressure (his victim) to take the drug with him...The press (were) riveted by Dixon and his "crazy eyes", an affectation he adopted to support his insanity plea. The image of his goggle-eyed face (later) appeared on tshirts and on comedy shows... (NZ Herald 27 January 2013)."

\footnotetext{
${ }^{20}$ Locally methamphetamine is often referred to as 'crack' due to its association with being smoked in a glass 'crack pipe'. However in the US, Canada and UK crack refers exclusively to crack-cocaine, or cocaine hydrochloride.

${ }^{21}$ Antoine Dixon's convictions for severing the hands and arms of two women with a samurai sword while under the influence of methamphetamine attracted nationwide attention in 2003. Having attacked the two women, Dixon went on to steal a car and kill a man, and then take another hostage. In the same year Stephen Williams was convicted for beating to death his six year old step daughter while also under the influence of methamphetamine. Williams was later convicted of attempting to murder a fellow inmate in 2016. Both crimes continue to be referenced in the media. See http://www.nzherald.co.nz/nz/news/article.cfm?c id=1\&objectid=10861717
} 
In keeping with discourses deployed during earlier meth panics, meth users have continued to be demonised and dehumanised, and portrayed as existing beyond the boundaries of both acceptable drug-using cultures and mainstream society generally (Jenkins: 1999). Antoine Dixon's vilification as a psychotic 'drug bully' exemplifies this process, his representation as an "extreme of otherness" (Greer and Jewkes: 2005:29) akin to the status afforded paedophiles and serial killers, aided significantly by the violent crimes attributed to his use of methamphetamine.

Various political 'claims makers' have also proffered outlandish warnings grounded in cultural myths supporting methamphetamine's notoriety. For example, in his 2007 Parliamentary Address, Māori Party Co-Leader Pita Sharples, evoked an enduring US drug myth which posited that meth dealers seduced children with strawberry and chocolate-flavoured methamphetamine:

"And when I think of children, I know too of children as young as 9 years old being sold (meth) in fruit flavoured tablets (Pita Sharples, Parliamentary Address. June 20, 2007)."

This statement was later de-bunked as a spurious claim ${ }^{22}$ based on misinformation, but the pervasiveness of the 'horror meth' narrative has remained in and beyond politicised domains. The Post Primary Teacher Associations' (PPTA) employed the narrative in an NCEA dance curriculum unit for year 11 students, entitled "The P Nightmare". They assert the "unit is relevant to students as problems associated with $\mathrm{P}$ use are constantly highlighted in the media", and go on to note that "even cool students...found this unit accessible and relevant to their world". The PPTA recommend accessing the 'appropriate' resources for teaching from National MP, Mike Sabin's methamphetamine

\footnotetext{
22 In common with US drug mythology which posited that strawberry flavoured methamphetamine was being marketed to children, the NZ Drug Foundation identified this story as a fallacy. Colour variations in meth result from 'rinsing' processes and typically produce white, pink, yellow or brown variants, and in differing consistencies - from powdered to paste like. Hence brown coloured meth in a paste like form has been aptly referred to as peanut butter meth, referencing its poor processing a rinsing, rather than an imagined flavour quality.

See http://www.drugfoundation.org.nz/media/drug-myth
} 
'education'23 company, Methcon. This include the graphic anti-meth imagery of his familiarly titled DVD, “Welcome to the Ice Age” (Cited in Neal and O'Brien: 2011:1), which promises viewers "a journey through the nightmare world of methamphetamine addiction" (www.methcon.co.nz).

More recently, media commentary has continued to link methamphetamine to various social problems and marginal populations. For example, the Timaru Herald (22 December, 2014) reminded readers of meth's association with violence, addiction and community harm when reporting that,

\begin{abstract}
"A day rarely goes by without news of methamphetamine manufacture and use and its harmful impact on individuals, families and communities...A wealthy Auckland businessman who chained up a woman and forced her to perform sex acts has been jailed for 15 years on several charges, some resulting from his providing methamphetamine, or $\mathrm{P}$, to underage girls in return for sexual services. A Manawatu addiction service says former $\mathrm{P}$ addicts have resumed using the drug since the law on synthetic highs was changed."
\end{abstract}

The New Zealand Herald (2014) went on to establish a link between methamphetamine and state beneficiaries when reporting that half of New Zealand's state houses tested for the presence of methamphetamine in the past two years produced positive test results. Quoting 'experts', they warned that tests completed so far "... might be just the tip of the iceberg (Priestly: 2014)." The Wellington based anti-meth organisation 'Pipe Down' sponsored a full page advertisement in the Dominion Post which also warned of the imminent dangers of methamphetamine. Their advertisement reiterated familiar meth using tropes in a narrative warning readers that meth equals

“...P for pure evil. Some people believe they can dabble with it, weekend binges, no problems. Others definitely can't dabble. A tiny gateway in these chosen ones' brains allows this bloody awful drug to attack their sense and reasoning. And, self-control. These users suffer a terrible addiction far more complicated than the physical addiction of heroin. Meth makes them

\footnotetext{
${ }^{23}$ A former policeman, Mike Sabin became a prominent anti-meth spokesperson in the mid 2000's. He started a drug education and workplace testing company, Methcon, whose services aimed to "protect people and profits through education (www.methcon.co.nz)". Later Sabin became the MP for Northland, but resigned in 2011 following assault allegations.
} 
psychotic. They become monsters...So much crime comes back to one thing: methamphetamine...Go to a prison waiting room and 8 out of 10 people will be there as a direct or related result of methamphetamine use at some level. The meth invasion is out of control... (The Dominion Post, July 29, 2014)"

These examples of public discourse about methamphetamine provide some insight into common representational devices disseminated by the media, as well as the types of anti-meth language and symbolism frequently reiterated by politicians, lobbyists and criminal justice stakeholders. They go some way towards identifying a familiar cultural vocabulary, characterised by panic and the familiar tropes of 'possessed' users of demonic drugs (Brook: 2010). For Singer and Page (2013:25), in this discourse, drug using behaviour accrues layers of social judgement, stereotyping, and fear. In common with race, socioeconomic status and gender, this discourse functions as a way of ordering complex behaviours, where typically, "perceptions of drug users tend to push perceptions in the direction of pejorative terms and discriminatory behaviour" (ibid).

Boyd and Carter (2010:233) argue that the language and symbolism evidenced in the media commentary discussed here also constructs a narrative which

“... separate(s) persons and events from their social contexts, creating portraits of 'addicts' so insanely ruled by their dependence on drugs that they cannot act as moral subjects, nor can they operate in their own best interests. Typically, these forms of (representation) depict the worst possible effects of drug use."

What is striking in comparison by country, is the homogenous nature of this meth-panic discourse; its cultural 'sameness'. There is little, if any, variation in representations of meth users within the global drug-panic narrative ${ }^{24}$. Structured as pathological and threatening, meth users sit alongside other feared drug-using protagonists in the wider, trans-historical discourse which continues to frame explanations of drugs, crime and social disorder (see Reinarman:1994, Hartman and Golub:1999, Armstrong: 2007,

\footnotetext{
24 Wallace's (2006) MA thesis offers additional guidance on media portrayals of methamphetamine use in New Zealand. She confirms that media representations of meth use can be located in the process of moral panic, as evidenced by the headline examples presented here.
} 
Linnemann: 2009, Chitwood et al:2009, Lancaster et al :2010). This point resonates with the work of Brown (2007:27) and other scholars (see Reinarman and Levine: 1997, Foster: 2000, Brooke and Stringer: 2005:323), who argue that it is by using stylised caricatures - a sort of global pop culture iconography - to represent "filthy, diseasebearing junkies" or psychotic 'tweakers' "that drug demonization serves a very powerful ideological objective; by providing a single point of explanation and blame for a vast variety of structural social problems."

Dichotomising 'the real' from the mediated is less of a theoretical concern for this thesis than attempting to establish how drug panic discourse communicates specific kinds of knowledge about meth and meth users, and what effect this might have on public and political audiences. Addressing this point Lancaster et al. (2010:1) have argued that because media representations of drugs and drug users intersect public and political thinking, the media can set the agenda about drug issues and define public interest; frame drug issues through selection and salience; indirectly shape attitudes towards drug risks, and feed into political debates and decision making where drug problems are concerned. They evidence this process in high volume reporting on the use of the 'legal high', mephedrone, in the UK. They demonstrate that media campaigns exaggerating mephedrone's links with violence and 27 unsubstantiated drug-deaths resulted in changing mephedrone's legal status to a class B controlled substance within a six month period.

Lancaster et al. (2010:4) point out that the role of the media in shaping policy and prompting government action is often assumed, although it is unlikely to work in a linear fashion. The media undoubtedly raises the public profile of drug problems and therefore a drug problem's political efficacy, as evidenced in an early parliamentary briefing paper on methamphetamine use in New Zealand:

“...the media has highlighted the link between drug use and violence. It has been reported that the convicted murderer of two people in South Auckland and the convicted murderer of another three people at the Mt wellington-Panmure RSA in 2002 used methamphetamine. The media has 
also reported that health sector workers, especially emergency department staff, have experienced more violence and outbursts directed at them, and increase that has been linked to methamphetamine use (Bellamy and McNab: 2003:8)."

To what extent media commentary drives political processes or necessitates urgent political responses cannot be adequately explored within the confines of this thesis. It is worth citing the work of Nice $(2007: 3, V)$ however, who at least reinforces the view that reporting on methamphetamine in New Zealand was proceeded by a rapid expansion of meth security measures not dissimilar to post 9/11 border controls. In his comparative review of US and NZ drug policies, Nice documents that following increasing public awareness of the threat posed by methamphetamine

“...the government moved quickly to enact 'whole of government' drug action plans....The approach focussed on strong law enforcement actions to diminish drug availability. Precursor chemical controls, increased enforcement staffing, specialist drug teams, increased drug apprehensions, re-scheduling of drugs and precursor chemicals, adding new drug offences, (and) expanded Police and Customs powers, among other interventions, swiftly ensued. These investments led immediately to...increased methamphetamine seizures...and a doubling of methamphetamine-related apprehensions (Nice: 2007: 3, V)".

Reflecting on the role of panic discourses in representing the problem of meth raises questions about why meth and those who use it have been framed as more harmful, abhorrent and threatening than other drugs and drug using populations, and how this mediated knowledge might uphold particular ideologies about the strategies which best govern those identified as meth users (Brown: 2007, Linnemman: 2012). It is with these questions in mind that the next section examines how mediated representations of methamphetamine use are also generated and regenerated through government enquiries, policy developments, economic research, the enactment of new laws and substance re-classifications, and in various health promotion initiatives (Lancaster and Ritter: 2016). 
Like the media, policy, research and law and order responses function as communicative instruments which convey knowledge about the nature of drugs and those who use them; they inform and legitimise an official discourse about drug use, which also problematizes methamphetamine and methamphetamine users (Bright et al:2008, Lancaster, Duke and Ritter: 2015). Simply put, the problem of drugs - like immigration, welfarism and other so-called 'social problems', and the populations associated with such issues, are socially constructed through policy, research and governance. Identifying the presence of these discursive arrangements is useful in foregrounding how individualised understandings of drug use and risk are brought into being through particular discursive arrangements. These arrangements locate the problem of drugs in individual failings and poor choices, rather than in power disparities or structural constraints. Politicised responses to drug use, as the next section sets out, similarly imagine drug users as 'troubled individuals', who necessitate governance through rationale choice policies informed by the logic of risk calculation and the freedom of choice.

\section{The individualisation of drug use in authoritative discourses}

Comparatively, policy and law and order discourses share much in common with representations of drugs and drug users proffered by media pundits: lurid newspaper images of meth users restrict our analytical gaze so that we are only permitted to see chaotic lifestyles characterised by bodily degradation, irrationality and psychosis (Ayres and Jewkes: 2012). These pictures reiterate and normalise the idea that these atypical examples of drug use represent typical meth users; they freeze into place what are highly contestable depictions of those living with methamphetamine (Boyd and Carter: 2010:228). Similarly, official discourses telling the story of drugs through 'evidencebased' policies enact methamphetamine and methamphetamine users as particular kinds of problematic, and inherently dangerous, 'objects' (Dwyer and Moore: 2013). The 'policy picture' reveals the identities of those it has located as responsible for drug related problems and makes clear how they should be governed. At the same time 
policies and the research which supports them excludes the possibility of engaging with alternative explanatory discourses about drug use in much the same way media representations of methamphetamine obfuscate other drug-use realities. This point is reiterated by Lancaster et al. (2010:3), who note that just as the media frame social issues by selecting aspects of a perceived reality to emphasise salience and develop a narrative,

"...in a policy context, framing affects what is said about (drug) issues, by whom and the definition of optimum solutions. Framing influences the type of public debate that can occur through the way a (drug) problem is defined."

Lancaster and Ritter (2014:82) emphasise the need to engage with the role of policy in representing various drug issues, given that policies construct and represent policy problems over time. Citing Fraser and Moore (2011:505) they add that, ultimately, policy produces problems rather than merely addressing them.

Taking a lead from Lancaster and Ritter (2014), it is clear that policy responses to methamphetamine use in New Zealand, and the evidence employed to justify their implementation, has structured how we are permitted to think about meth and meth users, and by extension, how other drugs and the various groups who use them might be viewed. The pharmacological effects of methamphetamine as distinct from other drugs, and the stigmatised identities and criminal behaviours attributed to meth users, have been reiterated in the ontological politics of official discourses (Dwyer and Moore: 2013). Specifically, in government sponsored research used as evidence to measure the extent of meth use, its availability, and its causal links with crime and other social harms, in health and education resources confirming the psychological effects of meth consumption, and in various policy outcomes which distinguish methamphetamine and meth users from other drugs. Further, structural explanations of drug-taking behaviour are negated in the construction of an identity paradox; that meth users are rational, agential decision makers who simply choose their chaotic lifestyles. 
"Rigorous research" is identified in New Zealand's National Drug Policy as fundamental to developing "evidence-based" strategies which reduce the health, economic and social inequalities that intersect drug use. Importantly, National Drug Policy urges that responses to drugs and drug users should be informed by research which accounts for:

“...the characteristics of individual drug users (including age, ethnicity and gender), the setting in which drug use occurs, the characteristics and effects of the drug in question, and the physical, economic, social, and legal environment in which drugs are used (Policy Advisory Group: 2009:15)."

While these are laudable intentions, what exists instead is a significant corpus of government sponsored, quantitative 'evidence' or 'knowledge', which seeks only to demonstrate the existence and extent of various meth problems, rather than question the structural context of meth use, and the intentions of individuals who use meth in the face of pervasive vilification (Hallam and Bewley-Taylor: 2010). Importantly, this research structures representations of methamphetamine use, and the use of other drugs, in accordance with the lived experiences of problematic drug users, whose social, psychological or physical dependence on drugs results in experiences of harm, both to themselves and those around them (Buchannan and Young:2000).

In much the same way as gender, sexual orientation, ethnicity and other social categories of 'being' are socially constructed, the distinct identity of the problematic drug user is stitched together using the various quantitative measures which inform policy tools (Seddon, 2011) The annual Illicit Drug Monitoring surveys (IDMS) exemplify this approach and are likely the most widely cited source of meth-problem evidence in reporting on methamphetamine use in New Zealand. Funded by various Government agencies and business associations ${ }^{25}$, IDMS survey data provides an annual snapshot of

\footnotetext{
25 The IDMS is conducted by SHORE (Social Health Outcomes Research and Evaluation) and Te Ropu Whairiki, at Massey University Auckland. They report being funded by the Health Research Council of New Zealand, Ministry of Health, the World Health Organization, Ministry of Social Development, Ministry of Business, Innovation and Employment, Marsden Fund, Building Research Capacity in the Social Sciences, Health Promotion Agency, New Zealand Police, Auckland Council and the ASB Trust. (see - www.shore.ac.nz)
} 
drug use, drug markets, drug related harm, and, "social disruption related to drug use" in New Zealand (Wilkins et al:2013:7). This snapshot is legitimised by its purported methodological veracity in surveying small sentinel drug using populations. These populations are regarded as an informed, "expert" microcosm of a wider, as yet 'unseen' drug-using community, whose knowledge of new drugs, their price, availability and purity, is hailed as indicative of revealing nationwide mega trends (Ritter:2006, Wilkins and Sweetsur 2009:168). Such is the pervasiveness of IDMS data that citations can be found in international drug use reports (for example the UNODC World Drug Report 2013 ) in current policy documentation (see for example the Methamphetamine Action Plan and www.drugfoundation.org ), in NCEA qualification assessments ${ }^{26}$ and in marketing material proffered by private drug detection agencies (see www.scenttech.co.nz).

Similarly, the annual New Zealand Arrestee Drug-Use Monitoring (NZ ADUM) reports also employ the sentinel-population survey methodology to aggregate expert knowledge about methamphetamine use. Funded by the New Zealand Police, NZ ADUM reports record drug using trends and various patterns of "related criminal behaviour and other harms" among populations of police arrestees (Wilkins et al. :2013:21). In common with the IDMS, investigating the economic transactions of meth - gram price, ease of purchase and quality (or purity) - are cornerstone survey questions, as are identifying various social profile categories (age, ethnicity, educational attainment, employment status, family structure), and self-reported levels of drug use, and most importantly for policy makers, self-reports of criminal activities in the month prior to arrest.

NZ ADUM data is thus fundamental to links between drug use and criminal activity. However, as Stevens (2011: 33) explains in reference to similar drug-testing efforts used

\footnotetext{
${ }^{26}$ See www.nzqa.govt.nz/assets/qualifications-and-standards/qualifications/ncea/NCEA-subjectresources/Health/91461-B/91461-EXP-B-student1-001.pdf
} 
in the United Kindom, testing the urine of arestees for various substances and asking them questions about their drug use, feeds into a longstanding narrative which exaggerates drug use as causing crime. The same narrative usefully justifies prohibitionist efforts, by positing that, by decreasing drug use, crime will also decrease. Three causal links are frequently cited to support this assertion; that drug use negatively affects behaviour, that addicts must access money by illegal means in order to maintain their 'habit', and that crime results from black-market drug economies (Boyum and Kleiman:2003). These assertions are evidenced for example in the 2013 NZ ADUM survey, which notes that " drug intoxication can precipitate criminal acts and escalate the seriousness of offending", that an individual's offending "may be motivated by the need to obtain money to pay for alcohol and drug use", and in the broader context of an illegal drugs market, where "violence may be used to resolve disputes, protect market share and rob participants" (Wilkins et al: 2013:190).

These linkages argues Stevens (2011), enable authoritative voices to greatly inflate the correlation between drug use and a range of criminal activities, as the New Zealand Police Association President Chris Cahill recently demonstrated when discussing methamphetamine use: "Whether it's family violence, whether it's burglaries, whether it's serious robberies, it's all being driven by meth" (Newshub Live at 6, 31 August 2017). Again, just as media accounts of drug use individualise social dysfunction, emphasising the drugs crime relationship also discounts complex social inequalities which are most often experienced by those whose problematic drug use has attracted police attention.

Methodologically enumerating the 'kinds of people' who use methamphetamine by aggregating employment status, offending behaviour and other social markers also reinforces the idea that problematic drug users represent a distinctive class or category of person (Seddon:2011:340). Subset identities are then promulgated in policy documents, by employing code words like "high risk youth", "underclass drug user" or "minority drug user" to denote where problematic drug users are located and the levels of potential harm we are told to expect from their drug-using behaviour (Covington: 
1997:117). These identity references help build an overall picture of the 'drugs problem', and highlight where law enforcement resources are best deployed.

As an extensive body of drug scholarship has demonstrated crime causation and problematic drug use are thus inextricably linked to experiences of structural disadvantage (Buchanan and Young: 2000, Seddon: 2006, Stevens: 2011). Put simply, social exclusion increases the likelihood that individuals will engage in problematic drug use, which in turn places individuals at much greater risk of being subject to arrest, conviction and incarceration. This further exacerbates over estimations of the volume of crime committed by drug users, given that populations of offenders who are not involved in drug supply or consumption are less likely to receive police attention (Stevens:2011).

Correlations between methamphetamine use and criminality have also been asserted by emphasising how methamphetamine's pharmacological properties effect the behaviour of those who dare use it. This has problematized users in ways which immediately re-visit and reiterate the 'speed freak' stereotype by dichotomising problematic users of meth from other drug using groups. According to Dwyer and Moore (2013:203) this is because causal explanations of violent offending routinely invoke the links between methamphetamine consumption and psychosis. Consequently, policy, research and health education texts commonly make ontological assumptions about the psychological effects of methamphetamine as being conclusively indicative of a pathology unique to methamphetamine users. This point is also reflected in IDMS reporting, which cites before introducing its 2013 findings on meth use that methamphetamine

“...known colloquially in New Zealand as 'meth' or ' $\mathrm{P}$ ', is a powerful psycho-stimulant which can cause hostility, hallucinations, obsessive behaviour and episodes of paranoid psychosis resembling schizophrenia (Gawin \& Ellinwood, 1988; Hall \& Hando, 1994; Kuhn et al., 1998; Shearer et al., 2002, cited in Wilkins et al:2014:68)." 
Similarly, the NZ ADUM reports advise that,

"Chronic and high doses of methamphetamine can cause hostility, paranoia, hallucinations, obsessive behaviour, (and) psychosis... (Wilkins et al: 2013:65)"

Dwyer and Moore add that (2013:206) within such discursive representations of methamphetamine's psychological effects, "pharmacology is inscribed as the primary driver of the drug's experienced effects."

When situated in the context of broader debates about drug taking and drug dependency, emphasising that methamphetamine use changes brain structure gives currency to the notion that drug addiction is a brain disease (Heather, Best, Kawalek, Field, Lewis, Rotgers, Wiers and Heim:2017). Accordingly, it is structural and functional changes in the brain that are viewed as underpinning transitions from recreational drug use to drug addiction, changes which occur through repeated consumption of addictive drugs (Heather et al:2017). This results in biologically-based understandings of compulsive behaviour, which posit that problematic drug use is akin to the experience of obesity, whereby vulnerable individuals are unable to refrain from consuming drugs or food, due to changes in the brain's ability to regulate "reward sensitivity, incentive motivation and self-control (Heather et al:2017:1)."

A positive view of the brain disease model might be that it provides a policy rationale for what at face value appear to be beneficial policies, such as offering problematic drug users 'treatment' for their addiction, rather than simply defaulting to incarceration for drug-related crimes. However, as critics have identified, defining drug users as brain damaged justifies the development and expansion of coercive treatment requirements (Meurk, Carter, Partridge, Lucke, and Hall: 2014). As Brook (2009:100) explains, once meth users are defined by criminal justice agencies as "people whose faculty of choice has been usurped and supplanted by a substance which controls their being and behaviour", they are identified as unable to recognise their own interests. Policy 
instruments are then designed to change drug users' individualised deficiencies through approved authoritarian means, rather than attack structural issues that are the basis of the problem itself (Schneider and Ingram:1993). Buchanan (2000:389) for example notes that criminal justice responses to drug addiction can include regular drug testing, counselling, abstinence orders, anti-social behaviour orders, community rehabilitation orders as well as the development of abstinence based drug courts. ${ }^{27}$. Participation is mandatory; compliance failures usually resulting in prolonged community sentences, and often, incarceration. Ultimately, these responses offer a form of conditional citizenship for meth users which are attractive to policy makers and the populist sentiments of 'war on drugs' rhetoric.

The demonic effects of meth on the physiology of addicts is further confirmed by antimeth campaign imagery which depict users of methamphetamine suffering from paranoid delusions and picking their skins free of bugs (see www.montanamethproject.org). This message is reiterated in resources for those wanting to help meth users, which include lists of 'typical' meth-user signs, such as changes in physical appearance, including deteriorating hair, skin or teeth, excessive sweating, users letting themselves go physically, abnormal weight loss, dilated pupils and rapid eye movement, acting paranoid and talking about being in danger (from www.methproject.org/action/get-help.html). The pervasiveness of pathologising meth users as inherently criminal and more dangerous than other drug users is cogently demonstrated by Taylor and Covey (2008:41), who's handbook for clinicians 'helping' people addicted to meth warns us that meth users are different:

"People familiar with meth are aware of the unique subculture of people who tend to use together. The sordid, undesirable subculture of meth use is insidious; it tends to be selfprotective and self-consuming....members of the meth subculture will commonly steal from one

\footnotetext{
27 This point is evidenced for example in New Zealand's recent Substance Addiction Compulsory Assessment and Treatment Act 2017, which allows for legally mandated third parties to make people with "severely impaired capacity" participate in compulsory residential treatment programs (Ministry of Health 2017).
} 
another, sleep with one another's romantic partners, and even sexually abuse one another's children or teenage daughters..."

In New Zealand and elsewhere, private drug education companies ${ }^{28}$ have re-referenced and re-deployed the identities of meth users in marketing services to protect rational citizens and their property from the inevitability of irrational meth-induced behaviour. As the Methcon Group website warns, children are particularly vulnerable when faced with the psychotic and sexually abusive meth user:

"In America, many of the worst affected states report between $60-90 \%$ of referrals and child removals for child abuse relate to methamphetamine, a trend seemingly being mirrored in New Zealand, with over a $60 \%$ increase in reported child abuse over recent years. These children are often unaware of, or unable to communicate the danger they are in, and become silent victims, potentially being exposed to...violent psychotic behaviour (and) sexual abuse... (From http://www.methcon.co.nz/Abuse-in-Our-Family)."

These 'official' representations of meth users as distinctly pathological and inextricably linked to chaotic and criminogenic behaviour work in concert with mediated drug panic discourses. They ascribe profoundly stigmatised identities to meth users in much the same way as alarmist media narratives construct drug using identities using negative images of persistent, addicted, offenders (Stevens:2011). The complex array of social, cultural, psychological, historical and economic factors that influence drug using realities are then inevitably excluded by causal explanations mobilised through the construction of stigmatising tropes. McKenna (2013:359) explains that the macro effect of this exclusionary discourse is to "essentialise the impact of specific drugs (like methamphetamine), emphasising their direct effects", positing that reported health complications, mental illness, addiction and criminality are to be equated with "the presumed moral weakness of the user". Brown (2007:13) defines this as the classical 'mode of (illicit drug) representation', a superficial approach to explanation; one that is

\footnotetext{
${ }^{28}$ See for example www.methcon.co.nz or www.methsolutions.co.nz or www.scenttech.co.nz
} 
routinely widespread and available in the wider cultural discourses which surround drugs and those who use them.

The work of Schneider and Ingram $(1993,2005)$ is of significant value in considering how the interrelationship between these stigmatising representations of meth users, research as problem 'evidence', and the policy tools which govern drugs and drug users, might be theorised. Exploring the relationship between socially constructed groups and public policy, they establish that

“...there are many different sources of social constructions besides policy, and that, overall, policies are not the most important tools constructing groups. The role of governance in social construction probably is smaller than the combined influences of market advertisements, music, film, and other aspects of historical custom and popular culture. Yet, policy is the dynamic element through which governments anchor, legitimise, or change social constructions. It is the means used by government to powerfully support or undercut widespread practices of social separation... (Schneider and Ingram 2005:5)."

Their observations resonate with the arguments presented in this thesis because they acknowledge that culturally mediated discourses structure the identities of groups such as drug users, and conceptualise socially produced group identities as intersecting policy making decisions and influencing the ideologies supporting those decisions. This intersection and influence is explained as being determined by the shared characteristics which distinguish the 'deservedness' of particular groups or 'target populations' (1993:335). Degrees of deservedness are correlated with the positive or negative characteristics socially ascribed to either, politically strong or politically weak target populations. It is in this process that Schneider and Ingram (1993) make clear how stigmatising meth-users feeds into the formulation of policies which both define and govern their behaviour.

As they outline, positively constructed and politically powerful target populations like families, property owners and the elderly are ascribed characteristics which suggest they 
are more deserving of supportive policies facilitating community engagement and full citizenship, such as tax credits, home ownership loans or reductions in healthcare costs. In a policy context these initiatives are easily legitimised, because, not only will the groups who benefit react favourably, others will approve of beneficial, capacity building policies being conferred on deserving people (Schneider and Ingram,1993 p.336) . In stark contrast, negatively constructed target populations with little political power, such as gangs, criminals, and, as we are concerned with here - addicted drug users - become "proximate targets of punishment policy", and therefore deserving of various coercive policy tools. Further, there is little fear of political retaliation from groups such as problematic drug users, because the general public approves of punishment for groups that it has constructed negatively (ibid: 336,337 ).

Applying Schneider and Ingram's $(1993,2005)$ framework to the arguments presented I this thesis, methamphetamine users are emblematic of a group or target population that has been ascribed profoundly negative characteristics. These negative characteristics have been further amplified by research and political commentary correlating meth use with other, stigmatised and deviant groups, notably gangs, solo parents, welfare recipients and child abusers (Covington:1997). Not surprisingly then, meth users have been subject to a myriad of coercive sanctions, as evidenced by the policies deployed through the New Zealand government's Methamphetamine Action Plan (MAP). These policies have included the re-classification of methamphetamine as a Class A drug to increase sentencing tariffs (life imprisonment for importation, manufacture or supply), and reductions in the quantity of methamphetamine needed for the presumption of supply, to increase the penalty risks associated with retail distribution and possession. Simple possession of a pipe or utensil for smoking methamphetamine has also been made an offence, and can attract a year of imprisonment, or a fine of up to $\$ 1000$ (Misuse of Drugs Act 1975$)^{29}$. 
These policy responses 'bring into being' the very population whose behaviour they seek to address when positive outcomes are cited in public and political commentary. This 'policy success' discourse reiterates and reinforces public perceptions of meth-users as responsible for crime and other social harms, and therefore as logically deserving of the punishments they receive (Schneider and Ingram:2005). This is demonstrated in regular updates on the government's Methamphetamine Action Plan (MAP), which clearly locates the 'typical' meth user in references to its 'performance indicators'. Widely cited by the media and other government agency stakeholders ${ }^{30}$, the MAP reports its successes as including 1246 offenders convicted of methamphetamine offences, 1023 prisoners receiving compulsory drug treatment, and the Criminal Proceeds Recovery Act (2009) diverting 1.74 million dollars from methamphetamine dealing into improved police and customs enforcement (MAP October 2014) $)^{31}$.

This is not to argue meth users are unique in that coercive, punishment-based policies govern their behaviour. Illicit drug use generally is subject to a 'war against drugs' ideology and the punishment based policies it inflicts on drug users, as many authors have actively demonstrated (see Reinarman:1994, Young: 2000, Brown: 2007, Bright et al. 2007). However, meth-users identities have been constructed in accordance with exclusively negative attributes, and in relation to public, political and policy demonization of meth's crime-inducing effects. In this respect they are unique, given that, comparatively, the identities of other groups using amphetamines (and many other drugs) have been ascribed positively viewed characteristics, and in accordance with culturally approved drug use, which has removed them from discursive stigmatisation and policy interventions.

\footnotetext{
30 See http://www.ssc.govt.nz/bps-celebrating-success-reducing-meth-use and http://www.stuff.co.nz/timaruherald/opinion/64407617/Cracks-show-in-drug-crackdown

31 Prime Minister John Key recently cited MAP policy successes, announcing that "(w)hen the Methamphetamine Action Plan was launched, New Zealand had one of the highest (meth) prevalence rates in the world...The fact that rate has more than halved is testament to the efforts of law enforcement, border and health agencies over the past five years. That effort has to be maintained in order to squeeze the trade in illicit drugs and to prevent New Zealanders becoming addicted to (meth) (www.national.org.nz)."
} 
For example, in spite of methamphetamine being pharmacologically similar to commercially produced amphetamines such as Ritalin (methylphenidate), and pharmacologically identical to others, such as Adderall (methamphetamine hydrochloride) (Rasmussen: 2008), when used by university students in a non-medical context these substances are constructed favourably as 'cognitive enhancers' (Holloway et al: 2013, Quintero: 2012). Explaining their use relies on accentuating the positively ascribed characteristics of students to achieve culturally celebrated goals by enhancing their concentration and prolonging their ability to study. Thus an enhancement related discourse helps maintain negative class distinctions between the identities of those using illegally produced methamphetamine and the users of prescription amphetamines (McKenna, 2011).

Ultimately, stigmatising methamphetamine users - and by extension the problematic users of other illicit drugs - serves an important ideological purpose. As Schneider and Ingram (2005) explain, constructing groups as underserving and then inflicting punishment on them is a means of gaining political advantage. It allows political leaders to subject 'dangerous' drug-using populations to draconian policies, which reiterates Linnemann's notion of 'governing through meth' by dramatically increasing securitisation measures to control the users of meth and other drugs. This is evident in the New Zealand government's recent initiative to administer welfare sanctions when welfare recipients fail compulsory drug tests, US citizens with felony drug convictions being unable to vote, the implementation of 'three strikes' and mandatory sentencing policies, and in some US states, revising child abuse laws by including 'meth crimes', which protect children from parents who use meth during or after pregnancy (Linnemman: 2012, Heather: $2013^{32}$ ).

\footnotetext{
32 See also http://www.sentencingproject.org/template/page.cfm?id=133
} 
Punishments however, are not levelled at the whole target population, they are tailored to individuals who are held responsible for their own actions. This allows policy makers to silence the role of structural forces in the lives of those who use drugs, because drug policy is underpinned by a belief in the absolute power of individual agency. Consequently, policies may tell us that, the causes of underweight and unhealthy babies at birth are traced back to mothers who use meth, not the unavailability of prenatal care; the over-representation of minorities in prison is to be explained by their drug use, not by "racial profiling, joblessness, loitering, vagrancy or gang laws that unfairly target gatherings of men of 'colour "(Schneider and Ingram: 2005:12).

Individual agency and rationality are thus core to constructing the identity of problematic users of methamphetamine and other illicit drugs in a policy context. Hence economic policy tools have commonly been deployed to regulate their behaviour, informed by the price, purity and ease of purchase data collated in IDMS ${ }^{33}$ and ADUM reports. These policies have been concerned with understanding the motivations, opportunities and decisions of meth users by first defining them as unfettered economic actors participating in a clandestine market (Ritter:2003).

Problematic users of methamphetamine and other drugs are thus regarded as having made defective choices, irrespective of policy approaches which at the same time assert that drug dependency is biologically determined (Brook: 2009). Much like obesity, drug addiction is viewed as an affliction which individuals 'choose', rather than as illness that individuals suffer from, resulting in affected individuals being judged as responsible for their condition. When compared with populations suffering from depression, anxiety or schizophrenia for example, individuals identified as 'addicts' are notably subject to harsh judgement, with attitudinal surveys demonstrating that individuals who are known to be drug 'addicts' are considered to more dangerous and less worthy of interpersonal

\footnotetext{
33 For example, according to the 2013 IDMS trend analysis, the price per gram of meth was also noted as decreasing sharply since 2011 (from $\$ 815$ in 2011 to $\$ 678$ in 2012), as 'easy to very easy' to purchase, with strength described as fluctuating to high (Wilkins et al 2013:104, 275, 293).
} 
relationships (Mannarini and Boffo: 2015). The reality that meth users and other problematic drug using groups manage unresolvable structural inequalities (see for example Bourgeois: 2003, and Bourgeois and Schonberg: 2009) is subjugated by preoccupations with the irresistible properties of methamphetamine and the chaotic lifestyles which accompany 'choosing' meth-use.

If social disadvantage is to be identified as explaining why some drug users engage in problematic drug-use, it is more commonly confined to understanding drug use as a direct, individualised response to economic disadvantage. In this narrative 'poor people' choose to use drugs to escape the day to day realities of poverty, and engage in criminal acts to fund their drug-using lifestyles (Covington: 1997, Foster: 2000). Again, this is another exercise in correlating crime with drug use and the dysfunctional choices made by those with few economic resources. Here crime, violence and social disorder are naturally equated with problematic drug use, a perception re-enforced by conflating representations of drug 'addicts' - see previous comment, drug using sex workers, and drug dealers, with welfare dependant young people, single parent families, people of colour - or people who 'naturally' populate deprived communities (Covington:1997, Measham et al:2001). As Covington (1997) explains, deprived communities and their inhabitants then become emblematic of the 'drug world', given that the marginalised drug user is represented as more dangerous and deviant. They are more likely to use drugs than their middle-class counterparts because they are reacting to unique social conditions. This in turn necessitates their policy categorisation as an 'at-risk' community, where risk is defined by the potential of poor choices being made by its members.

In this sense, despite being ascribed profoundly abhorrent identities ruled by the pharmacological effects of meth and likely governed by social disadvantage, in a policy context meth users remain, paradoxically, consumers, who are 'just like us' (Seddon: 2010) . The defective choice narrative is then re-deployed in a myriad of anti-meth and anti-drug campaigns, which warn consumers to 'just say no' (www.drugfoundation.org.nz). If non-coercive responses are offered to those making 
defective choices, these inevitably involve various harm reduction strategies, the logic of which re-enforces the view of drug-users' as rational actors who can be readily blamed for defective decision making (Seddon: 2010:87). Put another way, harm reduction aligns with this particular vision of the drug user, as evidenced by the provision of syringe-exchange systems, condom supply, and the production of resources conveying information about safer drug-using practices. Armed with the right resources, it is believed that meth users would therefore make the right choices when using drugs, and engage in less harmful drug-taking behaviour (ibid). Failures in self-governance are then recognised as justifications for punishing 'uncontrollable' drug users, as Rose explains,

"Those who refuse to become responsible, to govern for themselves ethically, have also refused the offer to become members of our moral community. Hence, for them, harsh measures are entirely appropriate. Three strikes and you are out: citizenship becomes conditional upon conduct (Rose: 2000:202, cited in Seddon: 2010:91)."

It is evident then, that in New Zealand and elsewhere, drug use has been defined in a policy context in accordance with identities and behaviours typically associated with problematic drug use and drug addiction. This has enabled official representations of drug use to privilege the drugs-crime relationship, while at the same time silencing another, more politically challenging narrative: "that drug use is, of itself, largely unproblematic - not deviant, but rather, an ever-present feature of human life" (Stevens:2007:86). Recreational drug use for example is widely understood as the most common experience of drug-taking behaviour, a view supported by the ongoing development of Measham, Newcombe and Parker's (1994, in Parker: 2005) normalisation thesis. As they have asserted, the prevalence of recreational drug use among young people is now a 'normal' and more acceptable feature of youth culture, and is no longer viewed "as deviant, unorthodox or anchored in specific subcultures"34 (ibid, and Pennay and Moore:2010:558).

\footnotetext{
${ }^{34}$ In response to earlier research which had located drug use within socially marginalised locations or among distinct subcultures, Measham, Newcombe and Parker (1994) shifted attention to populations of young people in the northwest of England. Noting that recreational drug use was widespread and evidenced as more acceptable among
} 
Acknowledging that many young people from diverse backgrounds frequently use what are assumed as being addictive drugs in a recreational context, has been difficult for policy makers to reconcile. The disease model of addiction is also problematized by the presence of widespread recreational drug use, given its core assertion that repeated exposure to addictive drugs results in changes in brain structure. That frequent drug use results in individuals who are unable to biologically regulate self-control is challenged by longitudinal studies which reveal the successful management of recreational drug use among 'responsible' citizens, as evidenced by McCoy et al's (2005:830) exploration of heroin use among a sample of white, female, middle class professionals. Their study presents a view of the mature drug user negotiating use alongside the cultural obligations of employment and parenthood. They demonstrate that, contrary to the view of casual heroin users being in the early stages of an inevitable journey towards addiction, the women in their sample adhered to well-planned cycles of use, thereby making a conscious decision to defy that expectation. Similarly, Pearson's (2001:195) ethnographic account of drug use among a social network of male adults and their partners revealed 'routine' recreational use of cannabis, amphetamines and cocaine. Conducting his research over a period of seven years, Pearson (2001) concluded that the participants he observed had valued life commitments including families and long-term employment, with many demonstrating they were able to live with drugs well into adulthood.

Policy tools have thus relied on understanding all drug use as problematic, but have targeted their coercive outcomes disproportionately at visible populations of drug users

\footnotetext{
young people, Measham et al. argued that recreational drug use, notably the use of 'club drugs' such as ecstasy, cocaine and LSD, had become normalised within 90s youth culture. However, critics of the normalisation thesis have pointed out that recreational drug use had already been documented as common among every social class throughout the $19^{\text {th }}$ and $20^{\text {th }}$ centuries (Stevens: 2011). Equally, not all forms of drug use have been culturally accommodated as they initially suggested, with many forms of drug use - notably the use of methamphetamine or intravenous drug use - remaining subject to heavy stigmatisation (Shiner:2009). Ongoing development of the normalisation thesis has since acknowledged that normalisation is contingent upon a process which is "negotiated by distinct social groups operating in bounded situations" (Measham and Shiner: 2009:502) Put another way, behaviours normalised in one social context may be disapproved of in another (Stevens: 2011).
} 
experiencing easily detectable drug-related harms. This contributes to a social division in the enactment of various law enforcement and harm reduction initiatives, which are unlikely to impede drug taking among those with considerably more resources, a point Weston (2010, cited in Singer and Page:2014:45) cogently makes:

"The pot, coke and ecstasy that enliven college dorms, soothe the middle class time bind and ignite the octane of capitalism on Wall Street are unimpeded by the street sweep, the prison cell and the parole-mandated urine tests that are routine in poor neighbourhoods."

To summarise the debates explored so far, authoritative understandings of problematic drug use have emphasised the drugs-crime relationship, thus justifying 'tough on crime' policies to tackle the 'disease' of meth addiction and the crime it allegedly causes. This has resulted in what Stevens (2011:74) describes as a symbolic and imaginary fragmentation between abstinent law-abiders and meth consuming predators. Despite having located the problem of methamphetamine in communities and among groups disproportionately subject to social disadvantage, this fragmentation enables policy makers to filter out the inequality of education, housing, employment and income when explaining problematic drug use (Stevens:2011, Wilkins et al: 2011). Utilising law enforcement approaches to respond to problematic drug use also helps legitimise these inequalities, as well as wielding unequal power on those who experience the harms they induce. Consequently, government claims of helping individuals limit problems associated with their drug use are unlikely to be accompanied by policy efforts which address the political and economic conditions contributing to the marginalisation of drug users (Moore and Fraser:2006:3041, Ministry of Health:2015).

Additionally, by using rational-choice models to locate decisions about using drugs at an individual level, authoritative understandings of drug use reiterate the ways in which contemporary social arrangements have been structured by preoccupations with risk (Williams:2013). As Seddon (2010:80) observes, the neo-liberal citizen is compelled to be a choice-maker, who must at all times act responsibly by minimising and avoiding negative risks. At the same time they must also be competitive and engage in culturally 
acceptable risk-taking in order to be innovative and economically successful. Drug use however, is deemed irreconcilably 'risky' and those who choose to use drugs will be held accountable, and likely blamed for, the risks they might endure. Thus violence, incarceration, HIV infection, addiction, and a myriad of other drug-related harms are to be understood as being 'self-induced' afflictions.

Tying these points to the aims and objectives of this thesis, these politicised representations of drug use fail to acknowledge that the responsibilities and capacities of drug-using individuals are constrained by a complex array of structural forces (Moore and Fraser:2006). By binding causal explanations of social problems and individual failings to assumptions about risk and drug-taking decisions, there remains a pressing need to theoretically illuminate "the complex ecological relationships between problematic drug use and social structures" (Valentine and Fraser: 2008:411).This is particularly relevant in a New Zealand context, given the dearth of theoretically robust scholarship exploring the lived experience of using methamphetamine and other illicit drugs.

This is not to suggest that understandings of drug-taking behaviour should therefore privilege social or structural explanations at the expense of accounting for individual agency and choice. Instead, as the scholarship which follows highlights, choice and agency are invariably constituted in social contexts, and are always constrained. Moreover, socially excluded and structurally vulnerable individuals who engage in problematic drug use are also far more constrained than individuals who are not subject to the same disadvantaging forces (Valentaine and Fraser:2008:411). These power dynamics, and the research evidence which communicates their importance in theorising drug use, are thus foundational to the arguments developed throughout this thesis: that drug-taking behaviours, and the decision-making processes which underpin them, result from what Measham and Shiner (2009:507) summarise as "a complex and fluid interplay" between structure and agency which can be understood in terms of "situated choice or structured action." 


\section{Theorising risk and decisions about starting, using and stopping drug use}

Deconstructing 'drug problems' and the assumptions which underpin them has been achieved by scholarship theorising links the between individualised experiences of drug use and the socially situated context of their occurrence (Hallam and Bewley-Taylor: 2010). Ethnographic research efforts in particular have contributed to this aim, by revealing a more complex, contextualised drug user, whose agency is both constrained, and at times facilitated by, the power relations of gender, class, ethnicity, culture, group membership, and economic marginalisation (Moore and Fraser:2006). This scholarship usefully foregrounds the narratives analysed in proceeding chapters, by introducing how these, and other, macro and meso-level factors have been theorised as conditioning individual responses to risk and drug taking behaviour (Williams:2013: Pilkington:2007): While the emic perspective of drug use analysed by other authors has acknowledged links between individual or group drug-taking behaviour and broader environmental factors (Becker: 1963, Young: 1979, Zinberg: 1984), Bourgois' (1995, 1996, 2002, 2003, and Bourgois and Schonberg: 2009) work has provided a more comprehensive appraisal of what would later be conceptualised as the inter-play between macro-level forces, social environments and drug-taking behaviour. Although not concerned with meth use, Bourgois' (1995, 1996, 2003:32) ethnographies of drug use among socially excluded immigrant and African American communities' highlight similar themes explored in this thesis in relation to politically mediated constructions of meth epidemics and its causal association with social deprivation.

Of note is his assertion that the pharmacological properties of 'addictive' drugs "are virtually meaningless" outside of their socio-cultural and political-economic contexts. As his work demonstrates to support this assertion, the racialized problem of 'crack' addiction throughout the 1980 s and 1990s, cannot be explained by attributing its attendant harms to distinctions between the effects of smoking, rather than simply snorting, cocaine. Given that populations of individuals addicted to crack are disproportionately concentrated in profoundly disadvantaged inner-city communities, it 
is more likely that structurally vulnerable individuals are at much greater risk of engaging in problematic crack-cocaine use (Bourgois 2003)

By exploring the social impact of urban de-industrialisation and the "carceral dragnet" set in place through mandatory sentencing requirements for drug users, Bourgois's work succeeds in challenging authoritative efforts to locate drug problems in individual, rather than structural or institutional, failings (Bourgois: 1996, 2003:36). His work also resonates with contemporary preoccupations with methamphetamine use, given that much of his scholarship formed a response to very similar panicked reactions overstating the nature and extent of the alleged US crack epidemic ${ }^{35}$.

In proceeding works, Bourgois (1999) extends his theorising about the relationship between politically and economically structured macro-level environments and individualised experiences of drug addiction. By documenting the lived experience of heroin addiction among homeless people, Bourgois (1999, Bourgois, Prince and Moss:2004, Bourgois and Schonberg:2009) asserts the importance of needing to account for the social and environment arrangements which expose homeless addicts to an array of deprivation harms. Here links are made between street-level environments, risk and specific drug-taking practices. Bourgois argues that the realities of environmental factors are often discounted, resulting in the misalignment of public health messaging with the day to day challenges of trying to use drugs 'safely' while homeless. As he observes,

\footnotetext{
35 The advent of smokable cocaine known as 'crack' and its visible use among America's urban poor established a new discourse of 'drug war' rhetoric in the political landscape of the 1980s. The call for a 'war against drugs' was characterised by extreme media scapegoating of minority populations and punitive state responses to those who use crack. Consequently, the Regan Administration's punitive drug policies resulted in the mass incarceration of America's urban underclass, with the number of drug offenders in prison growing eightfold, from approximately 50,000 in the early Regan years to approximately 400,000 by the start of the second Bush administration (Reinarman and Levine: 2004:183).
} 
"...the absolutist, unrealistic message of "never share cookers, cotton, rinse water" cannot be acted upon by homeless addicts with no running water and with precarious income strategies and vulnerable legal status...Well-meaning outreach workers who have heated homes and take baths every day often spread a moralizing anxiety among addicts who cannot possibly live up to the expectations of public health doxa... (Bourgois:1999:2161,2162)."

Again, Bourgois' $(2009,2010)$ work communicates a principle assumption of this thesis; that there is significant theoretical, and pragmatic, value in contextualising the lives of drug users, and that by accounting for external constraints over 'reasoned' choicemaking, the 'how's and whys' of drug taking for individuals living with drug use are rendered more visible. Other authors have built on the prescience of Bourgois' ethnographic scholarship to further develop these theoretical objectives. For example, Agar and Reisinger (2002) take a similar approach to explain why African Americans living in socially disadvantaged Baltimore suburbs were at much greater risk of opiate addiction during the 1960s. Like Bourgois, they also identify the need for theoretical frameworks explaining drug use which account for "the dynamic interactions of factors at multiple levels (Agar and Reisinger: 2002:225)". Doing so, they argue, situates the drug-using individual in relation to the complexities of drug use within friendship groups, the influence of political-economic shifts in drug markets, and the wider implications of economic and racial exclusion.

Questioning how these environmental complexities intersect the lived experience of drug use has been central to scholarship shifting attention to the decision-making processes which underpin drug initiation and different drug-using practices in socially situated contexts. Rhodes' $(1997,2002)$ risk environment framework is fundamental to this shift in research focus, and is used in this thesis to help inform the analyses of poly drug-use and the influence of social relationships on drug-taking in chapters four and five. Rhodes' $(2002,2009)$ work contributes to the theoretical assertions developed throughout this thesis by problematizing the notion that engaging in 'risky' behaviour such as methamphetamine use is the outcome of individualised 'choice-making,' as assumed in neoliberal explanations of drug use. As Rhodes (2009:193) argues, primacy 
should instead be given to how individualised experiences of risk are situated differentially in the context of 'risk environments', and how these environments shape an individual's ability to avoid risks associated with problematic drug-taking behaviour.

Risk environments are defined by Rhodes (2002) as both social and physical environments, in which the interplay between micro, meso, and macro level factors increases the likelihood that drug users will experience harm. Rhodes $(2002,2009)$ and other authors (Rhodes and Quirk:1998, Rhodes, Singer, Bourgois, Friedman, and Strathdee:2005:1026, McKenna:2014) have applied this construct to evaluate how risk environments elevate the risk of individuals being exposed to HIV and other blood borne viruses. In demonstrating its efficacy in informing "structural HIV prevention", this work reveals that, at a micro-level HIV risk is exacerbated by the influence of interpersonal relationships, where sharing needles may be regarded in the context of intimate sexual relationships as low risk or symbolic of commitment to long-term romantic involvement. At the meso-level, gendered power disparities in social or group interactions may influence women with limited resources to engage in risky sexual practices when exchanging sex for drugs. Meso-level forces can also include community, institutional or organisational responses, such as localised policing strategies disturbing patterns of syringe exchange use or syringe availability (ibid:1027). Environmental factors operating at a macro-level include broader structural realities such as punitive laws and policies, as well as wider cultural beliefs exacerbating drug harm, such as the institutional stigmatising of drug users experiencing addiction.

Articulating many of the theoretical assertions in Bourgois, Agar and Reisinger's work, risk environment scholarship similarly highlights that vulnerability to HIV infection and other drug-related harms is not simply the product of agential decision-making or wilful self-destruction. It is more usefully theorised as resulting from the interplay between, and the impact of 
“...large scale social, physical, economic, organisational and policy systems which combine with micro level factors to 'structure' the risk environments in which HIV risk and harm is produced and reproduced (Rhodes et al:2005:1028)."

The theoretical perspective of drug-use and risk advanced in applications of the risk environment framework has been supported by other research efforts studying the epidemiology of disease infection and how it is influenced by drug taking behaviour (Bourgois: 1999). Epidemiological approaches to researching drug use account for structural vulnerabilities to explain why some drug users' engage in behaviours deemed 'risky' by public health experts. The perspectives of drug use provided by this research reiterate a central premise of this thesis: that authoritative understandings of drug use and harm reduction discount the role played by "intersecting social, spatial and material contexts in shaping the very experience of "choice'" (Fast et al.: 10). Moreover, often decision-making in the context of drug use and experiences of social disadvantage does not involve reflexive assessment, nor does the "flow and pace of experience" within problematic drug scenes "permit, let alone accommodate, 'reasoned choice-making"” (Mayock: 2004:363).

In taking this approach, in her evaluation of injection-related risks among a social network of drug users in western Sydney, Maher (2002) documents the unique practice of 'back-loading'. A technique that had not previously been documented in Australia, back-loading involved distributing drug solutions by using one syringe to 'squirt' solutions into the 'back' of other syringes. Maher (2002:318) explains that, from the perspective of individuals engaging in street-based injecting practices, back-loading is not a risk behaviour, nor is it irrational or self-destructive. It is regarded instead as an efficient, equitable and low risk technique of distributing a highly sought after resource among a group of drug users negotiating a sub-optimal injecting environment. Moreover, risks associated with cross-contamination are often less threatening to drugusers than the more immediate possibility of overdosing or being subject to arrest. 
Kirst's (2009) work reveals a similar logic in drug-using practices among a social network of crack users in Toronto, where the value in sharing crack pipes exposes group members to an array of health risks. Her participants noted that sharing a crack pipe was regarded as a practice which offered benefits to the pipe owner. Given that residue from smoking crack accumulates inside pipes each time it is used, the owner of the pipe can lay claim to the residue and smoke it at a later date. For socially excluded drug users with limited resources, crack residue is a valuable commodity, and the desire to accesses it influences the risk-behaviour of sharing crack pipes. Kirst (2009) also notes that the risk of pipe-sharing is further exacerbated by many users refraining from carrying pipes due to being fearful of police enforcing paraphernalia laws.

Damage to vascular health and increased risk of heroin overdose has also been explained by Mars, Fessel, Bourgois, Montero, Karandinos and Ciccarone's (2015) examination of how local heroin markets influence risk-taking behaviour. Comparing the localised heroin marketing and consumption practices they observed in San Francisco and Philadelphia, Mars et al (2015) noted that drug users in both locations would actively pursue heroin sources implicated in overdoses. This strategy provided users with a logical means of determining which heroin being sold by street dealers offered the most potent effects. As they describe, "the narrow margin between euphoria and overdose" encouraged frequent users to actively take risks when consuming more potent forms of overdose-implicated heroin (Mars et al.: 2015:50).

In addition to evidencing the methodological efficacy of capturing emic perspectives of drug use (a point explored more closely in chapter 3 ), these research examples highlight that understandings of drug-related health risks are subjective. The logic of what constitutes risk is constructed through shared understandings of risk-taking, which are in turn subject to the influence of specific drug-using environments (Rhodes:2002, Williams: 2013). These evaluations of risk-taking also signpost may of the experiential themes analysed in chapters five and six of this thesis. They accord with participants' 
decisions about initiating meth-use and modifying drug-using repertoires through the accumulation of socially mediated risk knowledge. They also communicate the significance of relational dynamics and connectedness with other drug users when decisions about drug use are made, as participants had similarly identified. Their value in helping inform appraisals of drug use and risk also highlights the limitations of, and pressing need for, similar qualitative evaluations of methamphetamine use in New Zealand.

Comparatively, New Zealand-based scholarship utilising qualitative methods to explore methamphetamine use in a similar health-focussed context has been confined to the efforts of Sheridan, Butler and Wheeler (2009:12, 15), and Butler, Wheeler and Sheridan (2010). These authors can be credited with providing the first, as well as two of only three, qualitative research examples (published at the time of writing this thesis) examining methamphetamine use in a New Zealand context. Sheridan et al.'s (2009) initial work is of value in revealing the route of ingestion by first time meth-users, and what influence 'specialist knowledge' provided by partners or friends had on the process of initiation. There are however, limitations to their findings: they conceptualise risk and risk taking behaviours in terms of negative health outcomes (associated with preparation and administration of methamphetamine), without exploring how risk is conceptualised by their participants. The focus of their work also excludes an account of how risk-taking behaviour is influenced by shared understandings of meth use and risk, or by broader environmental considerations, despite succeeding in revealing the social contexts in which meth was used.

In their proceeding work Butler, Wheeler and Sheridan (2010) take a similar approach to effectively detail an array of physical and psychological harms experienced by polydrug users who used methamphetamine. This research provides a comprehensive understanding of methamphetamine use and harms to health. However, it also excludes from its focus social, cultural and structural arrangements intersecting participants' 
experiences of methamphetamine use. Additionally, Butler et al. (2010) correlate methamphetamine use with participants' experiences of psychosis and acting violently. While there is logic in needing to summarise all harms, the exclusion of biographical data when contextualising participants' meth-using experiences can exacerbate stereotyped understandings of meth and meth users. ${ }^{36}$

Sheridan et al. (2009) also identify that the majority of their sample were experienced poly-drug users, re-enforcing other research findings which indicate that most first time methamphetamine users have experienced prior trajectories of poly-drug use (Kosten et al: 2012, Carbone-Lopez et al: 2012, Hobkirk et al: 2016). This raises broader questions about research limiting its focus to drug users' experiences of one particular drug, when poly-drug use is notably present, and highlights a common gap in both NZ-based and international drug scholarship. Importantly then, by situating meth use in the context of other forms of drug use, the intention of the research developed for this thesis is to examine how the meanings participants attached to the use of particular drugs, and the significance of poly-drug use in understanding transitions towards more harmful, or 'risky', drug-taking practices.

Scholarship which further demonstrates the need to account for agency, culture and structure in drug-taking decisions as this thesis argues, has incorporated in it analysis the role of ethnicity and gender in experiences of drug initiation and use. Research efforts accounting for these variables in decisions about drug use and risk help in further establishing how social and structural forces converge in ways to constrain decisionmaking processes and limit the capacity of individuals to engage in risk avoidance. Of note are two recent explorations of methamphetamine use which illustrate how

\footnotetext{
${ }^{36}$ For example, in Sommers and Baskin's (2006:672) evaluation of meth use and violent behaviour, work violence was not demonstrated as an inevitable outcome of chronic methamphetamine use, indicating that pharmacology was not "destiny" (2006:672). Their work challenges the prevailing view of methamphetamine use resulting in a homogenous experience for users, notably where pejorative meth using images have been anchored to the immediacy of psychosis and violence.
} 
environmental arrangements in disadvantaged non-white drug-using communities inter-play with individual level experiences of problematic methamphetamine use:

McClean, Hengsen, and Stephens (2017) provide one example when examining factors exacerbating methamphetamine initiation and dependency among Australian Aboriginal communities. Their work communicates how experiences of profound historical trauma, dispossession and punitive social policies had manifest in intergenerational drug addiction. These experiences increased the risk of proceeding generations engaging in problematic poly-drug use. Aggressive distribution of methamphetamine by motorcycle gangs also capitalised on Aboriginal people's experiences of social exclusion, resulting in dealers using the close-knit nature of Aboriginal communities to facilitate the sale of meth. Threats of violence towards family members from 'bikies' seeking compensation for 'ice' debts, and meth's association with violence, also contributed to disconnecting aboriginal youth identified as using meth from their families.

Hobkirk, Watt, Myers, Skinner and Meade (2016) similarly explore the confluence of social disadvantage and ethnicity in their evaluation of methamphetamine initiation in South Africa. Their work highlights that, among the black drug users they interviewed, methamphetamine was a ubiquitous feature of their communities. Initiation into meth use was also deemed by these drug users as an inevitable transition in their poly-drug use given ease of access and low cost. In contrast to the stigmatising of methamphetamine noted in other countries, methamphetamine in black South African communities was perceived as a fashionable and popular drug. Initiation was thus encouraged through a desire for social conformity and acceptance given its widespread use. 
Many of their participants also reported that family, friends and work colleagues were already users, and exposure to meth in their social networks facilitated their own experiences of meth initiation. A lack of familial supervision also made it easier for younger participants in black communities to start using methamphetamine without fear of reprisals from older, authority figures. Hobkirk et al. (2016) identify these socially situated factors as inter-playing with the broader realities of stress and trauma associated with high levels of social deprivation in the Cape Town area. This rendered black South Africans vulnerable to mental health issues, and in the absence of opportunities for counselling, the risk of engaging in drug use in response, increased significantly.

Although ethnicity and culturally specific experiences of methamphetamine use are variables excluded from the focus of this thesis ${ }^{37}$, research exploring the inter-play between historically bound experiences of race and drug use contributes to theoretical debates explored here: Accounting for race in analyses of drug use supports a key theoretical assertion, that 'choice', and the ability to avoid or minimise risks, is constrained within social contexts. For drug users subject to experiences of profound social exclusion and historical racism, choice is invariably constrained to a much greater extent by immutable structural forces (Valentine and Fraser: 2008). In revealing the dynamics of social relationships in a culturally specific context these analyses accord with the evaluation of social relationships presented in chapter six, which theorises their significance in exposing individuals to prolonged engagement in problematic drug use.

\footnotetext{
37 In the planning stages of this research, prior to ethics committee approval, it had been intended to focus exclusively on the meth-using experiences of Māori drug users. However, a revised focus followed a lack of available, and suitably qualified, co-supervisors, and concerns about successfully recruiting and appropriately engaging with the narratives of Māori respondents. The latter consideration also spoke to broader cultural realities about whether Pakeha (European) researchers - and notably an inexperienced Pakeha researcher - can, or should, contribute to kaupapa Māori thought and practice, given that a principle of kaupapa Māori is "for Māori, by Māori" (Jones:2012:100). Consequently, Māori participants' $(n=7)$ were not questioned about the lived experience of drug use in relation to their cultural identity.
} 
As McClean et al. (2017) and Hobkirk et al.'s (2016) work demonstrates, the prevalence of normalised drug use among social networks comprised of family members and peers facilitates exposure to opportunities for drug initiation. Coupled with exposure to druguse through the allure of achieving economic success in illicit drug markets, these mesolevel forces help replicate and entrench inter-generational experiences of drug-related harm. (Bourgois: 2002, O’Brien et al: 2008, Cooper, Fox, Rodriguez: 2012, Wilkins et al: 2015). Consequently, in historically disadvantaged communities where particular ethnic groups are over-represented, drug problems 'huddle together' with other social problems, resulting in these communities disproportionately experiencing their collaborative impact. Realities excluded in politicised constructions of drug problems, these factors more accurately explain why structurally vulnerable individuals experience drug dependence, more often than simply drug use (Stevens: 2011:28).

Identifying how gendered realities intermingle with experiences of drug use also contributes extensively to theorising the role of structure and agency in drug-taking decisions. By focussing on the "gendered contours" of the structural and symbolic constraints experienced by drug users, research examining the significance of gender further problematizes explanations of drug use privileging the individualisation of risk (Bourgois et al.:2004:253). It reiterates that formulations of risk are embedded within broader gender, class and race politics, challenging the idea that experiences of risk are neutral or apolitical in nature as assumed within pejorative understandings of drugs and drug users (Chan and Rigakos:2002). As Chan and Rigakos (2002:743) explain when examining the interplay between risk, crime and gender, demonstrating that risk is gendered succeeds in revealing how men and women are confronted by, and negotiate, a myriad of different environmental risks.

These theoretical imperatives have informed understandings of drug-use in an array of gendered contexts, which typically emphasise women's experiences of asymmetrical power relations when participating in 'male' drug-using scenes. As Bourgois' work illustrates (2004:255), in the context of problematic drug use and social disadvantage, 
the structural position of female street injectors is to be understood as being shaped by "abusive and parasitical relationships", and "sexual predation" at the hands of male partners, friends and family members. Women who use methamphetamine have been described by Joe (1995:284) as quickly becoming cognisant in relationships with male meth users, that "the 'ice scene' is a man's world", where men exert control over distribution of the drug and where women's use of methamphetamine is regulated by the men in their lives. Other researchers have also emphasised that female drug users occupy a marginal position in an inherently male drug culture, by theorising women's drug 'addiction' as being enabled by emotional dependency in the context of intimate relationships involving drug use (Gorman et al:2003, Moore and Fraser:2006). As Rivaux, Sohn, Armour and Bell (2008:973) describe, drugs and relationships with male partners are to be viewed as helping women manage feelings of sadness, anger, insecurity, and past experiences of sexual abuse, mistakes and abandonment.

While these appraisals of drug use are of theoretical value in highlighting gendered experiences of problematic drug use, over-emphasising power disparities has been criticised for discounting women's ability to negotiate power and navigate risk in drugusing contexts (Hutton:2004). Many of these themes accord with experiences storied by female participants in the research carried out for this thesis, notably in relation to significant experiences of victimisation. However, as their involvement in male dominated drug economies reveals, experiences of men exercising power and control do not automatically equate with women understanding themselves as being powerless or marginalised.

Morgan and Joe $(1996: 139,140)$ examine this in their account of women successfully engaging in the supply, manufacturing and distribution of methamphetamine. They provide a competing perspective of female drug use, where the risks of violence, gang rivalries and arrests were experienced by women alongside positive experiences attributed to being a successful meth 'dealer'. Dealing was acknowledged as enabling 
their control over social and intimate relationships, traditional household responsibilities, and exercising control over their own meth use. Thus, rather than being independent of power exercised by men, women incorporated into their lives multiple role expectations in order to manage tensions between being 'good' wives and morally virtuous mothers, and their doubly deviant status as female users and sellers of methamphetamine.

Hutton (2005) also advances perspectives of female involvement in drug dealing to explain how women can negotiate what has previously been assumed as being an exclusively masculine world. She notes that, in the absence of traditional subcultural capital, female dealers succeeded using social strategies. These included pooling resources with well-established male dealers and managing relationships with 'workers' distributing drugs to remain invisible from competing male dealers, who were more able to use violence and intimidation. This perspective of female involvement in drug use, suggests Hutton (2005:548), helps reveal an alternative view of women as central, rather than exclusively marginal, in drug-using contexts subject to hegemonic masculinity.

In other explorations of meth use, research has identified the ways in which culturally engrained gender ideologies intersect cultural meanings attached to using methamphetamine. These social and cultural processes are shown as converging in the manifestation of other gendered risk experiences, further demonstrating the inseparability of drug-taking from the social, cultural and politicised contexts of its occurrence.

Challenging policy scholarship's understandings of meth use as more often occurring among socially marginalised populations, Boeri, Harby and Gibson (2009:143) provide an example when exploring how meth's energy inducing effects enabled comparably affluent women to improve domestic productivity and succeed in the realisation of "a normal suburban life". Gorman et al. (2003) note similar gendered aspirations as 
contributing to female motivations to use methamphetamine. Women they interviewed identified the positive benefits of methamphetamine as inducing weight-loss and helping them stay 'thin', and improving social and sexual confidence in relationships. However, both of these studies noted that using methamphetamine and enjoying its positive effects had exposed women to the risk of meth dependency, with many eventually transitioning towards more harmful drug-taking practices. Lin and Zhang (2014:773) provide another example when documenting the relationship between methamphetamine use and gendered cultural mores in China. Noting that in many Chinese provinces, prostitution is considered "better than poverty", they identify how Chinese escorts aspire to earn more money by agreeing to becoming 'ice-skaters' escorts who use methamphetamine - and have sex with male clients. While this practice increased women's earning power, it also exposed them to police corruption, the risk of 'entrapment', and China's punitive responses to 'synthetic' drug users.

Scholarship exploring men's use of methamphetamine has posited that gendered rationales also underpin the social efficacy of using meth to enact, and conform to, traditional notions of heterosexual masculinity. As Boeri, Harby and Gibson (2009:143) noted in their evaluation of methamphetamine use within suburban households, men's motivations for using methamphetamine accorded with traditional gendered divisions in household labour. These included having more energy to work over-time in paid employment, and getting "more hours out of the day" to maintain a family and a job. Brown (2010) similarly identifies the role of methamphetamine in enhancing notions of masculinity, productivity and skill among young white and American Indian males engaged in seasonal manual labour. In this context Brown (2010:255) observes that meth use also facilitated the "display of young, bachelor male behaviour" outside of work, in order to help emphasise skills in fighting, drinking and other risk-taking behaviours. Other forms of masculinity have also been identified as influencing methtaking behaviour, notably in research exploring meth's normalised inclusion in sexual practices - or 'chem sex' - among groups of men having sex with other men (Ahmed et 
al:2016) ${ }^{38}$. Methamphetamine use among gay men attending gyms has also been described by Halkitis et al (2008:47) as indicative of a subculture which celebrates "physical prowess, drug use and sexual adventurism", factors they suggest manifest in what has been described as "the buff agenda" (ibid: 47).

There is then a similar gendered logic underpinning the motivations of women and men using methamphetamine to pursue and enact culturally celebrated gender ideals. Conversely, as the identity shifts in becoming 'meth addicts' storied by male and female meth users in this thesis reveal, behaviours indicating a loss of control over meth use are similarly understood in relation to gendered forms of cultural stigmatisation. Like institutional constructions of gender and ethnicity, stigma can also be theorised as a structural process, which interplays with other social, cultural, and individual level factors, shaping experiences of drug use, risk, and importantly, social identity. For Hansen, Bourgois and Drucker (2014:77) the stigmatising of 'those on the ground' is explained as being governed by overarching symbolic power and class relationships operating on multiple levels. They argue that it is these relationships which are "at the crux of what can be conceived of as structural in the processual concept of stigma." By including the process of stigma in theoretical debates about structure, agency and drug use, the ways that authoritative discourses have constructed understandings of drugtaking and risk are made more apparent.

\footnotetext{
38 Slavin (2004) sheds light on the recreational intravenous use of crystal methamphetamine among gay men in Sydney. Slavin builds on the presupposition that gay culture has a longstanding association with drug use given the contexts in which 'party drugs', dance music and social groups of gay men intersect. The use of crystal methamphetamine in particular, is associated with high risk sexual practices of some gay men and its attraction in magnifying and pro-longing sexual pleasure. As a result, meth has, in some contexts, attracted the moniker of being a 'gay drug' (see for example Shernoff: 2005 and Chartier et al.: 2009).
} 
Gender-based stigmatisation applied to those unable to control their meth use is powerfully communicated in the Montana Meth Project, the 'Faces of Meth' campaigns $^{39}$ and other anti-meth rhetoric. It has been observed by Webb, Deitzer and Copes (2017:1393) that in these campaigns, more than half of all the images used include demeaning and sexualising pictures of women associating female meth use with meth-induced prostitution ${ }^{40}$. These addiction tropes also communicate the effects of methamphetamine as being far more ruinous for women than men. Although stigmatising drug use affects all genders, women are also particularly vulnerable to stigma given that drug use is considered oppositional in nature to traditional notions of femininity and motherhood (Webb et al.: 2017). Their doubly deviant status places them at increased risk of drug-related harms resulting from stigma, a risk likely magnified for women who use methamphetamine, due to its cultural association with "an allencompassing sensation of dirtiness" (Manderson: 1995:802, McKenna: 2013).

Tropes associating meth use with a culture of poverty as immortalised in images of poor, toothless drug users have also resulted in assigning additional forms of stigma to both male and female meth users experiencing social disadvantage (Flynn and Hoffer:2017). These additional layers of stigma magnify the individual failings of those who are addicted, welfare-dependent, or unemployed, and suggest that meth use is itself the root cause of poverty, as imagined in authoritative explanations of drug use. Stigma is also further compounded when drug users' identities violate the cultural norms of communities they belong to.

While understandings of stigma are typically deployed to explain how users of meth and other drug users are imbued with a sense of individual failing and corrupted self-identity (McKenna:2013), stigma can, at the same time, constrain meth use and reduce exposure to risk. Copes, Kerley, Angulski and Zaleski (2014:435) evidence this process when

\footnotetext{
${ }^{39}$ See http://www.methproject.org/answers/will-using-meth-change-how-i-look.html\#Mug-Shot-Match$\underline{\text { Up }}$

${ }^{40}$ See appendix A - "15 Bucks for sex isn't normal. But on Meth it is."
} 
accounting for the confluence of gender and etnicity in shared understandings of methamphetamine's effects and the cultural construction of meth-using identities. They note that, compared to perceptions of crack cocaine as being more pure and less risky, 'Black' (African American) female drug users associated methamphetamine with an array of chemical impurities and deleterious health effects. Women they interviewed also expressed a fear of losing their teeth and picking bugs in their skin, visual cues they associated exclusively with White drug users. Copes et al. (2014:438) argue that "the powerful nexus between meth and lower-class Whites likely acted as a protective factor", encouraging black women to avoid meth use. Copes et al. (2014:438) also observed that the stigma of using meth among Black drug users was much stronger than for crack cocaine. As they summarise, women believed they could use crack, "just not White people's crack."

Further developing Measham et al.'s $(1994,2004,2009)$ normalisation thesis, Hutton (2010) provides another perspective of constrained methamphetamine use among socially included young New Zealand drug users involved in night clubbing scenes. Hutton's work provides the third of only three examples of published qualitative research examining meth use in a New Zealand context available at the time of writing this thesis. When examining the use of methamphetamine in the context of clubbing, Hutton's research suggests its use was less common among her participants, with meth being viewed "ambiguously" by those who had tried it. One 23 year old participant demonstrates this point, indicating their use of meth and an awareness of stigmatising meth discourses:

"Your first hit is like bam, you know, everything is so clear....But then it's a really horrible drug what it's done to people psychologically, what it's done to New Zealand, people lying to their friends so they can take it."

Researcher: "So you have taken it then?"

"Definitely. I tried it and you dabble in it every now and then. It's the sort of thing that every time you have it you know why you don't take it all the time, you know? (Cited in Hutton: 2010:105)." 
Hutton's (2010:107-108) work indicates that, unlike the use of cannabis and ecstasy, which were normalised in the sense of being culturally accepted by all participants, the use of methamphetamine divided attitudinal responses, with some 'clubbers' being vocal in their disapproval of its use. Situated in the context of clubbing, negative attitudes towards meth - and by extension meth users - suggest that "normalisation does not apply to all substances" (ibid: 108). Moreover, evaluating drug use in a recreational context suggests that, contrary to 'not even once' anti-meth campaigns, occasional, controlled, meth use does not automatically equate with frequent uncontrollable use and experiences of addiction.

Identifying how ethnicity, gender, and socio-economic status converge in highly stigmatised drug-using behaviours challenges the individualisation of risk assumed in authoritative accounts of problematic drug use. The individualisation of risk and its theoretical origins are explored more closely in chapter five, but to summarise here: fundamental to the process of individualisation envisaged by Beck (1992) and Giddens (1984), is the assertion that, structural forces previously exerted through traditional certainties such as the nuclear family, life-long careers, gender roles, class structures and other fixed norms, have now weakened. It is argued these forces now exert far less influence over decision-making, and that individuals have the freedom to craft, or 'choose', their own biographies, rather than conform with "the strictures of structures" (Denscombe: 2001:160). However, as theorising risk-taking in relation to its environmental context makes apparent, choosing how to act cannot be disentangled from the influence of wider cultural and structural realities.

Situating the decision-making processes which intersect the lived experience of methamphetamine use in the context of broader environmental influences thus offers theoretical utility in understanding how drug-taking risks are conceptualised, and negotiated in social settings. Making risk environments visible also makes the structurally vulnerable position of problematic drug users visible, and helps in explaining factors which constrain disengagement from problematic drug use. However, contrary 
to the pejorative understandings of drug use evidenced in the previous exploration of panic discourses, individuals exercise agency when confronted with options that necessitate desistance from drug use. This process has been theorised through the application of life course criminology, which similarly emphasises the importance of social and structural constraints in explaining why individuals desist from crime. The application of life course criminology to desistance from drug use is introduced in the next section, in order to signpost the theoretical approach taken in chapter seven to analyse participants' narratives of desistance from drug use

\section{Life course perspectives of desistance from drug use}

Theorising the role of 'traditional certainties' in shaping drug taking behaviour has also been achieved within the life course perspective of crime developed by Sampson and Laub $(2005,2016)$. Life course evaluations of drug use help identify critical events and factors leading to changes in drug-taking behaviour, and analytically sequence events to explain how drug use interplays with social processes across the life span (Hser et al:2007). Examining life time trajectories of drug use contributes to debates explored in this thesis by revealing how individuals engaged in extended periods of heavy drugtaking are able to transition towards a life stage marked by stopping drug use. This shifts theoretical attention to the significance of desistance, further explicating the ways in which agency, action, situations and structures intersect over time to influence decisions about disengaging from the lived experience of drug use and drug dependency (Williams: 2013).

Mapping decreases in criminal behaviour from adolescence to adulthood, Sampson and Laub (2016) conceptualise the life-course process by identifying how criminal activity is constrained through the convergence of time, maturation and structural or institutional 'turning points', such as employment, marriage, or military service. As they explain, structural turning points are life events which modify trajectories of crime by enabling individuals to create new social bonds and accumulate positive social capital, which increases informal controls over their behaviour. Marriage, employment and raising 
children also results in additional life responsibilities, limiting the potential for contact with social networks involved in offending. These transitions often require individuals to move to new social settings, further disrupting past behavioural routines and encouraging commitment to non-criminal self-identities (Sampson and Laub: 2016 and Williams: 2013).

Sharing conceptual similarities with the notion of inter-play, life course perspectives of offending articulate the reciprocal relationship which exists between each of these elements (Williams: 2013). To explain decision-making processes, individuals are understood as being able to exercise agency, but only through constant interaction with their environments, which results in their experiencing 'situated choice'. In this context, decision-making is not exclusively dependent upon personal choices, nor is it solely determined by the availability of institutional options (Hser et al: 2007). Instead, individual-level decision-making results from a dynamic and time-varying combination of agency and structural location (Sampson and Laub 2003).

Life course evaluations of drug use have expanded Sampson and Laub's (2005) conceptual framework to explore the decision-making processes which underpin desistance from drug use (van Royen, Anderson, Vanderplasschen, Colman, and Vander Laenen: 2017). These evaluations identify desistance experiences which accord with the narratives of stopping drug use analysed in chapter seven of this thesis. They help inform discussions about risk and drug taking by revealing how agential decision-making processes are shaped by different turning point experiences. In doing so they make apparent that desistance from using drugs is not dependent on positive factors being present as originally conceptualised by Sampson and Laub (2005); desistance also results from the lack of, or avoidance of, other factors, which are often profoundly negative (Van Royen et al: 2017). More broadly, life course evaluations of drug use also theorise thinking and behaviour discounted by authoritative accounts of drug use, challenging portrayals of addicted users as being pathologically incapable, or unwilling, to disengage from using drugs. 
Interviewing a sample of drug-involved offenders, Colman and Vander Laenen's (2012:3) work for example, emphasises that variations in individual level decision-making result in different motivations for desistance. They identify how stopping drug use and criminal offending was for some participants, influenced by a conscious process, which involved expressing a desire to avoid the risk of imprisonment. The prison experience itself however, was not regarded as a risk, rather, being in prison presented a risk to their ongoing participation in long-term intimate relationships. For other participants, motivations for stopping drug use were difficult to articulate beyond identifying what they described as "a click" or trigger. These typically followed a moment of selfreflection about becoming tired of their drug-using lifestyle. In some instances selfreflection had been initiated by their drug use having contributed to a loss of employment or damaged relationships with family members. These experiences accorded with stereotypical understandings of desistance requiring drug users to "hit rock bottom'.

Herbeck, Brecht, and Lovinger's (2014) evaluation of factors contributing to desistance from methamphetamine use notes similar variations in decision-making processes. Some of their respondents described being motivated to stop using methamphetamine due to an intrinsic acknowledgement of needing to change. This was signalled by their becoming guilty about using methamphetamine and increasingly aware that using methamphetamine was impacting negatively on their quality of life. For another group of respondents, decisions about stopping methamphetamine use were linked to external influences. These included the threat of losing access to children because of their drug use, pressure from partners and family members, and being offered the opportunity to engage in treatment for addiction.

The decision-making processes which initiate transitions towards desistance have also been theorised as contingent upon individuals re-constructing a meaningful sense of identity. According to van Royen et al. (2017:618), in the context of desistance, such an identity must contain a transition from an 'addict' or 'criminal', to a socially conforming, 
and culturally approved individual. This requires individuals to invest in new pro-social identities or a 'replacement-self', a process which often follows being 'awakened' by the impact of negative life events, and wanting to re-establish bonds with non-drug using social networks. When articulating a desire to create a new self-identity it is common for individuals' who stop using drugs to express being motivated to become 'good' parents, 'hard workers', or committed drug-free partners (Colman and Vander Laenen: 2012).

Analysing drug offenders' narratives, Bachman, Kerrison, Paternoster, O'Connell and Smith (2016) explain this as being a cognitive process where drug users are motivated by an increasing awareness that, if change does not occur, they will succumb to an addict identity, or, the 'feared self'. To sustain this change individuals actively seek out opportunities to accumulate positive social capital through employment, participation in sporting activities, or in relationships with non-drug using partners (van Royen et al: 2017). That self-identity and desistance are part of an inter-related cognitive process is also evidenced by Martin (2011:348) when looking at female injecting drug users who are mothers. As she describes in reference to the process of transitioning, one mother "had yet to find herself between the experiences of being a drug 'addict' and her role as being a 'mum'." For other mothers interviewed by Martin (2007), identity transformation occurred through a process of self-stigmatisation, where mothers' identified themselves as 'junkies' or 'druggies' in the past, in order to express their commitment to desistance in the future.

While there are often similarities in reasons and experiences cited by drug users as initiating desistance (van Royen et al 2017), as Hsr et al. (2007) note in reference to turning points, what motivates one drug user to stop may not motivate another. Stone's (2015) work make this apparent in relation to the constraining effects of motherhood, identifying that pregnancy and impending childcare responsibilities are not automatically experiences which motivate women to stop using drugs. Some of Stone's (2015:5) respondents reported that, although they were aware of the health and legal 
risks associated with using drugs while pregnant, those risks were mitigated by understanding their drug use as being "under control". In their evaluation of injecting 'careers', Levy and Anderson (2005) also note that theories assuming drug use is agegraded and changes across the life-course are problematized by trajectories of intravenous drug use among older injectors. As they summarise, despite the habitués of 'hitting rock bottom', retiring from a lifetime of chronic injecting drug use was doubtful for older users, except through serious illness or death. Older injecting drug users were permanently committed by choice, or necessity, to maintaining their drug using careers, "even in the face of personal anomie" (ibid: 255).

Life course evaluations of drug use thus demonstrate that desistance is a non-linear transformational process, which may be difficult to realise for some groups of drug users. Like drug initiation and drug use, desistance is influenced by similar structural factors such as employment, legal interventions and stigma, similar social factors such as social networks and intimate relationships, and similar subjective experiences of exercising agency when making decisions about drug use (van Royen:2017). In addition to creating an analytical space to account for why individuals desist from problematic drug use, life course evaluations of drug use re-affirm the theoretical importance of understanding agential decision-making in relation to, rather than as distinct from, social and structural forces. This relationship, as explored throughout this thesis, is particularly salient when formulating ways of empowering individuals to stop using drugs as Colman and Vander Laenen (2012:7) point out:

"Intrinsic motivation is important but not sufficient to abstain. The (immediate) social world plays an important role in this regard. It is not because you want to change that you will succeed. Structural constraints (and) barriers for instance the stigma of former drug users or the lack of job opportunities for former prisoners play a significant role." 


\section{Conclusion}

This chapter has argued that ongoing authoritative constructions of New Zealand's meth epidemic have re-deployed alarmist drug-user tropes alongside familiar 'war on drugs' rhetoric. This has rendered individuals identified as problematic methamphetamine users vulnerable to cultural stigmatisation, and typically, disproportionate experiences of arrest and incarceration. It is argued that, despite evidence that social disparities exacerbate drug harms, the logic of rational choice continues to inform policy instruments lauded as harm reduction initiatives. These policies imagine drug users as unfettered agential decision-makers who must at all times adhere to the cultural imperatives of prudent risk calculation and risk avoidance (Seddon:2008). In sum, these components have allowed for populist conceptions of drug use and social disadvantage as being a mutually inclusive set of self-induced afflictions, achieved through poor lifestyle 'choices'.

The ethnographic scholarship reviewed here introduces thinking which counters these assumptions by asserting the importance of agency, structure and culture in shaping individual-level experiences of risk assessment and decision-making where drug-use is concerned (Williams: 2013). As risk environment and life course perspectives of drug use help conceptualise, decisions about drug use are culturally and structurally situated. They occur within social environments where drug-use inter-plays with immutable structural forces. The cumulative impact of these forces determines how individuals' are exposed to exogenous risks, while at the same time constraining their ability to actively engage in risk avoidance (Rhodes: 2002). For some individuals, trajectories of life-time drug use can also change in accordance with shifting structural positions. These shifts act as turning points, which can disrupt social arrangements conducive to problematic drug use, and at particular points in the life course, open pathways to, and maintain transitions towards, desistance (Sampson and Laub:2005, Williams:2013). 
These processes are comprehensively evidenced in scholarship theorising how ethnicity, gender and social status shape the structural contexts which influence experiences of risk. Accounting for these variables demonstrates that the trajectory of drug 'epidemics' is determined by social, political and economic forces, rather than the pharmacology of particular substances, as policy experts suggest (Bourgois:2003). These variables highlight that historical trauma and contemporary disadvantage converge disproportionately in minority communities, increasing their risk of transitioning from drug use, to drug dependency (MacLean et al: 2017). Gendered understandings of risk similarly emphasise that "women and men do not enter a universe of potential risks independent of one another "(Chan and Rigakos: 2002:743). Thus drug use and risk are inherently gendered experiences. Like racial minorities' experiences of drug use, they manifest in institutionalised power disparities, and cannot be universalised through objective calculations (ibid: 2002).

The scholarship reviewed in this chapter is thus foundational to informing the proceeding analysis of starting, using, and stopping methamphetamine use. It signposts the theoretical focus of this research and identifies the imperatives used to engage with the contextual nuances of drug-taking decisions storied by $17 \mathrm{New}$ Zealand drug users. Reviewing this scholarship also counters prevailing cultural assumptions that methamphetamine users are wilfully self-destructive. As this thesis argues, 'choosing' to use methamphetamine is rarely the outcome of individualised risk assessments. It is instead a social accomplishment, which results from the inter-play between individual choices, and an inseparable constellation of forces beyond the control of the individual (Farrell et al: 2011). 


\section{Chapter three: research methodology}

\section{Introduction}

This chapter sets out the qualitative methodology employed to record, thematically analyse, and theoretically engage with, meth-users' narratives of starting, using and stopping methamphetamine use. Methodology is conceptualised here as a theory or analysis of the research process, rather than the mechanisms of the process itself (Pereira: 2013:390) which also encompasses exploration into the implications and theoretical efficacy of using specific research methods. Additionally, it is acknowledged that qualitative research procedures operate within a naturalistic interpretive domain. These procedures are guided by the epistemological and ontological principles of social constructionism (Sarantakos: 2013:36). In evaluating these theoretical imperatives, it is argued here that the methodological foundations of qualitative research align with the aim of capturing an emic perspective of methamphetamine use, a perspective which makes apparent social and structural constraints which intersect drug-taking decisions.

It is argued here that fundamental to achieving this aim is the application of narrative methods, which Polkinghorne (2007) defines in simple language, as methods used in the study of stories. Accordingly, this chapter sets out and details the practical sequencing, of undertaking a narrative approach to collating, interpreting and thematically analysing participants' stories. It evaluates the theoretical efficacy of narrative methods, and sets out how they facilitate theoretical engagement with the experiences of drug use participants' storied when recounting their trajectories of drug use.

Reflecting on the efficacy and validity of utilising narrative methods, it is also argued here that analytical engagement with participants' stories succeeds in contextualising their drug-taking decisions, and brings into being the social, cultural and structural realities shaping transitions between starting, using and stopping methamphetamine use. Moreover, narrative methods assert the theoretical importance of listening to the stories of drug users in order to challenge the discursive arrangements which de- 
contextualise experiences of problematic drug use. They provide a means of engagement in wider drug-policy debates by contributing to a broader cultural narrative which is attuned to personalising drug users and willing to open up discursive opportunities that initiate constructive social change (Chase:2005).

\section{Social constructionism, interpretivism and qualitative approaches to researching drug-use}

What follows is an evaluation of the interrelationship between social constructionism and the interpretive methodological framework set out in the remainder of this chapter (Wenneberg: 2000, cited in Lindgren: 2005:6). Some of the key theoretical debates which surface when advocating for the efficacy of qualitative approaches to researching drug use are considered, as well as how these debates inform understandings of the methodological framework, and research instruments, chosen for this study.

When conceptualised as a social theory or a philosophical standpoint (as developed in the work of Berger and Luckmann (1966), Kuhn (1970), Gergen (1994), Hacking (1999) and others), the social constructionist ${ }^{41}$ approach to knowledge creation begins by emphasising that "the world we live in and our place in it are not simply and evidently 'there', but rather variably brought into being" (Holstein and Grubrium 2011:341). Social constructionist accounts of social phenomena recognise that there are multiple realities or multiple truths based on the construction of that reality, that there is no access to reality independent of perceptions of it, and there is no external reverent by which to compare claims of truth (Neuman:1991). Put another way, social constructionism recognises there is no direct connection between an independent, objective world and human experience; it is grounded in a doctrine of realism where an external world exists independently of representations of it (Warmoth: 2000, Nightingale and Cromby: 702).

\footnotetext{
${ }^{41}$ Constructionism and constructivism are terms often used interchangeably when discussing the philosophical foundations of methodology (see Williamson: 2006, Holstein and Grubrium: 2011), although some authors emphasise a distinction between the two. Of note is Gergen (1994), who associates constructivism with individual subjects' consciousness and mental processes, and constructionism with relations and communication in the social sphere. It is the latter definition emphasised here.
} 
There is then neither objective reality nor objective truth when adopting a social constructionist perspective as a qualitative researcher. On the contrary, the reality that all people experience in everyday life is ultimately a constructed reality - unique to each individual - based exclusively on their personal interpretation. (Berger and Luckman: 1966, Sarantakos: 2013:37 -38). Gergen (1994:70) emphasises this point noting how the different traditions and conventions of language-use anchors human experiences to different and often conflicting metaphors, and argues that language itself cannot move beyond metaphor to depict "the thing in itself".

Importantly then, reality as it is experienced by the individual and as it is communicated through language or other social endeavours, is subject to the interpretive influences of socialisation (Sarantakos: 2013). Socialisation intersects the ways in which individuals construct reality, by conveying meanings and educating individuals in where, under what conditions, and how, to assign meanings to objects, experiences and processes in everyday life (ibid). As Becker (1996:61) explains:

"The general idea is that we act in a world on the basis of assumptions we never inspect but just act on, secure in the belief that when we do, others will react as we expect them to...In this view, 'everyday understandings' refers to...the deep epistemological beliefs that underpin all such shared ideas, the meta-analyses and ontologies we are not ordinarily aware of that make social life possible."

Reality construction is therefore understood as the product of the inter-subjective nature of social life and the ways in which everyday realities are actively constructed in, and through, various forms of social action (Holstein and Grubrium: 2011:341). Gergen, Josselson and Freeman (2015:4) conclude that, when viewed through a social constructionist lens, as products of human action these realities are likely to be acknowledged by the qualitative researcher as being highly malleable, subject to enormous variances, and as resulting in cultural and temporal variations in human conduct. It is in making these presuppositions about the nature of human action that social constructionism is philosophically and theoretically distinct from positivist enquiry 
into the social world. Causal explanations based on 'scientific' measures of an objective world which exists independently of the 'knowers' are deemed ontologically problematic; the focus instead is on interpretive understandings (Hollis 2002, cited in Bottoms: 2008:89).

The application of an interpretive methodological framework is thus foundational to social constructionist accounts of social phenomena (Sarantakos 2011). It is within this framework that qualitative research methodologies are deployed, and where the epistemological tenets of interpretivism reveal how the researcher is to consider the reflexive process of 'understanding' and 'interpretation'. From an interpretivist standpoint, the methodological objectives are to document the agentic processes - or the 'hows' - by which social reality is constructed, managed and sustained (Holstein and Grubrium: 2011). Crotty (1998:67) adds to this by explaining that, because knowledge and meaningful reality are constructed in and out of human interaction, and are developed and transmitted in social contexts, social worlds can only be understood from the standpoint of those who participate in them. Interpretivism is therefore tasked with looking for culturally derived and historically situated interpretations of social phenomena, it attempts to achieve verstehen, or 'meaningful understanding' of the social world from the participant's point of view. The importance of this task in qualitative theory-building is noted by Young (2004:1), who observes that,

“...given human beings are culture-creating beings and are endowed with free will, albeit in circumstances not of their own making, then the verstehen of human meaning is, by definition, a necessity in any explanation of human activity, criminal or otherwise."

Consequently, the qualitative research methods of participant observation, open-ended interviewing and other ethnographic - or 'ground level' - data collation techniques are to be viewed as processes of interpretation; they focus on recording traits and defining characteristics of events, people, interactions, settings, cultures and experiences (Carlson, Singer, Stephens and Sterk:2009, Page and Singer:2010). Bottoms (2008) asserts that the challenge for the qualitative researcher who is guided by the principles 
of social constructionism and who employs interpretive methods, is to capture and emphasise the meanings and understandings individuals ascribe to their actions. Each actor has individual frameworks for understanding the natural and social world; the qualitative researcher must therefore unpack those frameworks by de-constructing and unpacking 'social constructions' individuals use when observing and participating in social life. Accordingly, by engaging in the life-world of research participants using qualitative study designs, it becomes possible to assemble a picture of how individuals socially construct that world (Bottoms: 2008).

\section{Methodological tensions}

In broader philosophical debates about qualitative versus quantitative approaches to researching drug use, advocates for the methodological 'superiority' of qualitative approaches have argued that, when engaging with drug use at 'ground level', the strength of qualitative methods lies in their providing a means of theorising drug use as a phenomenon which is socially and culturally situated (Vitellone: 2013). As Neale, Adams and Coombes (2005) have also noted, qualitative approaches to researching drug use are methodologically attuned to appreciating why particular drug-using behaviours occur in specific social contexts, and how those behaviours are assessed, understood and rationalised among different social groups. It is because of this capacity to explain human behaviour that qualitative methods have been lauded as succeeding in replacing stereotypes and myths about drug taking behaviour with more accurate information reflecting the daily 'reality' of drug users' lives (Neal, Allen and Coombes:2005:1586).

Researchers who champion qualitative approaches to researching drug use typically view their quantitative counterparts as less able to explore the processes and meanings of drug-taking behaviour. Here it is assumed that, by enumerating drug-taking through coding and standardising, the 'objective' scientist 'destroys' valuable contextual data by over-emphasising the scientifically rigorous virtues of validity and reliability (Young:2004, Williamson: 2006, Atieno:2009). For example, in reference to large scale surveys aggregating drug use and health risks, Keane (2011:407) describes quantitative 
assessments as presenting drug users as "clinical objects... who are extracted from the social world and placed into the flat empty space of ...the data". When viewed through a statistical lens the individual drug user is then "massed into a distant and undifferentiated cast of thousands." Maher (2002:312) has also observed that, contrary to claims of achieving value free and objective measurements through 'science', politically loaded categories frequently applied in epidemiological studies of 'at-risk' groups have essentialised entire drug-using populations. This has obscured the complex realities of risk practices, and has left little room for understanding how social conditions shape their individual lives.

Kaplan (2010) further suggests that "speakers of quantitative idioms" need to invest in listening to the 'voices' presented by qualitative research, a suggestion which assumes that qualitative methods have somehow accessed a truth which is unobtainable through quantitative assessments. However, irrespective of their epistemological differences, research claims of having captured the emic perspective of drug using sub-worlds are subject to several theoretical caveats (Agar: 2010):

Contextualising the lived experience of drug use requires researchers to interact with drug users and describe their drug taking experiences. However, because the qualitative researcher is the primary instrument for data collection and analysis, this process cannot produce descriptions of drug-using experiences which are independent of the researcher (Atieno: 2012). The validity of complexity and context, which qualitative methods seek to capture, is influenced by uncontrollable variables, such as the ethnicity, gender or class of the researcher. Research outputs are also subject to a researcher's inbuilt biases and perspectives, as well as their expectations for the outcomes of the research. As such, reliability can only be partially determined by researchers' 'bracketing' these biases and influencing variables throughout the research process, so that readers can make informed judgements about the reliability of their results (Daniels and Grinnan: 2015:128). 
The theoretical utility of qualitative research is also challenged by the difficulties in replicating research processes that are inseparable from individual researchers, where the data they generate is contextually bound to a specific time and particular place (Newton et al.:2011). Bourgois $(1996,2009)$ for example researches drug-using practices at historical moments intersected by the widespread availability of particular substances and specific economic realities. These factors, coupled with a research perspective unique to Bourgois as an ethnographer, make it difficult to determine the validity of the research as having discovered a 'truth' by confirming results through replication at another time and in another location. To what extent qualitative results can be applied to a wider population of drug users is also constrained by a reliance on what are typically very small sample sizes.

Sheridan et al. (2009) demonstrate this in hypothesising influences on first time methamphetamine initiation based on interviews with only 20 New Zealand drug users. Unlike quantitative measures of drug use among much larger, generalizable samples, there are no in-built mechanisms in the research process to determine whether they are statistically significant or simply due to chance (Atieno: 2009). What is hypothesised instead draws on an inductive process, which assumes, rather than confirms, resulting in criticisms of qualitative methods as lacking methodological rigour.

While reconciling these different philosophical perspectives is beyond the scope of this thesis, it is important to note that quantitative assessments of drug-use are fundamental in contributing to the motivations of qualitative research. That quantitative methods are foundational in motivating qualitative theory-building is cogently demonstrated by normalisation scholarship, the conceptual origins of which resulted from quantitative methodologies. These included surveying 2000 respondents in conjunction with the collation of urine samples, and intoxication and monitoring tests (Measham et al: 2001, Demant et al: 2010). In setting out to measure drug use on a large scale, these methods 
succeeded in making a form of drug use visible in a specific social setting. This has since prompted qualitative scholars to question and develop the normalisation thesis by contextualising the lived experience of drug use within different nightclub environments (Hutton: 2010). Similarly, risk environment scholarship is underpinned by quantitative public health studies measuring the prevalence and incidence of HIV infection among specific populations. These epidemiological assessments of HIV risk have necessitated fieldwork with smaller samples of drug users in order to explore specific drug-using practices, such as the sharing of needles or the incorporation of drug-taking in sexual behaviours. They have prompted asking questions about why people use drugs in particular ways and in particular relational contexts, and make apparent how risks are understood in social contexts. This has helped identify interventions which limit the risk of HIV transmission (Rhodes and Singer et al: 2005).

Given the inter-dependence of different methodologies it is inherently problematic to delineate one methodology as being more able to represent a particular social phenomenon than another. When applied to the same subject matter, different methodologies have the ability to capture different kinds of data, which tells a story from a different epistemological perspective. Arguing in favour of qualitative approaches to research methamphetamine use in a New Zealand context can therefore be viewed as advocating for a different perspective of drug use, one excluded from the dominant framework of policy-based scholarship. In using a qualitative approach to research the lived experience of methamphetamine use, the intention in this thesis is to employ its strengths in giving meth users "a vivid presence with a name (albeit pseudonymous)", who have an important story to tell (Keane: 2011:407). By humanising the image of methamphetamine users, their identities can be appreciated in ways that help challenge and rearrange authoritative representations of problematic drug use.

\section{Thesis research methods}

Reflecting on the theoretical imperatives of qualitative research and the methodological constraints which structure the knowledge it produces, the following sections of this 
chapter evaluate the use of narrative research methods to engage a sample of 17 drug users in the process of telling their stories about starting, using, and stopping methamphetamine use. In reviewing the sequencing of methods used to collate, transcribe, and analyse the stories of research participants, the intention here is to demonstrate that this methodological approach has resulted in outcomes which are as faithful as possible to representing the stories of participants in this study.

\section{Sampling, recruitment and initiating a pilot study}

Initiating the research process began with needing to collate a random, and sufficiently sized sample of willing research participants who identified as being 'drug users'. As O'Brien and Madden (2007:54) observe, this objective was immediately problematic, given that "people who use drugs are not a single category, but rather a series of contingent categories depending on context". Gay drug users, male or female drug users, recreational drug users, functioning drug users, poly-drug users - all are categories employed by researchers which produce typologies of representation, both positive and negative. O'Brien and Madden (2007) suggest that what is important to consider is not whether someone identifies as a drug user, but instead that people have a social connectedness that enables them to feel an 'identification' with common issues and experiences. In relation to this research, these might include knowing about meth using rituals, pleasures or risks associated with the use of methamphetamine and other drugs, experiences of discrimination, police harassment or encountering certain methrelated health problems (ibid: 55 ).

Accessing a sample of drug users is also inherently difficult, given that drug users, like other groups subject to social stigmatisation - sex workers, HIV sufferers, sex offenders - are more likely to have low levels of visibility because of moral, legal or social sensitivities surrounding the behaviour in question (Jenkins: 1999, Ayres and Jewkes: 2012, Ahern, Stuber and Galea: 2006, Obrien and Madden: 2007). It was therefore anticipated that meth users would be similarly avoidant of public scrutiny, and perhaps more so than other drug-using populations, given the pervasiveness of anti-meth 
imagery representing meth users as dangerous and highly criminogenic (See also McKenna, 2013; Semple, Grant and Patterson, 2005).

To accumulate a sample of drug users it was decided to use snowball sampling techniques. By definition snowball sampling is a method of finding research subjects, where one subject gives the researcher the name of another, who in turn provides the name of another (Atkinson and Flint:2001). Snowball sampling is based on the logic of social networks, whereby individuals are linked by a set of social relationships and contacts, for example in gang situations or between drug users and drug sellers (Petersen and Valdez:2005:154). It is often defined as an ascending methodology, as it is employed to work in an upwards direction and locate those on the ground who are needed to shore up gaps in knowledge on various social contexts (Atkinson and Flint: 2001).

When using a snowball sampling method to access drug users, typically, advertisements for research participants are used to initiate a first point of contact with individuals who are willing to disclose their drug using experiences. This method assumes that individual drug users will be linked to other drug users through a network of social relationships and contacts, and that the initial contact may result in the researcher being referred to others willing to participate, or that other drug users will be told about the project and make contact with the researcher. Atkinson and Flint (2001) describe this as 'chain referral', and like Biernacki and Waldorf (1981), they reiterate that the method of snowball sampling is well suited to accessing groups with low social visibility, or 'hidden' populations. Hendricks and Blanken (1992, cited in Faugier and Sergeant: 1997:792) have also noted that if the aim of the research is explorative, qualitative and descriptive, snowball sampling offers practical advantages in obtaining information on "difficult to observe phenomena". This is especially true where behaviours involve illegal or 'deviant issues', as is the case with users of methamphetamine, and other groups with unusual or stigmatised conditions (Atkinson and Flint: 2001). 
Having discussed with my supervisors the challenges inherent in collating a sample of local drug users - notably with limited personal resources - it was decided that a pilot study comprised of six participants was undertaken. This would help determine whether 'snowball' sampling techniques would facilitate access to individuals willing to identify themselves as meth users and engage in the research process, as well as provide an early indication of how many participants could be recruited within a reasonable timeframe. A pilot study would also provide an opportunity to complete a preliminary evaluation of the proposed interview guide, and help develop my research skills by reflecting on interview experiences unique to each interaction with participants. To this end, employing a pilot study was also an effective means of helping me anticipate potential ethical or safety dilemmas when conducting interviews in unfamiliar environments.

Following ethics approval in May 2012 (approval number 19235), the snowball sampling process was initiated by placing recruitment posters around Wellington city which invited users to text 'Meth' to the researcher's mobile phone if they were interested in being interviewed. I also arranged meetings with the Prostitutes Collective, The Community Alcohol and Drug Service ${ }^{42}$, and the Salvation Army's Bridge Programme ${ }^{43}$ to request permission to recruit current or previous drug users for interviewing. Following a meeting with each service provider, and signing a set of terms and conditions provided by the Salvation Army, all three services agreed to promote the project to their clients. The Salvation Army Bridge Programme also offered to allow me access to their interview rooms if interviews were conducted after the daily counselling programme had finished.

\footnotetext{
42 The Community Alcohol and Drug Service (or CADS) is a component of the Capital Coast District Health Board's Mental Health and Addiction Services. CADS provides "assessment and treatment for people with substance dependence and a co-existing mental health and or serious physical health problems" (http://mentalhealthservices.org.nz/page/125-specialty+addiction-service).

${ }^{43}$ Established in 1959 to provided residential-based support for alcoholics, the Salvation Army Bridge Programme was formally recognised as an addiction service under the Alcoholism and Drug Addiction Act 1966. Since then it has developed into a suite of services which address multiple addictions, including gambling, alcohol and drug abuse. See http://www.salvationarmy.org.nz/our-community/bcm/archives-heritage/did-you-know/the-bridge-programme
} 
To be eligible to participate in an interview participants needed to be aged 18 years old or over, and identify as being a current or recent user of methamphetamine. A $\$ 20^{44}$ grocery voucher was also advertised as the method of payment for participating in the project (see appendix B). The idea of "enticing consent" with a form of payment (Sandberg and Copes:2012:6) is documented extensively as an acceptable means of recruiting research participants, although it has been noted that there can be deliberation when deciding on an appropriate fee. As Sandberg and Copes (2012:7) ask, "how much is enough to show respect for their time and expertise, but not so much as to be coercive?" Although the answer is unclear, it was an Ethics Committee stipulation that any payment should be made by way of a voucher only, as a cash payment might later be used for the procurement of drugs. This was viewed as a common sense and ethically appropriate approach to reducing the potential for drug related harm.

On refection though, in many respects this stipulation mirrored other financial controls imposed on drug users, such as benefit reductions following mandatory drug tests ${ }^{45}$. Contrary to demonstrating a belief in drug users exercising self-control, this approach to recruitment suggested a loss of control would be imminent upon exchanging their experiences for cash. Sandberg and Copes' (2012:8) study of US ethnographers undertaking illicit drug research noted that the recruitment of subjects was deemed worthy of cash payments. As one ethnographer reported, "I have no problem going to $\$ 50$ to $\$ 75$ or even $\$ 100$ for an interview if it's for somebody who is going to give me really good data." This research suggests ethics and payment issues are culturally specific, rather than universally agreed upon in all academic research processes.

\footnotetext{
${ }^{44}$ This is the maximum amount allowed by the Faculty of Humanities and Social Sciences for koha under their grant system.

45 Government policy introduced in July 2013 stipulates that Work and Income recipients must be willing to apply for all jobs and work programmes which require mandatory drug testing. If applicants fail a drug test the cost of that test is deducted from the benefit. If tests are failed or there are refusals to apply for drug tested jobs, beneficiaries must agree to ceasing all drug use or their benefits will be cut by $50 \%$. Second time failures will result in benefit suspension and the provision of a 'clean' drug test within 30 days. If the clean test is not provided the benefit is cancelled (NZ Herald August 29, 2012). See http://www.workandincome.govt.nz/community/health-and-disabilitypractitioners/drug-testing-for-beneficiaries-with-work-obligations.html
} 
While the focus of this thesis was not the correct forum to challenge or deviate from Ethics Committee stipulations regarding the method of payment to participants, the literature on the ethics of payment methods for research participants is worthy of acknowledgement, and suggests that how we treat research participants who are drug users may need to be reviewed. However, irrespective of the debates about ethical payment methods (see for example O'Brien and Madden: 2007), having advertised that participants would be rewarded with a twenty dollar grocery voucher, I had succeeded in recruiting 6 participants by December 2012. This indicated that a sample of methamphetamine users could be accessed, albeit in limited numbers, given it had taken six months to collate the first six interviews.

Sampling decisions are of course fundamental to the outcomes of illicit drug research; they determine what kinds of drug users will be afforded an opportunity to articulate the lived experience of drug-use, and the types of social phenomena which are likely to be revealed by those who agree to be interviewed (Bowden:2010). The stories recorded by researchers are then evaluated and distilled into smaller components to construct a convincing and meaningful research narrative. This makes sampling decisions critical, in terms of the results collected and the academically politicised implications that follow from their interpretation. The six interviews completed for the purposes of the pilot study thus provided an opportunity to reflect on how the decision to use social service providers as sites to access participants would influence the kinds of drug using experiences I would represent throughout this research.

While services tasked with reducing drug-related harms are logical places to find an audience of drug users, they provide "convenience samples", and an immediate gathering of "the usual suspects", which put the researcher in contact with drug users who are more inclined to share their drug using experiences. As McCoy et al. (2005:819) cogently observe in their study of middle-class female heroin users, this means the difference between participants who feel they have nothing to lose by discussing their drug use, "and those who have everything to lose should their invisibility and privacy be 
violated". Consequently, drug researchers have been guilty of "taking the path of least resistance" when recruiting study participants. This helps account for what McCoy et al. (2005: 819) describe as "seemingly homogeneous results", and worse, their reductive depictions of drug users as "dangerous and /or self-destructive 'others' or pitiable victims of gender, racial and class oppression." If this becomes the best available information about drug use, there is a significant risk that policy - or at least political rhetoric - will succeed in equating illicit drug use with problematic drug use and criminality (Hough:2001, cited in O'Brien and Madden:2005:53).

Acknowledging the implications of my sampling decisions, after the pilot study interviews were completed I focussed on trying to recruit participants who were not engaged with social services by distributing flyers and posters throughout the greater Wellington region. The objective was to recruit participants that might use methamphetamine in ways that were consistent with definitions of recreational drug use (see for example Quintero's (2009) study of US college students using pharmaceuticals, Kelly's (2010) study on club drug use in New York, or Pennay and Moore's (2010) study of Australian party-drug users) and who might be representative of other, less visible, drug-user categories.

This proved to be a very labour-intensive process, and in some respects the placement of posters still conformed to the idea of gathering 'The usual suspects'. Posters were placed in youth orientated cafes and in bar-toilets, on notice boards in large shopping mall complexes, on lamp posts and walls in youth specific areas within the city. At one point when placing a poster in a local shopping mall located in a lower socio-economic area, a previous respondent approached me to discuss his interview and talk about his life changes since our initial meeting. With each 'street level' poster placement I was very aware that I was still adhering to stereotyped perceptions of where drug users might engage in social activities and be more accessible, that they might be more inclined to be young, or that in less affluent areas the enticement of a $\$ 20$ voucher might be more appealing. 
By December 2014, I had recruited an additional 11 participants, giving me a total sample of 17 participants. Of those, nine participants had contacted me as a result of hearing about the project at the Bridge Programme, and for the most part the mechanics of arranging an appointment to conduct these interviews had been relatively straight forward. Comparatively, the eight participants I recruited in an effort to actively seek out and document a more diverse range of drug-using experiences was the result of a prolonged, and time consuming recruitment process. This process involved repeating weekly drives around the greater Wellington area to put up posters consistently torn down from the previous weeks' poster-placement cycle. In order to improve my odds of recruitment success $\mathrm{I}$ also pushed the parameters of my catchment area from Wellington city and surrounding suburbs, to Upper and Lower Hutt, Porirua and Kapiti ${ }^{46}$, and repeated the weekly poster cycle accordingly. During this process several potential participants made contact and agreed to be interviewed. This typically involved a frantic call-back having received a text message, re-arranging day-time work commitments or night-time parental responsibilities, and driving to an agreed upon location to meet the caller. This pattern of events occurred consistently throughout the recruitment stage, and in spite of follow up texts or calls, it was impossible to manage the risk of "no-shows" and avoid dozens of fruitless drives to suburbs 40 or so minutes away.

Reflecting on this experience, it was clear that, as a one person recruiting resource, the odds of accessing a large, and diverse sample of methamphetamine users was inevitably going to be challenging. Similar challenges were also noted by Sheridan et al. (2009) when recruiting research participants in the Auckland area. They remark that it was their intention to recruit 40 participants, but that by 20 , data saturation was almost complete, and further recruitment of participants was "extremely difficult". This indicates the difficulties in accessing meth users who are agreeable to being interviewed, even in a

\footnotetext{
46 These areas are suburbs which are distinct from the Wellington City area. Lower and Upper Hutt are located 15 to 25 minutes north of Wellington respectively. Porirua is located 15 minutes northwest, and Kapiti refers to a coastal region 45 minutes' drive north of Wellington.
} 
large urban setting with research funding, access to a network of addiction clinics, and a team of on-site interviewers.

Bowden and Green (2010:126) emphasise that sampling decisions are fundamental to determining the authenticity of "the voice of the researched". They note that, to achieve authenticity, the researcher must ensure they have accessed various relevant individual voices by making sampling choices which they describe as maximising "the range of ways of seeing the phenomenon represented amongst the researched." Reflecting on this objective, the final sample was comprised of 17 participants who varied in age, ethnicity, and in socio-economic status, with additional diversity in gender and the geographic location in which their use of drugs occurred (see appendix C for table of participants). While these social categories on their own are not the specific focus of this study, they provide diversity in the ways that each participant experienced using methamphetamine and other drugs, and how they communicated those experiences during the interview process.

However, the final sample did not include any participants who described using methamphetamine and other drugs in a 'recreational' context ${ }^{47}$, or in ways which indicated their drug use had not resulted in harm to themselves or others. In part this sampling outcome was the result of having recruited 9 participants from the Salvation Army Bridge Programme, all of whom were individuals managing an aggregation of substance addictions, who identified as previously engaging in the harmful use of methamphetamine, as well as a range of other licit and illicit drugs. Participants recruited outside of the Bridge Programme recounted similar experiences, and had either stopped using drugs because of serious harms or negative events they had

\footnotetext{
${ }^{47}$ The context of recreational drug use as it is referenced here is understood in relation to Measham et al.'s (1994, 2004, 2009) normalisation thesis and wider theoretical engagement with 'acceptable', or widespread normalisation of, recreational drug use (see limitations of this theorising in chapter two). Their work provides a contrasting perspective of methamphetamine use among, typically, socially included populations of young drug users. This scholarship acknowledges the increasingly visible poly-drug taking characteristics of recreational drug consumption, and locates poly-drug taking decisions in young peoples' "broader search for pleasure, excitement and enjoyment framed within consumption-orientated leisure lifestyles" (Measham and Shiner: 2009:1).
} 
experienced, or they identified as current drug users who were aware of their potentially harmful drug-taking behaviour, and who cited numerous incidents of drug use which had resulted in police involvement or serious health and wellbeing consequences.

All 17 participants' experiences of using methamphetamine and other drugs could therefore be understood as being more consistent with Buchannan and Young's (2000) definition of problematic drug users ${ }^{48}$. This general characteristic of the sample recruited was difficult to reconcile given that in representing the voices of a stigmatised population I was likely to confirm many of the stereotypes anchored to the problematic use of drugs and those managing drug addictions. However, the strength of using narrative methods, is in using collective stories which help connect an individual's life story to the broader story of a marginalised social group. Storytelling also names silenced lives, and "promotes empathy across different social locations" (Gamson: 2002:189, cited in Chase: 2005:668). Again, these achievements are viewed as fundamental outcomes, and validations, of narrative research.

O'Brien and Madden (2007:55) also note that the issue of 'representativeness' has been problematized more often in relation to drug users than other representative groups. They argue that there are a myriad of groups that 'represent' what are often diverse and complex communities, some of which do not identify as being a community at all, for example:

"One could easily ask how community-based AIDS organisations...are able to represent a category as broad as 'gay men.' It is interesting that on the one hand the ability to represent all drug users is questioned and that on the other hand drug users are told they need to get better as speaking with one voice. The fact is that no 'consumer type' organisation ever truly represents anyone other than their own experiences and perspectives (ibid)."

\footnotetext{
48 Problematic drug users are defined by Buchanan and Young (2000:414) as individuals who are "dependant socially, psychologically, and/or physically upon a substance or substances, to the extent that they experience problems and/or present problems to others."
} 
Ultimately issues of representation are common place with qualitative works utilising small interview samples, and these are likely to be compounded when recruiting takes place within social settings characterised by the presence of individuals who may be more likely to have similar life stories. The ways in which participants recounted their life experiences clearly demonstrated that I had recruited drug users who were more likely to be managing the negative consequences of their drug use. They were also more likely to be aware of, and function within, the socially ascribed parameters of drug-using or other 'deviant' identities. However, this does not make their narratives any less salient when they are subject to interpretation. The stories recounted by the sample of drug users recruited for this research effort can only reveal their particular drug using experiences, irrespective of what they may or may not have in common with other drugusing populations.

\section{The 17 research participants}

\section{Will}

The first participant interviewed, Will is a European male, aged 21, who at the time I had interviewed him was preparing to start fulltime employment. Will responded to one of the posters placed in the city, and as I note below, it took some organising to set up an interview with him near his home. Will presented as being obviously affected by his past drug use. Although he was taking medications for anxiety he was no longer using illicit drugs. The main drugs he identified during the interview as having caused him harm were cannabis, methamphetamine and benzodiazepines. Will self-identified as being an 'addict' and acknowledged having had past contact with addiction services.

\section{Tania}

Tania is a 21 year old Māori female I interviewed in a counselling room at the Bridge Programme. Tania identified she was attending the programme for her 'addiction' to methamphetamine, and had moved down to Wellington after an extensive history of involvement with gangs in her home town. She also disclosed that she was due to appear in court for sentencing, and this was connected to her involvement in a spate of 
burglaries, which received low level media attention at the time I had met her. Tania presented as being unaffected by her drug use, and described a series of events in ways that suggested she had enjoyed her status within her past criminal network. Although she described experiences of coercion and exposure to violence, Tania did not reflect on past events to convey her experiences as victimisation.

\section{Moana}

Moana is a 25 year old Māori female who identified that she had used methamphetamine extensively and that it had caused her harm in the past. At the time of our interview however, she was not using drugs. We met prior to the main interview in a café, and when she put her bag on the table I noticed she had several cell phones. We agreed to meet at a later date and the main interview took place on a university campus where she was studying. As the interview progressed she disclosed she was currently involved in sex work, and described her past drug use in relation to this. She asked me if I had experience with sex workers, and I explained I did not, and I avoided asking any questions about it. I assumed then, that the cell phoned may have been related to this. Before she disclosed her involvement in sex work she also requested that I turn off the voice recorder which I did. Moana was very concerned her family would find out. Later on she described that her extended family were meth users, and detailed how she became involved, despite trying to avoid meth use given her family's involvement.

\section{Ben}

Ben is a 31 year old Māori male. Ben was attending the Bridge Programme for his use of methamphetamine and cannabis. As I note in the methodology chapter, Ben had asked me to bring a camera. I had no idea what he meant by this and when I met with him I didn't ask until he brought up the subject of his missing teeth, which he then showed me. It was very clear he was unhappy about his past behaviour and how this had resulted in damaging his teeth. Ben described an extensive history of poly-drug use and his longterm involvement in a social network of drug users and drug dealers. Although he had engaged in daily use of cannabis and methamphetamine he had been employed and had 
undertaken some tertiary training during this experience, included a brief period of living and working in Australia. A few weeks after the interview had been completed I was putting posters up in a suburb 30 minutes north of Wellington and Ben recognised me and came over to say hello. He looked very different having returned to a normal eating pattern, and he said was successfully abstaining from drug use.

\section{Charlie}

Charlie is a 22 year old European male who identified as a current drug user when we met to undertake the interview in a Wellington park. He presented a being very confident and keen to display his extensive drug-knowledge. Charlie had moved to Wellington from provincial New Zealand, and had an extensive poly-drug history which had started in his hometown. Charlie described using methamphetamine and a number of different drugs, and relayed a number of stories about his preference for hallucinogens. Charlie talked about his use of drugs in a way that suggested he was in control of his drug taking. However he noted having experienced a number of drugrelated harms, which included being arrested by the police. Charlie was unemployed when I had met him, but identified he was participating in an adult learning art class.

\section{Steve}

Steve is a 33 year old European male who was also socially connected to Charlie. I met Steve at a café in Wellington before our main interview took place. We had a coffee and talked briefly about drug use, arranging another time to complete the full interview. I met with him a day or two later and we sat outside at the same café. Steve proceeded to tell me about being involved in the 'skater' scene and who he had come to get involved in frequent use of cannabis and methamphetamine. Steve talked in bursts of quick speech, sometimes repeating the same sentence very quickly, which may have indicated how his drug use had affected him. Although he did not identify as being an addict, the extensive experiences of drug use he described and his unusual speech suggested that he was very involved in the daily use of methamphetamine. 


\section{Angus}

Angus is a 33 year old European male who was interviewed at the Bridge Programme. Despite describing an extensive history of heavy methamphetamine and alcohol use Angus looked well, was clearly very bright, talked calmly, and was open about his past history of drug-related offending. Angus described initiating drug use at an early age and proceeding to becoming a frequent drug user while at secondary school. His involvement in offending led to a brief stay in a local boy's home, and eventually to a 5 year prison sentence for armed robbery. When released from prison Angus became heavily involved with gangs in the supply and manufacturing of methamphetamine. Throughout his story Angus reflected on past events by looking at his offending as a life style he had chosen, rather than one that had resulted from disadvantage or experiences of victimisation.

\section{Rayleen}

Rayleen is a 33 year old Māori female who responded to a poster placed in the city. I met her in a café and conducted the interview in an upstairs area away from other patrons. Rayleen disclosed than she was a sex worker, and went on to describe an extensive history of problematic drug use, which included the use of alcohol, benzodiazepines and methamphetamine. Rayleen was engaging in a methadone programme and identified as being an 'addict'. She described extensive, long-term family involvement in the supply of drugs and referenced her father as being a wellknown person in gang-related criminal networks. Rayleen was the second sex worker I interviewed, and although I did not prompt her to discuss this, she was very candid about her experiences with clients and the workings of sex as a business. During her interview Rayleen also described experiences of sexual assault and physical violence, as well as experiences of losing access to her children and being in state care. After the interview I received a text from her asking for assistance because she was needing to move from her current home due to conflict with her partner, who had recently been released from prison. Upon supervisory recommendations I did not respond to her text. 


\section{Amy}

Amy is a 23 year old Māori female who was attending the Bridge programme to address her methamphetamine addiction. She also described her history of drug use as involving harms from using alcohol and cannabis, and identified that she had been charged on four occasions for driving while under the influence of alcohol. Amy described growing up with her mother who she identified as having experienced a series of violent relationships which she had witnessed. Her exposure to methamphetamine occurred in the context of extended family members being involved in drug use, and through their networks Amy came into contact with 'high-level' dealers. Describing stereotypes of affluence achieved through associations with criminal networks, Amy storied a series of relationships with gang involved partners as the social contexts in which she became embedded within a meth-using lifestyle. This lifestyle was eventually disrupted by Amy's use of methamphetamine culminating in her losing access to her children. She conveyed during the interview a sense of nostalgia about the excitement of her past life, but was motivated by her desire to regain access to her children.

\section{Rebecca}

Rebecca is a 23 year-old European female who had self-referred to the Bridge Programme to address her use of methamphetamine, Ritalin and opiates. I interviewed Rebecca in one of the programme's counselling rooms and in telling her story she identified being sexually assaulted and exploited in the course of her drug-using experiences, and as eventually losing access to her son as the result of her controlling ex-partner. In sharing this it was clear that Rebecca had been significantly affected by these past events. This interview conveyed the vulnerable status of my research participants, and when describing particular events I was acutely aware of being an older male in a room with a younger female who was sharing very personal experiences. Rebecca's involvement in a sequence of dysfunctional intimate relationships with drug users had magnified the impact of experiences in her past, and her story clearly communicated the relationship between problematic drug use and personal trauma. 
Sean

Sean is a 33 year old European male who was participating in the Bridge Programme for his addiction to methamphetamine. Like all most of the participants' engaging in the Bridge programme, Sean had moved away from home to receive treatment. Sean had positioned himself in his story as a 'victim' of the social realities he experienced in the context of past drug-taking behaviour. In using this narrative device Sean's story was unique, as other male participants' had not reflected on their past identities in the same way. It was clear throughout the interview that Sean felt a tremendous amount of shame and regret about his past use of drugs, and when telling his story he never referenced any positive experiences or communicated a sense of nostalgia about his past, criminal lifestyle as other participants had. His motivations for successfully completing treatment were also referenced in relation to his being motivated to be a good father and wanting to re-connect with his daughter, and this was a unique aspect of his story when compared to other male participants.

\section{Jess}

Jess is a 25 year old European female who I interviewed in a café in Wellington. This proved to be too noisy and we ended up moving to an open, but quiet area in a shopping mall. Jess was the third of three participants' (the others being Charlie and Steve interviewed during the pilot) who identified as currently using methamphetamine and other drugs at the time she was interviewed. She also identified as being involved in sex work, and as having moved to New Zealand from the UK. In practical terms this was the hardest interview to complete because Jess wouldn't talk unless I prompted her, and often gave yes or no answers. I was unsure if it was my rapport building skills, or the environment we were in, or if she was simply uncomfortable talking about personal experiences. As I note when setting out my methodology, in many respects the texts she sent to disclose her use of methamphetamine and clarify where she worked proved to be more important experiential data. Despite the limitations in the depth of content in 
her interview, her experiences further confirmed the gendered realities of drug use described by other female participants.

\section{John}

I interviewed John, a 39 year old European male in an outdoor area at Massey University in the evening. The interview lasted about two hours and I had not dressed in warm clothes due to rushing to the meeting location, and it was extremely cold! John's story was unique because he was the only full time intravenous drug user I had interviewed. He storied extensive experiences of using an array of drugs and being heavily involved in drug supply for a number of years. Throughout his story John went to great lengths to demonstrate his comprehensive knowledge of drugs, their effects, chemical composition, his opinions of drug policy, how drug-dealing works and many other topic. Within those descriptions however, John revealed his coming to terms with having been a 'junkie' (his reference) for most of his life. He identified that he was often challenged by police because he was well known to them, and described having been imprisoned for drug use on a number of occasions.

\section{Terry}

Terry is a 40 year Māori male who identified as being a gang member. I interviewed Terry in a counselling room at the Bridge Programme, and at the beginning of the interview I felt nervous about asking Terry questions given that he presented as being 'staunch' (a New Zealand expression referring to a particular hegemonic masculine stance). However, as the interview progressed Terry was open and candid about his past experiences, and described events that had occurred in ways that communicated his ownership of past behaviour as a gang member. At one point in the interview Terry remarked that he was having trouble sleeping in the communal house in a bed because he had never had his own bed before. To address this he would sleep in the lounge on the sofa, which upset other residents. This simple description of life as it was for him at 
the point of the interview reminded me how far removed I was from the lived experience of drug use participants' were sharing with me. After the interview had finished, he asked me if I would drive him up the road to the communal house and I agreed. The house was located opposite the Wellington Zoo and as we drove up I asked if he wanted to see the view of Lyall Bay from the hill. We drove up and over to Lyall Bay, and he talked about all the things he loved doing and expressed an interest in one day going diving.

\section{Debbie}

Debbie is a 26 year old European female who was participating in the Bridge Programme for her addiction to methamphetamine. In common with my interview with Rebecca, this was also a confronting interview. Debbie presented as being affected by her drug use, and talked quietly when describing having been in state care and her life as the partner of a gang member involved in the supply of drugs. She was small in stature and looked older than 26 , and at times during the interview it was difficult for her to talk. Debbie's children had been removed from her care and she talked about wanting to regain access once she completed the programme. When hearing her experiences of violence in the context of her relationship with her partner it was difficult to reconcile that she had lived through this experience at her age. Again, as an older male researcher I was acutely aware of my position in relation to her when she disclosed personal experiences. After the interview finished I walked downstairs with her and she talked about hoping to become a nurse once she had her children back.

\section{Kiri}

Kiri is a 50 year old Māori female who responded to a poster I had put up in a Wellington suburb. We arranged to meet in a café and sat at an outside table where I conducted the interview. Kiri had become involved in drug use through her connections with Black Power (a New Zealand gang) at the age of 17, and after a history of poly-drug use had 
become involved in methamphetamine use at the age of 35 or 36. Kiri's story was unique in providing a gendered perspective of cooking methamphetamine, a skill she learnt from her partner's cousin. In 2000, controls in New Zealand over buying precursors such as cold medicines used to make methamphetamine were not in effect, and this made large scale production very easy, resulting in Kiri becoming heavily involved in using, manufacturing and selling methamphetamine. Kiri and her partner were eventually arrested and she served 8 years of a 10 year prison sentence.

\section{Matthew}

The youngest participant in this research, Matthew is an 18 year old European male who had moved to Wellington from a North Island town 5 hours away. Matthew responded to a poster placed in the city, and we met in a local café to conduct the interview. Matthew described the drug-related events that had led to him moving away from home, and as the youngest participant, his trajectory of drug use was not as complex or as long as most of the other participants'. Matthew was the only participant who identified that, in addition to cannabis and methamphetamine, he had also experienced harms from smoking 'synthetic cannabis'.

\section{The narrative interview: getting the story}

The advertisements I used to recruit participants were titled with the question, "are you interested in telling your story about using methamphetamine?" (See appendix B). This language was used in structuring this question, so that participants were invited to 'tell their story' was congruent with using narrative research methods as the research strategy for interviewing, and later, analysing the recorded transcriptions of participants' recounting their lived experience of methamphetamine use.

As Larson, Lilja, von Braun and Sjoblom (2013:1295) explain, a narrative approach to interviews takes the perspective of the storyteller, and in telling their story each 
participant "takes the listener to past times and recapitulating what happened." From a linguistic standpoint the ' $a$ then $b$ ' sequence is the most essential and defining characteristic of narratives (Labov and Waletzky: 1967, cited in Presser:2012), given that the events of daily life are, as Gergen (1994:186) explains, "laden with a storied sense." Their re-telling to others inevitably requires locating the beginning of an event, followed by a low point, a climax, and a conclusion or ending.

From a research perspective, documenting narratives provides rich analytical terrain because people "give meaning to their lives and relationships by storytelling their experience" (White and Epston: 1990:13, cited in Gergen: 1994:186). For Gergen, Josselson and Freeman (2015:2), it is the expression of emotion which is of particular importance to the narration of stories, and fundamental to achieving a sense of human understanding (verstehen). Holloway and Jefferson (2000:32, cited in Elliot: 2005:20) add to this view, by emphasising the methodological contribution of stories to research:

“...the stories themselves are a means to understand our subjects better. While stories are obviously not providing a transparent account through which we learn truths, story-telling stays closer to actual life events than methods that elicit explanations."

Narratives are also of theoretical importance in understanding how individuals construct, 'perform', and make sense of their personal identities (Gergen: 1994). As Larson, Lilja, von Braun and Sjoblom (2013:1296) and other proponents of narrative approaches to research have posited, in essence, narratives are people's identities; they provide an opportunity to highlight versions of 'the self', of reality and of experience through the act of storytelling, and become the means by which various identities may be fashioned. Thus analysing the role of narratives in self-identity construction helps reveal how drug users negotiate their identities in relation to stigmatising discourses, or in a therapeutic context, help reveal how individuals defined as 'recovering' negotiate 
the tension between their past identity as drug 'dependent', and their current identity as 'drug free'. 49

In addition to understanding the theoretical efficacy of narrative methods, the decision to methodologically conceptualise interviews with participants as opportunities to facilitate story-telling was also informed by the acknowledgment that a narrative approach was congruent with the objective of 'giving a voice' to research participants drawn from stigmatised populations (see for example Elliot: 2005, Larsson and Sjoblom: 2010, and Presser: 2012). Narrative interviewing methods support participants to assume the role of narrator, rather than defaulting to a more passive and disempowered role as 'the subject' in what might be deemed an 'ordinary' research interview, where talk is generated through open and closed question and answer exchanges (Chase:2005). For example, IDMS and ADAM surveys rely on closed question interview methodologies, and situate participants typically drawn from marginalised populations in a subservient role (notably when interviewed in police stations following their arrest), where researchers pre-determine the content, context and structure of their voices. Comparatively, as Pastor (2005:180, cited in Suarez-Ortega: 2013:190) explains, in the context of using narrative methods,

“...the concept of voice is related to the acknowledgement of the right to express oneself and to be taken into account... without the condition of having to adopt a strange, imposed language or way of representation..."

Suarez-Ortega (2013:190) also adds that, when researchers empower participants in their role as narrators, the stories and life histories they articulate can be used as a basis for processes of personal and social transformation.

\footnotetext{
${ }^{49}$ The role of narratives in self-identity construction are used by specialists to counsel persons identified as having substance disorders. Viewed in this context it becomes clear how identities are constructed, rather than existing in and of themselves. As Larson, Lilja, von Braun and Sjoblom (2013:1297) demonstrate when explaining how narrative identities are useful schemas, "...they...help (addiction specialists) understand, how for example, the 'alcoholic' lives his or her experiences through the altered state of mind that is associated with unhealthy alcohol consumption. It may be possible to understand the alcoholic emotionally divided self and the changes between "the alcoholic self" and "the sober self" and the internal dialogues or narratives of alcoholics, such as, "when I drink another side of me takes over, the drinking side."' End of quote?
} 
Using these methodological imperatives to inform the interview process, I set out to manage each interview in ways that empowered participants' to tell their stories about using methamphetamine and other drugs. This required actively inviting each participant to tell their story at the outset of the interview, so that they were empowered to assume the role of story-teller. To achieve this prompting questions were used at the beginning of each interview to help participants begin recounting their drug using histories, starting from the earliest point in their life history of having first experienced the use of licit or illicit drugs. As an example, having outlined ethical guidelines, I stated the intent in wanting to hear their story about using methamphetamine and that I believed their story was important, and then typically commenced each interview with the questions, "If you think back, can you tell me when 'taking drugs' began for you? Tell me about when you first took a drug, which might include using legal drugs like alcohol or tobacco?"

Participants were then left to narrate their life history in terms of drug related experiences, and relationships with partners, friends and social groups involved in their lives while using drugs. When appropriate, and in ways that did not interrupt natural storytelling, participants were occasionally prompted to help reveal the sequence of life experiences leading to their use of - or desistance from - meth and other drugs, how their drug-using journey arrived at the point of first engaging in methamphetamine use, their meth-using experiences, and where applicable, events leading to their desistance from using meth and/or other drugs. Taking a lead from Presser (2012:49), prompts that were generic and short were used, to allow, as she recommends, for "spontaneous storytelling". These included: "Would you tell me more about that?" "Is there a story behind that?" "That's interesting - what happened next?"

The use of simple prompts and open ended questions during interviews is in keeping with best practice recommendations for undertaking qualitative research, which follow with the assumption that the interviewer must maintain a neutral position during the interview in order to separate themselves from their data. However, from a narrative 
perspective, irrespective of minimising intrusions as participants' recounted their stories, I remained an active participant in the storytelling process. As Elliot (2005:10) explains, the act of narration cannot be achieved without a story teller interacting with, and being influenced by, a listener:

"The narrator needs at minimum the cooperation of a conversational partner...The listeners therefore immediately become active co-participants in the recounting of a narrative, (and) ...any speaker in an interaction needs to decide how best to communicate their message."

The prerequisite then for the production of a story is social interaction between two or more parties, who then make choices about what information to include in the story being told. Content choices might be made to arouse interest or prevent boredom, to determine how much detail to include to ensure the listener has understood what the speaker is trying to communicate, and what verbal or nonverbal cues should be used so that listeners can participate in the telling of a narrative (Elliot 2005).

Polkinghorne (2007) adds that communicative choices are also likely to be influenced by the interviewer's gender, clothing, ethnicity, accent, speech pattern, social status and body language, as participants use these cues to read what responses are expected and whether their responses are acceptable. Further, as the speaker narrates their experiences and actions, the narrative they construct is a socially situated interactive performance, or as Chase (2005:657) explains, the narrative is "produced in this particular setting, for this particular audience, for these particular purposes." Stories told by drug users to researchers in an informal setting will therefore differ from the same story told to a group participating in counselling, to a news journalist, or in another interview at a different time or in a different location.

Consequently, rather than being separate, or distant from the content of participants' stories, I understood that during the interview process I was helping create each story in collaboration with research participants. This resonated with the constructionist view of narratives provided by Gergen (1994), that narratives are not fundamentally the 
'possessions' of an individual, they are possessions of relationships and the products of social interchange. Hilden (2014:6) also articulates this view when examining what he describes as 'research conversations.' He argues that the meanings communicated between researchers and their participants cannot be conceptualised as straightforward, oral reports of actions, norms, or representations. For Hilden (2014:6),

"...they are special instances of social interaction - instances in which meanings take shape in dialogue between parties that mutually contribute to the sense being made."

Acknowledging my presence within the research process enabled me to develop a reflexive understanding of my role and influence as 'the researcher', and to consider the inter-subjectivity between my voice and the voices of participants. It prioritised the need to make myself visible in the process of my narrative, and delineate between my voice, and the voices emphasised in the stories recorded, and represented, in the analysis. As Chase (2005:666) has highlighted, researchers who examine their "interactive voices" are able to reflect on different subject positions, their interpretations, and their personal experiences of the research process as a product of communal interchange.

\section{The interview process}

When a text message was received from a potential participant I sent a follow up text to arrange a convenient time to call so that we could talk about the project in privacy. The scope of the research and the interview process was then explained during the initial phone call to make sure they felt comfortable with the idea of making an appointment with me and participating in an interview. From a gendered perspective I was aware that, for female respondents, the idea of meeting with an unknown male was potentially concerning and I made it clear who I was, where I worked, in what capacity (to clarify that I was a Victoria University staff member as well as a PhD student) and who my PhD supervisor was. 
Given the array of potential ethics and safety considerations, the decision to undertake a pilot study provided me with an excellent opportunity to familiarise myself with the realities of meeting unknown persons, and learn how to navigate the narrative interview experience as an "interactional event" (De Fina: 2009:237). Accordingly, each interview resulted in very different contextual experiences, and by reflecting on these during supervisory discussions about how the pilot study was progressing, I was able to develop research skills and become a more confident participant in the research process.

My first interview required meeting Will, a 21 year old male participant, in an agreed upon Wellington city location, however this appointment ended in a 'no-show', a very common experience noted by other researchers working with illicit drug users (see appendix B). A follow up phone-call resulted in agreeing to meet at a café I was familiar with thirty minutes north of Wellington, located in close proximity to Will's home. In many respects this was the most challenging interview of the six given that it was my first time formally interviewing a complete stranger about their personal history of drug use. It required my having to learn how to use questions and conversational prompts to assist in recording the participant's narrative, while at the same time minimising interruptions in the story-telling process.

Building rapport in the compressed time period of a one-off meeting was challenging, and in common with Mckenna (2013) who notes this experience in her study of female methamphetamine users, my initial contact with the first participant was characterised by wariness of my intentions and position as a middle-aged, white, male researcher. As the interview was conducted in a public space I had to consider the covert placement of the digital recorder so as to not draw unwanted attention, as well as maintain an acute awareness of people moving in close proximity who might potentially compromise confidentiality. Consequently there were several recording pauses and situations that required referring to meth and other drugs as 'it' in my questions, for fear of local passers-by recognising the participant and what he was talking about. Interviews with three other pilot study participants were also conducted in public spaces (notably a 
public park, at Victoria University and another café) and similar issues arose when there was an awareness that someone might overhear the conversation. In contrast the interviews I completed in counselling rooms at the Bridge Programme were free of interruptions and environmental noise, which contributed to a more seamless story telling exchange.

Although public spaces are challenging environments to manage the interview process, agreeing to meet in high visibility settings and in locations I was familiar with intuitively mitigated some of the risks associated with meeting 'strangers'. Again, the pilot study proved to be invaluable, given the number of discursive tensions which make conceptualising - and therefore managing - safety issues problematic. That fieldwork with drug users should be considered dangerous or risky is widely acknowledged in ethnographic scholarship on drug use (Lee: 1995, Wright et al: 1998, Borgeois: 2003, Sanberg and Copes: 2012). Reasons given include the potential of meeting participants with mental health problems, the risks associated with their involvement in violent criminal activity, police intervention and even risks to health through communicable diseases, although to what extent these risks are overstated and conform to stereotypes about people who use drugs, remains unclear. What is likely however, is that researchers are not immune from discursive influences (Lee: 1995), and methamphetamine's mediated notoriety may have elevated my own perceptions of 'stranger danger' at the outset of the pilot study.

Conversely, the use of public spaces to conduct interviews meant that participants were also afforded a degree of safety, given their agreement to meet with an older male as yet unknown to them. Public settings thus provided a degree of reassuring surveillance, which at the same time safeguarded against accusations of impropriety on my behalf. This was an important consideration where, typically, interviewees drawn from marginalised populations are often at an asymmetrical disadvantage (CavallaroJohnson: 2008). As the interviewer, I occupied a position of power in relation to my research participants, most of who were younger than myself, who presented as 
experiencing health complications arising from past drug use, and who recounted biographies which clearly indicated vulnerability in relation to their use of illicit substances ${ }^{50}$.

The vulnerable status of participants was immediately established during the pilot study. My first interview with Will was the most confronting in this regard, during which the young male participant recounted how his use of drugs had contributed to a significant anxiety disorder, which caused him to cough and clear his throat obsessively as he talked:

Do you mind me asking why you get (a sickness) benefit?

Aw, just ah....just got an anxiety disorder

Was that something that came out of using pot or...?

Yeah definitely...and if I smoke it now I just start huffing and puffing and then I just throw up...panic attacks, pretty much like a panic attack would last like an hour or so, pretty much until the weed wear's off is when it will stop happening...like I can't even have a drink now without.... without sort of um...going crazy...cause at times I'll take (cough)....I'll take real deep breaths and I'll cough and stuff and I haven't actually got a cold 'cause I'm hyper-ventilating....

(Interview one, Will, male, 21 years old)

Throughout this interview it was evident his use of drugs and current use of anti-anxiety medication also contributed to his erratic, often laboured speech pattern. He went on to describe having experienced drug induced seizures and his fear of them, given that his sister suffered from epilepsy and he had witnessed her having epileptic fits.

\footnotetext{
50 Thinking about vulnerability was also an important consideration, given that regulatory systems which uphold ethical standards in research acknowledge specific groups as vulnerable populations which should be afforded research protections. The question of participant vulnerability has been noted by other researchers, see for example Fry et al.: 2006, Anderson and Dubois: 2007, and Smith: 2007.
} 
Similarly, when interviewing two female pilot study participants, Tania, a 21 year old Māori, and Moana ${ }^{51}$, a 25 year old Māori, both disclosed significant histories of sexual abuse and abusive or controlling relationships with partners. As a male researcher these themes proved difficult to navigate in an interview context, and I consciously avoided asking questions about their experiences of victimisation in relation to their use of drugs. The pilot study thus provided an 'early warning' that disclosures of sexual violence could occur during interviews with female participants, and in order to manage these more effectively I made sure that when disclosures occurred in proceeding interviews I created a space to pause the conversation and remind participants that I did not want them to feel pressured to talk about their experiences or proceed with the interview if they felt uncomfortable.

Equally, each interview I completed reinforced my awareness of my own emotional investment in the research process. As Hockley (1996:50) has also noted when considering emotion and engagement in qualitative research, certain kinds of research “...may involve the researcher in considerable emotional investment; the particular project connecting intimately with the individual's subjectivity across a spectrum of feelings. Such research is likely to be initiated by the researcher's expressions of interest, curiosity, perceptions of use value and so on...Additionally, underlying such factors there may well be powerful emotional forces drawing the researcher to investigate a particular topic, forces emanating from within his or her biography."

Hockley's (1996) observations resonate with my own experience of the interview process. For example, when participating in my first interview with Will it was very difficult to be confronted by a young male drug user who presented as suffering considerable distress from managing a mental health condition I had also experienced

\footnotetext{
51 Lahman et al. (2015) note that assigning pseudonyms to research participants is typically random in nature. This would largely be true of the process I used, except where participants' actual name could be read as denoting their cultural identity. In the two instances this was the case (Moana and Kiri) I chose a name that I wanted to go some way towards preserving an element of their cultural identity. However, as I go on to note in this chapter, processes for naming research participants in order to preserve their anonymity have attracted criticisms which could be levelled at the process I use here.
} 
at a similar age and in similar circumstances. It was hard to reconcile that my interaction with him was limited to documenting his story for the broader objective of completing my research project, and that having shared his personal circumstances it was inappropriate for me to become involved by offering support. Upon completing the interview I also felt a sense of unease with the transactional nature of the interview experience, which I regarded as advancing my own social capital at the expense of using his personal story about the impact of having engaged in problematic drug use.

Tying these interview experiences back to the difficulties in conceptualising fieldwork safety, it is worth noting that listening to participants recounting extreme forms of victimisation and marginalisation, or interviewing participants who presented as being emotionally or psychologically distressed, would inevitably have a significant emotional impact on the interviewer. This raises further questions about the range of safety issues that need to be considered and then managed, given that University guidelines for undertaking 'ethical research' often emphasise the safety of research participants rather than the safety of the researcher. Roguski and Tauri (2013:26) evidence this point, noting that, in common with five of New Zealand's eight Universities, Victoria University's ethics committee does not consider researcher-related safety when approving ethics applications. In stark contrast to what they describe as "the myriad of questions focussing on the multidimensional nature of participant risk", Roguski and Tauri (2013) identify that no consideration is given to factors such as the emotional or psychological impact of the research process, even though researchers often have to record, and then repeatedly listen to, disturbing life stories (ibid).

The emotional impact of interviews signposted during the pilot study and experienced throughout the development of the thesis was however effectively managed through regular contact with, and support from, my supervisors, who were able to share their own 'field safety' experiences and discuss the realities of interviews with vulnerable individuals. Equally important during these discussions was ongoing supervisory monitoring of potential ethical issues and challenges arising during the data collection 
stages of the research process. These were assumed as being likely when undertaking fieldwork that involves exposure to criminal worlds, or participating in research conversations about crime and deviant behaviour (Worley, Worley and Wood:2016). This proved to be true in the development of this research, notably in relation to broader questions about the ethics of confidentiality when participants disclose wrongdoing during the interview process.

Two situations arose which necessitated asking questions about how to manage such disclosures, both of which occurred while interviewing at the Salvation Army Bridge Programme: a female participant disclosing during her interview has having been involved in serious offending, and a male participant disclosed having recently used drugs while engaging in a court-mandated abstinence-based drug treatment programme. In both instances the ethics of breaching confidentiality and trust were explored by reflecting on the scope of the confidentiality agreement participants' signed prior to being interviewed, and by considering the impact of breaching confidentiality in making this information known to a third party.

The interview consent form approved by the Ethics Committee in 2012 (see appendix B) did not include any clauses which indicated to participants that certain disclosures of information would not be subject to confidentiality. The focus of the agreement, and indeed the ethics approval process at that time, was on ensuring all steps were taken to ensure participants remained anonymous, and that care would be taken in managing confidentiality during the interview process, and when securely storing the interview data. To this end breaking confidentiality when the terms of consent presented to participants had already been agreed to in good faith seemed to be a much greater ethical compromise than not passing on information obtained during the interview to a relevant third party. 
Equally, if a disclosure was made to a third party such as the police or the Clinical Manager of the Bridge Programme, it would likely have made it impossible to use the interviews obtained from the participants who made the disclosures. It would also have damaged the relationship I had established with the programme staff, and given that breaching confidentiality would have negative consequences for both participants, it would have made it impossible to gain access to other research participants. Additionally, by disclosing information about offending to the police it would be expected that I would need to make a formal statement of some kind, and potentially hand over my interview transcript as evidence of a crime that may or may not have occurred as it was described. The time involved in doing this, as well as the impact on my ability to proceed with the research process, would have come at considerable personal cost.

Given these considerations it was agreed that these disclosures would not be communicated to a third party. However, discussions around the ethical issues of confidentiality highlighted by these examples was useful in clarifying situations where it would be necessary to advise participants that confidentiality could not be maintained. Supervisory guidance made it clear for example, that should participants disclose they were at risk of intentionally hurting themselves or others, it would be expected that, where possible, an appropriate third party would be notified to manage this risk.

Tying this experience to broader discussions about the ethics of confidentiality, it is well documented that in being made aware of, or witness, offending behaviour, researchers have traditionally taken courses of action which favour their research participants. Failing to do so is seen as likely to compromise the success of their research efforts (Hodgson, Parker and Seddon:2006). Consequently, some researchers have often gone to great lengths to ensure information about offending remains confidential. Ferrell for example notes that when researching graffiti he "destroyed tapes and stashed transcripts in a locked box in the bank" in order to prevent authorities forcing him to disclose information about the offending of his research participants (cited in Worley, 
Worley and Wood: 2016:301). Similarly, Marquart's research within Texas prisons had exposed him to witnessing extreme forms of violence, the ethics of which he managed by ensuring he "maintained the code of the researcher: collect the data, and at all costs, maintain silence". When later called upon to give evidence against his research subjects, Marquart redacted his research records and removed any information that might identify his research subjects (cited in Worley, Worley and Wood: 2016:301).

That researchers are prone to 'choosing the sides' of their research participants places them at risk of involvement in potential ethical violations. Thus, while this research was less likely to result in situations which might attract the attention of authorities, in hindsight it would have been beneficial to have a clearer understanding of how to manage confidentiality prior to commencing the interview process. Developing a more comprehensive interview consent form would also have helped in making sure participants understood prior to being interviewed, that disclosing unsolicited information about the commission of serious crimes could result in police involvement. Additionally, future ethics approval processes might also benefit from clarifying the legal requirements which govern the confidentiality of research interviews. Without this clarification, novice researchers may unwittingly place themselves in positions which impact negatively on their research efforts.

\section{Organising and analysing the interview data}

The first pragmatic step in preparing for data analysis began with the process of transcribing the stories that had been recorded: The first 6 of the 17 recorded interviews were transcribed during the pilot study phase of the research, and these were completed by December 2012. The remaining 11 recorded interviews were transcribed in 2013 and 2014. Again, the pilot study proved to be an effective way of being better prepared in proceeding interviews, as I was able to listen to myself interacting with participants as I transcribed each interview, and reflected on how I could improve my interview skills by making simple adjustments. For example, I noticed I had a bad habit of clicking my pen which might have been distracting to participants, that I had used 
colloquial language too frequently in a rather clumsy attempt to build rapport, as well as nervously having asked specific questions, rather than adhering to the use of more general conversational prompts. The quality of my interviewing skills improved in later interviews as a result of this reflective process.

Each recorded interview was transcribed as accurately as possible, rewinding the interview to listen to specific words or phrases. I also listened to each interview again when reading the completed text to check for accuracy. As Bowden and Green (2010) make clear, given the primacy of interview scripts to theory building, researchers must ensure transcribed interviews are complete and accurate.

Although not exclusively used, qualitative research usually relies on the detailed analysis of textual artefacts - documentary materials, interview transcripts and field notes. Typically this data is unstructured, and the researcher must "impose order and structure on them in order to generate meaning and significance" (Morton-Williams: 1985, cited in Neale, Allen and Combes: 2005:1589). Given that each interview involved prompting participants' to retrospectively describe past events and 'tell their story', these considerations were informed by having used research methods which produced texts that were sequential in nature and contained similar narrative, or story-telling, devices. Although not comparable with detailed longitudinal analyses of life time drug taking as provided by Williams (2013), this outcome produced a similar perspective of drug use as a patterning of behaviour occurring at specific moments in participants' lives. Consequently, the data collected during each interview was structured in ways that moved the reader from past events to the present. This produced a biographical trajectory of drug use, from the point of initiation, through various transitions of druguse, and for 13 of the 17 participants, to a life-point involving desistance from drugtaking. 
Having methodologically imposed this structure on the interview data, it was possible to examine and compare each text in order to identify similarities and differences in the trajectories of drug use each participant described. An initial grouping of experiential commonalities was created by noting similar story-telling elements in each text. These included when participants' first initiated drug use, the range of drugs participants' went on to reference when storying transitions towards methamphetamine initiation and use, and for those who were no longer using drugs at the time of their interview, the point in their trajectory of drug use which marked a transition away from heavy use of methamphetamine and other harmful drug-taking behaviours. By starting with these basic categories it was then possible to focus more closely on how individual-level decisions about drug initiation, use and desistance had been storied by participants' at specific life-points. The common narrative structure which resulted from asking participants to describe past drug-taking events also provided the rationale for describing the research project using language denoting movement through the stages of 'starting, using and stopping methamphetamine use.'

Fundamental to further developing the approach I would take in order to organise and analyse the interview data was completing a preliminary analysis of the first six interviews transcribed as part of the pilot study. The primary objective of this task was to encourage thinking about how I would thematically arrange and theoretically engage with the interview texts, with a short term goal of presenting some initial findings at a Criminal Justice Symposium ${ }^{52}$. Consequently, to begin analysing participants' descriptions of transitions in drug-taking behaviour, I grouped sets of inter-related experiences into three main thematic categories: 'narratives of poly-drug use experiences'; 'narratives of social relationships and drug use'; and 'narratives of desistance from drug use'. In doing this, I was able to communicate the sequential elements of participants' stories and preserve the context of inter-related events they described. Taking a lead from Elliot (2005), this stage in the methodology emphasised

\footnotetext{
52 This was held at Victoria University in 2013, as part of the Faculty of Law Symposium Series.
} 
the intuitive nature of qualitative analysis, where it becomes difficult to demonstrate that

“...insight is not achieved by laborious pondering, but rather at a stroke, whereby patterns in a complex whole are illuminated by a kind of mental flashlight, giving an immediate and complete overview (Elliot:2005:157)."

Each of these narrative themes organised a subset of common drug-using experiences in ways that facilitated deeper analytical engagement with the data. For example, grouping together participants' poly-drug using experiences helped make visible the relationship between past experiences of using multiple drug types and the individuallevel processes underpinning assessments of risk. This theme also flagged the need to theoretically engage with the conceptual limitations of aggregating drug users according to one particular substance, as is common in illicit drug research. Grouping social relationship experiences together allowed for making gendered comparisons of risk and drug-taking decisions, while also helping to emphasise similarities and difference in social contexts increasing the likelihood of problematic drug use. Similarly, grouping narratives of desistance helped identify experiential similarities in how turning point events and personal crises initiated structurally situated decisions about stopping drug use.

When the data was thematically organised in ways that multiple readings of it confirmed the context of each story had been preserved, I assigned each participant with a pseudonym. In addition to the obvious need of safeguarding anonymity (a contractual condition of participation), the assignment of pseudonyms also provided a pragmatic means of referring to participants as real people when presenting my research findings. While pseudonyms are widely acknowledged as being integral to the presenting of qualitative findings, it is worth noting that this occurred without consultation with my participants. The interview process did not include an opportunity for them to choose whether they wanted to be named, or an opportunity to choose their pseudonym. 
While making a request for this process was not incorporated in my ethics application, in retrospect, this could be viewed as disempowering participants. That researchers disempower their participants by failing to include them in this process has been recently noted by Lahman et al. (2016:449). They describe researchers' as having the power to strip a name to an assigned number (subject 1 ), to the identity of a disloyal person (informant 1), or to a joke ('Curly Locks'). Accordingly, they view this process as "at best thoughtlessness on the part of the researcher and at worse an abuse of power" (ibid: 449). However, the intention in using pseudonyms here was to humanise structurally vulnerable participants, while ensuring they remained anonymous.

Using the Justice Symposium presentation as a platform to test the utility of the thematic organisation of the pilot study interview texts proved to be invaluable in developing my research methodology. With an hour of allotted presentation time, I had an excellent opportunity to demonstrate the effectiveness of how I was intending to thematically represent the stories of my participants. Feedback from the audience after the event indicated that I had succeeded in presenting their stories authentically, and in ways that conveyed the complexity and context of their drug-using experiences. Importantly, this signalled that the narrative groupings I had chosen to use were also in alignment with the broader thesis objective of theorising the social and structural contexts of drug-taking decisions (Rhodes: 2002, Sampson and Laub: 2005, Williams: 2013).

Having developed a robust 'content lens' using these main thematic categories, consideration was then given to the subjective aspects of the interview process. Focussing on different narrative devices participants used to tell their stories facilitated analytical engagement with how they made sense of past drug-taking decisions and the impact of traumatic life events. Riesmann (2002:19) has highlighted the importance of undertaking this task, emphasising that, in order to understand the meaning of a narrative, narrative researchers must evaluate how meaning is transferred in different ways within the context of narrative co-production. This requires the researcher to ask, 
"Why was the story told in that way?" (Cited in Larsson and Sjoblom: 2009:276). Additionally, it requires the researcher to reflect upon, and evaluate the interactional context of storytelling within research interviews, given that "the interactional rules and social relationships involved are different from those of ordinary conversations and other environments" (De Fina: 2009:237).

By incorporating this approach to assess layers of contextual data, I became attuned to similarities and differences in the construction and awareness of self-identity communicated by participants as they recounted their drug-using histories. This resulted in identifying additional thematic differences when comparing stories told by participants engaging with therapeutic environments, to those told by participants who identified as not having had any contact with addiction support services. For example, when participants who had received counselling or support from addiction services explained their past drug use, or their need to desist from drug use in the future, it was common for participants to refer to themselves as "having an addicted personality", "coping with drugs", being a "meth-addict", or being a "recovering addict". In contrast, participants who had not had contact with these services were unlikely to refer to themselves or to reflect on drug-use in their life histories by using the same language to define themselves.

The use of language typically characteristic of conversations which take place in therapeutic settings indicated that participants who had received counselling made sense of past drug-taking events as individuals 'identified - or labelled - as 'addicts' by addiction specialists. Referencing this discourse signalled the construction of a new selfidentity, within their new story of 'recovery' from past events. Comparatively, participants who did not use this discourse to understand their use of drugs maintained different character positions. The use of drugs was described in ways that had signalled harms, but which also communicated their being able to exercise control and desist of their own accord. 
Reflecting on the theoretical debates explored in the previous chapter, this stage in the analysis of the interview data evidenced how drug users are unlikely to be able to extricate their own understandings of drug use from authoritative understandings of drugs and drug users. As Martin and Stenner (2004) explain, from a narrative perspective, when constructing a narrative individuals can actively make sense of their personal and social worlds and exercise agency in telling their story, but agency can only be exercised within the parameters of a limited repertoire of available social, cultural and public discourses. Holstein and Gubrium (2000:103, cited in Presser: 2012:47) add to this view, asserting that narratives cannot be conveyed in a "pristine or authentic form separate from the institutions and events of the day." Therefore, the circulating discourses which structure understandings of drugs and drug users - such as those invoked in therapeutic settings, determined the repertoire of discursive positions available to each participant when recounting their story as a 'drug-user', 'addict', 'recovering addict', or 'meth-user' (Martin and Stenner:2004, Lilja 2013, Hilden:2014). Equally, when explanations for problematic drug-taking had been proffered by addiction experts, participants made sense of past drug-taking behaviour by identifying themselves as having 'addictive personalities', as 'self-medicating', as recognising their 'triggers', or in locating the relationship between their drug use and past experiences of trauma. As Will demonstrated during his interview:

I was selling a lot of their property just to cash converters and things, to fund, to fund, even just the weed habit, like, that's how addictive my personality is...l mean weed isn't a physically addictive drug, but I was.... but to me it was....but really it was the underlying anxiety issue, I was trying to self-medicate, and I was so desperate to self-medicate that's why I was using pot, and that's why I was like so desperately trying to source pot....

(Interview one, Will, male, 21 years)

Participants also engaged in the interview process by demonstrating their awareness of the physical and behavioural characteristics assigned to problematic drug users through authoritative discourses. This point was brought to the fore by Ben, a 31 year old Māori male participant, who suggested in a text message that I should bring a camera to the 
interview we had arranged. I didn't respond to his text as I was unsure what he had meant, but when I eventually met with him to complete the interview he pointed to his physical appearance as an upsetting and stigmatising indicator of his previous use of methamphetamine:

I was going to see if you wanted to take a photo of my teeth just from here down or something (points) because they are probably some of the worst teeth you've ever seen.

When somebody says something funny I smile but I don't open my mouth.... I don't show too many people but I'll give you an example (shows teeth) - see what I mean?

When you do that do you worry about people's perception of where that's come from?

Every time I look in the mirror and I see my teeth I'm really, really ashamed...if that's how ashamed I am and if that's how I judge myself imagine what these people are going to say, you know what I mean?

(Interview four, Ben, Māori male, 31 years)

In keeping with scholarship exploring stigmatised drug using identities (Goffman: 1963, Szasz: 1974, Ahern et al: 2007, McKenna: 2013, Green and Moore: 2013), the selfperceptions of this participant reiterated that drug users are acutely aware of the stigmatised identities discursively ascribed to them as a result of their drug use. The loss of teeth, in common with bruising from intravenous drug use or lesions associated with blood borne viruses, makes visible the physical characterisations that are essential in ascribing individuals' stigmatised identities: the 'tweaker', the 'junkie', the 'dope fiend', the drug 'addict' 53 . For this respondent, the visual cue of "meth mouth" confirmed his awareness of the deeply discrediting stereotypes of meth users as dirty or self-defiling, stereotypes actively promoted through the pervasive imagery of ant-meth campaigns and online addiction support resources (McKenna:2013, http://methhelp.org.nz/). Not

\footnotetext{
53 Goffman's (1963:2-3) seminal work on stigma and identity explains that categorising individuals or populations with social identities primarily occurs through visual cues, and that as a result "we lean on these anticipations...transforming them into normative expectations, into righteously presented demands". When evidence arises that an individual possesses "an attribute that makes him different from others in the category of persons available to him to be, and of a less desirable kind.... (He) is reduced in our minds to from a whole and usual person to a tainted, discounted one". These attributes concludes Goffman, are stigmas, "a failing, a shortcoming, a handicap" (ibid).
} 
surprisingly, individuals who are aware that their own personal attributes are "a defiling thing to possess" internalise shame, self-hate and self-degradation (Whittaker et al: 2011:1087). This point was further demonstrated by Will, who described being upset by his parents continuing to treat him as an 'addict', due to his ongoing use of medically prescribed drugs to manage his mental health:

...how they treat me about it I don't like, 'cause they just say aw you're just a drug addict and they're sort of just negative about it, they're not saying aw you're on the road to recovery, we're proud of you son, they're just aw fuck you're a drug addict, you're still on that Valium, and I try saying well look, I have to be weaned off that stuff, if I stop suddenly I can go into what's called status epileptus and die, but they don't understand, they're not willing to do the research themselves because they don't give a fuck, so they're just like oh whatever, you're just a drug addict - get off the Valium, stop taking that shit you don't need it, you're fine without it and they just know better somehow.

(Interview one, Will, male, 21 years)

During interviews with female participants who identified as sex workers, it was evident that internalising feelings of shame were also compounded by their awareness of being subject to further stigmatisation having transgressed gendered social norms. For example, before recounting her experiences as a sex worker Moana (interview three, female Māori 25 years), requested that I turn the recorder off for fear that her family might find out about it, in spite of my reassurances of maintaining strict confidentiality. A similar theme was evidenced by Jess (interview twelve, female 25 years), who told me she worked in a strip club which she identified, and that recently she and her sister had bought a gram of what she described as being 'crack cocaine'. However, having completed the interview I received a text half an hour later, thanking me for the interview and saying that she actually worked in a different strip club, and that she had bought methamphetamine, not 'crack cocaine'. Jess said she didn't know why she had told a different story and thought I should know. This aspect of how Jess told her story suggested it was very difficult for her to disclose as someone who used methamphetamine and that she was fearful of being identified as working in the sex 
industry. Like Moana, Jess's participation in the story-telling process powerfully communicated her awareness of judgement and condemnation in relation to the stigmatising discourses framing understandings of drug use and sex work as 'deviant' behaviours.

Of equal importance in noting the differences in how each story was told was my awareness of having assumed a different position in the story telling process in relation to the individual characteristics of participants and the situational context of the interview. Undertaking this reflexive process acknowledged how my presence as the researcher had influenced the data that had been collected. It prompted questioning about what experiential themes may have been excluded from the research as a result of my behaviour, attitudes and perceptions during the interview process:

When interviewing participants on the premises of the Bridge Programme I avoiding asking questions about whether participants had enjoyed particular drugs and disliked others. This was largely the outcome of my assuming that discussions involving the pleasures of drug-taking might somehow encourage drug use and undermine participants' 'recovery'. In contrast, interviews with participants recruited outside of the Bridge Programme took place in public meeting places and were informal, typically involving purchasing coffee and talking freely without my needing to negotiate an awareness of institutional constraints. When interviewing participants who had not had contact with addiction services I was less apprehensive about my presence, and noted that participants were more candid about discussing the meanings they ascribed to the use and effects of certain drugs in relation to others. I read this as a cue for the appropriate use of prompts to encourage them talking about using particular drugs, and an outcome of this was my documenting a more detailed biography of poly-drug use, as well as the meanings they ascribed to methamphetamine in relation to other drugs. 
Variations in how each story was told in relation to my position as the researcher was also evidenced by participants disclosing their experiences of sexual, physical and psychological victimisation. These references were also more likely to be made when I interviewed participants on the premises of the Bridge Programme, which suggested that as an older, white, middle-class male who identified as working at a University, my role in listening to the stories of vulnerable individuals centred on assuming a position of power, similar to that of a counsellor, a position likely influenced by using counselling rooms to conduct each interview. For example, during one interview a female participant recounted experiencing sexual abuse in the context of her drug using biography, and remarked after the disclosure that she had never talked about the experience previously. When I revisited this experience during my analysis I was reminded that by sharing deeply personal experiences with me, participants were using the interview to make sense of those experiences, and recounted them in ways that allowed them to consider the possibility of whether or not their experiences of victimisation might have influenced their drug-using behaviour.

Reflecting then on what might be thought of as the analytical 'mechanics' of narrative analysis, the process of moving between the content of participants stories, and listening to how their voices communicated their sense making helped identify distinct themes and sub themes across the interviews. Taking this approach provided rich and detailed descriptions of individual experience, as well as "the meanings made of those experiences" (Elliot: 2005:22). This outcome was also congruent with the primary objective of using narrative methods, the purpose of which is to step beyond quantitative descriptions of group characteristics which are less able to offer a perspective of the individual, by focussing instead on the unique qualities of each case in the sample (ibid: 118).

\section{Validating narrative research claims}

The validity of knowledge claims reliant on assertions of having captured a competing, emic, perspective of methamphetamine use is of course subject to methodological 
constraints. Consequently, Polkinghorne (2007:471) advises that if researchers are to convince readers their claims are valid and have significant theoretical purchase - as I endeavour to do here, it is essential they take steps towards reconciling the threats to validity inherent in their methodological designs.

This discussion starts by grappling with what Elliot (2005:23) defines as the internal validity of narrative data, given that narratives are never simply reports of experiences; narratives are produced to make sense of - and therefore inevitably distort - those experiences. Reismann (1993) refers to the issue of distortion as the "thorny problem" of truth in narrative research, and makes clear that truth as a transparent reflection of reality is unrealisable in a narrative context:

"When talking about their lives people lie sometimes, forget a lot, exaggerate, become confused and get things wrong. Yet they are revealing truths. These truths don't reveal the past as it actually was, aspiring to a standard of objectivity...Unlike the truth of the scientific ideal, the truths of personal narratives are neither open to proof nor self-evident (Reismann: 1993:22)."

However, as Guba and Lincoln (2005:208) make clear, no methodology can render visible an objective truth. As they describe it, objectivity is an unobtainable communicative achievement, "a mythical creature that never existed", except in the imaginations of those invested in the belief that "knowing can be separated from the knower". When compared to other research methods, it is therefore more useful to view narrative research, like other qualitative approaches to researching drug use, as an effective strategy for moving closer to the truth, rather than as a means of locating the truth (Page and Singer: 2010:23).

Polkinghorne (2007:479) also attempts to reconcile the question of truth in reference to narrative methods, by arguing that storied evidence is not gathered by the researcher to determine if events actually happened. Rather, this evidence is gathered to determine the meaning experienced by people, whether or not the events are accurately described or happened in the way they were recounted. For Polkinghorne, the truths which are 
sought by those using narrative methods are 'narrative truths', not historical truths. Sandberg (2012:65) offers a similar, supporting view of narrative truths, and argues that whether true or not, the myriad of stories people relay to the researcher reflect, and help understand, the complex nature of their values, identities, cultures and communities -a point evidenced by the complexity and richness of the narrative data successfully collated using narrative methods. The storied texts collated and analysed for this thesis should therefore be understood as providing important evidence to support claims about personal meaning, not to support claims about the factual occurrence of the events reported in the stories (Polkinghorne, 2007:479).

Assessing the validity of data analysis also requires acknowledging that qualitative methodologies are processes of interpretation, which are also akin to storytelling; they produce socially constructed truths, realities and meanings to make sense of observed or experienced social phenomena (Guba and Lincoln: 2005). As Martin and Stenner (2004:398) explain, as ways of knowing, interviewing drug users or observing the social contexts in which their drug taking behaviour occurs are not methodological conduits to reality; they become, as techniques, one of the means by which drug using realities are actively constructed. This argument is central to criticisms of those who advocate for the methodological superiority of qualitative research and uphold their research findings as grounds to claim to 'know what's really going on' (ibid). Ethnographers for example assert their own methodology as being superior to those where the researcher is distanced from the subject and that by conducting research on the "home turf" of their participants' they access data that is "more self-revealing than other types of behavioural research"(Carlson et al: 2009:62). Yet, irrespective of the proximity of the researcher to the subject, the act of research cannot disengage itself from the processes of interpretation. As Whyte illustrates when addressing critique of his defining ethnographic work 'Street Corner Society', what is observed is brought into being by the researcher through an individualised process of selection:

"I picked out for comment those events that seemed to illustrate the relationship between the individual and the informal group structure and the relationship of the group to larger 
organisations. I gave particular emphasis to the time dimension - how these relations changed with time (Whyte: 1996:242)."

Similarly, Bourgeois'(1996,2003) seminal ethnography on crack dealing in New York, regarded by many as the pinnacle of the ethnographic method, relied mainly on selfreported stories of violence, rape, and large scale drug dealing, rather than first hand observations of such events. Therefore even the best ethnographers must rely on retrospective, verbal descriptions of crime and re-present them in culturally specific ways which are attuned to academic readerships, a point downplayed in ethnographic debates within criminology (Sanberg:2012). Gergen, Josselson and Freeman (2014:7) also articulate the view of qualitative research as a creative and selective process, observing that the researcher is not only providing their participants with a means for self-expression, but they are also acting as a conduit for disseminating those expressions, and ultimately determine what is said and what is not, how it is said and for what purpose, to a broader public.

Given the selectivity and creative processes inherent in qualitative methods, Polkinghorne (2007:476), argues that the question of validity in a narrative context, is therefore to be answered by what he describes as "the process of argumentation": Readers are able to follow the evidence presented, identify the impact of representational decisions in the sequencing of the methods used, and follow the overall argument, so that they can make their own judgement relative to the cogency and soundness of the evidence-based arguments used to validate claims, about the meanings methamphetamine users ascribe to events and behaviours when making sense of their drug use (ibid: 485).

The process of argumentation in narrative research is also fundamental to a much broader research objective, the success of which is determined by an assessment of transgressive validity, defined by Guba and Lincoln (2005:208) as the extent that qualitative research methods produce authentic accounts of social phenomena, which 
resist, transgress, or disrupt the status quo. Sandberg (2012) reiterates a similar view in reference to the objectives of narrative research, emphasising that narratives are of theoretical importance because they have the capacity to influence future behaviour. They are, as Suarez-Ortega (2013) has argued, emancipatory; they generate possibilities of social transformation by identifying those elements which produce inequalities. For Chase (2005:667), the efficacy of analysing narratives, and re-presenting them to an audience through the act of interpretation, is therefore realised in the capacity of the analysis to influence social justice and democratic processes, and to question "for whom are these processes disrupted and encouraged?" The notion of transgressive validity resonates with the objectives of this thesis, and it is argued here that the stories collated and analysed, succeed in this project by providing an individual level perspective of methamphetamine use in a New Zealand context.

\section{Conclusion}

In taking a narrative approach to analysing participants' stories, this chapter sets out how this research was able to successfully attend to the primary methodological objectives of this qualitative research: to obtain contextually rich descriptions of the lived experience of methamphetamine use, to organise the research data in ways that advanced analytical engagement, to find thematic similarities in narrative content, to identify patterns occurring across trajectories of drug use at different transitional lifepoints in co-occurrence with changing structural positions, and most importantly, to be able to induce theoretical assertions about social and structural constraints on decisionmaking processes (Tewksbury: 2009).

Having reviewed the epistemological and pragmatic realities of qualitative research, there are a number of theoretical caveats to what can be inferred from the qualitative data analysed in proceeding chapters: as noted, it is not possible to make populationlevel generalisations about behaviour using data based on studies of small groups (Chase: 2005, Tewksbury: 2009). The reasoning here is twofold; first, replicating the narrative research process using a different researcher would produce different results, 
as would conducting the same research project in a different location or time given the changing nature and unique characteristics of local drug economies. Second, the methods used to recruit participants for this research are subject to the same criticisms levelled at government sponsored illicit drug research - they have disproportionately represented experiences of problematic drug use. The experiences of this sample of research participants are therefore not indicative of other meth-users experiences, notably those who use methamphetamine in a recreational context. However this outcome could be viewed as insightful, and may lend weight to the assertion that the challenge of recruiting individuals willing to identify as meth users evidences the pervasiveness, and discrediting effects, of anti-meth discourses.

Taking these caveats into consideration, the methodology used in collating qualitative data to inform theory building in this research succeeds in providing a new and underresearched perspective of methamphetamine use in New Zealand. The stories presented in proceeding chapters evidence the pragmatic and theoretical utility of taking a narrative approach to reveal the meanings methamphetamine users ascribe to their behaviours and their self-identities. They render visible the inter-play between individual, social and structural constraints on agential decision-making, a perspective which contributes to the broader theoretical objective of what Ferrell (2013:263) identifies as the need to

“...disseminate a replacement discourse that can re-constitute the meaning of crime and justice in the interest of progressive social change."

The next chapter introduces the methodological utility of narrative approaches to researching drug use as set out here by providing a detailed analysis of the first thematic grouping, 'narratives of poly-drug use experiences'. Participants' life course experiences of poly-drug taking behaviour and transitions towards methamphetamine initiation are then examined by introducing the theoretical efficacy and application of risk environment scholarship to understanding decisions about starting, using, and stopping methamphetamine use. 


\section{Chapter four: narratives of poly-drug use experiences}

\section{Introduction}

Although scholarship has identified that poly drug-use is a defining characteristic of both recreational and problematic drug consumption practices, when the use of multiple drug types has been reported in policy-based research, the experiential and contextual nuances of poly-drug use have typically been excluded. Instead, attention has more often been paid to statistical aggregations of drug repertoires, in order to identify cause and effect pathways between the use of licit and illicit drugs, and better calculate a myriad of poly-drug related risks and harms (Brecht et al:2008).

The narratives of poly-drug use examined in this chapter problematize these research efforts by shifting theoretical attention to the situated context in which drug-taking decisions are made. Given that all drugs are normatively defined as risky (and perhaps none more so than methamphetamine), decisions about using drugs such as methamphetamine are of theoretical importance; they necessitate asking questions about how drug-taking decisions are made, and identifying what influences the decision making process (Williams:2013:23).

In taking this approach, this chapter sets out the theoretical framework used in analysing the narratives of poly-drug use presented here, as well as the inter-related narratives of social relationships and drug use presented in chapter five, and narratives of desistance from drug use presented in chapter six. In doing this it introduces the theoretical underpinnings of risk environment scholarship and applies them in analysing the individual-level risk- assessment and decision-making processes which had resulted in participants starting and using methamphetamine . 
As the application of a risk environment framework helps explain, although drug-taking risks are often understood and negotiated at an individual or agential level, risk awareness and risk assessments invariably take place within social situations, structures and places (Rhodes et al:2003, Fast, Small, Krusi, Wood and Kerr:2010, Mayock, Cronly and Clatts:2015). Within these different social contexts micro, meso, and macro-level forces converge in ways that make risk avoidance difficult, and where it becomes less possible to avoid transitioning towards increasingly harmful drug taking practices, such as smoking or injecting methamphetamine (Fast et al: 2010).

The aim of this chapter is to demonstrate the theoretical utility of employing risk environment scholarship to theorise decisions about starting, using and stopping methamphetamine use. Its application in analysing the stories presented here and through this research helps in redressing the limitations of theorising the reflexive individual as cognitively assessing drug-taking risks in a vacuum. This has resulted in decontextualizing the process of reflexivity, and provides only a partial explanation for the how's and whys of drug taking decisions (Williams: 2013:68).

\section{Individualising risk}

Fundamental to the exploration of policy constructions of drug use presented in chapter two was the identification of how drug users are conceptualised as agential risk calculators, and how this conception is rooted in neoliberal pre-occupations with consumer freedom. This section returns to these themes, and identifies how risk environment scholarship redresses the limitations of contemporary risk theorising by providing a more nuanced, and context-specific understanding of risk assessments and decision-making processes.

The policy tools employed to govern drug-using subjects are reflective of wider societal preoccupations with risk, risk avoidance and the technologies of risk factor research (Mayock: 2005). As Beck (1992) and Giddens (1991) explain when examining the 'rise of 
risk', in post-modern societies, people are involved in an ever-present exercise of risk assessment, where risks are assessed, calculated and managed at an individual level. For Beck (1992), increasingly positioning responsibility on the individual is symptomatic of the declining influence once exerted by traditional certainties, such as the nuclear family, life-long careers, gender, class and other fixed norms. As a result of this 'social surge of individualisation', Beck argues that individuals are now expected to craft their own biographies and create new certainties. This process is governed by the freedom of choice and the expectation that individuals will draw upon sources of objective information provided by scientific experts in order to assess, and then avoid, a bewildering array of risks, in order to make culturally approved life choices (Tulloch and Lupton: 2003, Mayock:2004, Williams:2013, Mythen:2014).

Giddens (1991, cited in Denscombe: 2001:160) adds to this view of risk, asserting that individuals are now 'risk navigators', who must undertake the 'reflexive project of the self' in order to shape their own identities. Like Beck (1992), Giddens (1991) also argues that structural factors such as class, gender, ethnicity or occupational status now exert far less influence within the social arrangements of reflexive modernisation, and that a new identity agenda has been created, where the ' $m e^{\prime}$ of a permanent relationship in what was a traditional community has now given way to multiple 'mes'. The exercising of choice demands that individuals must therefore take responsibility for decisions affecting 'who they are' and 'what they stand for', in order to consciously construct and maintain a personal identity shaped in relation to its changing social environment (ibid:161).

When viewed from this theoretical perspective, drug-taking decisions are to be understood as the product of cognitive agential decision making, where drug users simply undertake risk assessments in much the same way they might assess risks associated with other life decisions, such as choosing careers, investments, insurances, or education. Employing Brook's (2010) phraseology, 'choosing using' thus requires 
drug-taking citizens to calculate the perceived costs of drug consumption in relation to the perceived benefits, before they initiate use. Williams (2013:42) adds that in relation to decisions about drug taking, the type of expert knowledge which aligns with Beck and Gidden's theorising, and which typically informs drug policy efforts, is that proffered by medical experts, who identify an array of irreconcilable physical, cognitive and psychological harms, all of which threaten users' health and wellbeing.

Yet despite the valorising of individual choice and undertaking such risk assessments, 'choosing using' is also deemed to be an irrational choice in the context of neo-liberal mores; people who choose to engage in activities scientifically determined to present an extreme risk to themselves and others, are, in the context of Beck (1991) and Gidden's (1992) view of risk, thought to be irrational or incapable of assessing critically the consequences of their own behaviour (Tulloch and Lupton: 2003). This accords with the standpoint taken by prohibitionists, where any use of drugs is deemed inherently problematic and is subsumed under the ideological umbrella that all drug use is a defective choice which invariably leads to addiction. For Brook (2010), drugs like methamphetamine are posited by prohibitionists as substances which are beyond resistance and which incite temptation, resulting in those who use them being 'possessed' in ways that compromise their ability to exercise free will and engage in rational decision making.

From a harm reduction perspective, the problematic drug user also remains an agential decision maker. Irrespective of their status as an 'addict' or 'alcoholic', harm reduction discourses present all drug users as ordinary people in high risk situations ( $O^{\prime}$ Malley and Valverde:2004). Typically informed by medical 'experts' drawing upon the science of epidemiology, resources such as needle exchange programmes, access to condoms, and hygienic settings to use drugs are provided to control the spread of diseases and other factors relating to health. These resources empower users to negate such risks, given 
that the freedom of choice renders individuals more personally responsible for the governance of harms resulting from their decision to use drugs (ibid).

Institutional understandings of how drug users assess risk and mitigate drug related harms are thus firmly anchored to a theoretical vision of risk assessment where agential decision makers engage in risk avoidance by "extoling and prioritising scientific expert knowledge above all other sources of knowledge" (Williams: 2013:26). While individual agency is intimately associated with drug-related risk taking (Fast et al:2010:2), asserting the role of the over-agential risk taker in accounts of contemporary life falsely assumes that decisions about drug taking will play out in what Stevens (2011:399) describes as

“...flat, hypothetical social worlds...in which people respond directly to stimuli that are applied to them as to units in a giant calculator."

Reflecting on these assertions, it is evident that the experiences of drug users interviewed for this research have demarcated the theoretical limitations of decontextualised assessments of risk and decision-making. This is not to argue that individual level evaluations of risk are simply over-ridden by deterministic outcomes induced by social and structural forces, rather, understandings of risk and risk avoidance are always socially and structurally situated. This assertion is the cornerstone of risk environment scholarship, which is explored in this chapter to begin contextualising the social processes which underpin transitions between starting, using and stopping, the use of multiple drug types.

\section{Risk environments}

Countering econometric understandings of risk and drug use, a more comprehensive appraisal of risk and drug-taking behaviour has been developed in the work Rhodes (2002), and advanced in the work of other scholars (Rhodes, Lilly, Fernandez, Giorgino, Kemmesis, Ossebard, Lalam, Faasen, and Spannow:2003, Fast et al:2010, McKenna:2014, and Mayock et al:2015,). This work challenges the predominance of 
these "extra-environmental and individualistic interpretations" of risk, by shifting attention to what he conceptualises as the risk environment, a heuristic framework which facilitates theoretical engagement with the lived experience of risk and problematic drug use (Rhodes:2002, and Rhodes et al. 2003:303). As argued in chapter two, this framework allows for theorising the significance of factors operating on multiple levels, which influence drug initiation, use and desistance. Its application in understanding poly-drug taking behaviour helps situate individual-level risk assessment processes in relation to the social and structural conditions which shape them.

Rhodes' conceptualising of environmental risks builds on the foundational work of Douglas (1985), whose cultural theory of risk similarly argues that individual understandings of risk are contingent upon intersubjective relations. As Douglas explains, expert appraisals of risk typically focus on the individual agent, thereby excluding from their decision-making processes any moral, political or structural 'feedback' they may have received from the surrounding social or cultural context they occupy (Douglas: 1985). In doing so Douglas (1985) describes the individual agent as being "de-cultured" by the individuation of risk, and argues that appraisals of risk cannot be separated from the cultural context in which they occur.

From Douglas' (1986) standpoint then, risk is not exclusively 'scientific' as Beck (1992) would later emphasise, nor is it the product of individual knowledge and perception. Risk is instead conceptualised as being open to cultural definition; it is the product of a way of seeing rather than a set of objective facts, where an individual's perception of what constitutes a risk is mediated by social and institutional prescriptions of what risk is. Douglas's view of risk thus resonates with the focus of this thesis in understanding how risk is negotiated within social groups who engage in risk-taking when using methamphetamine, as she demonstrates: 
"If a group of individuals ignore some manifest risks, it must be because their social network encourages them to do so. Their social interaction presumably does a large part of the perceptual coding on risks (Douglas: 1986:66, cited in Rhodes: 1997:216)."

In order to account for broader structural influences intersecting risk negotiation within social relationships Rhodes (2002:88) similarly conceptualises risk environments in order to encourage thinking about the social contexts in which "harm is produced and reduced." He defines the risk environment as a social or physical space, in which an aggregation of factors interact in the construction of drug initiation experiences, and which contributed to the production of drug-related harms. More specifically, the risk environment framework is accounts for the theoretical significance of risk factors which are exogenous to the individual, and which impact on drug-related perceptions and behaviour. These include physical, social, economic, and political forces, which structure the risk environment when operating at micro, meso and macro levels (Rhodes: 2002, Mayock: 2015).

The theoretical imperatives of the risk environment approach to understanding the how's and whys of drug initiation have been developed in scholarship which is identified for this thesis as useful in foregrounding the analysis of transitions in poly-drug use storied by drug users. For example, Bourgois and Schoenberg's (2009:19) ethnographic account of addiction and social exclusion in 'Righteous Dopefiend' reiterates the inseparability of macro level influences from the realities of drug use, extreme poverty and repression. As they identify, the lived experience of drug addiction and destitution is "a politically structured phenomenon imposed by punitive corporate neoliberalism and other forces such as the war on drugs (2009:19)."

O'Gorman's (2016:247) exploration of young Irish drug users and how they experience "differentiated normalisation in risk environments" similarly explores the inter-play between micro-level drug taking decisions and structural realities shaping young 
people's drug use within impoverished communities. She challenges how the normalisation thesis inadvertently privileges certain types of drugs and drug using behaviours "by focussing on the drugs being used at the expense of the power and status of its users" (2016:253). Accounting for the socially excluded context in which her participants' were exposed to, and experienced, the use of drugs, O'Gorman (2016:252) argues that,

“...by inhabiting a high-risk environment their consumption practices remain outside of the normalisation thesis and its derivatives. The concept of normalised drug use is inseparable from the context of commodified leisure whereas these marginalised youth have a largely decommodified existence and they are excluded from the licenced leisure economy through lack of resources and the cultural habitus to pass muster of the nightclub security."

The theoretical purchase of taking a risk environment approach is demonstrated in Aguilar and Sen's (2013:373) appraisal of risk environments as situated contexts where drug taking behaviour is intersected by gendered role and identity expectations. In their examination of how gay and bi-sexual men initiate methamphetamine use within social settings conducive to having sex with other men, they describe initiation as typically beginning "in bath houses, cruising areas, sex parties and clubs and neighbourhoods with high numbers of sex workers." The use of methamphetamine in these contexts enables men to be more social and act in ways that afford them social prestige, and help facilitate sexual inhibition (ibid). As they note in reference to literature examining gay and bi-sexual men's use of methamphetamine, meth was viewed as part of the culture of these events and was not pressed upon but, made available, to those participating, the setting thus providing an opportunity for non-users to casually initiate use. Reflecting on why some men initially choose to use methamphetamine in these settings, they articulate the inter-play between drug initiation and the lived experience of being gay within the structural realities of the MSM (men who have sex with men) community. 
In common with Aguilar and Sen's (2013) work, Mayock, Cronly and Clatts (2015) analysis of the gendered experience of risk and initiating intravenous drug use also highlights the importance of needing to account for the ways that gender, ethnicity or class influence drug use, variables which are evidenced in chapter two as being essential to contemporary theorizing about drug taking decisions (Williams: 2013). Analysing the situated experience of initiating heroin use in the context of intimate or 'drug' relationships with males, Mayock et al. (2015:778) explore the relational dynamics underpinning women's experiences of heroin initiation, as well as the emotional fabric of intimate relationships supporting drug use. By viewing female heroin initiation from this perspective, they demonstrate how drug relationships were described by female heroin users as complex risk environments which influenced the exercising of agency in inter-related ways.

It is argued here then, that taking a risk environment approach to analyse the environmental contexts of risk and drug taking redresses the theoretical limitations of relying on "an overly calculative and context free vision of risk decision-making" (Rhodes:2002:86). Such explanations when applied to drug use are, as Stevens (2011:399) rightfully observes, at odds with social and economic reality, given that people do not always act in their own best interests, they can be ignorant and irrational in their use of information, and that this irrationality can be multiplied when it is shared with others.

The narratives of poly-drug use which follow are thus fundamental to contextualising the complexities of navigating risk within environments that powerfully shaped and influenced participants' experiences of poly-drug taking and transitions towards methamphetamine initiation and use. Theoretical engagement with these experiences contributes to wider debates about risk and drug use by illuminating the social processes operating within drug-using contexts, and how these processes push drug users towards 
more harmful drug-taking practices such as smoking methamphetamine, and make it increasingly difficult to avoid "risking risk" (Fast et al: 2010:3).

\section{Beginning journeys of poly-drug use}

As noted in the previous chapter, the interview process had imposed a chronological structure on the 17 interview texts. Each text represented a sequence of drug-taking experiences, the sum of which plotted a trajectory of drug use from having first ever used a drug, to experiencing the use of multiple drug-types prior to methamphetamine initiation, and where applicable, to desistance from drug use. Given this structure, the first stage in thematically organising the texts into subsets of data was undertaken by comparing patterns and sequences of behaviours between participants' trajectories of drug use. This highlighted a range of experiential commonalities relating to the patterns of poly-drug taking behaviour that participants had described, the significance of which informed the first thematic grouping of participants' experiences as 'narratives of polydrug use experiences'.

The 13 participants who self-identified as 'addicts' typically responded by positioning themselves within their story in ways that enabled them to narrate their history of polydrug use and convey how they understood past events as contributing to their becoming a problematic drug user. In contrast, the 4 participants who did not refer to themselves as 'addicts', but described using drugs in ways that had caused significant disruptions in their lives, positioned themselves in their stories more as 'expert' drug users who had exercised control over their use of methamphetamine, and who, at the time of being interviewed, presented as coping with their drug using lifestyles, in spite of also describing negative drug-related life events that were similar to those who identified as being addicted to methamphetamine and other drugs. 
When recounting the beginning of their drug using journeys, all participants referenced their families, school experiences and the situated context in which their initiation into drug use occurred. No participant identified methamphetamine as being the first drug they had tried; instead, alcohol, tobacco and cannabis were consistently described in the sequencing of drugs all 17 participants had first tried, initiating first use as early as age 8 , up to age 14 . These experiences reiterated the findings of scholarship examining the types of drugs common to the poly-drug repertoires of both recreational and problematic drug users, that early initiation in alcohol, tobacco and cannabis use, for reasons which remain unclear and under-studied, invariably precedes the use of other illicit drugs (Measham:2004, Byqvist:2006, Staiger, Richardson, Long, Carr, and Marlatt:2012).

When participants reflected on how their journeys of drug use had begun, there was uniformity in identifying that exposure to licit and illicit drugs at an early age had been influenced by the availability, and use, of drugs within their social and familial networks. Exposure to alcohol, cannabis and tobacco in their homes, and when socialising with peers and extended family members, contributed to situated contexts where participants described drug initiations as being opportunistic and impulsive, and for many participants, as signifying initiation into long-term trajectories of problematic drug use.

For Angus, a 33 year old European male imprisoned for armed robbery at age 18 who described an extensive history of poly-drug use, his initiation into a trajectory of heavy cannabis use proceeded regular tobacco use. However, this transition resulted from an opportunistic encounter with cannabis in his family home, as he identified when I asked him when he first started using drugs:

I was 10 when I started smoking 'ciggies' and pot 
How did that come about?

...the first time I smoked pot and this will kill my parents because they're very straight laced, but um, I was rummaging through their drawers looking for money to by some ciggies and I found, I found a cigarette packet with a couple of massive joints in it, and I knew what they were and stuff and that's where I started from...I'd smoked (cannabis) from 10 to 13, by the time I hit high school it was every day...same with ciggies, not a packet a day, you know a pretty good habit...

(Interview seven, Angus, male, 33 years)

Describing a theme that was common to almost all participants, Angus went on to recount his early use of drugs by referencing disruptions in schooling and changes in peer associations. When he reflected on these experiences Angus positioned himself at this point in his story as being on an immovable path to increasingly problematic druguse:

...did anyone ever become aware of (your drug use), or observe any changes in you?

I got caught when I was in Form 2. So, when I was 12, a neighbour had seen me smoking a cigarette on the way to school. So, my mum had searched my room, and she didn't find cigarettes; they were on me. She found some pot in my sock. She came and dragged me out of school that day...I got in major shit over it. High School was certainly where it - like, I say; every day - and alcohol. I did speed by 14 and ecstasy at 14, and tripped.

How did you get into contact with those (drugs)?

It's not hard. I remember scoring my first - one of my first tinnies was from the old Highway 61 pad in Seaview; just rock up, ring the bell, put your money in and away you go. Like I say, I always hung out with older people...Yeah, so it wasn't hard. I've got a pretty lengthy criminal record, starting off at about 15. I held a dairy up with a knife and got caught for that; into Epuni Boys Home.

...I was pretty out of control really by 15. I left school. I went to four high schools, and in the second week of fifth form, I left high school. I was on my own flatting and working, but of course it didn't last that long. So yeah; then into Epuni Boys. One night I broke into one of the manager's sheds at Epuni Boys, and stole some master keys, and the next day let about half of Epuni Boys go. I was on the run for about three weeks and then one day I got hungry, run out of money, and 
walked into Lower Hutt Police Station, handed myself in, and kind of continued that. So I did my time for that.

Were (your family) involved in your life then?

Yeah, definitely. They always have been. I've had a step-dad since I was four; haven't really got on at all well with him. It wasn't until I got out of job that we kind of started getting along. I was pretty loose. All I wanted to do was have fun. I think for my drug-use, it was I got a real kick out of being out of control; that was my goal.

So, how do you define 'out of control'? What does that mean to you?

I don't mean massively violent or anything like that, but just no inhibitions - just right out there. I'm really highly strung. I've got a massively fast metabolism, and I've always lived life to the extreme.

(Interview seven, Angus, male, 33 years)

Rayleen, a 33 year old female Māori who identified as a sex worker, described a similar experience of initiating an early trajectory of problematic drug use, which had also resulted in major disruptions to her schooling, involvement with criminal justice agencies and in her losing custody of her children. When reflecting on her first experience of drug use, she described opportunities to use alcohol being facilitated by her father at a very early age in her home, and identified that cannabis was also readily available due to extensive parental involvement in drug dealing. Like Angus, Rayleen also described her initiation into using cannabis as resulting from an opportunistic encounter:

...it would have been here in Paraparaumu with my - Dad used to have wines at the table. So we were allowed little bits of glasses of wine, through dinner.

How were - older were you then?

I was only six. So I got my first taste of it then, and my drug-using started nine in Christchurch when I found a joint in my mum's bag. (Laughter).

So, you came into contact quite accidentally with this joint, and you had it? 
Yeah, and I - obviously I didn't know what the feeling of being stoned was, and I got paranoid, and um, Mum came home and sort of looked at me, and said, what's wrong with you? I was crying (laughter) and didn't know what was wrong, and I said, I'm hungry - I'm hungry. She sort of just looked at me, but she went into her stuff, because I think she knew something wasn't right, and noticed her joint was gone, and yeah sort of just yelled at me a bit, but...

...Was she really mad?

No, because of course she had ounces of it everywhere. So, I think she was mad that I stole it, and went in her stuff, but um, she seen it as a joke. It was hilarious that her nine year old got high. (Laughter)...Yeah, I was scared. Yeah, because I didn't know. In my head I really didn't know how long this was going to last, and - because l'd never felt anything like it (laughter) and I was on the ground sort of rolling around crying, and paranoid feelings and yeah like, she swore and declared l'd never do it again. (Laughter)

(Interview eight, Rayleen, female 33 years)

For Amy, a 33 year old Māori female interviewed at the Salvation Army Bridge Programme, a friend accessing a large amount of cannabis oil at age 13 would also cause significant disruption to her schooling, and then later be proceeded by a transition to her use of alcohol and cannabis:

....my friend, um, she had an uncle, who was um, a drug dealer, and she had gone into his (car) boot and stolen 20 litres in the big margarine containers full of caps (pill sized measures of cannabis oil), you know, oil? Anyway so just ended up - I wasn't smoking then - ended up handing them around in school, yeah and just went...nuts and nuts and nuts until someone ODed (overdosed), someone swallowed a cap and ODed....so that was my first experience with drugs like hands on drugs, ended up getting kicked out of school and everything...

Presumably you would have used it?

I actually, probably did I think I might have had a puff on tin foil ${ }^{54}$, ah, it wasn't really my thing, yeah, I didn't start smoking drugs, probably, I think about seven months later I ran away from

\footnotetext{
54 When boiled in isopropyl alcohol, cannabis plant material is reduced to a thick oil which is similar in viscosity and colour to Marmite. Oil is traditionally sold in capsules or in pill trays such as those used for Panadol. Users smoke cannabis oil by placing it on tin foil, heating it with a flame and inhaling the vapours.
} 
home...I changed schools...started drinking and wagging and getting stoned, that's when I started getting stoned...

(Interview nine, Amy, female 33 years)

In other participants' narratives the use of alcohol, tobacco and cannabis was presented as being normative adolescent behaviour. For Rebecca, a 23 year old female who described herself as trying to re-start her life in Wellington having escaped from an abusive and controlling partner, when asked about having first used a drug, she identified using tobacco with older sisters, its use becoming a temporary feature of her character's behaviour in her narrative as a 'typical teen'. Alcohol and cannabis use was also described as occurring in this context, with cannabis being introduced by one of her peers:

Um...I think ah my - probably it would be a cigarette, but it would have been my sister's. I must have been about $11-11,12$ sh... Um, I remember it was just ah, my sisters used to smoke around me and used to make us roll them, and so it was just like a cheeky, I wonder what they do it for, kind of. Like, it was me and friend, I remember and we hated it and we coughed heaps (laughter) but yeah, it was a few years after that I started really smoking properly. I was still quite young, yeah.

(At school)...probably by then we're like smoking all the cigarettes and we'd had the odd drink and sneak out at night. You know, 15 little - little shits, really... Um (laughter) and then um, yeah no, one of the girls came over and goes, oh I've got this (cannabis), and so we tried a little bit. I remember just like running through the field. I think there was an ice-cream truck or something, and it was funny. (Laughter)

(Interview ten, Rebecca, female 23 years)

For Kiri, a 50 year old Māori female who had completed an eight year prison sentence for manufacturing methamphetamine, her early experiences with alcohol resulted in a very different transition to the use of other substances. When describing her initial 
experiences with alcohol as negative, Keri reflected on how she rationalised her preference for using solvents at an early age:

How old were you.... when you first used a substance?

...12 years old and I started using solvents...so, and I used those for the next 5 years when all my mates were drinking alcohol and smoking dope, I just loved sniffing petrol.

So how did that come about?

Umm, I just, I liked the smell when I was young, so, I don't know, some of my friends were doing it so, I don't know, I just loved it...I think alcohol freaks me out a bit because I like to know what I'm doing, and I like to remember, so you know, the few experiences I had when I was drunk um, I didn't like it, I didn't know what I'd done, or...got to have your wits about you, can't do that when you're drunk on the ground...

(Interview seventeen, Kiri, female 50 years)

All participants described the normalised presence of alcohol in their biographies, with some citing similar experiences to Kiri when identifying their preference for other drugs as resulting from negative experiences when drinking. However, for other participants, the use of alcohol signalled their initiation into a trajectory of problematic poly-drug use. These experiences were described in ways that illustrated how alcohol use permeated participants' social and familial environments, and where negative outcomes associated with its use were identified as common-place experiences.

When Rebecca started by reflecting on the normalisation of alcohol in her life as a teenager, she identified her father as an alcoholic and described the social context of her beginning to use alcohol:

I was probably about 13 or so when I started drinking. My dad's an alcoholic...

...you identified him as an alcoholic?

Yes. 
So, how - how did you become aware of that?

... I can identify now l've been through - going through quite a few addictions now since about the age of 16. So I can identify as, that he is an alcoholic. He would never identify that himself ever. (Laughter) He's one of those happy - happy drunks. He's, you know, but he does - he used to drink-drive coz he used to think he was fine. So at 16 he taught me to drive, so I could drive him back from the pub, coz I told him he can't keep drink-driving.

How would you have viewed his drinking (then)?

... I just thought - ah, he's a shearer, and kind of we got, you know, we grew up with shearers, so for us it's very normal. (Laughter) Like we, you know, I was 16; I could go to the pub and buy myself a drink, because they knew Dad. Yeah, so...

As Rebecca progressed in the telling of her story she described her excessive use of alcohol, reflecting on her understanding of alcohol in relation to her father's drinking behaviour:

I used to drink um - coz Dad drunk beer I didn't see beer as like really alcohol. It was - everyone else was drinking Vodka or wine, so we were drinking Vodka, and it was straight Vodka half the time. It's not good - actually really bad, yeah.

...at that time it was more just like get off your face drunk. I don't know why. I guess everyone was just, you know, doing it as well, and yeah I used to be really bad at sculling straight Vodka, which I think is disgusting, coz I can't touch the stuff now (laughter), but you know, yeah just got into that kind of like - yeah, crowd I guess, yeah.

In order to make sense of her past alcohol use Rebecca referenced herself within her story as being an 'addict', but at the same time identified a potential future where she might achieve a non-addict identity, and thus be able to use alcohol in a culturally acceptable way:

...Like, now if I was to drink - I don't drink at the moment anymore at all um, but you know, if I when I got older and when I got out of that kind of stuff, I could have a wine, you know, or like, you know, just normal kind of thing, but I'm an addict, so I actually know that can lead to more things now...

(Interview ten, Rebecca, female 23 years) 
Like Rebecca, the progression of Rayleen's drug-using journey featured problematic alcohol use. Rayleen also reflected on her using alcohol by referencing her parents' drinking behaviour, and identified that her drinking had led to disruptions in schooling and contact with addiction services at an early age:

...I wasn't a normal teenage drinker; I was drinking straight bottles off the top shelf, and - and blacking out and coming home and smashing up the house. (Laughter)...Causing my mother grief and - (laughter).

Did (your parents) ever express any opinions about alcohol versus drugs?

Um, I - I think, because Mum was brought up with - around alcoholics, so she only knew the violent side of things, and when Dad was drunk, obviously he used to hit her, so that was her version of what alcohol does, but yet I couldn't get it, because she was a drinker, too and I thought, well how come you get to drink - why can't I drink? But my drinking was so excessive that I was an alcoholic by 14. So I was drinking at school, in class...Sneaking it in my drink bottles and yeah I was in and out of rehab.

So, how did - if you were engaging in using alcohol at school, how did that...impact on schooling...at that point in your life?

Um, school was always ringing up. I was always in trouble. Um, I was always arrested. In the end I just didn't go to school. I just left school, because I just wanted to party all day long...

(Interview eight, Rayleen, female 33 years)

As identified at the outset of this chapter, theoretical engagement with poly drug use has largely been subsumed by aggregates of poly-drug users being assigned identities in accordance with whichever substance 'experts' highlight as presenting the greatest risk, to the user and the 'community' they occupy. Where meth use is concerned, this typically results in identifying enduring problematic social conditions experienced by some users as being the direct outcome of methamphetamine alone, rather than a longer term accumulation of drug related experiences and events, as these users' stories of early poly-drug initiation clearly demonstrate. 
The prevalence of alcohol, tobacco and cannabis use in the initial sequencing of substances used by poly-drug takers as illustrated here, has often been theorised as indicative of the 'gateway effect's5 - the progression towards poly-drug use which begins with tobacco and alcohol use, moving to cannabis and then 'harder' illicit drugs (Degenhart, Chiu, Conway, Dierker, Glantz, Kalaydjian, Merikangas, Sampson, Swendsen and Kessler: 2008:157). It has been argued in relation to early onset of tobacco use for example, that smokers are significantly more likely to engage in future risk-taking behaviours, including poly-drug use and high-risk sexual behaviour, and be more susceptible to the risk of alcohol disorders during young adulthood (O'Cathail, O'Connell, Long, Morgan, Eustace, Plant, Hourihane:2011:547). However, in spite of the correlation between the use of licit drugs and future drug taking, the decision-making processes which sit behind the association of these drugs with transitions to pejoratively labelled 'hard' drugs, remains unclear.

For these drug users it was evident that at this stage in their drug-using journeys, exposure to alcohol, tobacco and cannabis occurred within environments that were shaped by the drug use of family and peers, and the broader normalising presence of societal alcohol and tobacco use. The aggregation of these elements contributed to situated contexts which facilitated exposure to drugs and opportunistic initiation into drug taking. Using one or more of these drugs was also not causal, in that it resulted in a linear transition - or pathway - to using another, but was more likely to be experiential, as Kiri demonstrated when rationalising her decision to use solvents as the result of not enjoying the effects of alcohol. Rhodes, Lily, Fernndez, Giorgino, Kemmesis, Ossebaard, Lalam, Faasen, and Spannow (2003:311) suggest that early initiation into the use of

\footnotetext{
55 The gateway hypothesis assumes that the use of one drug increases the likelihood of using another. Cannabis has been most often theorised as a gateway drug, where it is argued that using cannabis increases the likelihood of progressing to use other, more harmful drugs. However, the gateway hypothesis suggests that patterns of drug use are normative, and fails to account for individuals moving in and out of particular drug using trajectories. The gateway hypothesis also assumes that illicit drugs are the first stepping stones to other forms of drug use, without adequately accounting for the role of licit substances as the experiences explored here suggest is important. Additionally, gate way explanations of drug use discount social contexts to explain drug initiation, causal relationships are determined instead solely by the substances themselves, as though there is a chemical nexus between substance $A$ and substance B. See Kleinig (2015) for further discussion.
} 
alcohol, tobacco and cannabis is more likely a marker or indicator of other risk factors, notably a propensity for using drugs at an early age in ways that would cause both personal harms and significant life disruptions as Rayleen and Angus had experienced.

When viewed from a risk environment perspective, the social worlds that participants described when storying drug initiation evidenced cultural environments which had exposed them to drug use and provided opportunities for drug taking. In this context, it was more likely that the age of first initiation, and the drugs used were less the issue than the inter-play of environmental influences which brought about drug use earlier than would normally be the case (Rhodes et al. 2003). As has been identified in using risk environment frameworks to explain drug initiation and use, drug takers are often more likely to be exposed to attitudes supportive of drug taking behaviour, given that drug users' social relationships are frequently with other drug users and drug suppliers. It is within these social settings that "understandings of risk are formulated" through the observation of behaviours introduced to them by others. These settings function as sites for initiating the process of drug normalisation, where users are exposed to seeing or hearing stories about drug taking activities, whose attitudes and decision making processes about drugs are in turn influenced by pro-drug behaviours (Williams: 2013:81).

\section{Transitions in repertoires of poly-drug use}

Common to all participants' stories were descriptions of opportunities being presented to try new drugs, sometimes including them for extended periods of time in their repertories, and then stopping their use in favour of using other drugs. This was in keeping with experiences of drug use noted in scholarship examining drug pathways, transitions and decision-making, where drug taking practices are unlikely to remain stable over the course of a users' lifetime (Mayock:2002, Brecht, Huang, Evans and Hser:2008, Williams:2013). Similarities with other qualitative works examining polydrug use were also apparent when participants' reported transitions between different drug types as being influenced by what drugs became available in their social networks 
(Boeri et al., 2008), and as changing in accordance with personal drug preferences being "altered alongside new knowledge and experiences of a range of substances" (Mayock: 2002:127).

In their examination of how urban drug scenes in Vancouver shape "the evolution of risk and harm among specific drug using populations", Fast et al. (2010:3) define these movements between the consumption of different drugs, notably when users transition towards increasingly problematic drug use, in two inter-related ways, providing useful terms of reference for the stories examined throughout this research. In the development of their work they define a transition as being a self-identified, significant change in drug-using practices, which includes initiation into drug use and any subsequent changes in patterns of drug use, such as changes in the types of drugs used, methods of ingestion, and intensity of use (ibid:4). They also define the sequential nature of problematic drug use by employing the term, risk trajectory, a perspective they identify as emphasising

“...the sequences of transitions experienced by young people in relation to drug use and risk over time, (recognising) that transitions are oftentimes shaped by particular critical moments (e.g. becoming homeless), as well as broader contexts (e.g. exclusion from mainstream opportunity structures) that can greatly influence long-term patterns of risk and harm."

The experiences participants described when referencing the environmental contexts of their drug use accorded with these definitions in a number of ways. All participants' identified an array of distinct transitions in their drug using behaviour, which included identifying periods of indiscriminately using multiple drug types before 'settling' on a repertoire of preferred drugs, or as some authors have defined in poly-drug scholarship, 'primary drugs of dependence' (Darke et al.:2012:784). These shifts were typically identified by statements about using an array of drugs, which participants' aggregated using category references, such as 'legals', uppers, downers, pharmaceuticals or hallucinogens. In the progression of storying their drug use, participants then referenced 
transitions to more stable drug taking practices, marked by transitions towards preferred drug types, and preferred methods of ingestion.

As these transitions were identified, participants also frequently referenced navigating a range of critical life experiences, which included terms of imprisonment, losing the custody of their children, experiencing gang-related violence, police harassment, sexual assault, domestic violence, and a range of profoundly negative health consequences resulting from their use of drugs. When retrospectively storied these experiences cogently brought into being the risk trajectories they had experienced when gravitating towards more harmful forms of drug use. Again, these experiences pointed to environments conducive to opportunities for drug taking, as well as social circumstances which had increased the likelihood of exposure to risk as a result of their drug-taking decisions.

As with other participants' identifying as 'addicts', Sean's story was structured in accordance with retrospectively reflecting on how past events had contributed to his becoming a problematic drug user. A 33 year old European male participating in the Bridge Programme, Sean had extensive experience with a variety of drugs, the use of which had preceded his eventual addiction to his 'primary drug of dependence', methamphetamine. When telling his story Sean described using several different drugs when he was younger, positioning himself at the start of his drug using journey as 'experimenting with drugs':

So, you used (cannabis) for a while. What might have been the next thing you tried?

Um, well I remember at quite a young age, trying um - well, a few things. I know magic mushrooms and LSD. Um, NOS - another one - Nitrous Oxide. Um...You know, I had fun on um, things like LSD and NOS for a while. It's um - you have a bit of a laugh on them, but um, they were appealing and they were fun, but I-you know, um there wasn't a physical addiction to them. You know? It's - yeah um - yeah, and I think um, had - yeah, had a bit of Speed as well when I was younger. That was something I experimented with and - and did enjoy... 
Sean went on to identify his past use of ecstasy and described his use of this drug as signalling his transition from recreational poly-drug use to problematic drug use:

...I think with Ecstasy, you know, I took - I took a shitload of them, but it wasn't every day of the week. You know? Take a lot of them on a Friday or Saturday night - maybe drop five at a time, or something like that, but it wasn't um - there wasn't a physical addict - you know, like I mean, maybe some...

Would you have described yourself...as a recreational user?

Yeah, I - I would. I would, because it wasn't ah um - it wasn't do or die. You know? You know when you're an addict, eh? Things change very quickly.

(Interview eleven, Sean, male 33 years)

Sean then reflected on his transition between a period of ecstasy use and the problematic use of BZP (Benzylpiperazine), and in doing so identified himself as becoming an 'addict' by comparing his drug use to that of his partner, who he identified as a 'recreational' user of drugs:

...for me, there was a transition from E into Methamphetamine and - and that was herbal pills, you know, like I got really hooked to the BZP, eh like - and I know a lot of people that did, and I feel that...

What did you like about them?

Um, it was like taking - you know, 10 Ecstasy at once, and it'd last for 10 hours. You know? The buzz went a lot longer um, but there was definitely an addiction. You know? Um, that was the first time I felt that I had a problem with drugs um, and my partner at the time did, too. Um...

She was using drugs as well?

Um, oh she was a recreational user - not like I was. Um, and ah, it even started to affect my behaviour, ah my moods, ah my priorities.

In what ways?

Um, well you can't - you know, um I think when you're using a drug it's - you know, there's a chemical imbalance that it creates in - in your brain and - and your emotions. You're emotionally unstable, and you're unpredictable as well. You know, and unreasonable, um but yeah that was 
- for me, that was a turning point, and you know, I really - in some ways I think the New Zealand Government has a lot of responsibility for a lot of the - this plague of Meth addiction. I know a lot of people that were hooked to um, you know - to herbal pills that - when the herbal pills were banned, made that change to um - to Methamphetamine.

(Interview eleven, Sean, male 33 years)

Sean articulated a theme that was common to other participants reflecting on their histories of problematic drug use, when he identified that in spite of the negative impact of his drug taking he still continued to use drugs. This was also evidenced at another juncture in his story, when he described his cannabis use:

I never particularly enjoyed marijuana. It's not-you know, I discovered other drugs later on. It was um...

What didn't you like about it?

Um, I didn't like the 'slothishness' of it, you know? I felt for me it's a drug that makes you really lazy. You know? Um, you smoke a joint in the morning and you don't get anything done, really. It was, you know um - and it's still very much my opinion of it now. That was my opinion of it then. It didn't stop me from using it a lot though.

Did you become a more frequent user...?

Oh yeah, I smoked it every day for years. Um, I was expelled from school um, for drug use

(Interview eleven, Sean, male 33 years)

Other participants' recounted similar experiences: although Jess, a 25 year old female was one of the four participants who didn't identify herself in her story as being a problematic drug user, her drug use had also resulted in negative health outcomes. Rather than constraining her future use of drugs, these negative experiences resulted in her temporarily modifying her drug-using repertoire: 
You mentioned when you stopped using (cannabis) you had some negative effects...?

Umm...sure well I had insomnia and schizophrenia, just, just, for a few days really, but umm...yeah that was kind of worrying, that I might have to go into an institution...cause of course, your delusions are so convincing that you don't realise they are delusions so some else has to explain it to you...kind of troubling

Did that create a...moment where you're going, 'hang on maybe I should stop (using drugs)?'...

Well not exactly because, you don't really get that, you know, every drug is different, but umm, I certainly stayed off the cannabis for a long time...

(Interview twelve, Jess, female 25 years)

Reflecting on the drugs she had tried prior to initiating in methamphetamine use, Amy also reported having a negative experience as a result of her prolonged cannabis use. Amy described the social dynamics of this experience, and noted how this had informed her decision to stop using cannabis in favour of only using methamphetamine and alcohol:

I didn't really start using trips until about last year - end of last year. What else? I stopped smoking dope when I was 22. Oh hold on - no, about 23, because it made me paranoid. Yeah, I didn't like that so I just stuck to strictly P and alcohol.

When you say that (cannabis) started to make you feel paranoid; was that a particular episode, do you remember?

Yeah. I stopped smoking dope, because my friend - I ended up staying with her for a couple of months and she was jealous, because she had a partner and it made me and the partner feel uncomfortable - obviously she was uncomfortable with it, too - just like I explained with that whole girlfriend thing. Obviously that was going on, and she knew but you just can't stop getting yourself in those states. Anyway, I stopped smoking dope from then on - from the exact moment on, because it made me paranoid - over-thinking; of fuck, are they talking about me? That's when I stopped smoking dope, and I just stuck to $P$.

(Interview nine, Amy, female 33 years) 
For Will, prior experiences with other drugs highlighted the decision-making process which informed his preference for, and eventual addiction to prescription-only medicines. Like Amy, rather than constraining his use of drugs, negative experiences with particular drugs highlighted the utility of continuing to use others, as Will revealed when reflecting on the unpredictable and 'scary' effects of drugs he had tried, and how these contributed to his preference for the predictable effects of prescription medicines such as Ritalin ${ }^{56}$ and Tramadol ${ }^{57}$ :

... What came after pot (cannabis)?

Pot to salvia ${ }^{58}$...sorta tried a few 'legals' and herbals and stuff....salvia...BZP....salvia was scary....I only did it once and I'll never do it again cause it fucken freaked the fuck out of me...

...I never got heavily into (Ecstasy) because it wasn't one of those....I don't know....just a party drug......wasn't one......wasn't a favourite.....wasn't a favourite like tramadol (an opiate) or methylphenidate (Ritalin)....wasn't like 'rushy'....

It didn't have the same appeal?

Yeah, didn't have the same appeal. (Ecstasy's) harder to get and because a lot is hit and miss....it just put me off straight away, um, I'm a real straight up kind of person, I just want what I get is what I want, you know what I mean aye?

(Interview one, Will, male, 21 years)

Later on in his story Will also reflected on how past events had contributed to his wanting to use tramadol more than other drug types. When doing this he communicated having exercised agency over past drug-taking decisions, and identified how positive experiences using tramadol had initiated his transitioning towards more harmful drugtaking behaviours:

\footnotetext{
${ }^{56}$ Ritalin is the brand name for methylphenidate, an amphetamine analogue used to treat ADHD which shares similar pharmacological properties to cocaine and methamphetamine. It has been described as 'legalised speed', 'Vitamin K' and 'Kiddies Coke'. ( Keane:2008, Quintero:2012, Kosten el al 2012)

${ }^{57}$ Tramadol is the brand name for an opiate based analgesic typically prescribed for moderate to severe pain. (see http://www.mymedicines.nz/home/sheet/Tramadol?format=pdfA4\&inline=true )

${ }^{58}$ Salvia divinorum is a hallucinogenic plant related to sage which is typically smoked. It contains a psychoactive substance called Salvinorin A, the effects of which are similar to LSD.
} 
I wouldn't blame my friends for my drug usage because after l'd become introduced to pot I started doing research for myself and then I started getting in drugs myself because my dad at that time had a hernia and he had an operation on his hernia and he got prescribed some tramadol, which is like a synthetic opiate, and I was doing all this research on it 'cause I was like real keen on it.... just obsessed over it really...so I got into opiates...real young....started doing tramadol, took his prescription straight away, man that was one of the best experiences of my life, and that's really where that started.

(Interview one, Will, 21 year old male)

For John, a 39 year old European male who identified as being a drug 'addict', navigating the negative effects of his drug taking occurred in the context of his becoming an intravenous drug user. When describing this experience, John described an extensive history of problematically using a myriad of drug types, as well as periods of heavy alcohol use. Reflecting on these early experiences with drugs, John went on to recount a series of transitions in his drug-taking behaviour, and his eventually learning to become an experienced drug injector, an experience he described as resulting in an infection from the use of 'dirty' injecting equipment:

...can you reflect on that first time you used it intravenously? Were you with someone who was showing you how to do it, or...?

Yeah, the very first time. Yeah, um and then subsequently to that I was left to my own devices. Um, unfortunately I gave myself a dirty taste. Um...

What do you mean by dirty taste?

Well, okay um, let's say - let's say you're using the same needle or something, and for instance ah - so the drugs have become dirty through whatever contamination there is. Um, and without realising it, you inject that. Um, like that's usually not so bad. It results in, you know, a bit of a bit of a headache and like, you know, can kill you, because it's an infection, really. Um, so um, this particular time, oh I was entirely wasted at a party, tried injecting myself, actually missed the vein as well, but because I was so wasted I didn't know this. So I had this bloody great big, like dirty water slowly seeping into me via intramuscular injection, which lasts like 16 hours or something. So that was - that was - that was very ill-forming.

(Interview thirteen, John, male 39 years) 
As he progressed in telling his story, John described his transition towards becoming a committed intravenous drug user, referencing the experience as being dependent on learning to navigate both positive and negative experiences when injecting drugs, notably in learning how to use and enjoy various opiates:

\section{What kind of opiate was...your first?}

Okay, that - that would have been - um, that would have been produced by an opium poppy plant. Ah, so it was a - it was a - you know, it wasn't that dirty a liquid - I've definitely had dirtier in the years following, but it's not exactly a clean heroine-like substance either. So, you know, so you definitely do get, you know slight headache, for instance - um, you know, things like this. Ah, but at the end of the day, like you know, if there's - if there's a couple of hour period there where you actually feel as though it's worthwhile, you will - you know, you're try it again, and then you try it again and, you know - and like with anything in life; you get a bit of a tolerance for it. You know?

If you jump into a cold water pool the first time, you'll be going, fuck - and jump out again. But then, you know, you'll - you'll be able to jump back in again, and the third of fourth time you'll you'll stay in there. Same with giving up smoking. You know? First, third time, doesn't work fourth time, work every time. Um, so yeah I think - yeah, it - it is a weird one; why people do that to themselves. I-I don't actually - you know, I've - I've got no answer for, other than um, at some point in time you must - you must really like the change of reality somewhere.

(Interview thirteen, John, male 39 years)

John then reflected on what he perceived as the effort required in order to manage the negative effects of using drugs in order to become a drug 'addict'. When doing this he continued to emphasise his exercising of agency when describing his preference to use opiates intravenously:

... I've actually said to people, like you know, because I've seen people like vomiting or whatever, and say like; how the hell did you guys ever become addicts? You know? Like; oh you know, takes dedication. You know? Yeah, the - the pros and the cons of - of the first using, you know, unless you used a very minimal amount - I was never really that way inclined, but you know, if - if you used a minimal amount I suppose the - the effects could be quite nice, but you'd still get a bit of a nauseation and, you know, not feel good. 
Yeah, it's a weird one; you're feeling really bad and ill, in the sense of like stomach or nauseas, but at the same time, you know, your head's actually not feeling that bad. You know? You're actually relaxed, which is one thing. You know? If you're - um, you know, again if you're like anxious or stressed or - or you know, um at a loss for things to do, you know, it's a great - it's a great way to fill the day. Um...like, to me I was like - not happy all the time using drugs when I was younger or anything, but um it was - you know, even with going to jail and everything, you know, I was - I was happy enough with that lifestyle at the time, which is absolutely shocking really, isn't it?

(Interview thirteen, John, male 39 years)

Other participants described their transitions towards increasingly problematic forms of drug use in ways that also emphasised their 'choosing to use' particular drugs in the context of living as drug 'addicts'. When doing this participants storied experiences of addiction which communicated how early initiation into the problematic use of alcohol had been followed by transitions towards chaotic and uncontrollable use of multiple drug types, with some describing a return to problematic drinking at various points in their narratives. Again, their use of alcohol and other drugs continued unabated, irrespective of the impact their drug-taking had on their own, and others wellbeing.

Rayleen for example described a series of profoundly negative experiences and events as resulting from a period of using benzodiazepines, which preceded her eventual relapse into problematic drinking ${ }^{59}$. She reflected on how her uncontrollable drug-taking behaviour during a second pregnancy had resulted in her impacting the health of her second baby:

I started - my two older boys - I started going out with their dad, about 13, 14 and his sister was a pill-popper, Heroin addict; you name it, she - she done it all. Um, so he used to bring them, and because he was a bit older - he was 18, so um he used to bring pills and that, and so I used to try

\footnotetext{
${ }^{59}$ Benzodiazepines include commercially produced medications for anxiety, sleep deprivation and pain relief, such as Valium, Halcion, and Temazepam.
} 
them and got into them.... Valiums and lowies and stuff, yeah. Um, Halcion and yeah I got addicted to them. Um...

When you say you - you got addicted to them, you - how did you know?

I couldn't live without them. I had to have them daily, and I lost a tremendous amount of weight, too and um, I ended up falling pregnant with my older boy, but I was in Kingslea at that time. So um...

(What's) Kingslea if you don't mind me asking?

Um, it's a children's jail.

Oh okay.

At the Juvenile Detention in Christchurch. Um, so I found out I was pregnant in there, and I stayed there for eight months. So I didn't come out till I was eight months pregnant. So I was clean and sober, and ended up having him, and as soon as he was born I started drinking, and back into it again. Um, three months later I'm pregnant again. (Laughter) Um, but this time I didn't give up drugs. I ended up taking pills and drinking all the way through the pregnancy, and he's still alive, but he ended up being a benzo baby, which is a baby born with a drug addiction.

They told you that in the hospital?

Yeah, and I wasn't big and fat like I was with the first one. I was skinny and just a little bump and he was premature, too. So...

...how did that make you feel hearing that?

At the back of my mind I was pissed off because he was getting free drugs, because he was on when he was born he was a count-down program, because he was shaking and detoxing. I was pissed off because he was getting free drugs (laughter) and I wasn't, and so I was more like, well why is he getting (laughter) yeah. Um, but he was a difficult baby in one way, yeah. Out of all of them, he was the difficult one.

(Interview eight, Rayleen, female 33 years) 
Rayleen's experiences illustrated how participants storied an absence of agency during periods of heavy, and often uncontrollable drug use that, while sometimes life threatening, typically resulted in them modifying, rather than stopping their use of drugs. Importantly, these stories of addiction and uncontrollable drug use also highlighted that participant's often managed multiple addictions over the course of their drug using journeys, the type of drug dependence changing at different points in their lives. Angus demonstrated this point when describing his ongoing addiction to alcohol, cannabis and methamphetamine in the sequencing of his drug using journey, during which he recalled a transition back to problematic alcohol use after having begun to control his use of methamphetamine:

...Earlier on this year I was at a gang pad - a bikie club, and guys I've known for a long time; I was that drunk I was jumping all over their Harley's, and I got the worst hiding I've ever had in my life. I woke up in a park just up the road here. I had these white shoes on and they'd written, I'm a faggot - free blow jobs; and just dumped me in this park. I lost three days. I don't remember what happened; I just heard what I did. I had a haematoma on this temple, and one just in front of this one. My two front teeth were knocked out. All this side was all banged up. I've had some good hidings, but that was the worst one l've ever had. That wasn't even on any drugs.

That was just the alcohol. I managed to get home and basically somebody from the street had stopped me and taken my phone and managed to get through to my brother. He came and picked me up and he took me home. For three days I was at home. On the third day one of my best mates came round. I was sitting on the end of the bed and I was looking at him going, I know who you are - I just don't know your name. He basically bundled me up into the car, took me to the hospital and they CAT scanned me, and I was in hospital for about 10 days. I still didn't think I had a drinking problem; this is the point I'm trying to make.

Right, so you had that on top of dealing with other substances as well?

Yeah. I cleaned right up. My meth use over the last few years has definitely decreased for sure, but it was just alcohol that I guess filled the void, I suppose. Yeah, I drank a lot.

(Interview seven, Angus, male 33 years) 
The poly-drug using experiences articulated by participants when storying important transitions in drug-taking behaviour succeed in highlighting the theoretical significance of how previous poly-drug using experiences had informed future risk assessments and decision-making processes. They indicate that the accumulation of drug-risk knowledge which underpins decision-making processes helps determine whether to start using a particular drug or desist from using others, or whether there is a need to modify the route of drug ingestion when confronted with undesirable, or harmful effects.

These processes align with experiences of poly-drug use documented elsewhere (Measham: 2004, Pennay and Moore: 2010, Kosten et al. 2012, Quintero: 2012, Williams: 2013). For example, when evaluating decisions about drug use among young drug users, Boys et al. (2001) identify that the perceived utility of a particular drug will predict the likelihood of future consumption. Similarly, in his evaluation of farm labourers using multiple drug types, Bletzer (2009:340) notes that, how poly-drug users view their reasons for using or not using different drug-types centres on what they expect from the drugs they use, and what works to fulfil that expectation on given occasions. In these contexts of understanding, poly-drug users construct 'a repertoire of use' by learning which drugs, their effects, their associated risks, and which administration routes serve them best.

Scholarship highlighting the theoretical significance of poly-drug using repertoires in explorations of methamphetamine use is rare, given the dominance of single-substance focussed drug research. This research disproportionately examines harms caused by the problematic use of specific drugs, and generally, a specific route of ingestion, as evidenced by the comparable volume of scholarship exploring injecting drug use. Incorporating other research efforts for the purpose of making detailed comparisons with the poly-drug using experiences of these research participants is therefore difficult. However, their stories had evidenced similar decision-making processes to those documented in qualitative evaluations of poly-drug users using methamphetamine in a recreational context. For example, in Green and Moore's (2013:696) ethnographic 
exploration of Australian recreational drug users, participants recounted both the desirable effects of meth in relation to other amphetamines. As one male participant in their study reflected:

"It's just, it's a really smooth feeling, more so than speed, especially snorting which was really...gave you a real jump at first and made you really agitated, and that. Smoking meth specifically was a lot smoother and it would just make you feel good and chatty for hours and hours and hours..."

Pennay's (2012) interviews with Australian 'party-drug' users similarly reveals how recreational use of methamphetamine was rationalised as a pragmatic choice. Pennay's (2012) research demonstrates how methamphetamine's effects were understood as enabling recreational users to exercise control over their behaviour and 'act normal', rather than succumb to cultural disapproval following public displays of intoxication. As a female participant in her study recounted:

"If we are too pissed we'd usually have it (methamphetamine) to straighten us out. I never go anywhere without my little vial, just in case. If someone gets too fucked up on ecstasy or too pissed or something I always carry it around, like an emergency, to straighten them out." (Pennay: 2012: 414)

While the participants in the research undertaken for this thesis are not recreational drug users, they described comparable understandings of drugs and their effects. In the context of describing past histories involving the use of multiple drug types, it was evident that transitions towards methamphetamine use were underpinned by individual-level decision making processes, where risk comparisons were made to past experiences of other, equally harmful drugs. These experiences, and those documented in other qualitative appraisals of drug use, challenge pejorative understandings of drug users as being biologically incapable of exercising control over their drug consumption. However, as Mayock (2005:351) notes, caution should be taken in over-emphasising agential decision-making to reject deterministic and pathological explanations of drug use. This can feed moralistic debates about the need for much greater individual responsibility as a means of solving the 'problem' of drugs, as she explains: 
"Paradoxically then, the emphasis on rational decision making, guided in the main by cost/benefit analysis, can serve to reinforce the notion of drug users as "other", seeing them not simply outside the social order, but as outsiders who refuse to conform to the advice of experts" (ibid:351).

The extent that agency over drug use was exercised can also be theorised in relation to the environmental contexts of drug use participants described. Their stories reveal that drugs were highly visible and accessible within the social and familial environments they experienced, and that entrenchment within these environments provided what Fast et al. (2010:10) describe as, a context in which transitioning into the use of different drugs and into increasingly harmful drug taking practices became, "over time, an obvious, 'nonchalant' or even inevitable choice, particularly in the context of exclusion from alternatives to this choice." The early onset of problematic drug using behaviour that had been signalled by participants' exposure to, and then use of, alcohol and cannabis for example, suggested that the likelihood of exiting their drug-using environments was difficult to enact or even conceptualise. This situated experience was also further exacerbated by the continuous presence, and normalised use of, drugs associated with drug-dependency and an increased risk of drug-related harm (ibid: 10, and O’Gorman:2016).

Importantly, as participants' storied the risk trajectory structuring their past use of drugs, they also illuminated how the risks inherent in transitioning to more harmful drug taking practices were inseparable from the myriad of other risks they had experienced in their drug-using environments. As many authors have made clear (Rhodes and Singer: 2005, Bourgeois and Schoenberg: 2009, Ivins et al: 2013), drug users attend to the multiple risks of their social realities, such as the threat of arrest, violence within drug economies, the management of tenuous relationships, fluctuations in income, housing availability and employment, and when managing addiction, coping with the biology of drug dependence and withdrawal. Participants consistently pointed to these environmental risk experiences as they described the situated contexts of their 
transitioning between different drugs and different methods of ingestion, and notably, as they initiated methamphetamine use and became more entrenched in problematic drug-taking behaviour.

A broader theoretical question signalled by the range of poly-drug using experiences these drug users described is how to accurately define their behaviour according to accepted definitions of poly-drug use. As Shensul, Convey and Burkholder (2005:572) emphasise, clarifying what is meant by poly-drug use is critical, given that the nomenclature employed when referencing poly-drug use in research is often confusing and inconsistent. There is a need to establish what is meant by poly-drug use at the outset of research by including sufficient "measures of time, combination, or agency/intentionality in drug selection, combination, sequencing, use, and mediation of effects."

This can be challenging due to the range and scope of definitions of poly-drug use, which can be as simple as "the interaction of two or more drugs used during a specified time period" (ibid p.572). However they can also include definitions such as simultaneous poly-drug mixing or concurrent drug use, which account for the time period in which drugs were combined, for example, when drugs are mixed only while at a nightclub, or daily over the course of a lifetime (ibid). The term alternating poly-drug mixing has also been used to define the mixing of drugs in irregular patterns, as evidenced in weekend binging, as has sequential poly-drug mixing, to identify "the sequenced use of multiple drugs over a period of time, measured in terms of hours, days, weeks, months or longer" (ibid, p.572). Poly-drug use is additionally defined by the synergistic effects of drug combinations on the consumer. Here synergistic use of two or more drugs is viewed as an intentional mixing process, where drug users modify the effects of their drug use. This can involve a number of behaviours, such as magnifying the positive effects of one drug by including another, using a drug to dampen the effects of the first drug used, 
consuming a drug to neutralise or counteract the effects of other drugs, or replacing the effect of one drug by using another (Schensul et al. 2005:573).

Importantly, attempts to define the poly-drug using experiences here using these definitions must reconcile the influence of methodological constraints identified in the previous chapter. Questions about drug-taking, recreation, and pleasure for example, or whether participants used particular drugs in combinations for a desired purpose were not asked during interviews due to the vulnerable status of participants 'recovering' from long-term experiences of drug addiction. Equally, participants had not offered descriptions of using drugs, on their own, or in combination, in the context of actively seeking a desirable or pleasurable effect. Given the pervasiveness of disapproval for drug use, this may have evidenced their wanting to avoid judgement by not talking about the pleasures of drug-taking with someone who was viewed as a non-drug user.

Consequently the stories presented in this research exclude explorations of synergistic poly-drug experiences, rendering the intentionality and agency in aspects of drug selection that participants may have undertaken to achieve different effects, largely invisible. The definition of behaviour that was most in alignment with the picture of polydrug use presented here was 'sequential' poly-drug mixing. However, this definition is only useful in describing how participants' had been encouraged to story past drug taking experiences in a sequential fashion. It is likely that participants had engaged in a range of poly-drug taking behaviours, which have not been captured within the scope of this research.

\section{Transitions to starting and using methamphetamine}

In common with their previous experiences initiating the use of other drugs, the transition to methamphetamine use was strongly influenced by the availability of methamphetamine within the social network participants described, as well as the social and structural context facilitating their experience of initiation into use (Mayock:2002, 
Fast et al:2010). When narrating the context of their meth initiation, all participants identified the opportunity to use it as occurring in the presence of drug using friends, family members, partners and associates. The decision to try methamphetamine was typically attributed to evolving curiosity or their reacting to a chance encounter with its availability. Initiating methamphetamine use was also informed by drawing upon past drug-taking experiences in order to understand the utility of using meth and enjoy its effects, compared to other kinds of drugs:

For Ben, methamphetamine initiation had occurred as a result of an opportunity to try it while purchasing cannabis from a friend:

I walked in one day just to score a tinny and he was sitting there with some tinfoil and he was smoking it (meth). I said 'what are you doing?' And he said 'I'm chasing the dragon mate', and I said 'what's that?' ... and that's when he told me 'do you want to try some?', and...I tried some... When you had your first time did (he) give you some information about it....? He says yeah, this is pure speed, he says 'we call it $P$ ', and I said, and I asked, 'why are you smoking it?', he says 'this is what you do with this stuff, its better, and cleaner, and it's a nicer buzz'... (Interview four, Ben, 31 year old male)

In order to make an assessment of methamphetamine's effects, Ben reflected on less pleasurable experiences he associated with the method of 'snorting' 'speed' (amphetamine sulphate). This provided Ben with an experiential reference point to compare, and enjoy more, the method and effect of smoking methamphetamine:

I tried some (meth) and (pause) wow, it went straight to my head and I felt it and I thought this is cool, because being able to smoke it...l'd actually never liked snorting speed, you know the 'drip'60 and the process that goes with it. I liked the feeling but I didn't like the 'throatiness' to it...so I really enjoyed smoking this speed that got me up faster and ahh didn't give me the 'drip'...

(Interview four, Ben, male, 31 years old)

\footnotetext{
60 Nasal inhalation of powdered drug such as amphetamine sulphate or cocaine require users to snort the powder, and then refrain from sniffing or swallowing in order to prolong the absorbing of drugs through the nasal membrane. This process typically results in a 'dripping' sensation at the back of the throat and a bitter after-taste.
} 
For Charlie, one of the four participants who did not identify as being an 'addict', previous drug-using experiences mitigated his perceptions of the risks associated with using methamphetamine. This risk assessment resulted from his associating more extreme levels of intoxication, loss of control and potentially harmful consequences with other substances, and from his exercising a greater degree of control over comparably more potent drugs as an experienced, rather than 'addicted', drug user. This point was evidenced at an early juncture in Charlie's story prior to methamphetamine initiation, when he recounted his experience of using datura ${ }^{61}$ with a friend:

The first time I took datura I took it with a friend who ended up in a psych ward and he's kinda been a bit funny since then...l just figured he was being a bitch about it cause main thing was it was just a trip that goes for like three or four days and I was like "you just can't handle that"

(Interview five, Charlie, male, 22 years).

As his story proceeded, Charlie then recounted his first time using methamphetamine by comparing it to his past experiences using the previously legal stimulant Benzylpiperazine - or BZP62. Again, when doing this, Charlie emphasised his remaining in control while experiencing methamphetamine's effects:

I definitely got more fried off that stuff (BZP powder) than I ever did of meth, or most llegals....like I was real disappointed when I started trying like ecstasy, because I'd been trying party pills, I was like woah this is hardly even doing anything, compared to that like BZP.... (Meth) was just mellow!!!!...like, I was just awake, I wasn't tired anymore, I didn't experience any mental effects really, didn't change my thought patterns at all...

(Interview five, Charlie, Male, 22 years)

\footnotetext{
${ }^{61}$ Datura stramonium, also known as devil's trumpet, moon flowers and hells bells, is a powerful hallucinogenic plant which can be smoked or consumed orally.

62 Benzylpiperazine is known as one of the principle psychoactive substances contained in previously legal 'party pills', designed to mimic the effects of ecstasy. From 1 April 2008, BZP became a Class C1 controlled drug under the Misuse of Drugs Act (www.drugfoundation.org.nz/party-pills/what-it-is).
} 
For participants who self-identified as being 'addicts', methamphetamine initiation had occurred at a point when they were also coping with the experience of addiction to other drugs, notably alcohol, cannabis, and prescription medicines. As their stories progressed, the decision to initiate use was recognised as a past event that had grave consequences in prompting a transition to what would become another, increasingly harmful, form of drug use (Fast et al: 2010). Although participants described similar experiences of harms resulting from using meth and other drugs, the transition from having first started using methamphetamine to the lived reality of daily methamphetamine use as an 'addict' was storied in different ways.

Participants' achieved this by positioning themselves to communicate fluctuations in their exercising of agency over drug-taking decisions, and to highlight their negotiating the risks of using meth use whilst being aware of its association with violence, addiction and psychosis, in both lay and authoritative understandings of its attendant harms. Participants' stories also demonstrated variations in how using methamphetamine contributed to a shift in identity when becoming an addict, and the ways in which they understood this identity transition in relation to the trajectories of risk that had intersected their initiation into, and ongoing use, of methamphetamine.

For Angus, the inclusion of methamphetamine in his drug using repertoire was identified as signalling a more rapid, and ultimately more harmful progression in his drug taking lifestyle. Angus highlighted this shift in drug taking behaviour when describing his initiation into methamphetamine use as occurring after having been in prison from the age of 18 to 22 , an experience which he identified as facilitating his participation in gang life after his release, and with that, more opportunities for involvement in the use and supply of methamphetamine:

So, you've used methamphetamine?

Yeah. So, 18-22 I was in jail; plenty of drugs in jail. 
Can you remember how that happened?

How did it happen?

Yeah.

Man, the hook-ups you meet in jail. I've had a drink-driving since jail, but I got out and my criminality was just massive but never got caught. I was hooked up with a gang, and I moved to Christchurch and was hanging out with one of the bikie clubs down there, through guys that I'd done jail with. That was just the next level. I'm not going to go into any of that. That's just a death-wish asking. I'm not even going to name - you don't use people's names.

That's quite alright.

The meth changed me, for sure. I guess I was addicted to other drugs, but nothing like - it's a powerful drug, eh? Definitely.

Can you remember the first time you actually used it?

Yeah. I didn't feel like I was wasted. I didn't have a girlfriend till I got out of jail. I was 22. She was my first girlfriend, and I remember using it, and I met her out at a pub one night, and she looked at me and she was like, what the fuck are you on? I didn't even feel like I was high, but I must have been. I was quick to take it up; instantly. Then I moved to Christchurch and got heavily into the distribution.

(Interview seven, Angus, male 33 years)

Angus went on to describe his heavy use of methamphetamine, and identified himself at one point in his drug using journey as being 'fucked':

So, when you describe that you're fucked, was that a mental impact, or a physical...? Mentally, emotionally, physically; when you sleep twice a week maybe for seven years - in that time I didn't used to eat or drink either - imagine what it does to you, when you sit back and think about it. I'm not exaggerating; I'd go to sleep and I'd sleep for a day or more, and I used to even do things like before I'd go to sleep I'd clean my pipe and stack it ready for wake-up time. I had so much drugs it'd be a teaspoon in my coffee in the morning. So that was my type of - and I didn't sleep for days and days and days.

(Interview seven, Angus, male 33 years) 
In spite of his acknowledging being addicted to smoking methamphetamine, Angus referred to intravenous drug users as 'junkies', and expressed both his preference for smoking methamphetamine, as well as his being thankful he had never injected meth or other drugs. Distinguishing his drug using behaviour in this way communicated his understandings of acceptable and unacceptable drug use, and his exercising of control in avoiding a stigmatised identity by smoking, rather than injecting methamphetamine. Angus also communicated his maintaining control over methamphetamines potential harmful effects when describing his meth-using experiences in ways that both challenged authoritative representations of meth users invariably experiencing psychosis. How he described his experiences of methamphetamine use also highlighted his having exercised agency in using methamphetamine, given his acknowledgement that he enjoyed using it:

So, there's a lot of information about the mental health aspects of (meth use), as well. Did you have any strategies for managing that?

Nah, I didn't give a shit.

.... I never got paranoid, and I never picked myself like a lot of people do. I never saw things. I've always had a pretty good - I've always thought about it; maybe it was my good upbringing and things like that. I've walked into places and I've looked at people and I'd ask them what they're doing, and they were like, I'm picking shells out of myself. What you mean? Oh yeah, there's shells growing out of me. That never got like that for me, thank fuck, but plenty of people did. I've still got all my teeth. So, I consider myself very lucky. I've got a lot of friends with no teeth, and scars; they've been stabbed and shot and all sorts of shit.

I grew up pretty quick and I consider myself half switched-on. I've always been aware of my surroundings, and I've always thought about what I'm doing, which again; that's another thing that makes me feel bad in my behaviour. I can't just blame it on (meth) - I liked doing it.

(Interview seven, Angus, male 33 years)

For Terry, a 40 year old Māori male who was engaging in the Bridge Programme to address his addiction to cannabis and methamphetamine, initiation into 
methamphetamine use occurred in the context of his involvement in drugs as a patched gang member. Terry described being exposed to an opportunity to use methamphetamine as resulting from his regular use of cannabis with a group of friends, noting his awareness of its potency and his concerns about the effect meth might have on him as a first time user:

I met this group of people through - through a place where I was working um, and I used to watch them. I used to go in the room with them and I used to watch them with this crystal in the pipe and you know, they were turning it and they were - and I - I was right against it for a start.

Oh, I said, no just give me your bud. So l'd just sit there and smoke all their buds while they were on the fucken crackalack, and then my mate, he was looking at jail for five years, and he got off, and we're sitting in the back of his car, and they were talking about getting - you know, having some Crack-getting some Crack, and I was - been talking to my mate, asking him silly questions; what would it do to me - do you think I can handle it, and that. He says, yeah yeah. So I thought about it, and he got off so I thought, oh well. They were putting the hat around. So, oh - I'll chuck in a $\$ 20$, just - you know, and he said, oh you're going to have some? I said, yeah I'll give it a fucken - give it a go. Well, they say the first puff you're fucken hooked. Well, yeah. We had a bag. In that day we spent about $\$ 800$ - $\$ 900$ on it, mate.

(Interview fourteen, Terry, male 40 years)

I asked Terry to describe his experience using methamphetamine and before he began to reflect on what he had experienced, he made another reference to his awareness of the risks associated with meth use and his asking a friend about the effect it might have on him. When doing this he noted a shift in his identity occurring after his first experience using meth, which he highlighted by comparing himself to his meth-using cousin:

How would you describe (methamphetamine)?

Well, I was quite scared to take it after I heard that fella cut - cut those women up. You know? That's why I keep asking my mate will it do that, and I asked my cousin. We were having a pipe and I said to him, cuz you know l've been up for about three days now - so have you. He goes, yeah. I says, well how come we ain't going stupid out fucking killing people - hitting things and 
that? He says, cuz it - it does different things to different people. When I'm on Methamphetamine I can't sit still. I used to clean my house at bloody two, three o'clock in the morning, mate and that's vacuuming, walls, windows - everything. My house used to be spotless. I'm still cleaning myself, even - you know, when I was using and that. Um, yeah I just liked to keep busy.

...do you remember - why you were not into it...?

Because my cousin, he - my cousin used to - he deals in it, and I've seen how he turned out, and everybody used to call him the animal and that, in the family and that. I didn't want to turn out like that, but guess what? I did. I had my first hit; after that I was smoking it all the time.

(Interview fourteen, Terry, male 40 years)

Terry then went on to describe his heavy use of methamphetamine, as well as continuing to maintain his ongoing addiction to cannabis, in the context of his participating in gang life:

It kept me up - kept me going. Even last Christmas I was up for about five, six days on the Meth, but it's the come-downs that are the cunt. You get mood swings. You - oh, it's shocking, the come-downs.

So how do you manage that in your life...?

Well, I didn't pay my rent. I wasn't paying power. Um, I wasn't buying food. I was living off the food bank of Wanganui. All my money was going to Meth - Meth and drugs - Meth and cannabis, but mainly Meth, and then I'd go out and do burglaries to support my cannabis habit, and my Meth habit, because my - I was living with my cousin, then and he was getting it on top. You know, he's one of the dealers, so every time he had a pipe I made sure I was in his room.

So, if you're involved in a gang, how would they look at it, you know - being a Methuser? Would it - is it something that would be frowned upon or...

Oh, hell no. (Laughter) They - most gangs deal in the old Methamphetamine. You know? So no it wasn't frowned up, mate. No. It was (laughter) more encouraging really, because (laughter) before I came here I did a cook - I know how to cook it, mate. We had all the gears and that, and me and my mate, we did a cook, and yeah it turned out good, but that was only for persie (personal use) though, but yeah.... We just had to do the finishing touches, and that was ours. We 
didn't have to give it to anybody. You know? We didn't have to take the money back to anybody. That was ours. So yeah.

...that would make life a bit easier then, in a way?

Well, we just smoked it anyway. (Laughter) Money went on cannabis.

(Interview fourteen, Terry, male 40 years)

Like Terry, when recounting his initiation into methamphetamine use, Sean also described a similar opportunistic experience as resulting from his participation in a network of drug-using associates. Describing the social context of his initiation, he recalled his becoming instantly addicted to methamphetamine following its introduction into his life, but distinguished his story from Terry's by positioning himself as being unwittingly influenced by an 'untrustworthy meth-user':

Oh yeah, I remember it distinctly. I would have been about 23 years old. I was 23 at the time, and um I was actually - ah, I got a phone call from a friend whom at the time I foolishly trusted. You know, I - I didn't realise he was a Meth smoker. I'd known the guy for a couple of years, and he really pulled the wool over my eyes, and everyone's around him, and I'd been at the pub, and it must have been a Friday or a Saturday night and I was walking home, and I got a phone call from him about three in the morning. It was, you know; come-come to my house now - get - get here - you know, you'll be stoked if you do. I sort of presumed, you know, he might have some $E$ or some coke or something - you know, something like that. I - and um, I turned up there... and there was a bag of pills and there was Methamphetamine there, and um, I didn't give a fuck about the Methamphetamine.

I saw the bag of pills and I thought, yeah righto. But um, there was a big rock, and it was, you know, getting chucked into this pipe, and I didn't know how to smoke it at the time... It's not like smoking a joint or a cigarette. You know? There's - there's a knack to smoking Crack...Um, we chuffed away on this pipe, and someone else lit it for me, because I didn't know how to do it, and um, it was an instant - it was instant addiction, eh?

(Interview eleven, Sean, male 33 years) 
Reflecting on the experience of his initiation, Sean described this event in ways that signalled his transitioning from being a 'good person', to a state of 'instant' addiction to methamphetamine, a theme that was common to other participants' 'before and after' narratives when reflecting on becoming addicts. Recounting the events which followed, Sean also identified his loss of agency and control over his life by describing experiences which accorded with stereotypical constructions of addiction as uncontrollable drug taking behaviour, but which at the same time emphasised his exercising of 'choice' in using drugs:

... I mean, I've always considered myself a good person - maybe not so much now, but I did at the time. You know? I had high morals. I cared a lot about my family um, and my friends, and um, I mean I did silly things like other people, but I certainly never intended to hurt anyone, and um from that moment, for me, that was when I really lost control of my life, really.

....what kind of impact did that transition ...have on your work?

It's had huge impacts. You know? Um, I've always been a hard worker. Um, people at work could see the change in me. You know, I went from this guy who was joking and laughing all the time, to sort of staring at the wall and not wanting to talk to other people. I mean, I was really depressed. Um, but - um, I collapsed at work. I mean, you know, you'd stay up - sometimes I stayed - I think the longest I've stayed up for is 16 days, you know, without sleep. I mean, it's just - it's - um, I collapsed at work...

When you got to that stage...did you use other (drugs)?

You know, that drug has overruled my enjoyment of any other drug, eh? Like, I don't drink, and I was never a huge drinker, anyway. Drugs were always my first choice, but I don't - you know, no other drug has the same effect, eh? It's - you do everything for that drug; all your money goes to that drug. You don't want that other drug. You want that drug. If someone else turns up with a drug that's not your drug of choice, it's just, oh. You know? It's disappointment...l used it every fucken day, you know, for a long, long time. Um, the only time I ever used something else was I stopped for a bit, and I just bought people's Ritalin scripts, and snorted that instead.

(Interview eleven, Sean, male 33 years) 
Towards the end of his story, Sean then reflected on his heavy use of methamphetamine and the effect it had on him. Like Angus, Sean also communicated his awareness of stigmatising discourses when acknowledging that he never experienced methamphetamine induced psychosis, and when expressing his gratitude in avoiding a more permanent meth-using identity by maintaining his physical appearance.

That was going to be my next question, because obviously there's a lot of information around the psychological impact of sleep-deprivation when using Meth.

Oh, yeah. Oh, there's huge - huge side-effects.

Yeah. How did you manage that?

Um, you know, it's interesting, because people - I mean, there's lot of schizophrenia that's induced through Meth use. I'm lucky I'm not a schizophrenic, but if anything it probably made me a manicdepressant. You know, I never heard voices. I never saw anything that wasn't there. I mean, if I did I'd openly tell you, but I didn't. You know, and um, I think my saving grace is I'm not a silly person. You know?

...I'd get bleeding - my gums would just start bleeding from it, just - you know, like I mean, I'm lucky; I've still got - you know, my teeth. You know? A lot of people haven't. Um, and I don't know how. (Laughter) I don't know how that is.

(Interview eleven, Sean, male 33 years)

For John, the opportunity to first use methamphetamine had resulted from 'hanging out' with another female drug user. In contrast to the stories of other participants, John's use of methamphetamine signalled a modification to his already well established repertoire of addiction to opiates, rather than marking a transition in his story where he assumed an addict identity and lifestyle. Like Terry, John also noted his awareness of the risks associated with meth use prior to his initiation, but reconciled these in his story by reflecting on meth's utility as being both 'cost effective' and enjoyable when compared to other drugs: 
...yeah, the first - the first sort of ah, amphetamine thing was - yeah it was a bit of an eye-opener actually, because up until that point um, amphetamines - you know, I'd use them, um but, yeah like, you know, P was - was strong enough to actually be enjoyable. Whereas, coke and, you know, all of this kind of stuff, you know, they're sort of girlie drugs, really. You know? They're they just weren't - weren't strong enough....

For a relatively low dose - you know, $\$ 50$ or something like that, you know, you - um, you know charge around for half the day. You know? It's actually value for money.

So how did (methamphetamine) come to you?

...that was actually um, oh purely by accident really. Um, the girl I was hanging around with, um had been into it, and you know, just - yeah, just by accident...

Had you heard about it before?

Yeah. Yeah, I was kind of against it because you know, you hear - you hear um, you know, dangerous stories. Ah...

...did you smoke it or use it intravenously?

Um, I - the very first time I smoked it um - the very next time, which would have been all of about an hour later, it would have been IV. (Laughter) Yeah, um..

Right, because that was your preferred way of doing things?

Yeah. Yeah, um just because it's a - well, it's a more efficient route. That's all there is to it. You know? You're not - you're not wasting anything. Smoking it is actually um - there are points to be argued for it. Um, it actually lasts longer. Um, it's - yeah, so it's probably-yeah, it's debatable whether it's more economic, because you've got the - you know, you've got the instant high and the instant euphoria versus a - a gradual tapering thing. So, you know, I can do either. I'd - I would prefer to IV though. Depends on social context, but...

(Interview thirteen, John, male 39 years)

Towards the end of his story John challenged 'expert' understandings of drug-related risks, notably the negative effects of using benzodiazepines and meth's reputation as being more addictive than other drugs. In spite of his own experiences of significant harm when using these drugs, John resisted associating these experiences with 
authoritative definitions of harm, by positioning himself as the authentic 'expert' within his story of drug use and drug addiction:

Like, they say, like you know, take benzo's and it kills your brain. But, you know, I know people who have been on benzo's years mate, and they're still more intelligent than the person who made that fucken advert. You know? Then ah, you know, so obviously that - that's just bollocks, and then people will say things like, oh you know, you get hooked on - you know, you get hooked on $P$ after fucken the first time. Well, no you don't. You know? Fucken bunch of shit. Um, you know; it's really addictive. Well, it kind of is, kind of isn't. You know? Just all these - all these things, eh; there's just no way that you can scare people out of, you know, doing something which makes them feel good. You know?

(Interview thirteen, John, male 39 years)

Rayleen's story of meth initiation was similar to John's, initiation into its use signalling a transition in a well-established trajectory of risk towards ongoing drug addiction and drug-related harms. Rayleen described the normalising of an opportunity to use methamphetamine intravenously when helping her network of drug-using family and friends to inject meth. When storying this experience, she reflected on her sister's warning about methamphetamine as being addictive, and then identified her meth use as signalling a lifestyle transition by her becoming involved in sex work to maintain what she described as her meth 'habit':

So when...does ...Methamphetamine come into your life?

Um, my sister-in-law - the one that has the pills, when I sort of got out of detox and sort of done my own thing for a year, I went to her house and they were all injecting the stuff, and they asked me hold their arms and help them, and I was, you know; what's this shit, type thing. They told me what it was. They said, oh it's Speed - Crack, because by then it wasn't Meth, because I was only 19 then. So it was called Ice, and um so they were all injecting it, and I thought, oh can I can I try some? So they - instead of saying no, because most users, when someone asks for some, you usually say no - hell no. 
Yeah, and they said, oh yeah - we'll give you the left-overs. Oh, the dregs, they call them, and I thought, oh yeah okay. Well, when I had them, oh my god I thought it was the best thing since sliced bread. Um, my whole body - it was a rush that I'd never experienced.

How old were you at this time?

Nineteen. Um, yeah it was - it was better than sex. (Laughter) My sister warned me, if I'd taken it three or four times in a row, in those days, that l'd be addicted to it (finger-click) like that. My body would need it. I didn't believe it. I thought, pfft whatever. So, the next day I had some more of their stuff, and the day after, and two weeks after that - boom, I was hooked, and it was an expensive habit. So, I had to start working on as a sex worker. Um, I had no interests getting my kids back then. That - that whole thing just went out the window. Um, me and my partner had split up, or l'd left him because he wasn't good enough (laughter). Um, it seems a whole new life had sort of popped up, because of this drug, and I was in a different scene; in the sex scene and in a different kind of drug scene.

(Interview eight, Rayleen, female 33 years)

Having described an extensive history of addiction to multiple drug types, Rayleen then went on to identify that her transition to methamphetamine was facilitated by her understanding of its effects when compared to other drugs. In contrast to the health complications that had resulted from her long-term use of alcohol, cannabis and benzodiazepines, Rayleen reported using methamphetamine intravenously as being more enjoyable. In this context the pleasure of using methamphetamine was described in relation to previous experiences of drug use which had resulted in experiences of psychosis:

Did you use (methamphetamine) intravenously or did you smoke?

Yeah, intravenously.

Did you ever smoke it...?

Oh, I tried to, but I never got - it doesn't do to me what it does to other people when they smoke it, and people say you get paranoid and stuff off it. You don't. It's all on the person - all on their $\operatorname{mind} \ldots$ 
That was the next question I was going to ask...

Even off weed - like, I stopped smoking weed, because um, I could hear voices and stuff. So, but this drug was different, because with the Speed um, that stuff didn't come up for me...... I can sleep on it. I will say that. After a few days I can sleep, and I can eat on it. So there are those stories where; oh you can't eat on it - I can't eat on it. I forced myself to eat on it. (Laughter)

Also, as you've said, you didn't have the - the psychosis that goes with it, for you.

Yes. Yeah, if its downers, yeah obviously different mental side of me comes up, which is - I think that's why I fell in love with Meth - I didn't have those down times.

Right. Did other people in your using circle - it did happen to them?

Yeah. They used to be paranoid and think someone was following us, or pick their skin and pick their faces. Um, that I couldn't get over, because I used to think, what the - why are you fixated on picking something that's not there...I used to have a friend too, as soon as she would have it, she used to think spiders were all over her body, and start stripping off naked and I used to get angry because it's like, oh for god's sakes - why do we have to go - why take it, if you're going to do this?

(Interview eight, Rayleen, female 33 years)

Like other participants, Rayleen also reflected on her meth-using identity, but did so in ways which challenged the othering of meth users typically associated with authoritative representations of meth addiction. In spite of identifying as both a meth user, sex worker and intravenous drug user - an aggregate of traditionally stigmatised identities Rayleen viewed being an experienced intravenous meth user positively, and in ways that distinguished her from 'dirty' drug users. Like Sean and Angus, this demonstrated her awareness of stigmatising tropes and illustrated how she mitigated negative constructions of her identity as a meth user by communicating understanding intravenous heroin users as being inherently more problematic. When doing this Rayleen also referenced the gendered context of her drug using experiences, identifying the relational dynamics of gender and power when participating in sex work, and the positive effects of her using methamphetamine in conforming to gendered role expectations: 
...these drug dealers were the guys I was sleeping with, so everything was free. (Laughter) So, and these were big time dealers in Christchurch that people didn't really mess with, or fuck with, but - and obviously I earned that trust, because I could sit around and not steal anything when other girls would steal the shit off them. Well, I don't want my fingers chopped off or be in the boot of a car. So yeah, and um, I got - yeah, real hooked real bad, and working on the streets as a sex worker $24 / 7$...

.. and I was a nice - you know, weight. Um, people wouldn't think I was a user or an injector at all, because of the - because I can still talk politely and (laughter) you know, hold a conversation in the car with a client....

Do you think Meth-users are different from other drug-users?

Yeah...Um, well see Heroin-users, compared to a Meth - a Heroin-user, they're 'more dirty'. Um... Why are they dirty?

They will use old needles, and like anyone's drugs, even if there's blood in it. You know? With Meth-users, we were very clean and very pedantic.... You have to up there with all that money, so there is a different scene than the heroin scene, because even though heroin is expensive, too but it's not as expensive as Meth, and there's a big difference. You can get killed over Meth. You know?

(Interview eight, Rayleen, female 33 years)

At another juncture in her story Rayleen returned to this theme, describing how the positive effects of using meth contribute to identities that are 'clean', when compared to 'dirty' heroin using identities she had experienced:

...I used to get up in the morning and; we're going to clean this house rah, rah, rah. Even when I had borders, they used to shut their doors, like oh my god she's up. But now I'm more relaxed and even my kids said I used to colour coordinate the washing, like hang reds and blacks. I never noticed, and yeah they said I'd colour coordinate the pegs and be real pedantic, and see a spot on the -you know, wool and l'd be scrubbing and scrubbing. So yeah, because that's what it does, too. Meth, you just like - everything's got to be freshly cleaned and white (laughter).

Which is why Heroin-users are dirty? 
Some are clean, but the ones that are clean you find are the ones that um, were tidy in the first place, but yeah - but my sister-in-law, she used Heroin, too and she's - her house was disgusting and I never used to send my kids there, because she used to have needles on the ground and all in the driveway and everywhere, and she was the one I got the Hep-C off, because back when I was younger...

(Interview eight, Rayleen, female 33 years)

The stories of initiating and then engaging in ongoing problematic use of methamphetamine, and for several participants', the accompanying problematic use of other drugs, helped to detail the social processes operating within the risk environments these drug users had experienced, compared to other environmental contexts of drug use. For example, as qualitative evaluations of recreational drug use demonstrate, when methamphetamine and other drugs are typically purchased in the environmental context of recreational use, purchasers seldom come in contact with high level dealers or organised criminal networks (Aldridge et al:2011, cited in O'Gorman:2016). Recreational drug users are more likely to be buffered by "several degrees of separation from direct contact with the drugs economy" (ibid: 252). Drugs are therefore more likely to be accessed through layers of friends and social networks, the provision of which is acknowledged as a trust building exercise by "sorting friends out" (ibid: 252).

The presence of methamphetamine itself is also widely regarded as disrupting the acceptable social arrangements of drug-taking in other environmental contexts. Green and Moore $(2013: 693,694)$ identify this when examining methamphetamine use among a group of Australian users, pointing out that, among the drug 'scensters' they interviewed, some viewed using methamphetamine as signalling a serious transgression between recreational and non-recreational drug-taking practices as emphasised by one respondent: 
“Crack (methamphetamine) fucking disgusts me. The smoking, 'fiending, pipes, lightbulbs - all the amounts of contraptions you can make, the way people change, act, think, feel, psychosis, the comedowns...It's an incredibly addictive fucked up drug..."

Similarly, Fazio, Hunt and Maloney (2011:633) identified the acceptability of cocaine use within the recreational context of gay culture, but noted that, although methamphetamine was used also, its presence was dismissed as "dangerous and shameful", its use being associated with unacceptable high-risk sexual behaviour. As one of their respondents noted when differentiating between the acceptability of cocaine and meth:

“I don't think there are spaces like...you know, like after a, a gallery show, like with artists, like where you do coke you know. I don't think there's spaces like those where people are like, "oh my God you guys, let's just do some Meth because this is like the space where we do meth." I think meth is totally like a shame drug" (ibid: 634).

Comparatively, these drug users described events and experiences which revealed environments conducive to the normalising of methamphetamine initiation, procurement and use, and where the use of methamphetamine and other drugs was not time-bound as is characteristic of recreational drug taking, but instead a daily activity which structured participants' day to day lives. No participant identified drug-using associates as having explicitly anti-meth attitudes. Instead, they consistently described being in close proximity to meth-using criminal associates and family members, with some disclosing being heavily involved in the sale and distribution of methamphetamine, and for three participants, being involved in the 'cooking' (manufacturing) of methamphetamine.

The transitions in drug using behaviour described by participants' in moving towards more harmful drug-using practices are also documented extensively in qualitative evaluations of drug use and risk. This scholarship universally emphasises how particular 
social and physical environments where drug use occurs can influence, define and organise drug-users' perceptions of risk acceptability (Rhodes: 1997, 2002, 2003, Mayock: 2004, Fast et al: 2010, Williams: 2013, O’Gorman:2016). In such environments, rationality is understood as situationally dependent, notably in cultural explanations of risk (Douglas: 1986, Tulloch and Lupton: 2003) However, as Rayleen demonstrated when describing her meth-using experiences in the wider context of sex work, different rationalities are inevitably socially structured within risk environments, "where not all individuals have equal power to act rationally in negotiations with others" (Rhodes: 1997:220).

For female participants', this meant transitions in drug-using behaviour were often inseparable from gendered power differentials. Rayleen's story highlighted this point when she described her drug use as facilitating gendered behaviour and appearance expectations required of her as a sex worker, and when identifying her provision of sex to male drug dealers in order to access 'free' methamphetamine. Rayleen's experience is similarly evidenced in other qualitative evaluations of female drug use. For example, McKenna's (2014:113) evaluation of structural vulnerabilities experienced by women who exchange sex for methamphetamine illuminates how female methamphetamine users navigate high risk environments. McKenna notes that in response to economic realities, female drug users often strategically embed themselves in what they describe as complex moral economies, where the reciprocal ties that facilitate their survival at the same time hinder their ability to effectively manage their drug use and sexual practices in ways promoted in harm reduction efforts (ibid).

The dangers of prolonged methamphetamine use were also described by participants in ways that at times clearly corresponded with authoritative representations of meth harms, but which equally challenged the unified meth-using experience promoted in public health discourses. For some participants' the notable absence of meth-induced psychosis suggested their being more able to reconcile their using methamphetamine, 
notably when other meth users in their social networks presented in ways that corresponded with images communicated in anti-meth campaigns.

Dwyer and Moore (2013:205) make a similar observation when examining public discourse on methamphetamine and its psychological effects, typically identified as including psychosis, hallucinations, delusions and paranoia. They note that medical research texts routinely focus upon the prevalence and risks of psychotic symptoms among dependant and recreational methamphetamine users, resulting in a singular and stable view which implies that," for any individual, each of their encounters will follow a similar pattern" (ibid:206). They provide a contrasting view when documenting 'consumer accounts of methamphetamine', where any hallucinatory and paranoid experiences were recognised by meth users as the temporary effects of the drug, rather than signalling a permanent compromising of their mental health. Thus authoritative predictions of mental health risks were negotiated by their participants' understanding these experiences as at the same time being transitory, pleasurable and even humorous.

It was also made apparent that, for the drug users interviewed for this thesis, in spite of engaging in chaotic and uncontrollable drug use which had caused themselves and others significant harm, they resisted associations with stigmatised drug using identities by differentiating their drug using behaviour from the behaviour of 'other' drug addicts. In doing so, participants revealed the presence of stigmatised others within their drugusing environments, and their awareness of, and avoiding, being identified in ways that accorded with mediated representations of typical meth users. As Copes (2016) explains, narrating their drug using experiences in this way functioned as a means of maintaining symbolic boundaries, in order to avoid both authoritative and lay attachments of low-status labels, such as crackheads, fienders ${ }^{63}$, or junkies.

\footnotetext{
63 The term fienders refers to individuals who are singularly focussed on the pursuit of using their drug of choice. The term is used for example by Bourgois and Shoenberg (2009) in their work 'Righteous Dope Fiend', and has featured in early drug panic discourses in reference to 'Negro cocaine fiends'.
} 
This was evident when participants positioned their use of methamphetamine as being functional, rather than disordered, by referencing their having maintained an outwardly 'normal' physical appearance and maintaining a good state of mind. Copes (2016:202) suggests that, when making comparisons to dysfunctional drug users, these qualities help signify the functional and controlled use of drugs, irrespective of whether the functional user is a drug 'addict'. As he notes in relation to the physical distinctions between a 'drug addict' and a 'smack head' (heroin user), users are thought to care about their personal hygiene, whereas 'smack heads' either did not care or are no longer capable of maintaining their physical appearance. Similarly, functional meth users distance themselves from the unstable and erratic behaviours attributed to 'tweakers ${ }^{64}$ ' and 'fienders,' by claiming to maintain clear heads and healthy mental states (ibid: 203).

By employing these narrative devices, participants' identified the inter-play between the presence of larger cultural narratives about drugs and drug users, and their drawing upon them to develop personal boundaries, as well as communicate their understanding of acceptable and unacceptable drug using behaviours (Fast et al: 2010, Copes:2016). Articulating a process which resonates with the narratives explored here, Rhodes et al. (2011:449) also point out that accounts of initiation into drug use seldom deny a cultural awareness of smoking methamphetamine or injecting drugs as 'a social bad'. Instead, users show they are reflexive to this awareness of cultural admonishment, and narrate their experiences "as a means of negotiating the contradictions which emanate from situating (stigmatised forms of drug use) simultaneously as normative yet unacceptable, as pleasurable yet dangerous."

\section{Conclusion}

The aim of this chapter has been to provide a deeper analysis of poly-drug use. To do so it has foregrounded this analysis by revisiting some of the theoretical underpinnings

\footnotetext{
${ }^{64}$ Tweakers refers to individuals whose prolonged binge use of methamphetamine has resulted in manic or obsessive behaviour, which can include long periods of cleaning, or organising, hence 'tweaking' details in work undertaken while on meth.
} 
used in promoting authoritative understandings of drug use, risk and decision-making. This has made apparent the conceptual contradictions in expert explanations of drug use. These explanations offer de-contextualised accounts of drug taking, where individuals who engage in problematic drug use are envisaged as being both pathological, and imbued with the ability to cognitively assess and avoid drug-taking risks.

To counter what are viewed as being atheoretical explanations of drug use, this chapter introduces a foundational understanding of risk environments as conceptualised by Rhodes $(2002,2003)$, and sets out the theoretical utility of applying risk environment perspectives of drug use in order to contextualise the social processes which inform drug initiation, use and desistance. It is argued that, in applying it's imperatives here, risk environment scholarship helps theorise the inter-play between individual-level decisions participants storied in relation to poly-drug taking, and the social and structural constraints they identified when transitioning towards more harmful drugtaking behaviour.

Taking this approach to analyse the narratives of poly-drug use storied throughout this chapter provides a more nuanced understanding of how individuals come to engage in a form of drug use which has been subject to unrelenting vilification. These stories explain how public warnings about the health risks of methamphetamine and the behaviour of those who dare use it, are reconciled, by demonstrating that "risk actions are rarely the product of any one individuals' rational decisions"(Rhodes:1997:216). It is more likely that risk taking behaviour is the outcome of negotiations between people in relational contexts. Moreover, behaviours deemed inherently risky by 'experts' such as smoking or injecting methamphetamine, were contextualised as routine activities within the social environments that participants described, which did not always require any calculated risk assessment; they were simply done (Rhodes:1997). These environments 
were evidenced by the normalising presence of drug -using partners, family members, peers and wider social networks of drug users and suppliers.

Importantly, when describing the social environments which had supported their initiation into methamphetamine use, participants' stories highlighted the ways in which social and structural forces had manifest in everyday experiences of environmental risks, notably through exposure to gang related violence and the embeddedness of gendered power disparities in male dominated drug economies. Evidence of these realities pointed to the need to theorise drug use in relation to what Rhodes (2002) describes as the contradictory and situated pressures of risk decision-making, as well as the presence of power inequalities in risk negotiation, themes explored more closely in the proceeding chapter. 


\section{Chapter five: narratives of social relationships and drug use}

\section{Introduction}

This chapter builds on the previous analysis of transitions in poly-drug use by examining more closely the social relationships, connections and assemblages participants described when storying their experiences of using multiple drug types and initiating methamphetamine use. The imperatives of risk environment scholarship set out in chapter four are also used here used to examine how these social processes facilitated participants' embeddedness within structurally vulnerable networks of problematic drug users, and elevated their exposure to an array of drug-related risks.

The divergence between male and female participants' risk experiences signposted throughout the previous analysis of poly-drug taking behaviour is also explored to illuminate the gendering of structural vulnerabilities. By evaluating gendered experiences of risk, the inter-play between broader structural power disparities and individual-level decision-making processes is demonstrated as constraining participants' ability to engage in risk avoidance. By examining these constraints in the context of intimate and peer relationships enmeshed with the wider social organisation of gendered drug economies, it is argued here that these social relationships functioned not only as an important source of understanding about risk, but also exposed participants to risk.

The aim of this chapter is to further develop the argument presented in this thesis, that drug use should be viewed as a social, rather than individual, process, where decisions about using drugs are often subject to the influence of factors which are beyond the control of the individual. This point is critical to the researching of problematic drug use, given that, in this context, networks of social relationships are bound together by the daily use of drugs, in drug-using environments which inevitably place individuals at risk of drug taking, as well as rendering them vulnerable to risks from drug taking (Williams: 2013:84) 


\section{Family, friends and drug use}

Almost all participants had been exposed to drugs at a relatively early age, typically throughout adolescence, and for some participants, exposure prior to the age of 13 . These age-specific biographical reference points prompted participants to retrospectively story the social context of their pathway to drug initiation and use. When doing this participants' typically positioned themselves within their story by reflecting on 'what life was like for me growing up', and by pointing to the ways in which relationships and socially situated experiences at this point in their lives had influenced decisions leading to their becoming more involved in increasingly harmful forms of drugtaking.

Without exception, all 17 partcipants storied their initiation into drug use and proceeding transitions towards methamphetamine initiation by describing exposure to pro-drug attitudes and drug-taking behaviour via their social relationships (Williams:2013:79). Each participant's story highlighted different types of relationship experiences with family, friends and social networks, and communicated their understanding of how these experiences facilitated their entering structurally vulnerable social networks of drug users (O'Brien, Bretch and Casey :2008) ${ }^{65}$. These experiences also reflected the consensus of an extensive corpus of drug scholarship which confirms that, fundamental to opportunities for initiating drug use are social relationships with other drug users (Williams:2013).

While not typical of this sample of drug users, two partcipants signposted early, and extensive exposure to drug taking opportunities by identifying the influence of relationships with immediate and extended family members who also used drugs. Rayleen's story of drug initiation was situated in the context of her relationship with her

\footnotetext{
65 However, not all relationship experiences are adequately explored here. At times during the interview process participants made passing references to poor relationships with fathers, being subjected to sexual abuse by family members and controlling behaviour by partners. In the context of participating in the interview ethically and safely I deemed it inappropriate to encourage deeper exploration of these references as I note when detailing my methodology.
} 
parents', who were drug experienced and heavily involved in the use and supply of drugs. Rayleen described her early exposure to drugs and opportunities to use them as routinely occurring in her childhood experience of family life, and noted that because of her father's high level involvement in the wholesale supply of drugs, both her parents inevitably had 'pro-drug' attitudes:

My father was a big-time drug warlord in Wellington so I knew what it (cannabis) all was...

Did they ever give you....warnings or advice?

They made out it was okay - that um, it was natural and yeah it was legal and (laughter) - yeah they never really gave anything about it, but I used to watch the fights and the beatings and that, but because my dad was so rich from it, yeah I - I seen another lifestyle.

(Interview eight, Rayleen, female 33 years)

As Rayleen storied her exposure to drugs as a child she pointed to other family members also being involved in, and aware of, her father's involvement in drug dealing:

What did other family members think about that?

Oh, they hated it, but um, my little sister didn't know. She just thought Dad was rich, and was a big businessman (laughter) that had all these companies, and - and um, but I - they never told us, but I sort of knew from - because I mean, he used to take us on his drug runs, and you know; what kid sits in the car and watches men in suits swap suitcases and open up boots (laughter)? And I used to think; oh I've seen these in the movies - what's going on here? (Laughter) And he used to just give us $\$ 100$ notes to keep our mouth closed. So as I got older I started realising, and he used to put ounces and ounces of drugs in our luggage when we'd fly to Christchurch to see Mum. As in - as in cannabis?

Yeah, and heroin and Speed and everything, and knowing if we got caught - like it was me and my sister - we'd go down for something (laughter), and he'd never drop us off at the airport. He'd get someone to run us to the airport, and make sure we're on the plane, and never let my mum pick us up at the airport. He'd make someone else pick us up. So, obviously if they got caught they would have to take the rap.

(Interview eight, Rayleen, female 33 years) 
Although having a father involved in drug supply facilitated Rayleen's ability to access and use large amounts of cannabis as a teenager, she also noted that, comparatively, her use of alcohol was viewed less favourably than her use of drugs:

I mean, on my 13th birthday he (Dad) gave me an ounce and - which me and five girls smoked, and I mean we was absolutely off our chops, and - and it's just so strange, because my parents never - you know, any other parent would go ballistic, but my parents - they just - they had more of a problem with my drinking than me smoking weed.

(Interview eight, Rayleen, female 33 years)

Amy also pointed to the influence of family members when describing her trajectory of drug use. She identified her transition from problematic alcohol and cannabis use as a teenager to being exposed to, and initiating, methamphetamine use as resulting from her relationship with her cousin:

Yeah, 18 is when I started smoking P...

... I can't think of the day, but I'm realising now that we're talking about it, my cousin is how I got into smoking $P$. She was with a gang member, and her life was chaotic. She's two years older than me. That's how I got into smoking P; when I was with my boyfriend at 18 I started staying with her as well, babysitting her kids. Then she was seeing another guy, and he was a big drug dealer, so I'd go with her and I'd sit there with her and smoke free P. That's how I got started smoking $P$.

Later on in her story, Amy described her use of methamphetamine and other drugs by referencing her brother's involvement in drug use, as well as other members of her extended family. She then described using methamphetamine with her mother:

My mother; she was studying at the time and she didn't like how I was acting, and the behaviour but then again she would smoke $P$ with me. Then she'd go back to that high-class - you know, and then next minute - two weeks later; Mum. She's got money too sometimes. Then, of course she's going to want to smoke P; who doesn't? Then it would come back to the same level and then she'd go off and be a mother again - the mother that looks down on me, kind of thing. (Interview nine, Amy, female 33 years) 
Participants' also frequently described their understanding of how relationships with family members had contributed to their embeddedness in drug-using scenes, and often referenced experiences of childhood emotional, physical or sexual abuse. When disclosing having been victimised participants reflected on how this had influenced their transitioning towards more harmful forms of drug use. For example, Terry recounted his experiences of family life by describing his family's negative reactions to his drug taking and being subjected to abuse as something he understood as contributing to his involvement in a gang, which in turn provided social currency that supported his drug use:

... When I was growing up, when I first started I used to live at home. I used to sneak out, and get a hiding and they used to come around - I used to go home whacked as, and they used to come in and always nig at me; why are you on drugs - you know - leave it alone - it's not good for you bloody hell, tidy yourself up, and that. It - people niggling at me made more determined to go and do it. If they shut their mouth and said nothing, I'd be totally different. The more people go on at me about something, it makes me more determined to piss them off. Plus, we didn't have a good upbringing actually, so I was rebellious through that...

....My biological dad lives in Shannon, and I haven't seen him since I was about two years old. So I've got a step-father, and he just physically and mentally abused me. So - and that made me more - more determined to go to the - to the gang side, and to the under-world, as I call it...Don't worry about the top world; stay under-world, underground. Yet I got - you know, I can go to any tinny house in Wanganui and ask for tick (credit). I'll get it, but I can't go to any business here up-ground. I don't get credit, but in the under-world, I get heaps of credit.

(Interview fourteen, Terry, male 40 years)

For Debbie, early exposure to drug use had resulted from a confluence of negative childhood experiences. These included her needing to use prescription amphetamines to manage Attention Deficit Disorder (ADD) as a child, experiences of abuse at home leading to her accessing care from Child, Youth and Family Services (CYF's) and her moving in with a new, drug-using partner:

Where did it all begin - your first interactions with drugs? 
When I left home.

...Why did that happen?

A lot of abuse from parents, so I signed myself into CYFS care, and got sent up to Auckland to (a) girl's school and try to get me better. I just didn't want to live at home. I was ADD when I was a child, too. So, drugs have been a factor in my life for actually a while, because I was on medication.

....I was good managing it, but when I was getting off it, I was still self-medicating myself...I used to steal my pills, and Mum had to take them off me. I'd been used to taking them every day for so long.

...How long did you stay at school for?

Half way through fifth form.

Then, from there where did you go?

Streets, running away from home, getting drunk, getting sent home by the cops...l got on the benefit. I got on a de-facto benefit with my partner at the time. We went on a couples benefit, because I couldn't get the independent youth, because my parents wouldn't sign it.

(Interview fifteen, Debbie, female 26 years)

As Debbie progressed in the telling of her story she reflected on how these experiences had preceded her becoming involved in a social network of much older drug users who provided her with support:

So, when you're talking about going out and partying and doing things, was that a seven day a week thing?

It was mainly every day, because I wasn't living at home, and I was around the alcoholics and all that. Yeah, it was practically every day.

(With) people in a similar age group to you?

Older...Yeah, a lot older...Yeah, they used to look after me....It was good, because I was looked after and treated right.

(Interview fifteen, Debbie, female, 26 years) 
Rayleen had also experienced sexual abuse at an early age, an experience she identified as an underlying contributing factor to her progression towards more harmful forms of drug use and entrenchment in drug using scenes:

...one time I was in the toilet, and I'd rung my mother. I just - I remember sitting in the toilet and the walls were closing in and I hadn't had anything. I'd just woken up and I was shaking and there was something wrong; I could hear things and I could see things, and I could see demons and um, then I couldn't breathe, and I knew then something was going on with me mentally.

Um, so I rung my mum, and I told her what was going on, and I think she rung like a mental institution or something, and um, then I rung my social worker. Because of me being 17 and giving up the kids, I was always a state of the ward child. So, they come bowling in and they'd brought a mental health worker with them, and um, my dad come flying down from Wellington and they put me in a um, like a Kennedy's Detox Centre out in Hillmorton, and l'd lost - sort of lost the plot mentally, um because things started popping up from my childhood, that obviously I had put behind me and hadn't dealt with, and other things too that had happened to me when I was younger, and um, yeah I sort of...

Um, I was sexually raped when we first moved to Christchurch by my mum's new boyfriend, and...

I'm sorry to hear that.

She didn't believe me, which is why I think I turned out the way I did, because all my anger did revolve around her, and my family knew I was telling the truth because you know, why would you know, a 10 year old make something up like that? Um, but l'd pushed it aside and left it, because obviously she wasn't going to believe me, so I just had to move on from it, and so when that started popping up, yeah I just - yeah, lost it, and my partner was in jail at this time again (laughter) so um, I was sort of all on my own.

(Interview eight, Rayleen, female 33 years)

For other participants, initial exposure to drug use during adolescence had resulted from situated contexts involving relationships with drug-using peers of a similar age. Participants' identified these relationships as providing the social context in which their decision to try drugs was opportunistic and impulsive, and which invariably involved the use of tobacco, alcohol and cannabis. When participants reflected on how their journeys of drug use progressed from unplanned exposure to these drugs as teenagers, to more 
frequent use of other drugs in young adulthood, there was uniformity in identifying their becoming involved with much older, and more experienced drug-using peers. Of note were frequent descriptions of how key relationships with older, male drug users had facilitated both male and female participants' becoming entrenched in 'drug scenes'. When participating in these scenes, participants' were exposed to opportunities to try new drugs, which provided the social context for their initiation into starting, and using more frequently, methamphetamine.

Participants reflected on 'entry points' into a particular drug scene when describing the progression of their drug using journeys. Entry points were typically identified as occurring from several months, up until one or two years prior to their needing to manage an array of problems resulting from their problematic use of methamphetamine and other drugs. Storying initial involvement in drug scenes was also characterised by descriptions of exciting and positive drug using experiences, and by emphasising what Mayock (2005:355) describes as the different ways "drug scenes conferred social and personal rewards linked to displays of experience, and opened up opportunities for status achievement."

John's story illustrated this when he recounted his experience of developing a relationship with an older male drug user at the age of 13 as a chance occurrence resulting from an incident at school. He emphasised how this relationship afforded him a degree of social capital as a teenager, and facilitated his entry into to a new social group who provided new opportunities to access different types of drugs:

..... got into a fight with a kid at school and - and his old man was a - was a hard bugger, and he come round and picked me up by me ear, and one of the ah-one of the bystanders saw this and decided to ring the - ring the cops.... Um, anyway the um - so the cops come round and I wouldn't say anything, and so this - this old guy who has been in a lot of trouble with the law before decides to um - decides to congratulate me in some respects, you could say, by paying for some tattoos for me, which is quite cool, because I'm 13 and I'm getting my first professional tattoos. You know? So - so that kind of put me in contact with um - with a lot older people, who you know, 
obviously were probably not aware I was 13 um, and - so anyway, by the time I was 15 I had no trouble at all sourcing - sourcing pretty much anything I could ask for in Wellington, at the time.

(Interview thirteen, John, male 39 years)

As John's story progressed he described his escalating involvement in this new social network of drug users and his becoming known to the police as a result of his drug use: So, when did you first come into contact with police? For - the first drug one was when I was um, probably about 17. Yeah. Yeah, I got caught out rather un-fortuitously; I had a preserving jar full of mushrooms, and a couple of sheets of LSD and um, managed to hide the LSD and stuff, but I think I had a syringe as well, which I threw somewhere, but um yeah, getting rid of a preserving jar full of mushrooms - because you know, kind of tricky when you've got a policeman looking at you. So, yeah I got - I got, you know, a Class A drugs charge, I think when I was like pretty young. Um...

(Interview thirteen, John, male 39 years)

For Matthew, a relationship with an older male involved in drug dealing developed as a result of his moving away from home at the age of 16 . Matthew identified this relationship and his participation in the social network it afforded him access to, as contributing to his becoming increasingly involved in problematic drug use:

(When you left home) where did you go and stay?

Just stayed at my mates - different - crashing at everyone's houses for a few months until I was 16. My parents had no idea where I was, and then when I was 16 I signed up to the independent youth benefit, and then from there it just went really downhill... I moved in with this well known drug dealer in Fitzroy. Just from there on, we just - like, every so often he would just offer me new drugs like Speed or Cocaine a few times, but I don't really reckon it was the proper stuff, but...we got kicked out of there for parties and all that, so then we moved up the road onto Evans Street, and we were in a two-storied flat above there, and the second drug dealer moved in and that's when it started going good. Well, for me it was good then. Like it was just free pot every day started getting like, deals and we just got all these bags and all that - dollar bags, and we just - 
you know, just started smoking all that, and they just offered it and then it just became a regular habit.

Were they older?

One of them was 39 and one was 30-something; both a lot older than me, yeah. I got into that place by - because one of my good mates who we smoked with, it was his uncle and we just always went around there, and then like, one day I just - this is when I got kicked out of home like, on the verge of being kicked out. So then, one - one of the nights I got kicked out, and I just stayed there and then every night after that I just stayed there, and then after a few weeks he was like, oh do you want to live here? I was like, oh yeah.

(Interview sixteen, Matthew, male 18 years)

For Ben, having an established relationship with an older, respected, and more experienced drug-using male who had previously sold him drugs, mitigated perceptions of risk when deciding to use new drugs and try different routes of ingestion. This point was conveyed when Ben recounted his first experience injecting amphetamine intravenously:

....it was my first time, and I wasn't keen on needles and I remember looking this way (turns head) and he was doing it all for me and he said hold your arm up like this (lifts arm) so I held my arm up like that and he shot it in, and um, so he said "put your arm down", so I could feel it, just flow through me, and I could not sit still...it was more intense than ever snorting it...

When you were in that situation with that guy, did he give you...any advice or warnings...?

Not really, no no...I have to admit, I trusted him because he was a lot... he was double my age and he was like 42 and I was like in my early 20s, and he's been a junkie most of his life and I kind of just trusted that he would know what to do and that sort of stuff...

(Interview four, Ben, 31 year old male) 
Describing his initiation into methamphetamine use, Steve identified a similar influential relationship with an older male drug user who supplied him with methamphetamine. At the beginning of his story he described his use of methamphetamine as resulting from his own decision making and in spite of being warned about possible harms:

... it wasn't that he umm... was offering it to me or pushing it on me and stuff. I was around him, and smoking pot too but umm seeing what's going on, I wanted to be a part of what he was doing...I remember him clearly going "you shouldn't do this it's bad for you blah blah..." And he was trying to do the 'do as I say and not as I do' kinda thing, just like I do now to the young fellas! Fuckin' funny aye?

(Interview six, Steve, 33 year old male)

However, as his story progressed Steve reflected on how this relationship had provided the social context which supported his becoming a more experienced drug user. As a result of this relationship Steve became more independent, and went on to engage in methamphetamine use in different social contexts:

I call him a mentor because he sorta was to me, but this older guy...umm... he was the only place I knew of where I could ever get it (meth), so he controlled my use which he, you know, did his best to regulate. And I remember things changing... people started offering it in town...I remember that sorta became the catalyst for using away from...it was always in (his) garage, I remember the first, the first time I used it away from (his) garage, and it was like, it was like being unsupervised for the first time...I remember that being a catalyst for change, that being able to get it somewhere else besides, besides from (names friend) and, yeah, doing it all by myself.

(Interview six, Steve, 31 year old male)

Amy's story of increasing involvement in methamphetamine use also highlighted the influence of an older male who was involved in supplying drugs. When reflecting on this relationship, Amy understood the relationship as being similar to having 'an uncle', and that it afforded her social status within a meth-using scene, which in turn facilitated ready access to methamphetamine: 
Thinking about it, I felt really honoured to be in the presence of this big time P-dealer. That's the truth. It's the truth of it.

You use the word honoured; why would you feel honoured?

I guess in the drug world, there are classes; people put you in categories. There are the ones that go around and chase it, or the ones that do petty little crimes - do anything, sell anything for it. Whereas, if you know somebody, you can go straight in there - VIP - sit there and smoke, however you want. So, yes and it was very cool, because I didn't know anything about it; here I was sitting with all these people with heaps of $P$.

...Yeah, and all of a sudden in my head I was thinking they were my friends. I was only ever with my cousin, but then in saying that, the fella - why we were allowed to do that is because we were kids of his friend when they grew up in their area. So, I suppose I looked at it like he was my uncle, but he's not. When I started getting obviously addicted, I could use that (to get methamphetamine), because my dad did tattoos on him when they were kids, and my dad is now dead.

(Interview nine, Amy, female, 33 years)

Comparably, Angus's story was not typical of other participants, due to his being imprisoned at the age of 18 . However, this experience similarly exposed him to networks of more experienced male drug users, and rapidly facilitated his trajectory towards becoming heavily involved in the use, manufacture and supply of methamphetamine. Angus articulated this experience by describing a transition from being an 'impressionable 18 year old boy', to becoming more involved in crime through social acceptance within a social network of gang members:

...I did 18-22 in jail. You meet all these people.

How did you cope with that?

I loved it. I did some good things in jail, too; did my degree, I did my School C - maths and English as well, so I could get my correspondence. I did heaps of cool shit, but at the same time you just meet these people that that's what they've done their whole lives - the connections...I thought it was great. You're pretty impressionable when you're 18. I was a young little white boy, prettyfaced; I got the shit kicked out of me for the first six months. So when people started to finally get to know me and think something of me, it was cool. 
...were all your friends' also using drugs as well?

Yeah, I've hung out with some pretty loose people, and again always older than me.... It's not just the drugs either; you get addicted to the life - the girls, knowing people, being hooked up. You know what I mean? That's addictive. That seems fun and glamorous.

Is that how you funded (your meth use)?

Oh, yes. It wasn't just that - a lot of other drugs; rinse, ecstasy, MDMA - was selling it all - big quantities. I was burying buckets of money. I remember thinking one day, the money is the next problem - what do you do with it? You've got to count it, you've got to store it, you can't spend it - you can't even go buy a car. Who goes and buys a car, like - fuck, you know? The addiction took over, and by the time I left Christchurch I had no money. I owed.

(Interview seven, Angus, male 33 years)

Although participants' described differences in the type and sequencing of relationship experiences they understood as influencing their use of drugs, commonalities in their stories demonstrated that, for this sample of problematic drug users, relationships with drug using family members and friends provided environments which placed them at risk of witnessing substance use and being exposed to attitudes favourable to substance use in familial and peer contexts (Zimmerman and Farrell 2017). Along with the transitions in drug using repertories they described when storying their poly-drug use, their relationship experiences supported a broad literature which confirms that family and friendship groups are primary sources of supply and contact with drugs, notably for first time users. They also confirmed that, in addition to drug exposure, one of "the most consistent antecedent risk factors" for adolescent drug initiation and use is peer and parental approval (Pilkington:2007, Williams:2013, Zimmerman and Farrell:2017:229).

The experiential themes conveyed by these drug users also illustrate that relationships with drug experienced family members and peer networks are not only fundamental to drug-use initiation; they facilitate embeddedness within drug using social networks, where users are exposed to new drug taking opportunities and subject to an elevated risk of drug dependency (Mayock 2002, Finlinson et al: 2006, Pilkington: 2007, Mayock 
et al: 2015). Participants exposure to drugs during childhood and adolescence had contributed to their becoming what Mayock (2005:359) refers to as "early risk-takers", where "extending the boundaries of normal risk" was facilitated by their entry into drugexperienced social networks, in which the use of 'hard drugs' was both accepted, and for some, understood as a means of achieving self-confidence, status and social acceptance.

Qualitative scholarship engaging with samples of problematic drug users highlights similar relationship pathways to eventual entrenchment in social environments conducive to more frequent, and more harmful, drug taking practices. For example, Joe's (1996:205) evaluation of Hawaiian female methamphetamine users identified that the women in her sample had been exposed to first-time drug taking opportunities at an early age through relationships with immediate and extended family members. As the use of new drugs broadened their social networks, initiation into methamphetamine use was described as occurring with small groups of female friends, or as being introduced by a relative, most often a cousin or sister in law heavily involved in drug use, an experience described by one of Joe's research participants which resonated with Amy's story of meth initiation:

"I started buying from one of my cousins. I used to always burn myself 'cause I was trying to learn how to do this without wasting 'em. My cousin used to see me do that so she taught me...I stayed with her for three months. They were big time dealers..." (Cited in Joe: 1996:205)

Additionally, Joe's $(1995,1996)$ work reiterates that, for many problematic drug users gravitation towards, and eventual entrenchment within drug using scenes results from experiences of victimisation as children and adolescents. Many of her female participants recounted similar experiences of physical and sexual abuse by family members and family friends. These victimisation experiences are consistently identified in other qualitative evaluations of problematic drug use, which similarly reiterate that structural vulnerabilities often manifest in individuals experiencing drug dependency. O'Brien, Brecht and Casey (2008:347-348) demonstrate this point when evaluating 
narratives of methamphetamine use articulated by a sample of male and female methamphetamine users from Los Angeles. They identify "pathways to drug abuse in childhood" described by all but one of their participants as being linked to experiences of physical and sexual abuse, where initiation into drug use occurred because participants had physically escaped their abusers by seeking "emotional refuge in the landscape of drug users and drug use."

Comparatively, five participants in this sample of drug users had also disclosed childhood experiences of physical and sexual abuse as a result of parents, extended family members and family friends (Rayleen, Debbie, Tania, and Rebecca), only one of who was male (Terry). Although presenting a nuanced understanding of these experiences was constrained by my awareness of participating in an abuse disclosure as a male researcher, all five participants had positioned these experiences in the context of storying their life history as a contributing factor to involvement in drug scenes, which in turn exposed them to a myriad of new drug-taking opportunities, including the use of methamphetamine.

Sheridan et al.'s (2009:13) evaluation of methamphetamine initiation among a sample of New Zealand methamphetamine users similarly pointed to exposure to drug taking opportunities as occurring through new relationships with drug experienced friends, as well as partners, and work colleagues. Although their work is hampered by the absence of contextual detail, their participants identified relationships as facilitating progression towards more risky forms of drug use, as one of their participants demonstrated when describing their initiation into using methamphetamine:

“...my friend's dad had it and it was like in a lightbulb. I think it would have been because we hadn't discovered pipes then. And so it was in a lightbulb and he showed us how to do it and then he told me when to suck and all of that." (Sheridan et al. 2009:13) 
Interviewing a sample of 100 methamphetamine users recruited in Atlanta, Boshears, Boeri and Harby (2011) similarly highlight the social contexts of initiation into the use of methamphetamine and other drugs. Their work identifies many of the experiential themes storied here when participants' described entry points into social networks which enabled them to access and use methamphetamine. Challenging the notion that drug addiction is exclusively biological, Boshears et al. (2011:294) argue that relationships with meth-using family members, peers and partners function as 'sites of sociality', which provide normalised opportunities for meth consumption and social cohesion with other meth users. In contrast to clinical understandings of chemical dependency which are reliant on the pre-condition of drug seeking behaviour, their participants demonstrated that, rather than seeking out methamphetamine,

“...the social fabric provided the people and connections to access methamphetamine (or other drugs), granted access to various settings in which to conduct illicit drug use, and provided social solidarity among the individuals involved."

The stories of social relationships and drug use participants' described in this chapter similarly communicated that becoming enmeshed in the social fabric of drug use had also created an environment conducive to their drug dependence. These social experiences of drug use are in stark contrast to those articulated within qualitative evaluations of non-problematic drug users (see for example Pearson: 2001, Measham, Williams and Aldridge: 2011). Young recreational drug users for example, have been identified as succeeding in prioritising the importance of education, employment and other valued life projects, over the short term rewards of intoxication for pleasure. This has enabled recreational drug users to integrate drug taking into their lives in positive and constructive ways, enabling them to move freely between the world of drugs, and the world of careers, family commitments and other responsibilities (Mayock: 2005). 
It is through confinement within the social boundaries of 'the drugs world' that participants had engaged in drug taking that would eventually become habitual, rather than calculated, or leisure orientated (Measham: 2002, Mayock: 2005), and where, behaviours imbued with risk such as smoking, injecting, manufacturing or distributing methamphetamine, appeared to participants in their socially supportive networks as being "everyday mundane activities" (Rhodes:1997: 216). As Rhodes (1997: 217) argues, "the fallacies of individual rationality and choice blur the habituation of risk behaviour." Thus, although participants may well have been cognitively aware of the potential costs associated with their drug taking, for problematic drug users, it is more likely that habitual drug use, which is less dependent on risk assessment, offered functional value which became incorporated into everyday normal life.

\section{Risk exposure and social relationships}

A universal theme intersecting the storying of becoming embedded in drug using social environments was the magnification of risk exposure participants' described as occurring alongside their escalating use of methamphetamine and other drugs. Thus entrance into networks of experienced drug users signalled not only the normalising of more harmful drug-taking practises, but also their becoming vulnerable to new environmental risks, as participants gravitated towards involvement in drug-related criminality, in street-based sex work, and becoming directly or indirectly involved with gangs. These socially situated experiences of risk supported Rhodes' assertion that 'decisions' about drug use - notably problematic drug use - invariably occur within environments comprised of "risk factors exogenous to the individual" (2002: 220).

Importantly, as participants described the complex social composition of their drug using worlds, their stories highlighted that, in the context of social relationships, their experiences of drug use were profoundly gendered. For female participants they typically involved navigating the lived reality of using methamphetamine in the context of an intimate relationship with a male partner who also used drugs, as a mother 
responsible for childcare, or while negotiating drug use in the landscape of sex work or as a gang associate.

For male participants, the lived reality of methamphetamine use was largely confined within social networks of other male drug users, where participants were involved in the manufacture and supply of drugs, or who were gang members or gang affiliates. Comparatively, male participants also described having intimate relationships with females who only used drugs in a recreational context, or who did not use drugs at all, and who provided the main source of childcare. The different types of relationship experiences male and female participants identified as influencing their drug-taking decisions demonstrated that social relationships are sites which subject or expose individuals to varying degrees of risk, and that risk itself is a gendered experience (Rhodes and Quirk: 1998).

Rebecca's storying of initiation into methamphetamine use and her involvement in a network of older male drug users powerfully communicated female participants' gendered experiences of drug use and risk. Rebecca's trajectory of problematic drug use was punctuated by multiple experiences of older male drug users exerting control over her drug-taking behaviour, experiences which began with her being introduced to a social network of male drug users as a teenager. Exposure to this new social network resulted in Rebecca unknowingly initiating methamphetamine use, and being confined within a profoundly negative drug using environment. As she proceeded in the telling of her story Rebecca described the social context of her drug taking as also contributing to her first time experience of intravenous drug use. When doing this Rebecca recounted that, because of her age and lack of drug-using experience, she was unaware of having lost agency over her drug-taking decisions, and she reflected on how this placed her at considerable risk: 
...so I ended up - we ended up in their - their house um, and I had my first shot, and I think the first one would have been morphine um, but I didn't even know what that was, at the time...You know, but ah, we were doing all these lines with this cocaine, and smoking heaps of weed...and it was fun - party time, and they're like, oh this will just - all it - it's actually safer and - you know, all this bullshit they gave me. I had no idea that you could even use injections, like you know, use syringes for drugs. I had fucken' not a clue.

I mean, this was literally just ongoing, ongoing, ongoing. Um, the negative - I remember there was a lot of um, sexual stuff going on. Like, that's base - basically I guess that's why we were allowed to be there... We weren't allowed - actually, we got kind of trapped in there, We had to lock our door - weren't allowed in the kitchen. Like, it was real-yeah, really dodgy, but I wouldn't let anyone know where I was. I - and I remember I called my dad at some point and said, no - no I'm fine - I just needed to get away coz I'm stressed, and all this crap.

...It was almost like - now that I think about it, it was almost like a joke for these guys. Like, they'd give us our shots first to see if we were okay and then they'd have theirs. So, I don't - you know, I knew nothing about drug-making until now, and I'm thinking, what they hell were they even mixing this stuff with?

(Interview ten, Rebecca, female 23 years)

Rebecca's ongoing involvement in this social network of male drug users culminated in her being told to engage in sex work in order to access money. When storying this experience she reflected on how difficult it was to reconcile the risks associated with her staying in this social network and continuing to use drugs, and finding the motivation to leave:

We were still so off our face that we actually - you know, they said we've got - you can go out on the streets, one of you. I was too scared to let my friend - my poor little friend go out, and I said, well I got us into this. So I did a night out on the street. I remember there was a - I - I felt somewhat safe, but not. Like, I was scared shitless. You know? It wasn't something I wanted to do, but I felt so much like, I have to do this now or something's going to happen to us. They had a gun. I didn't know they had guns. You know, and um, being 16, it's pretty scary, but the scariest thing I think about that was that I came back, I did - did three - I only actually slept with one of the people. I don't like going into that stuff, but three clients I needed to sleep with one of them. Other things were different. Um, but that night I got back and I was just in hysterics. 
...then they said, right the next day my friend...has to go, but the scariest things was as soon as we got back I'm like in hysterics trying to sleep, went and got some drinks, had a couple more shots. Then she was willing to go do it, and I was thinking, oh it wasn't actually that bad. You know, and that's quite scary, coz like that's something that really haunts me even now, was only one night on the streets. You know, it wasn't like what a lot of people do, but it's - yeah, scary that it breaks your morals like that.

The reason that we got out was not actually because we wanted to, which is really sad to admit. It's really hard to admit, coz I wish that I was brave enough to want to. You know, but um, it was because we wanted more fun time and that, and so we had to go home and get - ah, get different clothes and that, and um, luckily one of the girls - one of our friends that had come round to this house when we were there, and knew things weren't right - not that she knew exactly what we were doing, but had a clue, had told her parents. She was only about 14 or 15 - had told her parents, and um, so as soon as we got there, our parents were there waiting for us... Yeah, I was clean for a few years actually after that.

(Interview ten, Rebecca, female 23 years)

Other female participants described relationships and social settings involving male drug users which pointed to similar gendered experiences of exposure to environmental risks, often in the context of sexual relationships with older male drug users through participation in sex work, or in having an established relationship with a male gang member involved in the supply or manufacturing of methamphetamine. When storying these experiences female participants described their escalating use of methamphetamine in conjunction with managing the day to day realities of being vulnerable to experiences of physical, emotional, or sexual violence, to being subjected to arrest and imprisonment, and for the five participants who identified as being mothers, the risk of losing custody of their children through social service intervention. 
For Moana, the role of a profoundly negative relationship with her older male partner was described as contributing to her continued use of methamphetamine. Unlike the narrative positions emphasising autonomy adopted by male participants, the position in this narrative was the removal of autonomy through her partner's coercive behaviour:

I don't want to put all the blame on him, but I think a lot of it come from him pressuring me into doing it (meth) 'cause, he was...um, he just used to force it upon me, he would just feed it to me, like he'd come over to my place, we'd be sitting around you know, and he'd have it, like actually hold it in my mouth...'here, open your mouth'...I was like OK, I'd done it, and then, I'd get totally off my face.

(Interview three, Moana, 25 year old female)

As their use of methamphetamine progressed her partner then controlled their drug use by pressuring her to access meth:

....he'd be bringing it over for me and then he'll be asking me to find it for him, and then eventually it was me who was paying for it and then if I didn't find it then he would get angry with me and then he wouldn't see me....he'd kind of make me feel guilty for not getting it for him....for not supplying it..

(Interview three, Moana, 25 year old female)

That the social contexts of drug use and risk are gendered was further evidenced when Tania described the influence of a previous relationship with a partner who was a 'patched' gang member on her methamphetamine use, and her involvement in burglaries:

My ex, he used to yell at me and kind of...I don't know what the word is... he just kind of talked me into a lot of stuff, because when you are on $P$ (meth) and you smoke $P, I$ used to smoke a lot of $P$ with him, and I'd smoke the $P$, and then he'd kinda be in my ear telling me blah blah blah blah blah.... whatever he says just gets stuck in my mind kinda thing, so he used to like, amped me up quite a lot of the time to do stuff as well, um, and I remember the first burglary that I did, I didn't want to do it, and he made me do it, because I didn't want to get into that...

(Interview two, Tania, 21 year old female) 
Tania then went on to describe the utility of methamphetamine's effects in enabling her to participate as an associate in a male only gang environment. In this social context, increased energy, confidence and assertiveness induced through meth consumption enabled her to fulfil the behavioural expectations of being a gang associate:

When I wasn't on the drug I couldn't do certain things that other people could do...just like lots of crime...like burglaries, just like torturous crimes that all my friends do...

What do you mean by torturous crimes?

...basically I went around with the Mob taking them to drug dealers' houses and they'd stand them over with guns, and sometimes I'd torture them...um and I was doing shit like that with them.... I had to be as hard as them kinda thing, and when I had smoked P I didn't give a shit...

(Interview two, Tania, 21 year old female)

Describing her experiences of becoming involved in sex work, Rayleen identified entering a social network of methamphetamine users, where her drug use exposed her to the risk of male violence in the context of the methamphetamine economy. She noted these risks by differentiating between meth and heroin 'scenes':

...so there is a different (meth) scene than the heroin scene, because even though Heroin is expensive, too but it's not as expensive as meth, and there's a big difference. You can get killed over meth. You know?

Why is it easier to get killed over meth, do you think?

Money. All to do with money, because it's what you're selling, and I've sold it, too and you can see why. Shit, people tick that stuff up, and I can't understand why they would put themselves in that predicament, and knowing that if they don't pay it, you're going to be doubled and doubled, and then in the end, you know, thousands and what happens when you owe thousands; because the person you ticked it off, that's never the guy that owns the drug. (Laugher) that's just always the middle guy, and there's always the top guy who happens to be the big henchman guy, and if the money's not there, well yeah someone's going to get hurt.

That is scary.

Yeah, it is, and it - yeah, I've watched a lot of my friends being murdered because of it. 
....I've watched girls being murdered over it, on the street, because they owe thousands of dollars to a dealer, and then I - I always think, why take that much up?

(Interview eight, Rayleen, female 33 years)

For Kiri, a long-term intimate relationship with a male gang member provided the social context that facilitated her becoming involved in the manufacturing of methamphetamine as a 'cook', a role that afforded her a degree of status when compared to the experiences of male dominated drug scenes other female participants had described. When reflecting on this point in her trajectory of drug use Kiri pointed to how assumptions about gendered divisions of labour in conventional working environments similarly applied to her clandestine working environment:

... one of my partner's cousins owed him some money, and he couldn't pay it, but his cousin was a cook. He goes; oh you know, l'll show you how to make it. And then his bill was wiped. So he taught me how to make it, and it just went from there.

So, you made it as well?

Yeah. Yeah, and we had just - oh, coming out of our ears.

Wow, so being a cook must have been - because that's quite a status position. Especially for a female.

Yeah....although it was a bit scary as well, because um, yeah no-one knew I did it; they just presumed that my partner did it. So I - because I didn't want anyone to know; I didn't want to get kidnapped and you know, chucked in a boot and forced to make it somewhere, because that - that shit goes on.

Yeah. So, um it was really low-key. We kept that really quiet, but you know, my partner was organising everything, but I was actually doing all the - all of that, but that did scare me sometimes.

(Interview seventeen, Kiri, female, 50 years) 
At a later point in her story Kiri then reflected on being more resilient in managing the negative effects of methamphetamine than men, and that this advantage helped her in the context of meth production:

...did you have any kind of struggles with the symptoms - the psychological symptoms (of meth)?

I so didn't. You know? I don't know why, but I think from my experience, I think that males - um, they lose it, and I think it might be in the make-up of a male. I don't know, but females just seem to be able to keep it together. Yeah, but I - I saw a lot of males just lose their marbles. Yeah, just - I don't know why; they just - they can't handle the come-down - not there was ever was one, because we never ran out. Yeah, so...

It didn't scare you then, watching them go through some of those experiences?

Not really, because all the females I knew that were smoking a lot; they just weren't like that. It was only - just seemed to be the men. Yeah, I don't know - maybe now, thinking back, but at the time it was just smoke, stay awake and get the work done, because you know, we couldn't even keep up with the workload. There were so many people wanted it. You know?

(Interview seventeen, Kiri, female, 50 years)

Due to her involvement in manufacturing methamphetamine Kiri was eventually subject to a ten year imprisonment term, of which she completed 8 years. This resulted in her being separated from her 9 year old son, who was 18 years old at the time of her release. When storying this experience, Kiri reflected on her becoming entrenched in the world of meth production and the imprisonment which followed as being both a consequence of her intimate relationship, and a means of disassociating herself from the influence her partner and continued involvement in methamphetamine use:

...So, we got, you know, we got caught um, and five years later - been doing it for five years, and then you know, we got busted. Um, my partner got 12 years, I got 10, and - you know, because they wanted to make an example of us. Um, so I did eight of that 10 years - got out two years ago.

Um, you know, oh when I think back I just don't know how I did it - how. It got to the point where I wanted to get caught. I just wanted it to end, you know and my partner was dominant. He went nuts. He was like - I was like, I don't want to do it anymore. He goes, well you're just fucken 
doing it. You know? I didn't have a say. I just had to keep doing whatever, and then so when we got caught it was a big relief - big relief.

...I did the drug treatment unit, did a six month drug program; that's the best thing I've ever done. Actually, going to jail was the best thing that's ever happened to me.... I mean, that was all over. The manufacturing was over. I was able to get away from my partner.

So...when you reflect on that, he sounds like someone who was a strong influence in... Oh, he was just a bastard. There's just no other way to put it. Yeah, he was a right bastard. He um, controlled everyone. He was the ring-leader. He had like, another seven people working under him. You know; we did all the work, so - he gets out next week actually. This is great stuff but link it back to the theory at the beginning - structural constraints, gender and so $n$ and how these are important in the production of risk environments.

Is that worrying for you?

Nah. No, I used to be scared of him, but l just refuse to be now. You know?

(Interview seventeen, Kiri, female 50 years)

Debbie described significant experiences of domestic and gang related violence in the context of having an intimate relationship with a male gang member, also involved in the supply of drugs. In common with other female participants, Debbie's story was illustrative of intimate relationships with older males that were conducive to escalating methamphetamine use, and which eventually resulted in social service interventions and the severing of relationships with her children:

Dad was aware, because I was in CYFS - my kids had to have - about 14 months ago my son got taken off me because me and my partner, to this day, we were selling tinnies, and smoking crack heavily, because we could afford it. Part of the reason why my son got taken; we were apparently manufacturing it and supplying it, which we weren't, but that was the notification that was put in, because people were jealous of me, because I had a good thing. My partner's a gang member as well, so...

Your new partner? 
Yeah. Then we had the baby, and I smoked it all through my pregnancy - not proud of it. People were just jealous because I had a good thing going for me, and we could afford it, and sort of sell it, make our money back off it - yeah.

(Interview fifteen, Debbie, female, 26 years)

As Debbie proceed in telling her story, she identified being subject to violence in the course of her relationship during a period of heavy methamphetamine use, as well as being subject to violence from her partner's family. When doing this she also highlighted the realities of negotiating childcare responsibilities alongside her daily use of methamphetamine:

That must have been a hard time then?

Yeah, lots of hidings, with coming down with him. Lots of hidings - silent treatment - lots of it, yeah.

...Yeah, and that was the most trouble l've been in. My dad was like; you've got to get away.

He's the same age as you or older?

No, a lot older...45 now.

How did you manage being a mum amidst all of this?

Sleepless nights; I didn't have them. I didn't have them, but when I was tired I did fuck up a few times and I'd be so tired I couldn't wake. One morning I was feeding my baby and next minute I'm asleep and the baby bottle's still in my hand. That's the things I regret till now. I'd be that tired; I'd been up for two or three days and I'd just black out, because I was so tired.

At this time, was there any other family involvement?

His brothers.

...Two of them beat me up, because me and (my partner) had our kafuffles and they were on it (meth), too. They still are. I just had to get away, because they would think I had to answer to them as well as my partner. So it felt like I was having a relationship with all of them.

(Interview fifteen, Debbie, female, 26 years) 
Comparatively, Amy articulated a very different relationship experience which communicated her being able to exercise a degree of agency over her use of drugs by using her partner to fund her drug dependency. In the context of a past relationship Amy described herself as being in a position of power, where her partner provided childcare and was subjected to her negative drug-taking behaviour:

... I would lie to my partner, I would go missing for three or four days because I was driving out of town and going to my motels with my cousin, and then getting fried out of our heads and having a great time, and then reality would come back and l'd have to go back into life, and probably get a hiding from my boyfriend that was there with baby, and he had to go to work.

He was really placid. I was the boss. I'm going to feel horrible saying this, but he was just a straight Māori boy - drinker and stoner. I was the, fuck you - I'm going to go and get high on all these cool drugs, and you can stay home, and when I come home - yeah. Actually, that caused a lot of fights, because he was really probably jealous, felt belittled because here we are hanging out with these big time drug dealers, and you sit home.

How did (the relationship) end up?

As years went on, I would use his work money. It was supposed to be paying bills and the rent, and I ended up buying grams, and trying to sell it for money for the family. It would never work, because there was a competition going on between me and him - not a competition but who's in charge of that, because he had to go to work - here I am at home dealing drugs and obviously it was a dream of his, too - not a dream, but being a drug dealer was not - I kind of think cool in the status of the world - you know what I mean?.... and there was like a power struggle between me and him. So he'd have a try, and I'd love when it failed miserably but then I'd have to go pick up all the pieces....

(Interview nine, Amy, female, 33 years)

However, describing a more recent intimate relationship, Amy pointed to risk experiences that were shared by other female participants, whereby her partner's position of status within her social network of gang affiliates had resulted in her becoming dependant on the resources for drug use her partner provided:

Yeah. By then I had got another boyfriend, which he was another runner. 
(Was this a)...similar kind of relationship? You mentioned before that you were probably in the power position with your boyfriend?

I would so not have a say in this one. I sort of surrendered - succumbed to him. What was I doing? Yeah, it was just - I don't know the word to explain it. ..Yeah, it was a bit different because he was higher than these two; he had more respect in the community. Yeah that's why l'd do whatever he said, and I was happy with it.

(Interview nine, Amy, female, 33 years)

Amy's use of methamphetamine escalated in the context of this intimate relationship, which impacted on her ability to care for her children, exposing her to the risk of social service intervention and eventually losing custody of her children:

...He'd just got out of jail. It was just horrible - there was no domestic violence - it was just emotional; I wasn't there emotionally there for my kids, because I was too busy worrying about him and me, and smoking $P$ and going out of town and all that sort of shit - chucking the kids you know - yeah you can have the kids for a couple of nights because I'm going out of town. They didn't like that, so my mum went to CYFS and told them I'm smoking P. So that's how that came out. I admitted it, which I was told by everyone that uses $P$, whatever you do - don't admit using $P$, because that's when they've got ya; but I did.

...Then what happened after that?

I continued to use the P. I got my two kids taken off me eight months ago. I agreed for them to go to family.

(Interview nine, Amy, female, 33 years)

In contrast to the prominence of profoundly negative intimate relationship experiences in the stories articulated by female participants, male participants storied very different relationship experiences. For male participants, intimate relationships with female partners who also used drugs had not been identified as exposing them to risk, or identified as factors which had contributed to their becoming more involved in harmful drug-taking behaviour. Instead, references to relationships with female partners was 
confined to their having a positive influence on decisions about drug use. As Ben demonstrated when reflecting on his drug use during his relationship with his girlfriend:

She was a little bit younger than me and she was just coming out of college...and um...yeah so the marijuana was enough for her...even when the magic mushrooms came around she wasn't really interested, and in a way she kind of helped me keep slightly balanced which is hard to do when you're on the drugs you know what I mean?

How would she keep you slightly balanced?

...she would notice when I was going a bit too hard and she might say well lets go for a drive and see this person...pull me out of the situations. When we were at home we would only smoke in the evenings because she didn't want her parents knowing and that sort of stuff. She had rules that she made me adhere to and I have to admit I enjoyed those rules 'cause, you know, again it helped me to feel balanced...

(Interview four, Ben, 31 year old male)

For male participants, exposure to socially situated risks was more typically associated with their day to day participation in drug manufacture and supply: For example, Sean articulated a loss of agency over his decisions about using and supplying drugs by identifying himself as being vulnerable due to being younger, and physically small in stature. He identified these factors as contributing to being pressured to sell drugs, a role which exposed him to the risk of drug related violence and the potential for arrest. This acknowledgement was unique compared to other male participants, none of who described drug-related risks as resulting from a subordinate position within their social networks:

...I sold drugs for people as well. Um, you know, um at certain points um, you know? I'm not a big guy. I'm not a tough guy, you know, but tough guys see people like me, you know, and go, well I can use him to sell drugs, and I mean it worked both ways. You know? I got to sell drugs and I got a lot of free drugs...

...A lot of the time I was pushed into it. It - it wasn't a want or a need. It was - pushed into it. You know? I never liked it - never enjoyed it. Um... 
When you - you describe it as being pushed into it. So...what do you mean by being pushed into it?

Um, people - people hustle with drugs, eh and they see someone that might be weak or vulnerable, and that's who they go for. You know? They do. Um, you know, I've gotten a lot harder and um, smarter over the years through drug-use, but that's only because I've had to, to survive. You know? Um, you get used by people and um, you know, I never um - I never enjoyed the fear of like, you know um, getting busted or something like that. You know?

(Interview eleven, Sean, male, 33 years)

For Angus, the potential of being subject to violence similarly occurred through involvement drug manufacturing and supply. His story signposted how males were exposed to risk in the context of gang life:

The old man had gone down to set up a glass business down there, one time in Christchurch, and that was towards the end of it, and I was in debt, and stuff like that. I'd had this threat that basically a gang from Auckland who I'd been doing deals with some of the product to make it, weren't happy with the product they got back. So they'd given me a chemical, and in payment they were going to get some of the cook. They weren't happy with it, and I said, well fuck - what do you want me to do? Anyway, they'd found out where my old man - what hotel he'd been staying at, and shit like that, and said, oh well we'll go and see him, then. I was like, fuck. So I had to come clean with him and tell him to get out of his hotel. He ended up giving me $\$ 10,000$ and paying the debt.

(Interview seven, Angus, male 33 years)

The realities of being subject to gang related coercion and violence was also acknowledged by Terry, whose life experiences as a patched gang member pointed to the role of violence in gang life. At different points in his story Terry identified how violence had impacted on his trajectory of drug use, which included his own use of violence and being convicted for threatening to kill people. At the time of his interview his brother had been subject to a serious assault, which he also identified as being gang related: 
...you've made mention that your brother had been involved in a reprisal...

Yes...I didn't like to see him lying in the hospital bed. Um, I didn't like to see him lying on the hospital bed with tubes. He's got a tube in his throat, and I didn't like that. So that's - yeah.

(Interview fourteen, Terry, male, 40 years)

Matthew identified a different type of risk exposure when describing a negative relationship with his step-father who was a local policeman. His step father's awareness of his drug use had resulted in Matthew being subject to arrest and ongoing police attention in his local community:

Yeah, my step-dad; he arrested me once and he found some drugs on me.

...One time in town I was with my friends, and he just came up to me, like grabbed - he was in his uniform. He was with another police officer, and he just grabbed me, got me in an arm lock, marched me across the street and slammed me into a tree and started shouting at me, and then I just - I was ignoring him - can't remember any of what he was saying. I was pretty high off my face, but yeah definitely unlawful what they were doing, these cops in uniform, as a personal situation he was trying to use in his uniform.

....There's nothing you really can do, because you go to the cops - they're all his mates, and - yeah.

(Interview sixteen, Matthew, male, 18 years)

The relationships with partners and social networks identified as facilitating entry to the world of drugs and functioning within it illuminated the inseparability of participants' drug taking decisions from gendered ideologies structuring the social and economic organisation of illicit drug use (Bourgois:2004, Anderson:2005, Griffin and Rodriguez:2011). As such, the social relations and connections that constituted the drug scenes they occupied highlighted both their own and their families' exposure to profoundly gendered experiences of risk exacerbated by their vulnerable legal status as users, suppliers and manufacturers of illicit drugs (Bourgois: 2004, Mandler: 2016). 
Male participants' stories of relationships with drug-using male peers, and social connectedness with male dominated social networks such as gangs, had occurred in the wider context of drug scenes they described as being populated by other men involved in drug use, manufacturing and supply. Of note was that seven of the nine male participants interviewed (Terry, Angus, Ben, Sean, Matthew, Steve and John) were either heavily involved in drug dealing, or residing with drug dealers. Although their importance was acknowledged, relationships with women had not been described by male participants as being connected to the world of drug-dealing. Instead, women occupied roles in their stories as the mothers of their children, as girlfriends, sex workers, or as immediate or extended family members. Thus, the socially situated risk experiences that male participants described in many ways accorded with the dominant motif in ethnographic drugs scholarship, that illicit drug economies and 'street level' drug-using scenes are traditionally male dominated environments, where males are acknowledged as being more likely to exercise control over drug production and distribution resources (Bourgois:2004, Grundetjern and Sandberg:2012).

Within this male world of drugs, men have also been identified as displaying "a particular form of masculinity when they manoeuvre in the market", which, at street level, "is characterised by both hyper-masculinity and hyper-sexuality" (Grundetjern and Sandberg: 2012:624). In reference to men participating in drug economies as dealers, violence is also identified as fundamental to masculine role expectations, as Mullins (2006:152) summarises:

"Building a reputation for violence is seen as an integral part of drug dealing - to gain respect, deter attacks and punish people, especially when they have not paid their debts to the dealer. Moreover, displaying a violent attitude is the most common way to 'do gender' and thus be seen as 'a man' (Mullins, 2006: 152)." 
To what extent the males interviewed understood themselves and their behaviours in relation to this narrative of dominance and control was in many respects constrained by my not having asked specific questions about how they viewed their actions within the world of drugs as men (Anderson:2005). However, one reading of their experiences would be that, at various points in their drug journeys social connectedness with drug dealing peers and successful participation in the manufacturing and distribution of drugs had provided significant "masculine capital", elevating their status within networks of drug users (Mullins:2006:20). This was particularly evident in Terry and Angus's stories of gang involvement and drug dealing, both of who communicated a sense of valuing their ability to successfully manufacture and sell large quantities of drugs and therefore control the resources they needed to continue using methamphetamine, unlike the drug users who were dependant on their drug dealing efforts.

Another reading is that the ready supply of methamphetamine which accompanied their successful participation within these drug scenes had facilitated escalating problematic drug use. The impact of this eventually constrained their ability to successfully engage in the supply of drugs while managing their drug addiction. In this context, Terry and Angus were subject to a confluence of risk factors, where the need to use methamphetamine daily required full time participation in illegal economic activities. These factors exacerbated their exposure to the risk of drug-related violence and the threat of incarceration, as well as individualised health risks associated with their ongoing heavy use of methamphetamine.

These experiences signposted how they understood their changing structural position and status within drug and gang related social networks, which corresponded with constraints over their ability to exercise power within the world of drugs; for Sean this translated into communicating his understanding of being manipulated by older male drug users as he became increasingly involved in selling drugs to fund his addiction to methamphetamine. For Angus, funding his daily methamphetamine use had occurred alongside the increasing demands of functioning as a gang associate tasked with 
distributing drugs, which in turn subjected him to the threat of gang related violence and intimidation. During the pilot study Ben had also pointed to similar themes when describing his becoming exposed to gang-related violence, an experience he understood as signalling a loss of control over the risks associated with his increasing involvement in drug use and drug related crime.

Although male participants had referenced drug-using females in the context of their own drug use, notably in relation to the positive impact that partners had in moderating their drug taking, female involvement in drug scenes was largely invisible within the confines of their stories about starting and using methamphetamine. However, for female participants, storying their drug-using journeys had asserted their presence in, and contribution to, drug scenes enmeshed with their intimate relationships with men. In doing so they revealed the complexities of their position within the narrative of dominance and social control that presents female drug users as subjugated within the 'male world' of drugs, and which consistently emphasises "themes of dysfunction, dependence, exploitation and victimisation" (Anderson: 2005:393).

All of the female drug users in this sample had storied how their relationships with male partners, family members and associates had facilitated their direct or indirect participation in the wider context of the illicit drug economy as sex workers, meth cooks, drug dealers, and 'shoppers' ${ }^{66}$. In performing these roles female participants' navigated their problematic use of drugs alongside relationships that exposed them to coercive behaviour, physical and sexual violence, and forced participation in drug-taking and sex work. Inarguably, these experiences aligned with many of the themes within the subordination narrative that is central to female drugs research, as well as research

\footnotetext{
66 'Shoppers' can refer to either stealing precursors or preparing chemicals for the cooking methamphetamine, or stealing to order from retail stores.
} 
examining women's experiences of risk and crime in relation to prevailing gendered power disparities (Chan and Rigakos:2002).

One reading of the risk experiences female participants articulated is that intimate and peer relationships with male drug users and the connectivity of those relationships to the drug scenes they participated in had exacerbated risks associated with their problematic use of methamphetamine. Their stories aligned with other qualitative research efforts exploring female drug use, which highlight that women are exposed to "multiple levels of vulnerability" when navigating the day to day realities of problematic drug use (McKenna: 2014:115):

When using drugs in the context of an intimate relationship, women are often dependent on intimate partners for assistance with injecting or smoking processes, which gives men control over the timing of drug use, limiting women's access to drugs, and increasing the risks associated with drug ingestion (Carbone-Lopez et al:2012, McKenna: 2014:113, Mayock et al:2015, Gibson 2016)). These experiences were evidenced by Rebecca's story of being used by males in her social network to 'test shots' before they would inject themselves, and was also evidenced during the pilot study by Moana when describing her boyfriend pressuring her to smoke methamphetamine. Women are also often confined to exchanging for drugs "the most saleable commodity they have - their bodies" (Joe: 1995:271), a theme universally acknowledged in scholarship exploring female drug users' experiences of problematic drug use (Bourgois:2004; Jenkot:2008) For example, in Kerley et al.'s (2014:486) evaluation of female methamphetamine use, participants described using their "feminine wiles" to acquire methamphetamine, but noted that this typically necessitated exchanging sex, as one respondent illustrated:

"You know, if you smile right, you'll get what you want anyways. It's just how you carry yourself with a man...You don't even have to buy or purchase. All you have to do is sit down and smile. And then they'll give it to you...Sex was always involved. That's just how it is." 
Mckenna (2014:113) argues that because of the power disparities inherent in the gendered organisation of drug economies women are led to engage in risky sexual practices. This requires women who have limited access to money to provide sex in exchange for drugs, and to navigate cultural norms and power dynamics in negotiations of trust, "making condom use uncommon in long-term and romantic relationships." For example, in Lamonica and Boeri's (2015:105) evaluation of risk behaviours among suburban women who use methamphetamine, participants' described engaging in the exchange of sex for methamphetamine, which for some users had facilitated entry into fulltime sex work. When doing this participants identified that "negotiating condom use was very difficult when they were with a person who had the drug they desired". This experience exposed women to significant sexual health risks in settings far removed from the harm reduction efforts and resources offered by social services.

Given the gendered constraints governing my own research efforts, questions about the nature of health risks in sex work or the dynamics of sexual relationships with male partners were not asked in the course of interviewing female participants. However, Jess, Moana, Rebecca and Rayleen had all signposted experiences which suggested there was a relationship between their engagement in sex work and their needing money to fund their use of drugs. Additionally, in contrast to the risks associated with the economic activities of male participants, the risks female participants associated with sex work also emphasised that transactional sex perpetuates female drug users' structural vulnerability (McKenna:2014). This was demonstrated by Rayleen when storying her experiences of exchanging sex for methamphetamine in order to avoid the violence associated with becoming financially indebted to male drug dealers. During their interviews Moana and Jess had also demonstrated, through their wanting to avoid disclosing their involvement in sex work, how female drug users are forced to navigate and resist stigmatised identities propagated within discourses storying deviant women's 'fall from grace' (Anderson:2005:374). 
That female drug users are subject to structural vulnerabilities which differ to those experienced by men was perhaps most evident in relation to participants' roles as mothers. For Rayleen, Amy, Rebecca, Debbie and Kirri, managing the realities of drug dependence had occurred alongside the daily demands of childcare expected of them in the context of relationships with fathers who were equally drug dependant. Their methamphetamine use had eventually compromised their ability to function as the sole providers of childcare, which in turn exposed them to the risk of social service intervention and the trauma of separation from their children. As Haight et al. (2009) have argued mothers who are meth-dependent are required to navigate risks which are inseparable from gendered role expectations. Despite being drug dependent, female drug users who are mothers are acutely aware of how their use of drugs negatively impacts their ability to parent, and that in the context of their relationships with other meth users their children are exposed to physical danger, domestic violence, problematic family relationships and exposure to adult substance abuse. Moreover, engagement with social services and the loss of parental rights which follows invariably subjects them to stigmatising discourses that absent fathers avoid. As Haight et al. (2009) reiterate, substance use in general - but especially the use of methamphetamine, is highly stigmatising for women as it is "strongly dissonant with cultural ideals of femininity and motherhood" (ibid: 71).

Despite the agential constraints female participants' negotiated within the assemblage of intimate and peer relationships they described having with male drug users, storying their active involvement in drug scenes had at the same time communicated the complexities of gendered power and control within drug economies. To suggest that these drug users were confined to a static, and unwaveringly subordinate role in the world of drugs obscures a more "gender-intertwined reality", whereby the roles and undertakings of male and female drug users "are interdependent and facilitate the drug world's existence" (Anderson, 2005:373). 
An alternative reading of female participants' relationship experiences is one that accords with what McKenna (2014:113) describes as engagement in a moral economy of drug use, whereby female problematic drug users navigate high risk environments by embedding themselves in complex moral economies. She argues that participation in these high-risk environments requires female drug users to rely on systems of reciprocity that are based on mutually understood expectations for the sharing of resources such as drugs, housing, childcare, money and access to sex, and the provision of social support and protection. In this context, male participation in drug-related economic activities is therefore mutually dependent on the economic benefits that women provide by managing households where drug-related activities often take place, and by raising children to compensate for the absence of drug using or incarcerated fathers (Anderson:2005, Griffin and Rodriguez:2011). Anderson (2005:392) adds that, although women are disproportionately subject to stigmatising discourses, their identities as mothers can at the same time anchor female drug users to mainstream society, providing a source of empowerment outside of drugs. In contrast, because males involved in drug use and distribution are less likely to be involved in parenting or engage in the secondary labour market, they have limited means of empowerment outside of illicit drug economies.

Female participants' also storied experiences which evidenced their having the ability to exercise agency by making a significant economic contribution to the male enterprise of illicit drug use as sex workers, and as active participants' in the selling and manufacturing of drugs. In reference to sex work Anderson argues that, rather than symbolising subjugation in the male world of drugs, sex work can be viewed instead as empowering; it generates a stable source of revenue due to the consistent commercial demand for sex, which results in men transferring financial capital to women. This in turn sees women who are sex workers and who are also drug users transferring financial capital to male drug dealers when they purchase drugs for themselves, and often for their addicted male partners (Anderson:2004:383). 
Similarly, a contrasting view of female drug users who participate in drug dealing is that women are often more able to continue generating drug-related income, a point evidenced in Kiri's story of being skilled in 'cooking' methamphetamine, and being more able to cope than her male partner with the demands of 'cooking' while managing the effects of heavy methamphetamine use. That women who use methamphetamine are more capable of managing the dual demands of drug dealing and drug dependency is also evidenced in Joe's $(1995: 287,288)$ exploration of male and female methamphetamine use. Of note in her study is that men's escalating use of methamphetamine undermined their ability to function both sexually and economically, as she summarises when noting the differences in how males respond to their problematic use of meth when in relationships with women:

"...women handle it much better and make it work for them instead of work on them like men. Many men begin to feel their masculinity slipping away with their extended use, and consequently are more likely than women to act on their irritability and paranoia by resorting to 'domestics and beefs'. For these men, violence and intimidation are among the few resources left for demonstrating their manhood."

\section{Conclusion}

The experiences of social relationships, drug use and risk articulated in this chapter draw attention to a divergence between views of risk: public health initiatives remain anchored to the pharmacological notion that risk is inherent to a chemical and thus singularly focus on helping individuals make 'healthy' choices (Ivsins et al:2013, Mandler:2016). This point is illustrated by a current New Zealand Drug Policy document (Inter-Agency Committee on Drugs:2015:5), which advises that, reducing alcohol and drug related harm caused by those who use drugs requires "shifting thinking and behaviour" by making sure that "people have the knowledge and skill and support to make good decisions about their AOD (alcohol or drug) use".

Understanding the often profoundly negative experiences of problematic drug use storied by these drug users as occurring within risk environments provides a competing view of risk, where drug users navigate the lived experience of drug use in concert with 
a multiplicity of environmental risks (Ivsins et al:2013). Within these environments risk knowledge is socially situated and not "wholly individualised" (Williams: 2013:89). Instead decisions about using drugs and the social meanings of risk attached to the lived experience of drug dependency were shaped by the social relations, connections and assemblages structuring the environments these drug users occupied. Within these risk environments, decision-making is subject to the very nature of these relationships, and seldom involves reflexive assessment (Williams: 2013). The "flow and pace" of experience within problematic drug scenes is also unlikely to permit, or accommodate, "reasoned choice-making" (Mayock: 2004:363).

When describing the gendered social and economic realities of engaging in drug use as gang members, sex workers and drug dealers, these female drug users articulated experiences which communicated their navigation of high risk environments characterised by gendered vulnerability to physical, sexual, and emotional violence, and to the threats of social service intervention and arrest. This required participants to become embedded within complex moral economies, in which the social relationships that facilitated survival hindered their ability to manage their escalating use of methamphetamine and other drugs in ways suggested by the harm reduction ethos (McKenna:2014:113).

More broadly, in taking a risk environment approach to theoretically engage with these drug users' experiences of drug taking, a more comprehensive account of problematic drug use is provided. This helps in redressing individualised conceptions of risk which do not adequately capture the complex nature of risk taking, and therefore neglect to account for the constraints on volitional action these drug users' highlighted as structuring their 'risky' drug-taking behaviour (Mayock:2005). Acknowledging drug users' vulnerability to structural realities thus demonstrates that decisions about starting, using and stopping drug use are not always "the outcome of individual resolve" (Williams: 2013:90). This has wider implications in thinking about how risk operates, as 
well as the nature, form and ideology of interventions currently designed to delay entry into drug use (Mayock:2005). 


\section{Chapter six: narratives of desistance from drug use}

\section{Introduction}

This chapter further advances the theoretical debates developed throughout this thesis by examining the socially situated decision making processes which underpinned experiences of desisting from drug use. The stories which follow reveal the 'how's and whys' of stopping drug use as it was narrated by participants who identified as not using drugs at the time they were interviewed, and in doing so communicate the experience of moving from intensive periods of harmful and often uncontrollable drug use to eventual engagement in the process of desistance.

Shifting in theoretical focus, this chapter draws upon life course perspectives of offending behaviour advanced in the work of Sampson and Laub (2005). Their conceptualisation of desistance as a process which alters trajectories of drug use through the ongoing accumulation of positive social capital and long-term identity transformation is applied in analysing two sets of narratives: The first focuses on the experience of desistance storied as the process of recovery, by participants who were engaging in a residential therapeutic environment at the time they were interviewed. Here analysis focuses on the influence of therapeutic discourses in helping participants make sense of past drug-taking behaviours, placing theoretical emphasis on the role of 'turning points' in altering trajectories of drug use and initiating decisions about changing drug-using behaviour. The second focuses on the process of desistance as it had been experienced prior to, and beyond, the confines of clinical settings and methadone treatment programmes, highlighting the linkages between individualised experiences of desistance, and the meso-structural realities which had facilitated and constrained participants motivations for moderating, temporarily desisting, or abstaining from drug-taking behaviour. 
Collectively these desistance narratives reveal themes which allow for multiple readings of participants' experiences of stopping the use of methamphetamine and other drugs. They demonstrate how transitions involving prolonged periods of problematic drug use had exposed participants to unmanageable and unavoidable drug-related harms which culminated in different crisis points and significant life events. The impact of these crisis points and events opened multiple pathways to desistance across the life course by disrupting social relationships, connections and assemblages that facilitated past drugusing behaviour. The identity transformations which intersected the process of desistance were also storied in ways that signposted variations in how participants storied understandings of themselves through the narrative incorporation of therapeutic discourses about addiction and recovery, and by communicating a trajectory of ongoing identity and desistance navigation in the wake of legal interventions, the loss of access to children, negative relationships with intimate partners, managing therapeutic drug regimens, and their needing to re-enter and live within social networks connected to past drug-using scenes.

The stories presented here reveal, that decisions about stopping drug use require engagement in an ongoing process, where individuals must disentangle themselves from past drug using identities, and build a renewed sense of self in the face of powerful countervailing forces (Martin:2011). These stories help in developing previous theoretical assertions, by demonstrating that, like starting and using drugs, decisions about stopping drug use are social rather than individual accomplishments, which result through the interplay between social systems and structural realities across the life course (Hser, Longshore and Anglin:2007). 


\section{Turning points and desistance from drug use}

Although participants' who storied experiences of stopping drug use had described very similar patterns of drug use, desistance from drug taking had occurred at different points and in different ways in their drug-using biographies. For some participants, desistance from drug use had been preceded by an accumulation of harms resulting from a prolonged period of daily drug use, which for most had lasted several years, and which had typically subsumed all other life projects. For others, desistance had been preceded by periods of stopping and starting drug use at various points in their drug-using journeys, and which had similarly been influenced by their lives being subsumed by the effects of their ongoing problematic drug use and drug dependency.

As they storied these experiences and reflected on their decision making, each participant highlighted periods of heavy and often chaotic drug use by describing their diminishing ability to cope with an array of drug-related harms; these included being unable to financially support themselves as a result of their drug addiction, being subject to the impact of drug-related health complications, experiencing increasing involvement in the criminal justice system, losing access to children through legal interventions, being disconnected from family members, and being subjected to dysfunctional, and often traumatic, social relationships. Participants' highlighted these life experiences as factors they understood as influencing their drug use in different ways, and pointed to how a particular life event, or sequence of life events had been proceeded by changes in their drug taking behaviour.

By drawing upon understandings of life course dynamics and desistance from crime advanced in the work of Sampson and Laub (2003, 2005), it was evident these events demarcated experiences of 'turning points' in participants' trajectories of problematic drug use. As Sampson and Laub (2005:16) conceptualise, turning points can be understood as events or experiences which alter a long-term pathway or trajectory that had been initiated at an earlier point in a person's life course. The outcome of a turning 
point event can increase or decrease an individual's propensity to engage in criminal behaviour, such as drug use. In developing this theoretical approach, Sampson and Laub (2003) have argued that most offenders will inevitably desist from offending behaviour when confronted with structurally induced turning points, the impact of which can initiate a process which sustains their ability maintain long-term behavioural changes.

Importantly, Sampson and Laub (2005) identify structurally induced turning points as being initiated by the accumulation of positive social capital as individual's transition into meaningful employment, marriage, parenthood and other adult roles, which serve as pathways to change by opening up the possibility for

“...(1) a knifing off of the past from the present, (2) opportunities for the investment in new relationships that offer social support, growth and new social networks, (3) forms of direct and indirect supervision and monitoring of behaviour, (4) structured routines that centre more on family life and less on unstructured time with peers, and (5) situations that provide an opportunity for identity transformation and that allow for the emergence of a new self or script (Sampson and Laub: 2005:34)."

There are of course caveats when applying Sampson and Laub's (2003) theoretical constructs to examine the turning points described by the participants in this thesis, given that most had not yet had any opportunity to accumulate positive social capital in the form of employment or positive social relationships. For many, experiences of ongoing structural disadvantage would also likely hinder this process in the future. This was indicative of the sampling constraints identified in chapter three, which have resulted in confining the turning points and experiences of stopping drug use that followed, to the lived realities of problematic poly-drug use, drug addiction and their attendant harms. 
Eleven of the participants' were also currently engaging in, or had recently been in contact with a therapeutic environment or treatment programme at the time they were interviewed, and this had resulted in desistance narratives incorporating therapeutic understandings' of drug 'addiction' and 'recovery'. As such, participants' communicated events which had culminated in what read as being discursively similar, and invariably negative turning point experiences, rather than signposting the types of maturation experiences Sampson and Laub (2003) correlate with inhibiting motivations for offending. However, as Hser et al. (2007:521) point out, turning points which lead to desistance are often equally triggered by negative life experiences, such as prolonged incarceration, job insecurity, and, as the narratives explored here demonstrate, periods of prolonged heavy drinking and drug use.

This is also evidenced in scholarship which examines both positive and negative experiences underpinning desistance from drug use. For example, Jessup et al. (2014:450) identify in their longitudinal study of AOD outpatients that, in addition to positive roles such as parenting, death and near death experiences were also turning points that had led to drug users making a conscious decision to reduce and abstain from drug use, and which supported their recovery process. Liebregts et al. (2014:27) similarly note in their sample of heavy cannabis users, that desistance had been frequently initiated by turning points involving users experiencing acute negative effects, such as psychosis and respiratory problems.

These constraints aside, Sampson and Laub's $(2003,2005)$ work usefully foregrounds the analysis of participants' stories about stopping drug use by providing a view of desistance from offending as involving a process which occurs over time, rather than being the result of a single decision as proponents of rational choice theories have emphasised (Sampson and Laub: 2003, 2005). This allows for thinking about stopping drug use as a process where individuals 'drift' towards desistance from drug-taking behaviour, and which involves cycles of progression, relapse and remission as clinical 
discourses about addiction reiterate, instead of simply demarcating an absolute biographical end point where all offending stops (Carlsson: 2012, Leibregts et al. 2015:617).

Importantly, the stories of these drug users also introduce themes which allow for thinking about the theoretical utility of applying life course perspectives of desistance to the experience of stopping problematic drug use. They help in developing an account of how turning point experiences influence pathways to stopping drug use. This asserts the theoretical importance of macro-level structures and meso-level influences which Rhodes' (2002) also emphasises, but retains sufficient room to account for explanations of individual agency (Farrall et al. 2011:218, Carlsson: 2012). As Hsr et al. (2007:521) explain, the concept of turning points from a time-varying view of critical life events advanced by Sampson and Laub contributes to broader theoretical debates about drug use by stressing

“...the importance of human agency (or so called personal choice) in the development of criminal behaviour and envisioned development as the constant interaction between individuals and their environments, suggesting the notion of 'situated choice', in which the individual agency and structural location within society are inter-related. In other words, what happens in one's life is not all personal choice, nor is it all institutional options."

\section{Desistance, identity and treatment for addiction}

Of the 14 participants who were not using drugs at the time they were interviewed, 8 were attending the Bridge Programme. This sampling outcome produced stories which communicated common experiences, many of which accorded with popular addiction tropes and reiterated the influence of therapeutic self-assessments. However, the storying of desistance they revealed allowed for multiple readings of the experience. Participants engaged in this residential treatment setting highlighted differences in the ways they reflected on past decisions about changing their drug-taking behaviour. These decisions had occurred in the wake of turning points induced by personal crises, and in 
their responding to escalating environmental harms resulting from the use of methamphetamine and other drugs:

Sean's story highlighted the patterning of prolonged heavy drug use that other participants' had similarly recounted prior to turning points. He described using large quantities of methamphetamine daily throughout most of his adult life, during which he also managed the demands of his employment as a chef. As his trajectory of methamphetamine use continued unabated, Sean's ability to function at work had eventually become unsustainable, and after a prolonged period of sleep deprivation, he collapsed while working:

...what kind of impact did (methamphetamine) have on your work?

They didn't fire me, because I was a hard worker. You know? They tried to help me, actually which I take my hat off to them. You know? They did the best they could... There were times where I could have worked better, but you know, l'd been up for days. You know? Imagine looking through my eyes if you've been up for five days, mate or something. You know? It's fucking horrific. You know? Lucky l've got a strong mind, in some ways. You know? Um...

(Interview eleven, Sean, male, 33 years)

Later on in his story Sean identified this event as a turning point which had prompted a moment of self-reflection and his awareness of having lost control over his use of methamphetamine. Although his collapse at work initiated a series of unsuccessful attempts to seek help for his drug addiction, after a prolonged period of drug use Sean was able to self-refer himself to the Bridge Programme and move to Wellington. When noting this Sean drew upon broader cultural understandings of desistance from drug use as requiring users to 'hit rock bottom' when referencing his own perception of the desistance process. Reflecting on the time it had taken to stop using drugs, he communicated this by describing the experience of being subsumed by the effects of 
methamphetamine, and inevitably needing to reach a point where he could no longer cope before he was able to change his behaviour:

Ah, well I mean the first time I sort of realised I had a problem and I collapsed at work. You know? My family tried to help me. I started going to drug counselling. Um, but you tell yourself you can fix it by yourself, and it always leads back to the same path, eh? I lied to people all the time...I tried to go to Springhill in Napier in March - well, tried - piked out at, you know, the last minute and went, I can do this myself...but no-one can help you if - you know, you're in the midst of your addiction. You know? You've got to reach a point. Unfortunately it took about seven more years to get to that point, really... and um, the path that got me here (the Bridge Programme) is I lost everything. You know? I've lost my daughter. I've lost um, everything I care about. Everything that means something to me is gone...

... It's horrific. I wouldn't wish it upon anyone, but it's the addiction, eh? You - there's nothing I've come across in my life that has a hold on you like that, eh? Like, you - every part of your body screams for it, eh; your heart, your mind - it's all you care about eh, and it's - it breaks your heart at the same time, because it does - it's not a - it's not a way to live, man and I don't care what Meth addicts will say to you. There's no glory in it, eh? You know?

(Interview eleven, Sean, male, 33 years)

Further into his story Sean went on to describe his motivations for maintaining a drug free lifestyle as being driven by his wanting to become 'a good person'. Central to achieving this goal was re-establishing his role as being a 'good' father to his daughter, a role which had been compromised by his past identity as a methamphetamine addict:

I was 21 years old when she was born, yeah. Yeah, so she's going to be nine this year, and that's - that's my biggest regret about this situation; I was a good dad for such a long time - I had her two days a week and always got her the things she needed and, you know - and this drug has just - that was one of the last things to go. You know, but fuck it takes everything from you eh, and I don't care what anyone says, eh. Like, you're not a good person when you're on that stuff, eh and um, I've only just gotten back in contact with her in the last few days.

So I wrote her a letter on the weekend, and I'm allowed to ring her tonight. I'm really terrified of talking to her, you know, because it's um - really hurt her, and this - you know, I realise now this is so much more than just about me. You know? Like, she's a beautiful little person who deserves 
to have a good father in her life, and it's um - you know, it's a really hard thing to live with. It is. Um, but you know, I'm doing it day by day, and it's all I can - you know, that's all I can do, and I'm proud of myselffor making this change. I mean, none of my friends have. You know? They're still sitting - sitting there, chuffing on the Crack pipe, but you have to walk away. You know? I have to walk away from them. I don't - you know, there's no choice.

(Interview eleven, Sean, male, 33 years)

Other participants' storied their experience of desistance by describing events that had similarly culminated in personal crises, and which could also be read as evidencing experiences that aligned with the traditional imagery of resource loss associated with the often-cited 'downward spiral of addiction'67. For example, Terry's story involved recounting the impact of what would ultimately become an unsustainable daily routine organised around his use of methamphetamine and cannabis, and his increasing involvement in crime:

... I knew if I wasn't here I'd be - l'd be dead, in jail or back the way I was; burglaries, you know, in and out of court, all for me drug habit. Or, selling me clothes, selling me TVs, microwaves, furniture, bed - just for drugs. I've done all that. Go to Social Welfare, get a fridge, next day sell it. You know, and then I've got no fridge. I'm back to square one again.

Yeah it's a lot of work.

Yeah, so I go out and steal me a fridge. (Laughter) Yeah.

(Interview fourteen, Terry, male, 40 years)

As Terry progressed in telling his story he acknowledged that the likelihood of receiving a lengthy custodial sentence following his most recent court appearance had been a fundamental turning point in his drug-using journey. This experience had contributed to

\footnotetext{
${ }^{67}$ See for example https://www.addiction.org.uk/the-downward-spiral-of-addiction/
} 
both his motivation for stopping drug use, and his wanting to distance himself from the on-going realities of gang life in order to stop using drugs:

What was the moment that sort of made you think, I'm going to go and try and sort this out? My moment was finishing my $P D^{68}$, and getting busted for stolen property and a cannabis pipe, but the police didn't say it was a cannabis pipe when I went to court. They said it was needles and syringes.

...I was just sick of going in and - in front of the judge, and the judge says to me, you know l've got to - I've got a charge there, at least that if I stayed out of trouble for two years it'll be get wiped, otherwise I'm looking at about five to six years in jail. Ah, I don't want that, mate. That's why I checked myself in here. (Laughter) I'm trying to walk away from the gangs slowly.

(Interview fourteen, Terry, 40 year old male)

Further into his interview Terry presented as being visibly upset and made it apparent that a serious gang-related assault on his brother had also contributed to his motivations for stopping drug use and committing to the process of recovering from drug addiction:

...Well it's good me being down here, because the gang's back on Wanganui, and all my associates are on Wanganui, so - they were down here, because my brother was in hospital, but now he's been transferred to Auckland everybody's gone home. So I can concentrate on my recovery now, instead of smoking and getting side-tracked all the time.

(Interview fourteen, Terry, 40 year old male)

As he continued in his story Terry highlighted his experience of desistance as an ongoing process involving his stopping methamphetamine use, while navigating the challenges of relapsing when using cannabis. Although Terry had not yet arrived at the point of being drug-free, he communicated being motivated by wanting to move away from his

\footnotetext{
68 PD is an abbreviation for Periodic Detention, a non-custodial sentence which involved compulsory supervised community work, typically undertaken outdoors.
} 
past identity as a problematic drug user, and to continue to work towards a 'clean', drugfree identity:

Um, I wasn't - I didn't give up drugs when I first - when I came here. Um, I was cutting myself down. I didn't go into a detox. I wanted to, but there was no beds available. I used to tell my counsellor, yeah I've smoked cannabis and that, and I still do it today - tell my counsellor here, but I'm - I'm cutting right down, and I want to get to the point where no is no...

.... turned down Methamphetamine the other day. It got offered to me and it was the pure of the pure, and I was sitting in the circle and nah, I turned it down. I didn't know what made me turn it down, but I turned it down. I wasn't paying for it, either.

Yeah, but I've had - I've seen the light. Um, I was clean before my family come down. As soon as they come down, I was into it. So half of me seeing the clean side, and I've seen the - the ugly side, and - and I want the clean side. I love the clean side, where I can approach people uptown; gidday how's it going, or kia ora. I love say kia ora. You know? It could be Joe Bloggs on the street and I'm walking to court or something - someone walks past; oh, kia ora - or morning. You know? It goes a long way.

(Interview fourteen, Terry, male, 40 years)

Towards the end of his story Terry reflected on his involvement in gang life and his extensive history of problematic poly-drug use; he disclosed having an abusive relationship and no longer having custody of his daughter due to CYFS involvement. When discussing this Terry then recounted an experience which conveyed his sense of shame about his past drug-using behaviour:

Um, my relationship - we had a - got a daughter. She's 22. Um, me and her mother - our relationship - we were Once Were Warriors. Yeah, we beat each other up. Um, she liked her piss and drugs. Um, I just used to be right into my drugs.

Still see your daughter?

Very seldom. She got taken off us when CYFS were involved. Um, I've never had a father-daughter relationship...I went to her wedding. I was fried. I got up at seven, had a shower, had a pipe, made me some mushy juice-up - magic mushroom juice in a cup of tea. Um, we jumped in the 
car, went round to my dealers, got a couple of tinnies, went to my mate's aunties in Hawera where my daughter was getting married. We smoked a tinny, I walked her down the aisle.

Now, I feel rat-shit, because I got the DVD at home; every so often I look at that DVD, and the way I presented myself as her father, I feel ashamed, because I was in my own little buzz. Um, I took a - I took a dirty girl (sex worker) with me, and she had Methamphetamine on her. Me and my Tribie ${ }^{69}$ bro, we were um, smoking weed on the church lawn. Um, me and this chickie, we went into a little classroom where I was working the P-pipe. We looked on the wall and there was a photo of bloody Jesus. Kids were running past the window and that, and I was sitting by the door. She was sitting next to me, and here we are fucken chuffing on the P-pipe in the church, mate. It's disrespectful, really. So, you know, it's - I'm really ashamed of that.

(Interview fourteen, Terry, male, 40 years)

Like Terry, Angus had also been heavily involved in gang life, a lifestyle which had been accompanied by his heavy use of methamphetamine and alcohol. When recounting the events leading to his desisting from meth use, Angus had identified becoming increasingly aware that his involvement in drug distribution to fund his methamphetamine addiction had exposed him to serious, gang-related violence. Recognising the risks associated with his drug-using environment, Angus made a decision to 'get clean' after a period of having used methamphetamine daily for several years:

Being set up one night; got into a car, doing a drug deal, a dude had been in the back under a blanket, jumped up, pistol at me, I got kidnapped into a boot, taken away, stuff happened. That was my little wake-up call.

...Yeah, and I was playing in a world that I wasn't ready for. So, I actually got clean. I was clean for a year, but it was quite easy because I was so fucked. I didn't get off the couch for about eight months. I was fucked.

(Interview seven, Angus, male, 33 years)

\footnotetext{
69 'Tribie' refers to the New Zealand gang, the Tribesman.
} 
Although Angus had succeeded in initiating a self-imposed state of abstinence from methamphetamine use, he continued to engage in problematic drinking, the effects of which had culminated in his self-referral to the Bridge Programme. Once in this environment, Angus was able to acknowledge that he understood his past drug-taking behaviour as evidencing his drug addiction, and identified as being both a 'drug addict' and alcoholic:

... I'm glad I came here. The mother of my kids asked me to go a while ago, and I was like, I don't need it, but it's been great. It really has. I'd love to leave today, but I'm stoked I've come...

...When my first child was born I said I was getting clean, and I started going to NA, but I was doing that for other people - wholeheartedly I was.

It wasn't until just recently, and I've started this part of the journey, that I definitely am an addict and an alcoholic, without a doubt. For me it's very much day by day. I can't think of the future. It's really stupid; I'm afraid of - it may seem stupid, but it's not for me - of not being cool. I'm really unconfident at the moment. I've always had plenty of confidence, but I think my confidence was just a bit of a smoke-screen of my actual problems. So I'm quite happy at the moment not being - I'm slowing down and just taking the time to think about things, which is fucken massive.

(Interview seven, Angus, male, 33 years)

Like Sean, Angus had also reflected on his wanting to be a good father and role model, and talked about wanting to support his brother who had recently started using methamphetamine. However, when doing this, Sean reconciled his past behaviour by acknowledging that his motivations for offending were not solely influenced by his addiction to alcohol and methamphetamine:

You said you've got a brother.

Yeah, my younger brother, (name). Yeah.

Does he ever ask you about (your past) now?

Yeah, definitely. He's doing well, aside from the fact that he's using as well, but just bought his second house, he runs a good company; he's only 23. 
What's your take on that, given your journey?

Well, from what I've been learning, there's not a lot I can do. I'd love to just wave a magic wand, but a lot of guilt - you know? Who gave him his first one? When he goes and scores, who does he go to see? It's all secret. The family doesn't know. His own girlfriend doesn't know. Fuck.

That must be difficult.

Oh yeah, definitely. Real difficult, especially now seeing what he's achieved at such a young age, and what he's got to lose. He came to a meeting a couple of weeks ago. He realises, but I just still think that he still has that little piece of him that, it won't happen to me. We're really close, though. We're quite tight...That's one of the reasons why I want to get clean, too; I can hopefully portray that you can do it - and for my kids. I want to get clean for myself, but addiction runs in my family and who know what my girls are going to face. I fucken hope they don't, but I certainly want to be clean and a good example - someone that they're proud of.

When you say addiction runs in your family, you've seen it in your...

Yeah, my dad.

I don't know - I'm of the belief that environment is definitely more of a factor than genetics. I do feel that. I don't really know, but that's my take on it. So I don't want to give them an environment of even alcohol. They're three and a half, and two and a half; Dad's away in hospital because he takes too much alcohol. That's what l've told them. So they're already aware of it. ...would you say reflecting back to the moment of starting to take drugs fairly early on, that those experiences with your dad could have contributed to that...?

Well, I've had a step-dad since I was four, and my parents don't drink or take drugs. So it wasn't my environment. Dad's death definitely smashed me over. I'm just starting to learn about that now. I haven't dealt with it even. I'm just starting to, but yeah I can't even blame environment on my journey.

I honestly can't even blame it on that. I just loved being out of control. I just got a massive thrill of it. I've never even done a burglary. I used to like armed robberies at that age; that's fucked up, let's face it. I used to put on my balaclava and stand in the mirror with my gun and rev up for it - that type of shit. You know what I mean? Hard as it is to admit, but it's fucken deluded.

(Interview seven, Angus, male, 33 years) 
Female participants' had also described stopping drug use as a result of turning points that similarly communicated the experiences of what Teruya and Hser (2010:193) refer to as "bottom-hitting events". When contrasted with the desistance experiences of male participants, their stories also reiterated how female participants experienced turning points that manifest in events anchored to broader, gendered realities, and which influenced the process of desistance in profoundly gendered ways.

Debbie's story about methamphetamine use for example had followed a similar trajectory to that storied by other female participants' who identified as being mothers. Debbie had navigated the impact of her drug addiction alongside the realities of supporting her partner's involvement in drug distribution, while also being tasked with the responsibility of caring for their children. Having given birth to their third child, Debbie's use of methamphetamine had attracted the attention of her mid-wife, who reported her drug use to the Child, Youth and Family Service $\left(\mathrm{CYFS}^{70}\right)$. This resulted in Debbie's son being removed from her care, an experience that initiated her motivations for stopping methamphetamine use and her wanting to successfully complete the Bridge Programme:

Yeah, when my son got taken, that's when I really woke up.

...My longest binge was two weeks, and by that stage I was just about collapsing, wasn't sleeping - I wasn't eating. I was hallucinating and nearly collapsing basically, I was that ill. I'd been on it too much. Even throwing up - yeah.

At that time then, did you have any contact with any agencies, like for example, did you ...have a midwife for example, involved with (your son), or...

Yeah, she did the notification.

Did you tell you she was going to notify?

No, she just did it, but she's told me to this day, you were just a mess back then.

\footnotetext{
${ }^{70}$ Although this agency is now known as Oranga Tamariki, The Ministry for Children.
} 
Do you still get to see (your son) now?

Yeah. I'm trying to fight for him back. That's why I'm here.

(Interview fifteen, Debbie, female, 26 years)

Towards the end of her story Debbie talked about her father being involved in the care of her daughter, who was similarly removed from Debbie's care as a result of her drug use. When reflecting on this Debbie also identified wanting to desist from using methamphetamine in order to make her father 'proud' in an effort to reconcile her past behaviour:

What did you dad say about that?

Well, Dad wasn't impressed. My dad's a straighty.

A straighty?

Yeah; doesn't drink, doesn't smoke. Yeah, very formal - set in his ways.

How is Dad viewing your success now? You're on this programme and things are successful.

Dad will believe it when he sees it. He's one of those men. I want to do these things to make him proud for once. I haven't made him proud for a long time. Last time I made him proud I gave birth to his grand-daughter.

(Interview fifteen, Debbie, female, 26 years)

Amy's story also communicated how female participants' had experienced prolonged periods of heavy methamphetamine use as mothers, and the cumulative impact of their drug use on their ability to adequately care for their children. Like Debbie, Amy's process of desistance had been initiated by CYFS removing a child from her care. As a result of this event, Amy was confronted with the choice of continuing with her drug use, or 
accepting treatment for her drug addiction in order to re-establish contact with her daughter:

I had my two year old with me, dragging her all around town, smoking P. I was so out of my head and it was crazy; you couldn't hold a conversation with me unless I wanted to talk to you....I must have looked like a piece of shit or idiot. I knew it, but I was around people that it was okay to act like that. That's why we don't go out in front of normal people; they just notice it. So, I did that with my baby until six weeks ago. I thought it was okay, because obviously we'd make sure that they've got food; they're okay - they're in the lounge - we'll just go over here and have sesh and a coffee and do what adult do. Then; bedtime - bath time - all that sort of stuff, and then we'll carry on doing what we're doing but we're fucken fried out of our heads. We don't sleep or eat, but we'd feed all the other kids that were coming over - my friends kids; put a movie on - yeah go to the park - come back at two.

... so was there a moment then in the story where it all ends, and you reach the point?

I got my three year old taken off me - uplifted. I was a mess. The only way to fix it is to come here, because I've lost here, and she's a baby. That's when I came here and I was a mess because I wasn't allowed to bring her. There was an option of me bringing her, but CYFS said, no. Family said, nah - you had your chance.

...Yeah and I just was a mess. I carried on using till the day I came in here. I came in here thinking I'm going to use still.

(Interview nine, Amy, female, 33 years)

In keeping with other participants' stories of desistance as 'recovery', Amy communicated her awareness of being embarrassed when reflecting on 'chaotic' moments involving her past drug-taking behaviour as a problematic drug user, and similarly assert her motivations for desistance by expressing her desire to regain access to her children after completing the programme:

It doesn't matter. I can't believe it. It doesn't matter. All these people that mattered - it's ridiculous. The people that really did matter - my children - it's horrible. My children were writing me notes, for goodness sakes - screaming, jumping out their window, running off to their bloody auntie's house. That just did not matter to me. 
Is it likely - there's hope that you'll be able to reconnect with them?

Definitely. I haven't lost them. The plan is that they can come back to my care once I address my issues. I'm so lucky - fucken lucky, man - really lucky. If I stuff up, that's it; the care for their life till their teenagers, gets handed over.

So, they're presumably with whanau back in Palmy?

Yeah, so I'm so lucky...and the good news of I'm coming here; shit, it's just opened my thing up to these people that don't matter. There's a part of me that feels embarrassed for my recovery. You know what I mean?

...You'd do stupid things and things and then I'd hide inside for like three days. My neighbours; they were like 40 years on the street, and here's my bad house - they can see everything that's going on, but they wouldn't say nothing, and I'd be like, I'm not going outside - I'm not walking to the shop for like three days. It would pass and I'd be fine and I'd be out there doing my gardens. It's so embarrassing and then I'd get that shame back again. It's like, how embarrassing. It's just what it does to you.

(Interview nine, Amy, female, 33 years)

The losing of social and economic resources and diminishing capacity for self-care that each participant had storied as resulting in their needing to desist from drug use communicated many of the themes which comprise authoritative understandings of drug addiction. The experience of being mentally and physically subsumed by the effects of methamphetamine that participants' described, alongside their experiencing a loss of control over all other life projects, accorded with lay understandings of addiction invested in the idea of users needing to experience a devastation of the self before they can desist from drug taking. This theme was amplified by participants' drawing upon understandings of desistance conveyed in therapeutic settings, where the experience of recovery is often communicated by employing the 'rock bottom' narrative, which posits that addicted drug users must 'hit' their lowest point before they can accept help to recover from their addiction (Kemp: 2013). 
As Kemp (2013:106) notes, the idea that problematic drug users must hit rock bottom "is commonplace in addiction treatment", and "almost any clinic filters the idea, even if it goes by other names." The rock bottom narrative also reinforces authoritative constructions of drug use and risk, the dominant motif of which is the addicted user, whose loss of self-control is presented as the result of a pharmacologically induced state of 'demonic possession' (Manderson:1995). Individual agency is negated by whichever substance has subsumed the individual, whose inevitable journey to rock bottom is explained by presenting the biological effects of drugs as diminishing or eliminating rationality, morality and legal responsibility, rather than simply temporarily distorting sensory or cognitive function (Hammersley and Reid:2002:9).

Understandings of addiction anchored to the rock bottom narrative have been challenged in scholarship examining desistance and recovery from drug use. When used as a construct to explain the desistance process, rock bottom assumes that drugaddicted individuals must reach - and be allowed to reach - an impossible to define point in their trajectory of drug use denoted by catastrophic loss, before treatment is viable. As Hsiao and Riggs (2016:15) emphasise when recommending reforms in approaches to adolescent substance abuse treatment:

"...it is important to dispel the residual notion that individuals suffering from addiction must "hit rock bottom" before they are willing to enter treatment. This notion has contributed to the development of interventions and a treatment system that predominantly serve only those at the most severe end of the spectrum."

While such assumptions inevitably compromise efforts to develop early intervention strategies, a reading of the turning point experiences described by participants in this PhD study reinforces the idea that the cumulative effects of addiction can and do manifest in what are often dramatic and harmful 'rock bottom' events or crises, and often occur in the wake of a prolonged period of uncontrollable drug-taking behaviour. These experiences suggest that the notion of rock bottom is of theoretical utility when 
examining the desistance process, given that crises of the self which result from profound social and economic resource loss, can, for some drug users, initiate changes in drug-taking behaviour across the life course. However, Carlsson (2012:3) points out that, although rock bottom experiences might help answer the question of how an individual came to desist from drug use at a point in their biography, life changing events are not, in and of themselves, experiences which bring about desistance. He suggests that of greater theoretical importance is understanding the way that changes in particular circumstances serve as the catalyst for other changes, the sum of which initiate and maintain the desistance process.

When examining the experience of rock bottom as it is presented in the context of Alcoholics Anonymous, like Carlsson, Kemp (2013) is also concerned with the process of change that follows rock bottom in whatever form it takes for the individual. For Kemp, rock bottom experiences can be understood as events of truth, which allow for individuals to become open to the potential for profound, and ongoing change.

Applying this understanding of events to the experience of alcoholism and recovery, Kemp goes on to explain that what emerges from crises is, in the context of being an alcoholic, a moment of truth and acceptance that the individual is no longer in control of their life as a result of their drinking. To fail to do so is to "dwell in untruth", thus the process of recovery is dependent upon an addicted individual accepting the truth of their uncontrollable drug-taking behaviour, as is made implicit in step one of the 12 step Alcoholics Anonymous programme:

"We admitted that we were powerless over alcohol - that our lives had become unmanageable" (AA, 1953:21, cited in Kemp: 2013:107).

That control over life projects had been lost as a result of past drug taking behaviour was fundamental to the stories of participants' who were engaging in treatment for their drug use. This theme was communicated by participants' referencing the impact of their 
past drug use as "the ugly side" (Terry), as being "fucked" (Angus), "fried" (Amy) and as inducing a state of being where "every part of your body screams for it, eh; your heart, your mind" (Sean). Crisis induced turning points had also been storied as experiences which had been followed by the acknowledgement that using drugs had resulted in irreconcilable harms, and had diminished participants' capacity to exercise full control over their lives. For Sean, losing "everything I care about" was storied as his rock bottom experience; a point of personal crisis which had been proceeded by accepting that his capacity to care for himself and others had been lost, and his needing to engage in counselling to re-gain control over his life. Similarly, both Debbie and Amy had communicated the emotionality of having used drugs to the 'lowest' point possible in their drug-using trajectories, whereby their children had been removed from their care. The 'truth' of their addiction had been demarcated by this profoundly negative experience, as Debbie highlighted when explaining her motivations' for attending the Bridge programme as a response to the loss of her son - "that is why I am here."

These experiences illuminated how turning points resulted in 'opening up' participants to the possibility of change, and at the same time revealed how pathways to stopping drug use were subject to individual and structural influences, the sum of which had shaped the desistance process in different ways. For some participants, turning point experiences had signalled the inter-play between uncontrollable drug use and its role in exposing individuals to criminal justice and government agency interventions. This had resulted in participants being coerced into accessing and complying with treatment programmes in order to avoid the threat of custodial sentences or being denied access to children. When viewed in the context of neo-liberal mores, these experiences reiterated how authoritative understandings of drug use assume that addicted individuals no longer possess the personal attributes required to regulate choice, and as such, desistance from using drugs necessitates governance measures which help regulate and control their 'addictive consumption' (Reith:2004). The rationale for stopping drug use through coercion is thus dependent upon defining drug users as agential decision-makers who are obliged to 'choose' from a set of available options in 
order to maintain full citizenship (Seddon: 2007). The paradox of consumer freedom, whereby addicted individuals with a diminished capacity to exercise free will are expected at the same time to behave as rational assessors of risk is then resolved within coerced treatment initiatives, where drug users are no longer required to exercise the full extent of their consumer freedom. Instead they are obliged to make a choice from a highly constrained set of available options, which typically include prison, treatment or the removal of children (Seddon: 2007).

While some participants had elected to participate in treatment when confronted with similar, threat induced, choices, for other participants, decisions about stopping drug use and accessing treatment had been subject to different influencing factors. For Angus, stopping drug use had occurred in stages, the first involving his desisting from methamphetamine use completely, as a result of his own, self-imposed state of abstinence. This experience problematizes authoritative understandings of meth use, where individual agency is negated by meth's unassailable biological effects (Manderson: 1995). It also supports the view of desistance as being a process rather than a definitive end point, as Bottoms et al. (2004:370) emphasise in their exploration of desistance among a sample of young recidivist offenders. Their work highlights the need to account for significant lulls or crime-free gaps in the course of a 'criminal career $^{71}$, and demonstrates that although periods of temporary desistance from drug use and crime can occur in supportive, pro-social environments, individuals may not have experienced any form of identity shift or cognitive transformation, opting instead to stop or start offending "on their own initiative."

\footnotetext{
${ }^{71} \mathrm{Hser}$ et al. (2007:517) note that the term 'career' as it is applied to drug using and other offending behaviours has an unwanted connotation, as it implies "something to be sought or encouraged, as in employment." Comparatively 'life course', or 'trajectory' are to be regarded as neutral terms and help avoid misinterpretation.
} 
The second stage in stopping drug use for Angus had occurred following encouragement from his partner to voluntarily access treatment for his alcohol use. This experience had marked a shift in identity when Angus acknowledged being an alcoholic and wanting to stop drinking in order to be "a good role model" for his kids. Sean had also cited similar motivations for his self-referral to the Bridge Programme when describing wanting to be "a good father", and again highlighted the notion of desistance as involving a drift towards an eventual stage of abstinence when storying his unsuccessful attempts to voluntarily access treatment.

These experiences accorded with Sampson and Laub's (2005) view of desistance as being dependent upon a process of accumulating positive social capital, which includes future investment in familial life. Seddon (2007:272) suggests that, when looking at pathways to treatment, the presence and influence of positive social relationships signals that coercive pressures are in fact "operative in multiple life spheres". This allows for thinking about the notion of coercion in different ways, given that coercive pressures can emanate from multiple sources, including family, friends, financial concerns, as well as through the criminal justice system and other government agencies. Citing Bean (2004:229, in Seddon: 2007:272) he notes that coercion results from diverse sources outside of the criminal justice system, and that it is rare for offenders

“...to enter treatment free of all forms of coercion, whether from friends, relatives or others. To talk, therefore, of coercion and compare this unfavourably with 'voluntary' decisions to enter treatment is to be too optimistic about the nature of many drug users' lives."

Although there was variation in the factors which influenced decisions about accessing and committing to a treatment programme, all participants who had been interviewed at the Bridge Programme communicated how therapeutic environments had assisted them in making sense of their past histories of problematic drug use, as well as how this influence informed their understanding of the desistance process. Not surprisingly, moments of truth born from personal crises had been proceeded by participants 
articulating the 'truth' of their addiction once in this setting, given that the success of recovery in a therapeutic environment necessitates the acceptance of an 'addict' identity. As Anderson (1993:137) notes, the notion of recovery is grounded in ideology within addiction programmes, which function as "mechanisms of socialisation or identity transformation organisations" that depend upon "retrospective interpretations of past selves". This ideological view accords with earlier theorising about the process of recovery from addiction originally advanced in the work of Biernaki (1986), who also conceptualised recovery as requiring drug users to construct a new self-identity and become involved in new social contexts where past 'addict' identities are depreciated or no longer possible to maintain.

That individuals must undertake an identity shift in order to stop offending is also fundamental to life course perspectives of desistance from crime, as Sampson and Laub (2005:34) suggest when explaining desistance as a 'knifing off' of past behaviours and events, where individuals open themselves to identity transformation opportunities and the emergence of "a new self or script." Other life-course scholars similarly emphasise desistance as a process invested in self-transformation, but envisage the process as being dependent upon individuals being cognisant of negative identities structured in relation to past offending behaviours. As Paternoster and Bushway (2009:1107-1108) theorise, desistance from drug use and other types of offending is contingent upon individuals discarding "their own identity in favour of an alternative one." This requires individuals to envisage two versions of themselves; a 'possible self' and a 'feared self', the former being the person they can become if they desist from offending, the latter being the person they could become if they continue to offend. The feared, or negative, self as it is conceptualised by Paternoster and Bushway (2009:1103), thus influences desistance from offending. Maruna (2001:87) also emphasises the dichotomy between a negative, and 'shameful' past self and the potential for a positive future self. Thinking about Sampson and Laub's (2005) notion of separating the past from the present by knifing off, Maura posits that desistance and identity transformation as a process might be better characterised as 'making good'. 
Tying these conceptualisations of identity and desistance to the experience of recovery articulated here, it is clear that participants' had similarly invested themselves in an identity transformation process, where desisting from drug use in the future was contingent upon associating past behaviours with profoundly negative self-perceptions. This was evidenced by participants' communicating their sense of shame about the impact of their drug-using behaviour, on children, family members and on past intimate relationships, as Amy signposted when describing "feeling embarrassed" about needing to recover from her drug use. Participants' desistance narratives also accorded with the sentiments of 'making good' and communicated their understanding of what shape their future identity would take by expressing their wanting to 'make their father proud' (Debbie), to be "a clean and good example" (Angus), and "wanting the clean side" (Terry).

These experiences highlighted the role and influence of a therapeutic community in shaping the desistance process, where 'recovery models' are dependent upon identity change processes through which "the internalised stigma and status of an addict identity is supplanted with a new identity" (Best et al: 2016:111). Negative self-perception rooted in past, drug using identities is thus fundamental to influencing recovery and desistance from drug use as the stories of those participating in this thesis demonstrate.

Having interviewed drug users engaging in residential treatment, the experiences of recovery and desistance articulated here are of course time bound; they cannot cast light on the 'un-spoiling' of spoiled identities as is intended in treatment objectives, nor can they reveal the process of desistance as it would unfold beyond the completion of the Salvation Army Bridge programme. They do however reiterate a theme which intersects the stories presented throughout this thesis; that all participants' were acutely aware of, and at times struggled with, being subject to stigmatisation as a result of their drug use, notably their use of methamphetamine. This theme had been clearly evidenced for example during the pilot study, when Ben described the impact of losing 
his teeth through meth use, and later, when Jess was unable to admit during her interview that she had recently purchased, and used, methamphetamine.

Participants' experiences of desistance as involving engagement in an identity transformation process predicated on accepting a stigmatised identity thus problematizes the extent to which the future process of desistance might accommodate a knifing off of the past, from the present. Knifing off criminal stigmatisation - which for some participants' was accompanied by additional layers of stigma associated with being 'bad mothers', sex workers, and gang members - is an ambitious proposition. The internalisation of deviant labels is widely acknowledged as inherently difficult to reconcile (Maruna and Roy: 2007); the very act of participating in treatment can cement an 'addict' or 'junkie' identity, which may also lead to rejection from family and friends. Additionally, stigma is often self-fulfilling, given that drug users who internalise stereotypical junkie identities will then continue to behave in the expected manner, and likely fear "they will not be able to get on with people in the conventional world" (Olszewski et al: 2012:21).

It was also clear that in moving to Wellington to attend treatment, participants' benefitted from a temporary geographical severing of ties with the social arrangements that had facilitated past drug-taking and engagement in drug-related criminality. That separation from these environments was regarded as a positive experience had been evidenced by Terry when noting his "wanting to break away from all that nonsense" and "concentrate on (his) recovery", and by Sean when describing his feeling proud of removing himself from his drug-using social network, who were "still sitting there, chuffing on the crack pipe." These experiences reinforced the notion of turning points as life events which initiate a sequence of ongoing changes, such as new living arrangements, which in turn allow the desistance process to develop (Kemp:2013). 
Maintaining recovery and desistance is also determined by the ongoing accumulation of positive social capital, and treatment settings provide a foundational opportunity for this process to occur by allowing individuals to become members of a new community, whose norms encourage drug abstinence, rather than drug use (Best et al. 2016). However, Boeri et al. (2015:96) make the point that treatment programmes "often destroy drug-using networks without linking people to new social networks beyond recovery networks". As a result, recovering drug users often return to the environments and relationships which had previously facilitated using drugs, without having access to non-drug using networks (ibid). What shape desistance and recovery took for participants' having completed treatment can only be assumed; although some participants' identified having support from, and connections with, family members and partners who were not involved in drug-use.

However, it was clear that other participants would be returning to social settings where drug and alcohol use was prevalent, and normalised. Female participants would also have to navigate relationships with the gang-involved fathers' of their children, relationships which had exposed them to violence and trauma prior to treatment. How problematic drug users who experience structural disadvantage go about separating themselves from stigmatised identities and past events, in order to desist from drugtaking, is thus difficult to reconcile.

\section{Desistance beyond therapeutic environments}

Six of the 13 desistance narratives had storied the process of desistance and recovery as it had developed over an extended period of time outside of therapeutic environments. In these narratives, two participants had described the process of stopping or moderating their drug use as occurring without any involvement or contact with addiction services, while four other participants described desistance as an ongoing process involving variations in past and current treatment experiences. These stories helped reveal the shape desistance and recovery took beyond the confines of a clinical setting, and highlight the inter-play between individual, meso and macro-level factors, 
and decisions about stopping or moderating drug use across the life-course. In doing so these stories further supported the notion of desistance and recovery as being a process, rather than the immediate state of abstinence assumed as following cognitive risk assessments of harmful drug-taking behaviour:

Matthew's story about stopping his use of methamphetamine and synthetic cannabis, was only one of two desistance narratives communicating the experience of desistance without the involvement of addiction services. Although he described experiences of problematic drug use that were similar to those revealed by participants engaging in treatment for their addiction, Matthew's story communicated an understanding of identity which highlighted the absence of therapeutic discourses. This was evidenced by his storying past events without associating with states of addiction or recovery. Instead, when reflecting on how his drug use had eventually undermined his ability for self-care, Matthew understood his past self as being 'drug fucked', rather than drug addicted:

...I'd never have food. It would always go straight onto drugs. The first time I did when I got money - I wasn't thinking about food or anything, or anything else. It was just straight to drugs. Like, everything I own from home, like my iPad, my iPhone, laptop; all swapped for drugs. So I ended up with nothing.

.....This one guy I've known all my life since I was born - like, his mum's my mum's best friend and... we were driving around one day and then he stopped me and he just said, bro you should you should move out - you're ruining your life. He just had a heart to heart talking about it. I was just too drug fucked to just take what he was saying.

You used that expression 'drug-fucked' - so reflecting back, how did you know that you were?

Just everything you spend is just drugs. Everything you think about is drugs. You don't give a shit about anything. Like, reality is nothing. Like, reality just fades away, so it's not even there. Like, the family don't even care about - like, you don't think about anything but drugs. Like, you don't think about, what will happen if I do this; you were thinking, "oh at least I'll get high".

(Interview sixteen, Matthew, male, 18 years) 
Matthew's story of desistance went on to highlight the impact of two, inter-related turning points, the first being initiated by a police raid of the property he shared with a drug-dealing associate. This experience resulted in a sudden, and unplanned disruption of the environmental arrangements which had facilitated his use of drugs:

...we were having a party at my house and then all of a sudden I was just drunk as, walked down the stairs and there was like 10 cops in the driveway about to raid us. So I just - I was like, fuck. I just didn't know what to do, so I just ran upstairs and I punched the window. Just - I don't know - just what a drunk person would do, and then all the cops just - obviously you can't continue to raid if someone's in a near-death situation, because they had to attend to me, and that paused the raid, and the dealer ran off with all the ounces and drugs and stuff, and then I went to hospital and almost died from that, so...

It was pretty shit. There was nothing for me there in the way I was going...I was within like, seconds of my life when this happened, but if the cops weren't there, apparently I would have actually died, because all the people around me knew what to do. Like the cops were - even the cops weren't that onto it, like they were tying everyone's tee-shirts around there to stop it and then one of them just sort of decided they'd actually have a look, and he just unwrapped it and it was like - spraying in his face, and yeah then all the paramedics got there and I just - I was like passed out by that point and yeah. My mum's a paramedic as well. Yeah, so everyone knew me. All the cops knew me. All the paramedics knew me, so it was - I don't know if they would have taken it personally because I was - they all knew me, but...

(Interview sixteen, Matthew, male, 18 years)

When in hospital, Matthew was able to pause his drug use and reflect on the events and behaviours that preceded his being injured during the police raid. As a result of his hospitalisation he was also able to re-connect with his Mother, which initiated his motivations for agreeing to allow his family to support him in moving away from the social context facilitated his methamphetamine and synthetic cannabis use. In much the same way participants at the Bridge Programme had experienced a sense of clarity when separated from drug using environments, Matthew's experience of hospitalisation had similarly contributed to his being able to re-assess his behaviour and begin 'recovering' from his past drug use. Recovery however, was not communicated as a transition away 
from a drug using identity, but as his needing to get "a fresh start", the outcome of which was improved health and opportunities to accumulate positive social capital:

That just - like, my mum had a really big talk to me about how I could have died, and how she would have felt, and my little sister and all that, so I just realised how fucked my life was when I had a few days in hospital drug-free and my mind started to clear a little bit, because before that I hadn't gone a single day without drugs. Like it was just cloudy in my mind, and I couldn't think of anything, and then I could suddenly think again, and just realise what was actually happening. So then we decided l'd move down with my uncle here and try and get a fresh start....

So you've only been down here for a couple of weeks; how has that worked out so far? A lot better. Like, all my family is like 'I'm a lot healthier'. Like, before it was just like cheek bones. I was just fully skinny as, like had nothing to me, and I wasn't happy. Like there was no time I was happy, unless I was high. I would just not be happy. Now sometimes I can sort of be happy without it, so...

And you've got some work?

Yeah; (names employer) - just three till seven, so that's doing good - gets my mind off things - get some money as well.

(Interview sixteen, Matthew, male, 18 years)

Rather than delineating a point between drug use and drug abstinence, Matthew's desistance narrative went on to highlight that he was still able to accommodate his ongoing use of cannabis. Just as other participants' had reconciled risks associated with various transitions in their poly-drug use, Matthew reconciled his use of cannabis by assessing it's risks in relation to the risks he associated with his problematic use of other, more 'addictive' drugs:

...so far (moving's) working because I've only been on Cannabis which actually I don't think ruins - does anything bad, apart from the memory loss - short term memory loss.

So, you think it doesn't do anything bad compared to other drugs? Nothing at all compared to other drugs. 
And compared to 'Not Pot'? (Synthetic cannabis) ${ }^{72}$

That is fucked. Even though it's cheaper and you get more and you get more high, you spend a lot more on it, because it's way more addictive. Can't go without it for a few hours - you just need it.

...Would you describe now, yourself as someone who uses drugs recreationally, or do you look at your drug use as a problem for yourself?

I don't see it as a problem now, because it's just Cannabis, which is a natural plant which I just see as - it's full of benefits, but it's got a few down sides, but l've already suffered all the down sides, so I don't see it getting any worse, so...

(Interview sixteen, Matthew, male, 18 years)

By providing an example of the desistance process as it occurred outside of a therapeutic environment, Matthew's story demonstrates how participants receiving treatment to recover from their drug use had assumed the identity of the recovering 'addict' in order to make sense of their past drug-taking behaviour. However, outside of these environments, as Matthew's story demonstrates, drug users can initiate changes in their behaviour having been confronted by moments of truth born from crises, without needing to accommodate a new, and highly stigmatised identity, or needing to re-write a shameful past as Maruna (2007) suggests. Matthew's story also accorded with a view of desistance from problematic drug use as being the outcome of multiple experiential pathways, rather than being contingent upon pejorative understandings of drug use as stopping only at the point of users hitting rock bottom.

\footnotetext{
72 Synthetic cannabis, more commonly referenced in New Zealand as 'synnies', or known in a media reporting through brand name references such as Kronic. Typically produced by spraying plant matter with synthetic cannabinoids designed to imitate THC, the compound found in real cannabis which produces its desired effects. However, in composition and effect, synthetic cannabinoids are unrelated to THC, and the term synthetic cannabis has been widely criticised for wrongly associating real cannabis with products that are chemically unrelated and more harmful to users. In 2017 reporting on a number of deaths in the Auckland area linked to the use of synthetic cannabis prompted extensive media coverage and references to harms documented in the US. See for example https://www.stuff.co.nz/national/crime/95397871/synthetic-cannabis-the-danger-drug-overwhelming-new-zealand
} 
As Biernacki's (1986) earlier conceptualising of pathways to overcoming heroin addiction established, although dramatic existential crises do explain why some drug users access treatment, a much larger population of drug users overcome problems resulting from their drug use outside of treatment settings, by consciously changing their behaviour after an accumulation of negative experiences. Olszewski et al. (2012:7) note in their interviews with European drug users who had controlled or stopped using drugs without treatment, that in such circumstances, ideas to control drug consumption develop rationally, often in response to personal values being undermined by drugtaking, such as work achievements, relationships with family members and having disposable income. For Matthew, this had meant being able to recognise and respond to the harms associated with his using methamphetamine and 'not pot', while at the same time being able to exercise control over his continuing to use cannabis during the process of "getting a fresh start". This suggested that problematic drug users who stop using particular drugs without any exposure to addiction services are more likely to understand desistance as a process which can accommodate calculated modifications in drug-using behaviour, rather than being dependent upon adhering to an absolute state of drug abstinence. In contrast, recovering drug users must distance themselves from their past behaviours and simultaneously regard using drugs as being incompatible with their new drug-free identity (King: 2013).

Although problematic cannabis use had led to his needing to engage with the Bridge Programme, Ben's desistance narrative revealed his stopping methamphetamine use without any therapeutic intervention. Reflecting on this past experience, Ben described an opportunistic encounter with the father of an established methamphetamine supplier who offered him room and board in his home. This had led to a change in Ben's social network and initiated a prolonged period of intense methamphetamine consumption:

His son was the local (names town) $P$ dealer, and um I saw $P$ in amounts that I'd never seen before... The flipside was we didn't really have to pay for it, because the son was such a big dealer...there was always so much to spare...it got to a point where it was there breakfast, lunch, 
and dinner in major, major quantities, and I got into it in a way I never had before...I was smoking that stuff like people smoke cigarettes, all day, all night, l'd probably sleep three nights out of seven, you know what I mean? I went from the size I am now to being so skinny it wasn't funny... Where it started getting hairy for me is I lost the ability to realise right from wrong...I knew I wasn't looking after myself but I was so out of it I couldn't comprehend it...

(Interview four, Ben, male 31 years)

As Ben progressed in telling his story, he described becoming more entrenched in a meth-using 'scene' as a result of his family's involvement in gang-related drug dealing. When his brother's car was taken in a dispute over payment for drugs, Ben then described a turning-point experience which resulted in his wanting to disengage from a drug-using lifestyle he labelled as being "addictive":

My brother had gone and through connections managed to find his way into the Mongrel Mob to help him (recover a car). He obviously had to pay for it... and um Mongrel Mob came down, and as soon as that happened, the Nomads turned up...so there's two gangs sitting in this street... and instead of going for it they went and sat down in one of the cars and managed to work out a deal....once that had happened, I thought to myself...I said to myself, in that one instant, I've just got caught up in gang life...that was the moment I knew I had to get out of there...

(Interview four, Ben, male 31 years)

In the wake of this event Ben initiated making a significant change in living arrangements in order to escape his meth-using social network. Once he had successfully relocated to another town, Ben was able to desist from using methamphetamine:

...it took me about a week (to move) but um, I managed to say to (the father I was staying with) hey look I am going to stay with my parents you know what I mean, um, my mum's sick she needs help and all this, so I just lied my way out of there and I ended up moving to (names place) from (names place), and um, in (names place) I knew some friends that I used to go to polytech with but I didn't know anyone I could score P directly off, that was the aim, to go someone where I couldn't get my hands on the stuff you know what I mean, and um I smoked, I smoked quite a bit of weed to, to sort of get me off the $P$, and funnily enough it worked, it took me about a month 
before I got rid of those hard core cravings...But it also helped looking in the mirror, seeing my teeth go to shit, the fact that I didn't weigh anything anymore...

(Interview four, Ben, male 31 years)

Like Ben, Moana also stopped using methamphetamine without any form of therapeutic intervention, and similarly described a turning-point event characterised by a process of self-reflection and a desire to move away from a social context supportive of drug use. Moana described this process as being preceded by financial circumstances that were increasingly difficult to manage, and her establishing a relationship with a new partner:

...I had gotten myself into a lot of debt...I wasn't paying my rent, it was just shocking, um...at the time the drugs were the number one priority...if I didn't have my fix, then, then I thought (pause) what am I doing?...I met my partner...I did end up telling him that I was on it, and then he told me to stop...and I said yep but I didn't (pause), and then he um, he knew, and then just gave me the ultimatum and just said if you don't stop this then that's us we're done. But I didn't, I still carried on...

(Interview three, Moana, female 25 years)

During the initial stages of this relationship Moana described getting "better at lying" to her partner and the challenge of managing her increasingly erratic behaviour as she continued to use methamphetamine. She identified wanting to control her methamphetamine use at this time but pointed to the difficulty in abstaining due to her friends continuing to use meth. As she progressed in telling her story, she identified how difficulties within her social network of female sex workers had led to a moment of selfreflection and becoming paranoid about the impact of her meth use on her appearance, an experience she identified as initiating her decision to break away from her social network and stop all drug use:

I think it was the girls I was with at the time, there were a lot of dramas between me and the others, and I started to notice them and how they were behaving, and then I kind of looked at myself and thought...'oh my God do I look like that? I would compare myself and think this must 
be what my partner is talking about. 'Do I act like that, do I talk like that?'...and I just decided like...nah...and that's what made me paranoid...I thought, 'oh my God, no, no, no, no...I look ugly!

(Interview three, Moana, female 25 years)

When compared with narratives of methamphetamine desistance explored in other qualitative works, both Ben and Moana's stories accord with the view that the desire to abstain from drug use can emerge from what Boeri et al. (2009:145) explain as "the looking glass effect", where users reflect on negative assessments of their appearance, personality or behaviour. Of note in undertaking these assessments was Ben's ongoing demonstration of being cognisant of the stigma associated with having lost his teeth as a result of his meth use. For Moana, references to her appearance and her behaviour also communicated an awareness of stigma, but in relation to broader gendered behavioural expectations. Exploring trajectories of methamphetamine use and desistance among a group of users recruited from rural areas in Arkansas and Kentucky, Sexton et al. (2008) add that in the wake of such assessments, meth users are often able to control their use of meth through willpower and concurrent self-imposed isolation from meth-using social networks.

The importance of changing the social contexts in which problematic methamphetamine use is supported and exacerbated is similarly emphasised in O'Brien, Brecht, and Casey's (2008:362) exploration of 'narratives of methamphetamine abuse'. Their respondents also reported curbing the use of methamphetamine by separating themselves from their peer groups and gang affiliations, following escalations in drug-related social problems. Active decision-making to change social networks was identified as minimising "social cues for drug use and the emotional distress associated with those cultures." That embeddedness within these cultures exacerbates problematic drug use is also acknowledged by Hammersley (2011:271), who describes them as unravelling positive and functional social relationships in the lives of drug users replacing them instead, as he describes in pejorative terms, with "dysfunctional networks of fellow junkies." Thus, 
given that many drug users are able to initiate self-imposed 'exile' from drug-using networks to regain control in their lives illustrates that the relational contexts of drug consumption are fundamental to theorising drug initiation, use and desistance.

Rebecca's experiences of stopping drug use provided another, profoundly gendered view of desistance, where her voluntary engagement in treatment had been preceded by several attempts to desist from using methamphetamine, Ritalin and morphine. As a result, her trajectory of drug use was markedly different to other participants, and illuminated the experience of having successfully abstained from drug use for periods lasting several months. Rebecca's story powerfully communicated the linkages between decisions about drug use, experiences of past trauma, and intimate relationships.

Rebecca identified the first period of desistance as emerging from her making a conscious decision to distance herself from a social network heavily involved in drug use and petty crime. This resulted in her establishing a long-term intimate relationship and having a baby, and in the initial stages of the relationship being positively supported by a partner who was not involved in problematic drug use:

I tried to get away from these people; went out to see a friend, and met someone who I ended up being with for four years - my ex-partner...I wanted to do everything. I - I worked for World Vision, I ah, paid half his mortgage, and I was only 17 at the time, and so like - you know, like being - having that responsibility I - we planned a baby, and had one at 19. We were going to get married. You know, he owned um - he was building up a business.

Were you both using drugs at this time?

No. Um, well he - he smoked marijuana, and I - I actually stopped smoking it, coz I didn't want drugs around me anymore, and this is the time that like, if people - if I knew people were starting to take ecstasy or something, I'd go and warn them about stuff, you know...

(Interview ten, Rebecca, female, 23 years) 
As her story progressed, Rebecca described her ongoing management of trauma associated with past experiences of sexual victimisation and the impact of the Christchurch earthquake on her mental health. These experiences culminated alongside the challenges of being a young mother, and the realisation that she was in an abusive relationship:

...throughout the earthquakes, that was a very hard time for me. You know, I'd given up work so I could be with my wee boy. It was a very hard pregnancy, too. I was - yeah, horrible um, physical pregnancy um, and I really found it hard to connect at stuff. Like, all I wanted was my son, and I'd just sit there and I'd play with my son. I didn't want to go out in the world. I didn't want to go and see people. I got quite depressed. Um, and a lot of that I think was a lot of the drug-use and that returned in my mind when pregnant, like horrors, like um, not terrors, and I - I hadn't gone near drugs in years, and I didn't want to go near drugs, but I'd have these flashing images of people after me, or those people in particular, and I'd freak out - had the worst anxiety. I had panic attacks all the time and that, and um, yeah I left. I left my ex because he did get physically - started getting quite physically abusive.

So I said, look I've got to go. I took my son, and went to see - stay with my mum, and ah, then I went to Women's Refuge and I learned a lot about that kind of relationship. Um, I tried to help him. Like, I always tried to. Even though you know, he'd hurt me, I'd still try and get us bloody help, or him help, or you know, I always try to give people a chance after chance, chance, chance.

(Interview ten, Rebecca, female, 23 years)

Having eventually removed herself from this relationship Rebecca described accessing support resources and maintaining a drug free lifestyle for a period of several months. However ongoing conflict with her ex-partner over the custody of her son resulted in her returning to drug use and establishing an intimate relationship with a new partner who was also a drug user:

...I was clean off drugs. I had got all the mental health support I needed. I got my own house and stuff. So this was a couple of months after we'd broken up - maybe like four or five months. I was starting to do really well.

... (My ex) started getting just horribly abusive, especially over texts and stuff. He took my son for a visit one day, and never brought him back, told me that he was going to Australia - I'd never 
find him again, and I was quite timid. I was still quite scared. I got scared and I met - rebound relationship, I guess you'd call it, for this guy for a few months, and I ended up smoking weed quite a bit there um, coz I was just stressed out, coz I - I wasn't allowed to see my son, coz he'd taken him and I had to wait for the court case to be able to do anything...

I was - just turned 21 at the time, yeah. So yeah, that was pretty horrible...Sorry yeah no so I try not to speak too much emotionally. I think that's probably one of the worst things. I usually get very tearful. I don't tell anyone any of my stories.

(Interview ten, Rebecca, female, 23 years)

Following a court ruling that her ex-partner would have custody of her son due to his disclosing her past drug taking behaviour, Rebecca became entrenched in her new relationship. She would later learn that her partner was also an ex-addict. As this relationship progressed, Rebecca and her partner became heavily involved in problematic drug use and entrenched in a profoundly negative drug-using environment, which necessitated funding her day to day use of drugs through shop-lifting:

Like, I wasn't - you know, I was very vulnerable, but I didn't have the feeling of using again, but he was also an ex-addict. So we basically ended up having our first shot of - together again, and ah just - yeah, well actually we took Ritalin - we'd taken a snort of Ritalin, coz I was - I always just lost the plot after that. I started drinking heaps and stuff and - and he was - I feel terrible, coz he was actually trying to recover himself, but that can't have been good for him as well, and I had no idea he'd been using for 15 years.

I was a professional shopper, so that was how I would get money, and so was he, so I didn't have to go out on the street. So that's a good - um, you know, I'm thankful for that, um but just the places we went to, I mean it was just disgusting - a lot of morphine addicts... Ah, yeah so I did that every day, even three times a day at times, but it was just ridiculous, and I still had that persona of, you know, looked perfect because I had that - still had that innocence really, and this - I was just trying to destroy myself. I didn't really find it fun anymore. I just wanted to be not be around but then it started to really take a hold...

So this is using Ritalin and morphine?

Yeah. Yeah, so Ritalin for me um, I guess that's why it was easy again to slip into meth after, because Ritalin ah, for me, like my mind will go at 1000 paces an hour... 
...You know, it was - it was fast, man. It was like - but as they say, you pick up drugs again and you literally end up back where you were. It's not a slow thing. You know, within a couple of months you've got nothing and no-one, living for - out of the mission bins basically. It's just disgusting.

(Interview ten, Rebecca, female, 23 years)

Recognising that her drug-using lifestyle was unsustainable, Rebecca and her partner accepted an offer of work from friends. This was offered in exchange for their being funded to move to Wellington in order to remove themselves from their local 'drug scene' and focus on 'getting clean'. At this point in her story Rebecca identified this opportunity as empowering her to desist from drug use, which she described by envisaging the possibility of having a drug free lifestyle in a new city:

...we got up (to Wellington) by actually people that owned the, ah, needle exchange - ah, were good friends of ours, and they don't use themselves but they promote that

They were trying to get us help with that, and for us, if we painted their house then we could they would pay for us to come up and relocate, coz they didn't want us to stay in Christchurch anymore. It was just - we were still young.... We really thought we had a choice. We were detoxed off um, heroin.

...was there something that - a sort of a moment where you went, we've got to do this? Oh yeah. We - we were trying to get out for a while. I went into respite for a couple of days. I couldn't do it. I'd run out, but we had nowhere to live. We had nowhere to go there. I mean, the only people that we knew were junkies.

Yeah, well actually I came up to Wellington and we were determined. God, we were determined, um but I still - you know, I knew my partner - I'm still with him, and I knew he was an addict, um but he always - he'd wanted to get us out...It was just like our new - we had like these dreams, like it was like New York or something. We'd sit there - junkie dreams almost - and we're going, we're going to be there one day, Babe - we're going to be in Wellington and it's going to be awesome.

(Interview ten, Rebecca, female, 23 years) 
Having moved to Wellington Rebecca and her partner took the opportunity to focus on establishing a drug-free lifestyle, and which eventually motivated Rebecca to self-refer to the Bridge Programme. In the first few months both succeeded in being drug free and enjoying new social connections through gaining employment and enrolling at University. However, despite her efforts to desist from drug use Rebecca continued to experience ongoing trauma having been separated from her son, which she identified as contributing to another period of problematic drug use while living in Wellington:

So my focus was on working or on studying and it was just - you know, I spent hours and hours trying to just study, study - do the best I could. Um - rung up and told him one day, you know, I've been doing really well - I've been clean five months now, and he goes, whatever - no-one fucken believes you. You know, he's still smoking marijuana. You know, and I hadn't done anything, and I was just crushed, and I just thought, this is never going to happen, eh.

(Are) there in the future, good prospects to get back with (son's name)?

Yeah, for me yeah definitely. I mean, um - yeah no, I've gone through hell and back with this stuff. You know, I came back up here, I had to relapse again. I think that was with methamphetamine...and then we'd done so well to stay clean, and it was just at a party one day, and someone said, hey have a smoke of this, and I was like, oh I dunno. My partner, you know, had already done it before, so he was like, nah it's alright by me Bub have some. I was like, okay well you know, I'm feeling pretty shit anyway about my life.

(Interview ten, Rebecca, female, 23 years)

At the time of the interview Rebecca was not using drugs and was receiving therapeutic support to help her manage an array of mental health issues which she identified as being exacerbated by her ex-partner continuing to exercise control over her through having custody of her son. Rebecca described her ongoing experiences of relapsing, and attributed her trajectory of problematic use of drugs to her mourning the loss of her son and remaining subject to the controlling behaviour of her abusive ex-partner:

I decided when he was almost taken off me, and there was always threats that he was going to go do this and that if I didn't do what he said - he said I'm not allowed to see him and that, before I started using again. This is after the court case. I mourned for him, and I blocked out so much 
that after my first shot and that um - ah, I couldn't remember being pregnant, couldn't remember having - I remembered my son, but I couldn't remember anything about it, which is horrible, and the um, I went - I went to go and see him, and I read - I think that was a real tipping point for me to turning to any hard addiction back in Christchurch, was I went - went to see my son, and um, I had to see him at my ex's house, which was hard anyway, because you know, I hadn't been there for a long time with him, but he was still an abusive - but he was trying to be nice to you, but then he was still horrible to you at the same time. Like, I just didn't know what to do.

...That's when I started using pretty hard core, coz I was just having - and it was more - you know, it was just that emotional state that I'd - had to basically grieve for my son, coz I was so scared that he was going to be ripped away from me, and there was nothing I could do...

(Interview ten, Rebecca, female, 23 years)

Rebecca's story is unique in the context of this research because it articulates experiential themes that were not present in other desistance narratives. While other participants had successfully altered their drug-using repertoires when confronted by various, and often dramatic turning point events, they had not storied prior experiences involving prolonged periods of abstinence. Equally, participants who had no experience of treatment and who were still regularly using drugs at the time they were interviewed had only modified their drug use, despite some experiencing significant harm during transitions involving the use of particular substances.

Rebecca's desistance journey accorded with both accepted understandings of problematic drug users likely relapsing several times before arriving at a point of complete abstinence (Boeri, Harby and Gibson:2009, Jessup et al:2014), and with life course perspectives of desistance from offending, which acknowledge that "criminal activity is sporadic, and that offenders have a tendency to drift or 'zig zag' in and out of crime" (King:2013:149). Her story also provides gendered insights into why her experience of the desistance process had been patterned in this way, by pointing to the role of intimate relationships in her drug-taking decisions. For Rebecca, the confluence 
of past victimisation experiences, her ex-partner' control over access to her son, and her becoming involved with a partner who was also 'in recovery', had contributed to a situated context which had exacerbated the risk of her repeatedly returning to drug use. Rebecca's desistance experiences are reiterated within research evaluations of desistance and relapse as being influenced by the social experience of recovery; Boeri, Harby and Gibson (2009:148) identify in their study of 40 current and previous methamphetamine users for example, that reasons cited for returning to meth use typically involved trauma in meth users lives, the use of methamphetamine offering a functional means of allowing individuals escape from ongoing psychological pain, which often resulted from ongoing relationship problems.

Boeri et al. (2016) also note in their interviews with 29 poly-drug users, that intimate relationships can affect patterns of drug use in different ways: as sites of positive social capital accumulation, relationships with supportive, non-drug using partners constrain drug use and facilitate access to new social networks outside of drug scenes. For some drug users, intimate relationships can function as a substitute for drug use, resulting in prolonged periods of abstinence. When the relationship ends, the risk of returning to drug use, or 'relapsing', increases. This risk multiplies when drug users are unable to establish intimate relationships outside of recovery groups, which reduces the likelihood of developing relationships outside of drug scenes, and "keeps individuals stuck in a perpetual recovery microcosm" (ibid:103). This observation resonates with the theoretical importance of accounting for the inseparability of social and structural factors, which constrain efforts to maintain desistance by limiting which social resources drug-abstainers are able to access, as well as the contexts which make those resources accessible. 
Rebecca's story also communicated her difficulty in reconciling her past drug using behaviour as a mother, and her ongoing struggle with the trauma of having lost custody of her son. In contrast to other female participants whose drug use was constrained by events culminating in losing access to children, Rebecca's story revealed how the ongoing impact of this experience had undermined her efforts to "stay clean" for several months, and had contributed to her continuing to use drugs in order to cope with feelings of grief. This experience emphasised how pathways to stopping drug use are subject to, and shaped by gendered realities, notably for female drug users who are mothers. As Martin (2011:338) explains having interviewing 21 intravenous drug users who were young mothers, mothers who identify as drug users often struggle to disentangle themselves from their previous identities; while the experience of birth is acknowledged as the most likely life event which constrains women's drug use and empowers them to abstain, " at the same time, becoming a mother can complicate and confound a woman's ability to restore her spoilt identity", given that mothers are heavily stigmatised for drug use. Martin (2011:353) goes on to make an observation that resonates with the emotion conveyed by Rebecca when communicating her awareness of not being able to be a mother to her son:

“...being a mother and avoiding one's former drug-using networks were not on their own enough for these women to re-event themselves. Some felt deeply discredited by their former lives as 'addicts' or 'junkies', and that, by virtue of having lived these lives, they had 'done wrong'. For these women, the ability to adopt a non-addict identity, to see themselves as worthy and capable of being mothers - seemed to require others support and recognition, which was not always forthcoming (Martin: 2011:353)."

Rayleen's desistance narrative also involved experiences of stopping drug use in the social context of being a mother, and in the context of her ongoing involvement in sex work. When describing the sequence of events that had led to her stopping drug use, Rayleen's story revealed further variations in gendered experiences of desistance and identity transformation: Rayleen's decision to stop using drugs had occurred in the wake of an extensive history of problematic drug taking and her managing multiple addictions. 
Her pathway to desistance had been influenced by a turning point experience culminating from having been involved in the criminal justice system for several years, and her facing the threat of having to abstain from drug use while in prison:

I was going in and out of jail a lot. Because of my drug habit I wasn't turning up to court (laughter), wasn't doing my probation, because I was so fixated on um...because was too - so busy scoring, so I was so busy worrying about scoring a drug, and like if I knew I had to go to probation or had to go to court, but I needed that drug to go to court,...otherwise I'd be sick all day, because my body would just - when you're detoxing off that stuff, yeah it's - it kills you.

What - what are the feelings like of detoxing?

Um, oh your body - oh, your whole body's cramped, you're sore, you're sick, you can barely walk. It's - it's like you're dying. Well, that's the term (laughter). It's like you're dying. Um, because I was such a heavy drug-user, um I started having seizures detoxing, so I had to have something, basically.

Did that scare you?

Yeah. Yeah, it did, and um I never expected to ever having something like that, and I still have until this day, which is sort of took - taken over my life, but yeah I had them in jail when I detoxed in there, because obviously when you go to prison, they don't just hand you stuff because you're detoxing.. and they sort of didn't know what to do, and um, took me to the hospital and um, yeah like I would (get) seizures, too from head injuries, also because I'd had so many hits to my head, too and I wasn't obviously taking care of myself properly when I'm on all these drugs, and obviously when you detox um, (laughter) parts of these sicknesses start coming up for you.

(Interview eight, Rayleen, female, 33 years)

Following a court appearance where the severity of her addiction was acknowledged, Rayleen completed a prison sentence and was referred to the Community Alcohol and Drug Service to access methadone. Although Rayleen was initially concerned about using this drug, when she reflected on this point in her story, she acknowledged that being prescribed methadone was fundamental to her being able to regain control over her problematic drug-taking behaviour: 
...I still had a filthy habit obviously when I went to prison. Um, but it was the judge that turned around and said - because he was worried, because obviously know your history, and all the judges in Christchurch know me, so they knew that - I think they were worried that I was going to get out of prison this time and OD and kill myself. So they decided to refer me to CADS properly, because if a judge does it, it gets done faster.

So the day I got out, he decided to put me on the Methadone program, which I was a bit stunned, because um, obviously Methadone another drug (laughter), um and I - because I've got liver problems, kidney problems, plus my seizures um, and I also picked up Hepatitis $C$, and I wanted the - the doctors and that wanted me to start the treatment - that treatment, and because when you use drugs you can't do it, so they were keen to get me better and well, for my own being. Um, yeah so the day I got out of prison I started Methadone, and if I wasn't on the Methadone within six months, I would have to finish the rest of my sentence, which was go back to jail.

So that was motivating you?

Yeah, that was my motivation really. If it wasn't for the judge putting me on the Methadone, um yeah I don't know where I'd be today, actually.

(Interview eight, Rayleen, female, 33 years)

Unlike other female participants' who were also mothers, and who had similarly experienced having children removed from their care at various points in their trajectories of drug use, Rayleen did not story her present experience of needing methadone to recover from her addiction by conveying any sense of shame about her drug-taking past behaviours. Instead Rayleen emphasised her coming to terms with no longer being able to use drugs or continue with her previous lifestyle, identifying the pragmatic and positive effects of using methadone, and its role in helping her transition away from the social arrangements that had facilitated her past use of methamphetamine:

... I had to cut my friends off that were in that scene, and it was really hard, because I had a mate - he was my best mate, and yes I used to support and help him with his habit, too and he was gutted, because the day I got out I - I think it was like, oh a couple of weeks, and I had a shot, and I didn't feel it, and was shitty because I'd just spent hundreds of dollars, and I was angry as, and 
you know, he was on the ground and wasted, and (laughter) and I was nutting, and so I said, give me that - give me that.

So I had another one, and it - still nothing worked, and I thought, oh no - and I was screaming at him; this is all your fault, rah rah rah. Then I thought, oh my god, the Methadone's working (laughter) shit. Then I thought - so I said to him, oh look I'm going home - this is a waste of time with me - nothing's happening anymore...

Yeah (laughter) so he rung up the next day and he was hanging out and I said, well what do you want me to do? He said, I need you to buy it. I said, well why should I buy you it - what's that going to do? You know, and he said, well let's have a shot. I said, well what's that going to do with me - didn't you see yesterday - I just spent thousands of dollars on something that didn't work. He - he ended up in jail a week later, because he did an armed robbery (laughter) and tried to blame me for it, but - but yeah there was - that was it from that day forward; I knew, oh shit this stuff's working - it does work. So I had my money to myself, which was amazing (laughter).

... I didn't have to work every night, and I didn't have to stay out till the crack of dawn, and um, you know, I could have two nights off work, because l'd already had-made thousands the night before, so I didn't have to go run off and buy a drug, and because I had all this money I was didn't know what to do with it, so I - yeah, I - clothes - I've got a clothes addiction (laughter).

(Interview eight, Rayleen, female, 33 years)

As her story progressed, Rayleen articulated her experience of transitioning from her previous identity as a methamphetamine user to her present identity as a user of methadone. This point in her trajectory of drug use was distinguished by her describing both the positive impact of using methadone, and by highlighting the challenges of managing ongoing health complications through a new form of drug dependency, and its potential to similarly change her appearance and outwardly identify her as being a drug user :

....since I've been on the Methadone, it's - um, me and my sister-in-law, because she's on it, too the one that got me into all the (laughter) drugs, um - me and her were discussing the other day how different thing are, like we're not fixated, waking up in the morning on scoring and um, just - you know? It's like your whole thinking changes. 
...It's - it's the one thing keeping me alive. It's - yeah, I still question it, because it just sort of plays with me a bit. Like, I get rid of one, but they've substituted with another, but obviously it's legal, because you know, the Government have approved it. Um, but then it's still a drug. You know? So I'm not completely drug-free.

But you want to be (drug free)?

Yeah, I want to be, but um, I - but then there's that part of me, too that if I don't actually have this drug, will I die because my body is so fucked-up with it, you know, as it is, and the doctors and my Methadone people say it is the one thing that is keeping me going.

...but - I've just found out, because my heart stopped um last month, and I just found out that the Methadone plays around with your heart, and - and I was a bit, why didn't you tell me this? They probably did tell me, but at - when they first probably told me about it in the prison I wouldn't have been onto it, and took in everything they said, and yeah I had no idea, and they told me I had to chew chewing gum a lot, because my teeth will start deteriorating.

...because your mouth dries out?

Um, something in the Methadone makes your teeth rot. So there are side-effects after all, and my other fear was putting on weight on the Methadone, but everyone's - I have put on heaps of weight, but to everyone else I look healthy (laughter).

...l actually tried to get off the Methadone last year and they were quite adamant and said, no you're not ready. I thought, oh yes I am (laughter). They said, no there's no way.

... so I guess you have to have a lot of faith then, in other people, or other people making drug decisions for you?

Yeah, I do, and obviously they're probably right. I probably am not ready. You know, and plus with my partner now, who's in and out of jail all the time, I think too they look at the - you know, my situations, too like; could I handle that if I was off the Methadone, and would I fall back into going back on the Meth if um, something happened. So like if me and partner had a fight, and I wasn't on the 'Done', would I rush off and go get a shot, or yeah would I not? There's a 90 per cent chance that I'd take off, and go get a shot (laughter).

It's good that you've got that awareness.

Yeah. I just - it does frustrate me, because if I want to go on a holiday I have to organise the chemists in the next town, and I have to ring that chemist up and make sure that I can come there and pick up, and get accepted in to that chemist, too. Um, which is a hassle, you know and then there's the - sometimes - some days I can't be bothered going to the chemist to pick it up 
(laughter). You know? I just want to stay home, but I have to um, because I know if I don't have it I'll be sick as, and - and just the fact - how long am I - you know - how long am I going to be on it, and I get worried because I think, will my teeth fall out, and (laughter) will I end up like me mother was...?

(Interview eight, Rayleen, female, 33 years)

Rayleen's story highlighted different understandings of problematic drug use, stigma and the desistance process in the context of her experience of transitioning from using methamphetamine to using methadone. For other participants, being 'in treatment' had resulted in their being geographically separated from drug scenes, an experience that was identified as being a positive outcome of their having stopped using drugs. Comparatively Rayleen's experience of stopping methamphetamine use was occurring within the risk environment that had previously facilitated her drug use. Disconnecting herself from this environment had not been storied as an exclusively positive experience. Instead, Rayleen communicated a sense of ambivalence and at times disappointment in moving away from her drug-using social network.

Using methadone had forced upon her a physiological state where she could no longer enjoy using drugs, which accorded with a view of recovery as process that Martin describes as often involving "the loss of a familiar way of life and its pleasures that are not easily forgotten or replaced" (Martin:2011:339). In examining the recovery process, Hughes (2007) also notes that to suddenly stop engaging in drug use individuals must give up past behaviours and identity practices which previously defined who they were, and this in essence, means individuals must learn to stop being 'themselves'. Recovery is thus a complex process which is dependent upon developing and expanding new relationships, and which may involve introducing different drugs such as methadone, whose pharmacological properties make new configurations in social relationships and self-identity possible (cited in Martin:2011:339). 
Stopping methamphetamine use through methadone treatment had significant positive effects, notably in eliminating Rayleen's motivation to access drugs, and enabling her to enjoy the financial benefits of engaging in sex work. Rayleen also makes other positive references to methadone, its use 'changing her thinking' and helping in 'keeping her live', which communicated themes in theoretical appraisals of methadone treatment as being a neo-liberal expression of governance over what Reith (2004) defines as 'disordered consumption'. As Reith (2004) explains, consumers who subjugate themselves to the effects of drugs and become problematic users are acknowledged as having failed to safeguard against threats to their individual freedom. In the absence of any capacity to 'regulate choice', mandatory treatment strategies such as methadone prescription are deployed which aim to restore control in individuals whose behaviour had previously been uncontrollable. This process enables newly controlled individuals to return to their previous, and culturally desired, status as consumers who have the capacity to maintain their responsibilities in making the right choices (Reith: 2004).

However, the experience of 'ordered consumption' and re-instatement of freedom methadone provided was clearly offset by Rayleen's fear of exposure to new forms of risk associated with this therapeutic form of governance and its anticipated impact on her appearance. Where methamphetamine use had previously been described by Rayleen as offering the benefits of assisting her in controlling her weight and making it easier to talk with clients, the risks of using methadone to desist from meth use were understood as contributing to her gaining weight, compromising her cardiovascular health, and the visually stigmatising effect of damaging her teeth - the hallmark of tropes warning others about disordered consumption.

The contradictions in identity transformation that result from using legally sanctioned drugs as part of the process of desisting from the problematic use of illegal drugs pointed to the challenges that recovering drug users face in fashioning a new sense of self within the context of treatment for addiction. For many drug users, methadone use - or "liquid 
handcuffs" - is widely understood in drug lore as constituting a transition towards the use of another addictive drug, which embroils its users in regular cycles of contact with treatment centre staff who re-enforce the stigmatisation of their 'clients' (Montagne:2002, Harris:2015, Notley et al. 2015). As one recovering user reported to Olszewski et al. (2012:23),

“Methadone keeps you from being sick, that's true, but you really get dependent on that drug, and, what's worse, you are dependent on the system and all the things that follow, all their demands and rules. You lose your freedom and if you are not strong you lose your self-respect."

John's desistance narrative communicated themes which aligned with this widely accepted understanding of using methadone. His trajectory of problematic drug use had unfolded over a period of almost 25 years, during which his lifestyle had been organised around daily involvement in buying, selling and using various drugs. At the time of his interviewed John identified as 'being clean' for roughly 70 to 80 days. His motivations for stopping drug use had been initiated by a turning point experience involving the death of his sister and his ongoing contact with the police. These experiences, coupled with the unsustainable financial demands of maintaining his 'habit' resulted in a process of self-reflection and John planning his stopping drug use:

...Um, what - what happened; it was a bit of a eureka moment to - well, it's not really. Um, my sister came back from England. Um, she should have died in England, but she didn't. She made it back here. Um, she had lung cancer, and I was looking after her in hospital doing anything from wiping her arse to feeding her, all night, every night for about two weeks. Um, I'd decided to kind of give up a little bit, before she came back, because I didn't want to, you know, I - you know, wanted to be, you know, relatively straight really, but she'd come back sort of unexpectedly. Ah, I thought she'd have another six months to live, but you know, anyway. So - so there I was, running a fucken habit, bloody spending, you know - so I was spending \$200-\$300 a day. Um, oh well \$100-\$200 let's say. Um...

- so I'd be up all night looking after her at the hospital, and then during the day l'd be trying to keep all of my things going as well. So you know, I was up for 60-70 hours here or there, and then I'd crash for 10 and then I'd be up for, you know, another 50-60, 70 hours, and then I'd crash for another 10, or you know, some days even a whole day. You know? I mean, I'd see the whole day 
sleeping. Um, and that was running me absolutely ragged, and everyone could see it, apart from me, of course.

...We had some good discussions about death and drugs and all sorts of stuff that we'd never usually talk about. Anyway, so she died. Um, and then about that point in time, I had another run-in with the police, actually that very day ah, which I'm in court for soon.

Um, and so I decided to give up the weekend after the funeral, because I had my daughter that weekend, so I'd be no good giving up any other time, because then the weekend following that when I had her again, I'd be - I'd be crook and irritable.

So yeah, it was not so much a eureka moment, but more a-you know, there's all of this shit going on, and really I'm 30-fucken-nine, and I shouldn't be being a teenager anymore. You know, because that's all I've done really. Like, I've said before that, you know, um oh you know, it's always just been a joke, but you know, this time it's kind of more serious, is that, you know, I went to a party when I was 14 or 15 and l've just sort of, you know, come back. You know? So that's about - that's about the face of it. Ah...

(Interview thirteen, John, male, 39 years)

Although John was not involved in the Bridge Programme, he had contacted the Community Alcohol and Drug (CADS) service to assist with his stopping drug use. This required his agreeing to use methadone, a decision which John found difficult to reconcile in the context of wanting to become drug free, as well as his understanding that methadone would likely be an ineffective form of treatment:

Are you involved with any addiction services at the moment?

Um, they are aware of me. Um, I did go to them, pfft 80 days ago, for some-for some help um, because I know detoxing was going to be shit....So, um yeah so I went to them to ask them for help anyway. Their answer was to put me on the Methadone program, which is the answer for everything nowadays. Um, so...

So, how would that be if you ... want to get away from drugs?

Yeah, well yeah um, it's - it's a bit of a disaster...Um, like you know I just want to, you know, like knock them on the head. You know? I'd um - so really, I just wanted to detox. Like, whether - 
whether it was in-patient, out-patient fucken whatever um, but they perceive - they still argue that - right, it's called mental health and addiction today.

...So once you decide that you don't want to be doing drugs, the really worst thing they can offer you is to go on Methadone, because Methadone's - you know, I was already using it. You know, and it's um - it's fucken addictive.

...so the psychiatrist, (names person) decides that um, it's better that I get put on the Methadone maintenance program so that I can ah, look at my underlying issues. Right?

Now, I don't know anyone in the history of Methadone who's ever managed to look at the underlying issues ah, whilst on Methadone. You know? It's just - it um - I know people who go to jail on Methadone. I know people who have fights with police on Methadone. I know people who commit crimes on Methadone, but I don't know anyone on Methadone who actually you know, um you know, makes advances in their own personal - personal welfare, really. You know?

(Interview thirteen, John, male, 39 years)

John's story communicates similar contradictory themes to those present in Rayleen's narrative of desistance. John had succeeded in stopping all drug use for approximately three months, and this was likely to have been assisted by his using methadone, although to what extent methadone had positively contributed to his 'staying clean' had been discounted by John emphasising the limitations of methadone treatment. Like Rayleen, using any kind of drug to achieve a state of abstinence from the long-term use of illegal drugs contradicted his understanding of being 'drug-free'. This experience accorded with other qualitative evaluations of desistance and methadone use, where methadone users commonly report that it is difficult to consider themselves recovered or separated from the world of illicit drug use, notably when many may have used methadone in illicit contexts outside of treatment settings, as John had reported (Notley et al. 2015). 


\section{Conclusion}

As I have noted, the arguments developed throughout this thesis have not avoided the pitfalls associated with drug scholarship's tendency to engage with easily accessible samples comprised of the 'usual suspects' (McCoy et al. 2005). Individuals engaging with addiction services are immediately visible to researchers and are less likely to fear disclosing who they are, or be reluctant to talk about their past drug taking behaviours. This is not to suggest that openly discussing the lived experience of addiction for recovering users is easy; however, drug users who have not needed therapeutic support or ever had police or other agency involvement are more likely to safeguard against disclosing who they are and remain out of reach of those researching stigmatised drugs such as methamphetamine.

Having defaulted to interviewing an easily accessible samples of drug users, the stories explored in this chapter thus unwittingly emphasise many of the drug-using stereotypes deployed in authoritative discourses that researchers set out to challenge. While problems of representation in the context of research conducted with individuals in treatment for addiction are difficult to reconcile, the utility of theoretical engagement with their stories about stopping drug use lies in helping to disentangle, and make apparent, that problematic drug users can and do exercise agency over drug-taking across the life course, contrary to pejorative understandings of addiction.

As the stories presented in this chapter demonstrate, there are multiple experiential pathways to desistance from problematic drug use, with variances across individuals, substances and social contexts resulting from an aggregation of structural, meso, and individual-level processes (German et al. 2006). Put simply, when viewed from a life course perspective, decisions about, and motivations for stopping drug use, like desistance from other criminal behaviours, are shaped by inter-play between individual choices and "a range of wider social forces, institutional and societal practices which are beyond the control of the individual (Farrall and Bowling: 1999:261)". Understandings 
of desistance from drug use as being an absolute state of abstinence which follows individualised risk assessments thus obfuscates a view of desistance as a process which involves movement across the life course, where turning points can empower and motivate individuals to move towards life projects which help in separating them from past drug-taking behaviour.

Examining the realities of stopping the use of methamphetamine and other drugs brings the confluence of these processes to the fore by revealing complexities which are often common to how individuals experience desistance from problematic drug use. The reciprocal nature of drug use and interaction with addiction services problematises the processes of identity transformation theorised as being fundamental to stopping offending behaviour, and in conferring 'addict' identities to those required to recover from their drug use, individuals wanting to desist from drug use invariably struggle to disentangle themselves from their past, and highly stigmatised, drug-using lives. Governance over their behaviour through mandated treatment instruments confines drug users to social settings populated by other, recovering users, where opportunities for engagement in non-drug using social networks are also constrained. Assimilating beyond treatment environments, recovering drug users are subject to the inevitable pull of past drug using networks, where previous experiences of social disadvantage, trauma, and dysfunctional intimate relationships must be reconciled without involvement in, or reliance upon, the use of drugs.

Despite these challenges, many of the stories presented here indicated that, at the same time, experiences of treatment can be positive, valued, and life changing for drug users. In temporarily separating drug users from profoundly negative social environments, therapeutic settings enable problematic drug users to exercise agency in ways that previous social arrangements had not allowed. Similarly, pharmacologically induced states of self-control through methadone prescription allow for new behaviours and motivations that drug use had previously excluded. Thus, even though individuals 
remain entangled with drug-using identities, the desistance process that follows treatment allows individuals to begin engaging in new relational configurations and "practices of the self", which initiates future pathways to desistance from problematic drug use (Martin:2011:339). 


\section{Chapter seven: thesis conclusion}

This thesis has made a case for the theoretical importance of agency, culture and structure when individuals make decisions about drug-taking. To do this it has set out to explore the role of agency in decisions about starting, using and stopping methamphetamine use storied by 17 individuals who had used methamphetamine, in addition to other legal and illegal drugs. Their stories revealed personal, and at times traumatic experiences, which powerfully communicated how their drug use had been subject to, and influenced by, an array of social and structural constraints.

Why their stories are essential in helping theorise, explain, and indeed humanise the processes which underpin drug-taking decisions was made apparent by introducing the social and political drugs-landscape which dominates debates about drug use. As I demonstrate when reviewing how the media frame issues about drugs and drug users, politically mediated discourses continue to enter the public domain when particular drugs are flagged as being subject to a 'dangerous' upsurgeance in use, and causally linked to a raft of escalating social ills. These 'panic' discourses structure how we are permitted to think about the identities of those who use illicit drugs, and what we come to understand as the reasons why individuals engage in problematic drug-taking behaviour. By applying these observations to evaluate cultural claims about methamphetamine use, it is revealed that media discourses have deployed familiar stigmatising tropes imbued with 'war on drugs' rhetoric to vilify those who 'choose to use' methamphetamine. When viewed through the lens of drug-panic scholarship, they help reveal stigmatised drug-using identities that are simply mediated accomplishments, which tap into and reinforce gendered, racialised and class-based fears of 'otherness', elevating the threat that drug-users pose to 'ordinary' New Zealanders (Greer and Jewkes: 2005). 
The discourses which feed into the creation of drug panics continue to cast a long shadow over the lived experience of drug use and drug addiction. They epitomise the typical cultural vocabularies surrounding drug use, which constitute what Brown (2007) summarises as atheoretical explanations of drug use; explanations that routinely theorise drug use as simply being the outcome of 'poor choices'. The ontological politics of these discourses prioritises the notion of drug addiction as being exclusively biological in origin, where changes in brain function resulting from the consumption of addictive drugs creates individuals who willingly subject themselves to experiences of poor mental health, engagement in sex work and incarceration (Dwyer and Moore:2013).

When these explanations leech into rational-choice policy instruments targeting those who 'choose' to use inherently dangerous drugs such as methamphetamine, drug users are expected to engage in agential risk assessments to determine the perceived costs and benefits associated with their drug-taking decisions. Individuals who are identified as unable to control their use of methamphetamine are understood as being wilfully self-destructive, and therefore pathologically incapable of self-regulation and full consumer citizenship. By locating decisions about using drugs at an individual level, rational choice policies also succeed in obfuscating the lived experience of drug use, thereby discounting the social, cultural, political and economic complexities intersecting drug use and drug addiction. Emic perspectives of drug-taking are thus fundamental to countering individualised assessments of drugs and drug users advanced within authoritative discourses and exacted through a range of punitive policy instruments. What is needed then, and what is intended using the stories presented here, is an effort to evaluate and theorise drug use rather than drug users (Hamersley: 2011).

As this thesis has argued, theorising drug use begins by 'deconstructing drug problems' and challenging the assumptions which underpin them. This endeavour has been advanced by the corpus of ethnographic scholarship theorising links between individualised experiences of drug use, and the socially situated context of their occurrence (Hallam and Bewley-Taylor: 2010). This research, which is seldom reconciled 
in the swathe of policy scholarship enumerating risks posed by drug users, is critical to informing debates about drug use and informs the arguments developed throughout this thesis. It succeeds in revealing the complex realities of lived experience, and contextualises the ways in which a behaviour normatively defined as 'risky', is incorporated into the everyday lives of individuals who use drugs. It also shows that, in the context of drug scene entrenchment, transitions towards more harmful drug taking practices are part of a much larger story, where drug users must negotiate a myriad of risks inherent in experiences of homelessness, poverty, law enforcement, and everyday violence, within the settings they occupy (Fast et al:2010:3). By questioning how these environmental complexities intersect the lived experience of drug use, theoretical attention has been shifted to the decision-making processes underpinning drug initiation and drug use as it occurs in socially situated contexts. This has contributed to theory building by rendering more visible external constraints over 'reasoned' choicemaking and risk avoidance, thus problematising the privileging of agency within authoritative accounts of drug use.

How these environmental complexities and constraints impact decisions about starting using and stopping methamphetamine use is the primary focus of this research, the evaluation of which has been undertaken using risk environment and life course perspectives of drug-taking behaviour. Both perspectives function as heuristic devices which help explain how factors exogenous to individuals influence decision-making processes, and have been applied here to evaluate understandings of drug use and risk. Both theorise the importance of social and structural forces, in different, but theoretically complementary ways, the sum of which provide a more nuanced understanding of drug-taking behaviour.

Risk environment perspectives of drug use emphasise that although drug-taking risks are often understood and negotiated at an individual or agential level, risk awareness and risk assessments are undertaken within social situations, structures and places, or, as Rhodes (2002) and other risk environment scholars have theorised, within risk 
environments (Rhodes et al: 2003, Fast, Small, Krusi, Wood and Kerr: 2010, Mayock, Cronly and Clatts: 2015). By building on the prescience of earlier research efforts examining how understandings of 'risk' and danger are socially organised, risk environment scholarship succeeds in demonstrating that, within such environments, social, structural and physical environmental factors interplay in ways that constrain agential decision-making and hinder risk avoidance.

Where a focus on risk environments makes visible the structurally vulnerable position of problematic drug users and identifies risk factors which exacerbate engagement in drug-taking, life-course criminology examines how positive and negative changes in the structural position of drug users can result in the re-assertion of agency and desistance from drug use (Sampson and Laub:2005). Life course criminology helps explain how cumulative experiences of environmental risk converge at specific turning points during lifetime trajectories of drug use. When confronted with these turning point experiences, individuals who are motivated to transition away from drug use must then choose from a limited array of structures, situations and networks offering support (Sampson and Laub:2003).

This research succeeds in synthesising the theoretical imperatives which inform these two perspectives, and uses them to analyse the lived experience of methamphetamine use as it was storied by 17 New Zealand drug users. In doing so it sets out to examine why individuals engage in culturally vilified behaviours imbued with risk, such as using methamphetamine. Making the social processes which underpinned their drug-taking decisions visible for analysis was achieved by developing and applying a qualitative methodology to examine life-course trajectories of poly-drug use described by participants during the interview process. The use of narrative methods allowed for thematically engaging with both the content of their stories, as well as the subjective elements of story-telling in the context of a research interview. This process revealed the meanings participants attached to different forms of drug use, and how those meanings had informed their transitioning towards methamphetamine initiation. When 
sharing these experiences, participants also storied self-identities which communicated tensions between their resisting or internalising profoundly negative attributes ascribed to methamphetamine users through stigmatising discourses, elements of which intersected the institutional requirements of identifying as 'addicts', in order to conform with therapeutic constructions of 'recovery'. This content-rich data was foundational to theory-building throughout this thesis, and provided a unique, emic perspective of methamphetamine use in New Zealand, which, like other forms of drug use, continues to be under-researched in a qualitative context.

Incorporating these theoretical and methodological components to provide a more nuanced perspective of drug use, risk and decision-making began with an analysis of participants' poly-drug using experiences. What emerges then from the storying of polydrug use is a user's perspective of how life-time trajectories of problematic drug use had resulted from early initiation into the problematic use of alcohol, tobacco and cannabis, with escalating exposure to drug-taking opportunities within drug scenes transitioning participants towards more harmful drug-taking behaviour. Storying these poly-drug using experiences helped contextualise when and how appraisals of risk were undertaken by participants. Early exposure to the presence of drugs in family homes and among peer groups revealed that some experiences of drug initiation were opportunistic and impulsive, which, for many participants, had signified engagement in long-term trajectories of problematic drug use. As drug use escalated, participants drew upon past experiences of drug use to determine the severity of risk associated with new drug-taking practices, notably those deemed irreconcilably risky, such as using methamphetamine. Thus authoritative or 'expert' definitions of risk associated with methamphetamine use were reconciled by using lay-risk knowledge accumulated across life-time trajectories of drug-taking behaviour. Equally, when new drug using opportunities were situated within the social context of their occurrence, rationalising risk was also evidenced as situationally dependent, where risk environments shaped participants' of risk acceptability (Rhodes: 2002, 2003, Mayock: 2004, Williams: 2013, O'Gorman: 2016). 
By accounting for the theoretical significance of poly-drug use, this research marks a significant departure away from the dominance of single-substance focussed explanations of drug use, which typically examine harms caused by the problematic use of a specific drug, and generally, a specific route of ingestion. Focussing on poly-drug use raises questions about the theoretical efficacy of conceptualising samples in illicit drug research using single substance categories, when more accurately, they should be defined as users of multiple drug types. Explanations of drug use which link an array of behaviours and attitudes to the use of a particular drug are also likely to be unhelpful given that poly-drug use is a defining feature of both recreational and problematic drug use. This is particularly salient when examining authoritative discourses which place methamphetamine at the apex of harmful drug use, when in fact other drug-using practices are often perceived as more 'risky' by problematic drug users. Moreover, categorising drug users according to the use of one drug-type may be helpful in allowing policy-makers to discursively demarcate those who are 'law abiding' users of licit drugs, from those who are 'criminal' users of illicit drugs (Taleff and Babcock: 1998, Taylor: 2008, Hellman: 2010). However, this is a false dichotomy, given the inseparable presence, influence and enduring negative consequences of legal drug use this research identified by analysing transitions in drug use across the life course.

Evaluating trajectories of poly-drug use also succeeded in revealing an array of social relationships, connections and assemblages intersecting participants' experiences of methamphetamine initiation and use. Providing this under-researched perspective of drug-taking in a New Zealand context reiterated the theoretical utility of understanding drug use as a social, rather than individual, accomplishment (Williams: 2013). This was evidenced by storying the presence of family, friends, intimate partners and drug-using associates, and by identifying their group memberships as gang members, sex workers, and active participants in economies of illicit drug use. These social arrangements supported decision-making that was not exclusively rational, nor simply opportunistic. Instead, exposure to pro-drug attitudes and normalised drug-taking behaviour during adolecence resulted in their becoming 'early risk-takers', where extending normative 
risk boundaries had facilitated entry into structurally vulnerable networks of other problematic drug users (Mayock: 2005). Within these drug-experienced social networks, the use of methamphetamine and other drugs was understood as a viable means of achieving self-confidence, status and social connectedness. These relational contexts also pointed to broader structural and material constraints, where participants were subject to an elevated risk of drug dependency.

That structural realities intersect and constrain agential decision-making was further evidenced by this research when revealing how gendered power disparities had impacted relationships with intimate partners, in performing sex work, through gang involvement, and by participating in drug manufacturing and distribution. These power disparities required participants to manage and negotiate profoundly gendered risks, experiences which disproportionately impacted female participants, including domestic violence, gang related intimidation, experiences of sexual assault, and the forcible removal of children through social service interventions. The inseparability of these relationships had in many instances compelled participants' to engage in risk-taking and increasingly harmful drug-taking practices, prolonging their experiences of problematic drug use. Contextualising these realities thus emphasised the positions of structural disadvantage that participants' occupied within specific risk environments, which did not always accommodate engagement in reasoned choice-making or judicious risk avoidance as is imagined in authoritative accounts of drug use.

Theoretical engagement with the social dynamics underpinning the use of methamphetamine and other drugs provides a more robust account of how and why individuals engage in risk-taking behaviours. This helps challenge individualised conceptions of risk which do not adequately capture the complex nature of risk taking, and contributes to broader debates about drug use by redressing the limitations of policy-based research, which continues to over emphasise extra-environmental or individualistic interpretations of drug taking and its associated risks (Rhodes et al: 
2003:303). That more nuanced appraisals of how individuals come to be entrenched in long-term drug use are required is particularly salient when thinking about harm reduction in a New Zealand context. Government indices used to measure various drug harms consistently evidence the social impact of problematic methamphetamine use as impacting structurally vulnerable communities which are disproportionately populated by socially and economically excluded individuals, groups at greater risk of experiencing mental health crises, and young Māori (Wilkins et al. 2011, 2013).

Reflecting on the divergent experiences of drug use storied by female participants, this research also evidenced a well-established theme in feminist perspectives of drug use; that women are exposed to multiple levels of vulnerability due to the power disparities inherent in the gendered organisation of illicit drug economies (McKenna: 2014). As the stories presented here revealed, embeddedness within these economies required female drug users to navigate experiences of social disadvantage within high-risk environments using systems of reciprocity to facilitate survival. These experiences were further compounded by managing the impact of traumatic events such as the loss of children and serious sexual and physical assaults, which hindered their ability to make prudent decisions about drug use. This perspective of problematic drug use reiterates that determining the distribution and impact of drug-related harms requires thinking about gendered experiences of drug use and risk, as indicated by recent government efforts to formulate a gender-informed Women's Strategy addressing the needs of female offenders in New Zealand prisons (Women's Strategy 2017-2021, The Department of Corrections). Acknowledging many of the gendered themes explored in this research, this strategy similarly emphasises that a high proportion of female offenders have "complex and entwined histories of severe trauma, mental health issues, substance abuse, unhealthy relationships and poverty", factors universally acknowledged as contributing to female offending (Women's Strategy 2017-2021, The Department of Corrections). 
By incorporating life-course criminology to theoretically engage with the role of 'turning points' in altering trajectories of drug-taking, this research provided another contextrich and under-researched perspective of drug use. This perspective builds on the analysis of decision-making processes which underpin drug use by demonstrating that participants' transitions away from harmful drug-taking behaviour were also dependant on agential decision-making inter-playing with life-course changes in social processes and structural influences (Sampson and Laub:2003, Hser, Longshore and Anglin:2007).

As the storying of their experiences involving desistance from using drugs revealed, turning point events that were often dramatic and profoundly negative were not, in and of themselves, experiences which brought about desistance (Carlsson:2012, Kemp:2013). Instead, the sequencing of increasingly unmanageable drug-related harms had culminated in events that disrupted social arrangements previously conducive to problematic drug-taking behaviour. By disrupting these arrangements dramatic life events opened pathways towards desistance, which in turn had required participants to exercise agency in order to initiate transitions away from long-term engagement in problematic drug-use (Sampson and Laub: 2005). For some participants, pathways to desistance had occurred following unmanageable drug-related harms and self-imposed stages of abstinence from particular drugs or exile from drug-using scenes, while for others, legal sanctions constraining drug-use had necessitated choosing from a limited array of pathway 'options'. These options resulted in various desistance pathways, including long-term imprisonment, engagement in therapeutic drug regimes, geographic relocation, and court-ordered engagement with addiction treatment programmes.

Where desistance was followed by engagement in therapeutic environments, stopping drug use was also contingent upon actively participating in an identity transformation process. Unlike participants' who disengaged from drug-use without clinical support, this required drawing upon therapeutic discourses in order to make sense of past drugtaking behaviours as 'recovering' 'addicts', constructions of self-identity which made it 
difficult for participants to distance themselves from stigmatising, anti-meth discourses. However, experiences of treatment and clinical intervention were also viewed positively by some participants, despite having to accept and manage the stigmatising realities of an 'addict' identity. Therapeutic environments created pathways to long-term desistance by allowing for the exercising of agency that previous drug-using scenes and dysfunctional intimate relationships may not have. Similarly, clinically prescribed medications opened up the possibility of behaving in ways that were not possible in the context of previous, chaotic, drug-using lifestyles.

In theorising the process of desistance from methamphetamine use by focussing on turning-point experiences, this research reveals that problematic drug users can and do exercise agency over their drug-taking in concert with changes in social and structural circumstances. This is contrary to pejorative understandings of addiction which disproportionately emphasise the pharmacological effects of drug use in controlling behaviour and impeding rational cognition. It also demonstrates that pathways leading to desistance are not contingent upon, or the direct result of, events that accord with the notion of 'hitting rock bottom', as is assumed in commonplace explanations of what is required in order for problematic drug users to successfully disengage from drug use. The storying of desistance presented here also demonstrates that motivations for stopping drug use will change in accordance with variances in individuals, substances social contexts, and the impact of wider social forces, the intersection of which is likely to result in multiple desistance experiences (German et al: 2006).

Importantly, the therapeutic discourses incorporated into the stories of participants engaging with drug treatment programmes or other forms of clinical support suggests that institutional identity transformation processes continue to prevent drug users from disentangling themselves from stigmatised drug-using identities. These identities continue to discount the underlying impact of past experiences of trauma, dysfunctional social relationships, and social disadvantage when examining drug-dependency. They also inevitably locate responsibility for drug use and drug-related harms by linking 
explanations for drug use to the clinical diagnosis of addiction. While therapeutic interventions open up valuable pathways to desistance, to what extent they open up pathways to social integration and an enduring sense of self-esteem is questionable. Although drug users may 'recover' from past experiences of chaotic drug use, there is no means available to recover from the enduring impact of stigma. For individuals who internalise meth-using identities, this is likely to be very difficult to reconcile in the face of enduring cultural vilification, and may serve as a barrier to genuine acceptance from non-drug using family members and friends (Maruna and Roy: 2007).

The sum of multiple perspectives of drug use, risk and decision-making presented in this research is of significant value in helping to theorise drug use, rather than drug users. They highlight the ways in which agency, culture and structure intersect decisions about starting, using and stopping methamphetamine use, and go some way towards explaining why individuals engage in a behaviour normatively defined as risky. However, as identified at various points throughout this research, there are of course limitations to what can be inferred from the analysis of narratives storied by this sample of New Zealand drug users:

Having employed a qualitative methodology to examine the lived experience of methamphetamine use it is not possible to make population-level generalisations about drug-using behaviour using data collated from a small sample of meth users. The experiences explored here, while valuable in providing a context-rich perspective of drug use, are not statistically indicative, and cannot be used to infer similarities with other meth-using populations, who still remain largely invisible and under-researched in New Zealand. As noted in the sequencing of the research process, there were also methodological constraints influencing the recruitment of participants, which resulted in a sample disproportionately representative of problematic drug users, notably users whose severity of drug use and experiences of drug-related harm had required engaging in a residential therapeutic environment. This sampling outcome, coupled with the 
constraints noted when conducting interviews in a clinical environment, influenced the thematic content of drug-using experiences collated and analysed throughout this research.

Consequently, excluded from the scope of this research were recreational experiences involving methamphetamine use, as well as any meaningful acknowledgement of drug use and pleasure. For example, excluding the theme of pleasure in relation to using multiple drug types had made it difficult to define the intentionality of participants' polydrug using experiences. Although employing the definition 'sequential poly-drug mixing' might be useful in identifying how participants' storied these experiences, this definition is not accurate given that other poly-drug using realities involving the pleasurable combined effects of drugs were highly likely. Reflecting on a point made by Valentine and Frazer (2008), excluding pleasure from accounts of problematic drug use results in specific constructions of drugs and drug users which are likely to accord with many of the negative stereotypes deployed in mediated representations of problematic drug users. An unintended outcome of these constructions is incorporating acceptable, pleasurable, drug use into the lives of middle-class professionals, while inevitably connecting the drug use of socially excluded individuals to experiences of drug-related crime, victimisation, and most often, drug addiction. As they rightfully observe, the binaries connecting pleasurable drug use to class privilege, and problematic drug use to poverty, deserve more attention than they have received.

Interviewing drug users who were engaged in a drug treatment programme and in contact with other forms of addiction support also limited theoretical engagement with experiences of desistance. While the efficacy of using the theoretical constructs of lifecourse criminology to examine how turning points initiated pathways to desistance was demonstrated, it was not possible to evaluate desistance in relation to participants' long-term experiences of accumulating positive social capital, a process fundamental to life-course explanations of desistance from offending. Instead, experiences of desistance storied by this sample of drug users were confined to the immediacy of 
having stopped drug use in the wake of dramatic life events. Opportunities for the accumulation of positive social capital were yet to be realised in the lives of this sample of drug users, which resulted in excluding from the scope of this research the ameliorating effects of employment and healthy intimate relationships on drug-taking behaviour.

Finally, the theoretical focus of this research is criminological in orientation and primarily concerned with the socially situated dynamics of drug use. Due to this focus, the psychology and pharmacology of addiction has not been explored, nor included in ensuing theory-building. Moreover, while this research is critical of overly biological explanations of drug use, it is acknowledged that experiences of clinically diagnosed substance use disorders are subject to biological and psychological realities, and that such diagnoses should not be discounted when explaining drug-taking decisions. Future research efforts designed to reduce the impact of drug-related harm and determine how best to live with problematic drug use, are therefore likely to benefit from incorporating biological, psychological and social explanations of drug-taking behaviour.

Beyond these caveats, this thesis has succeeded in demonstrating how social and structural constraints inter-play with agential decision-making processes. It contributes to the broader objective of creating a replacement discourse about living with problematic drug use and problematic drug users, one that is much needed in the current political climate. Despite more frequent discussions about the merits of continuing to criminalise drug users, public understandings of drug use remain anchored to its alleged causal association with crime and social disorder. Yet it is clear from the very personal experiences of problematic drug use shared in producing this research that socio-cultural motivations for drug use are far more complex and less individualised than the moral ideology proffered by drug 'experts' in media, public and policy discourses suggests. 
The ongoing stigmatisation of drug users also indicates that, while the structure of drug policy might be lauded as being more harm-reduction focussed in its intentions, the underlying principles remain unchanged (Taylor, Buchanan, and Ayres:2016). The simplistic rationale which informs variations in the arrest, convict and imprison approach to addressing drug use and drug harms, ultimately represents a form of institutional dishonesty. It denies the very real structural constraints that manifest in experiences of harm from problematic drug use, the effects of which continue to disproportionately impact those who are often least able to cope. Redressing the harms exacted by current responses to drug use thus requires developing policies which incorporate a fuller, and more nuanced appreciation of the place and role of drugs our communities, in order to humanise those who engage in their use (Taylor et al:2016). 


\section{References}

Adler. P. (1985) Wheeling and Dealing. An Ethnography of an Upper-Level Drug Dealing and Smuggling Community. Columbia University Press. New York.

Agar, M and Reisinger, H (2002) A Heroin Epidemic at the Intersection of Histories: The 1960s Epidemic Among African Americans in Baltimore, Medical Anthropology, Volume 21, Issue 2, pp 115-156.

Aguilar, J and sen, S (2013) the Culture of Methamphetamine: Reframing Gay Men's Methamphetamine Use, Journal of Human Behaviour in the Social Environment, Vol 23, Issue 3, pp $370-382$.

Ahmed, A, Weatherburn, P, Reid, D, Hickson, F, Torres-Rueda, Steinburg, P and Bourne, A (2016) Social Norms Related to Combining Drugs and Sex (Chem Sex) Among Gay Men in South London. International Journal of Drug Policy, Volume 38, pp 29-35.

Albertson, T, Derlet. R and Van Hoozen. B (1999) Methamphetamine and the Expanding Complications of Amphetamines. West J Med. 170 pp 214- 219.

Anderson. T. (1993) Types of Identity Transformation in Drug-Using and Recovery Careers. Sociological Focus, Volume 26, Number 2, pp 133-145.

Anderson. T. (2005) Dimensions of Women's Power in the Illicit Drug Economy. Theoretical Criminology, Volume 9, Number 4, pp 371-400.

Atkinson, A, and Flint, J. (2001) Accessing Hard to Reach Populations: Snowball Research Strategies. Social Research Update, Summer, 2001. Department of Sociology, University of Surrey.

Ayers, T, and Jewkes, Y. (2012) The Haunting Spectacle of Crystal Meth: A Media Created Mythology? Crime Media Culture. Volume 8, pp 315 - 332.

Bachman, R, Kerrinson, E, Paternoster, R, O'Connell, D, and Smith, L. (2016) Desistance for a Long-Term Drug-Involved Sample of Adult Offenders. The importance of Identity Transformation. Criminal Justice and Behaviour. Volume 43, Number 3, pp 164- 186.

Becker. H. (1963) The Outsiders. Studies in the Sociology of Deviance. New York. Free Press. 
Bellamy, P, and McNab J. (2003) Methamphetamine in New Zealand, Background Notes. Parliamentary Library.

Bertram, E, Blachman. M, Sharpe. K, Andreas. P (1996) Drug War Politics: The Price of Denial. University of California Press. Berkely and Los Angeles, California.

Best, D, Beckwith, M, Haslam, C, Haslam, A, Jetten, J, Mawson, E, and Lubman, D. (2016) Overcoming Alcohol and Other Drug Addiction as a Process of Social Identity Transition: the Social Identity Model of Recovery (SIMOR). Addiction Research and Theory, Volume 24, Number 2, pp 111-123.

Biernaki, P, and Waldorf, W. (1981) Snowball Sampling. Problems and Techniques of Chain Referral Sampling. Sociological Methods and Research. Volume 10, Number 2, pp $141-163$.

Biernaki. P. (1986) Pathways from Heroin Addiction: Recovery Without Treatment. Health Society and Policy. Temple University Press.

Bletzer, K. (2009) Modulation of Drug Use in Southern farming Communities: Social Origins of Poly Drug Use. Human Organisation, Volume 68, Number 3, pp 340-348.

Boden, J, Fergusson. D and Horwood, J. (2006) Illicit Drug Use and Dependence in a New Zealand Birth Cohort. Australian and New Zealand Journal of Psychiatry 2006. Volume 40, pp $156-163$.

Boeri, M, Sterk, C, Bahora, M and Elifson, K. (2008) Poly-Drug Use Among Ecstasy Users: Separate, Synergistic and Indiscriminate Patterns, The Journal of Drug Issues, Volume 38, Number 2, pp 517-542.

Boeri, M and Harbry, L. (2009) A Qualitative Exploration of Trajectories of Methamphetamine Use Among Suburban Users of Methamphetamine. Journal of Ethnographic and Qualitative Research. Volume 3, pp 139-151.

Boeri, M and Tyndall, B. (2012) A Contextual Comparison of Risk Behaviours among Older Adult Drug Users and Harm Reduction in Suburban versus Inner-city Social Environments. Journal of Applied Social Science. Volume 6, Issue one, pp 72-91.

Boeri. M, Gibson. D, and Boshears, P (2014) Conceptualizing Social Recovery: Recovery Routes of Methamphetamine Users. JQCJC, Volume 2, Number 1, April. 
Boeri, M, Gardner, E, Ross, M, and Wheeler, J. (2015) 'I don't know what fun is": Examining the Intersection of Social Capital, Social Networks, and Social Recovery. Drugs and Alcohol Today. Volume 16, Issue one.

Booth. B, Carlson. R, Leukefeld. C, and Sexton. R (2010) Tweaking and Geeking, Just having some fun: An Analysis of Methamphetamine Poems. Journal of Psychoactive Drugs. Volume 42, Issue 3, September, p 377.

Boshears, P, Boeri M, and Harbry, L. (2011) Addiction and Sociality: Perspectives from Methamphetamine Users in Suburban USA. Addiction Research and Theory. Volume 9, Issue 4 August, pp 289-301.

Bottoms, A, Shapland, J; Costello, A; Holmes, D; Muir, G. (2004) Towards Desistance: Theoretical Underpinnings for an Empirical Study, Howard Journal of Criminal Justice, September 2004, Volume 43, Number 4, pp 368-389.

Bottoms. A. (2008) The Relationship Between Theory and Empirical Observations in Criminology, in King, R and Wincup, E, eds. (2008) Doing Research on Crime and Justice. Second Edition. Oxford University Press. Oxford.

Bourgois. P. (1995) In Search of Respect. Second Edition. Cambridge University Press, New York.

Bourgois. P. (1996) In Search of Masculinity: Violence Respect and Sexuality Among Puerto Rican Crack Dealers in East Harlem. The British Journal of Criminology. Volume 36, Number 3, pp 412-427.

Bourgois. P. (1999) Theory, Method and Power in Drug and HIV Prevention Research: A Participant Observer's Critique. Substance Use and Misuse, Volume 33, Number 14, pp $2155-2172$.

Bourgois. P. (2002) Anthropology and Epidemiology on Drugs: The Challenges of CrossMethodological and Theoretical Dialogue. International Journal of Drug Policy. Volume 14, Number 4, pp 259-269.

Bourgois. P. (2003) Crack and the Political Economy of Suffering. Addiction Research and Theory. Volume 11, Number one, pp 31-37. 
Bourgois, P, Prince, P, and Moss, A. (2004) The Everyday Violence of Hepatitis C Among Young Women Who Inject Drugs in San Francisco. Human Organisation, Volume 63, Number 3, pp 253-264.

Bourgois. P. (2011) Lumpen Abuse: The Human Cost of Righteous Neoliberalism. City and Society. Volume 23, Issue 1. pp 2-12.

Bourgois. P and Schoenberg, J. (2009) Righteous Dopefiend. Berkeley. University of California Press.

Butler, R, Wheeler, A, and Sheridan, J. (2010) Physical and Psychological Harms and Health Consequences of Methamphetamine Users Amongst a Group of New Zealand Users. International Journal of Mental Health Addiction, Volume 8, pp 432-443.

Bowden. J and Green. P (2010) The Voice of the Researched in Qualitative Research: Rigour and Research Practices, in Higgs. J, Cherry. N, Macklin. R and Ajjawi. R (eds). Researching Practice. A Discourse on Qualitative Methodologies. Sense Publishers. Rotterdam.

Boyd, S and Carter, C. (2010) Methamphetamine Discourse: Media, Law and Policy. Canadian Journal of Communication. 2010. Volume 35, Issue 2, pp 219-237

Boys, A, Marsden, J and Strang, J. (2001) Understanding Reasons for Drug Use Amongst Young People: A Functional Perspective. Health, Education and Research. Volume 16, Number 4, pp 457-469.

Boyum, D and Kleiman, M. (2003) Breaking the Drugs-Crime Relationship. Public Interest, Volume 19, Issue 152.

Brandon, M and Werb. D, (2010) Health Outcomes Associated with Methamphetamine Use Among Young People: A Systematic Review. Addiction. Volume 105, pp 991 - 1002. Brecher. E. (1972) The Consumers Union Report on Illicit Drugs. Chapter 40. Downloaded from www.druglibrary.org/schaffer/library/studies/cu/cu40.htm

Brisman. A. (2007) Meth Chic and the Tyranny of the Immediate: Reflections on the Culture-Drug/Drug-Crime Relationships. North Dakota Law Review, Volume 8, pp 1275 -1385 . 
Brook. H. (2010) Choosing Using, Cultural Studies, Volume 24, Number 1, pp 95-109.

Brown. R. (2010) Crystal Methamphetamine Use Among American Indian and White Youth in Appalachia: Social Context, Masculinity, and Desistance. Addiction Research and Theory. Volume 18, Issue 3, pp 1-20.

Buchanan, J and Young, L. (2000) The War on Drugs - A War on Drug Users? Drugs: Education, Prevention and Policy: November 2000, Volume 7, Issue 4, pp 409-422.

Buchanan. J. (2015) Unmasking NZ's World Leading Drug Reform. Downloaded from: https://julianbuchanan.wordpress.com/2015/01/08/lessons-from-the-world-leadingkiwi-drug-reform-magic-trick/

Butler, B, Wheeler, A and Sheridan, J. (2010) Physical and Psychological Harms and Health Consequences of Methamphetamine Use Amongst a Group of New Zealand Users. International Journal Mental health Addiction. Volume 8, pp432-443.

Carbone-Lopez, Owens, J, and Miller, J. (2012) Women's "Storylines" of Methamphetamine Initiation in the Midwest. Journal of Drug Issues. Volume 42, Issue 3, pp $226-246$.

Carlson, R, Singer, M, Stephens, R, Sterk C. (2009) Reflections on 40 Years of Ethnographic Drug Abuse Research: Implications for the Future, Journal of Drug Issues, Winter, 2009, Volume 39, Issue one, pp 57-70.

Carlsson. C. (2011) Using Turning Points to Understand the Process of Changing in Offending. Notes from a Swedish Study on Life Courses and Crime. British Journal of Criminology, Volume 52, August, pp 1-16.

Chan, W and Rigakos, G. (2002) Risk, Crime and Gender. British Journal of Criminology. Volume 42, pp 743-761.

Chartier, M, Arneta. A, Duca. L, McGlynn. L, Gore-Felton. C, Goldblum. P, and Koopman, C. (2009) Personal Values and Meaning in the use of Methamphetamine Among HIV Positive Men Who Have Sex with Men. Qualitative Health Research. Volume 19, pp 504518.

Chase. S. (2005) Narrative Enquiry, in Denzin, N and Lincoln, $Y$ (eds) The Sage Handbook of Qualitative Research, Third Edition. Sage Publications. 
Ciccarone, D and Bourgois, P. (2016) Injecting Drugs in Tight Spaces: HIV, Cocaine and Collinearity in the Downtown Eastside, Vancouver, Canada. International Journal of Drug Policy, Volume 33, pp 36-43

Cohen. S. (2002) Folk Devils and Moral Panics: The Creation of the Mods and Rockers. $30^{\text {th }}$ Anniversary Edition. Routledge. London.

Colman, C and Vander Laenen, F. (2012) Recovery Came First: Desistance Versus Recovery in the Criminal Careers of Drug Using Offenders. The Scientific World Journal, pp 1-9.

Cooper, J, Fox, A, and Rodriguez, N. (2012) Race, Structural Disadvantage, and Illicit Drug Use Among Arrestees. Criminal Justice Policy Review. Volume 23, Issue one, pp18-39.

Copes. H. (2012) Advancing Qualitative Methods in Criminology and Criminal Justice. London. New York. Routledge.

Copes, H, Leban, L, Kerley, K, and Deitzer, J. (2016) Identities, Boundaries, and Accounts of Women Methamphetamine Users. Justice Quarterly, Volume 33, Issue one, pp134158.

Copes, H, Kerley, K, Angulski, K, and Zaleski, S. (2014) Meth's Not My Cup of Tea: Perceptions of Methamphetamine Among Black Women. Journal of Drug Issues, Volume 44, Issue 4, pp 430-441.

Copes. H. (2016) A Narrative Approach to Studying Symbolic Boundaries Among Drug Users: A Qualitative Meta-Synthesis. Crime, Media and Culture, Volume 12, Issue 2, pp 193-213.

Daniels, J, Angleman, A, and Grinnan, E. (2015) Aggression and Violent Behaviour. Volume 21, pp 125-132.

Degenhardt, L, Bucello, C, Calabria. C, Nelson, P, Roberts, A, Hall, W, Lynskey, M, Wiessing, L. (2011) What Data are Available on the Extent of Illicit Drug Use and Dependence Globally? Results of Four Systematic Reviews. Article in press: Drug and Alcohol Dependency. doi:10.1016/j.drugalcdep.2010.11.032, downloaded from https://www.ncbi.nlm.nih.gov/pubmed/21377813 
Degenhardt, L, Chiu, W, Dierker, L, Glantz, M, Kalaydjian, A, Merikangas, K, Sampson, N, Swendsen, J and Kessler, R. (2009) Does Gateway Matter? Associations Between the Order of Drug Use Initiation and the Development of Drug Dependence in the National Comorbidity Study Replication. Psychological Medicine, Volume 39, pp 157-167.

Demant, J, Ravn, S and Thorsen, S. (2010) Club Studies: Methodological Perspectives for Researching Drug use in a Central Youth Social Space. Leisure Studies, Volume 29, Number 3, pp $241-252$.

Denscombe. M. (2001) Uncertain Identities and Health-Risking Behaviour: The Case of Young People and Smoking in Late Modernity. British Journal of Sociology, Volume 52, Issue 1, pp 157-177.

Denzin, N, and Lincoln, Y. (2005) The Discipline and Practice of Qualitative Research, in Denzin, L and Lincoln, Y. (eds) The Sage Handbook of Qualitative Research. Third Edition. Sage Publications. pp 1-32.

Douglas. M. (1985) Risk Acceptability According to the Social Sciences. Routledge and Kegan Paul Limited. London.

Draus, P, Harvey, S, Carlson, R, Wang, F and Wang, T (2005) Cracking the Cornfields: Recruiting Illicit Stimulant Drug Users in Rural Ohio. The Sociological Quarterly, Volume 46, Number one, pp 165-189.

Drug and Alcohol Practitioners Association Aotearoa-New Zealand DAPANZ (2017) Government's Meth Proposals out of Balance. Press Release, Monday 4 September 2017, 12.01pm, downloaded from http://www.scoop.co.nz/stories/P01709/S00048/dapaanz-governments-methproposals-out-of-balance.htm

Duff. C. (2005) Party Drugs and Party People: Examining Normalisation of Recreational Drug use in Melbourne Australia. International Journal of Drug Policy, Volume 16, pp 161-170. 
Duff, C and Moore, D. (2014) Evading and Embracing Normality: Estrangement and Ambivalence in the Accounts of Methamphetamine Consumers. Critical Public Health, published online at http://www.tandfonline.com/doi/abs/10.1080/09581596.2014.913785

Dwyer, R and Moore, D. (2013) Enacting Multiple Methamphetamines: The Ontological Politics of Public Discourse and Consumer Accounts of a Drug and its Effects. International Journal of Drug Policy, Volume 24, pp 203-211.

Eldred-Grigg. S. (1984) Pleasures of the Flesh: Sex \& Drugs in Colonial New Zealand, 1840-1915. Reed. Wellington.

Elliott. J. (2005) Using Narrative in Social Research. London. Sage.

Ettorre. E. (2013) Drug User Researchers as Auto Ethnographers: “Doing Reflexivity" with Women Drug Users. Substance Use and Misuse. Volume 48, pp 1377 - 1385.

European monitoring Centre for Drugs and Drug Addiction. (2008) Prevalence of Problem Drug Use at National Level, downloaded from http://www.emcdda.europa.eu/stats08/pdutab1a

Farrall, S, Bowling, B. (1999) Structuration, Human Development and Desistence from Crime. British Journal of Criminology, Volume 39, Number 2, pp 253-268.

Farrall, S, Bottoms, A, and Shapland, J. (2010) Social Structures and Desistance from Crime. European Journal of Criminology, Volume 7, issue 6, pp 546-570.

Farrall, S, Sharpe, G, Hunter, B, and Calverley, A. (2011) Theorising Structural and Individual-Level Processes in Desistance and Persistence: Outlining an Integrated Perspective. Australian and New Zealand Journal of Criminology, Volume 44, Issue 2, pp 218-234.

Fasio, A, Hunt, G, and Moloney, M. (2011) It's One of the Better Drugs to Use: Perceptions of Cocaine Use Among Gay and Bisexual Asian American Men. Qualitative Health Research, Volume 21, Issue 5, pp 625-641.

Fast, D, Small, W, Krusi, A, Wood, E and Kerr, T. (2009) I Guess My Own Fancy Screwed Me Over: Transitions in Drug Use and the Context of Choice Among Young People 
Entrenched in an Open Drug Scene. BMC Public Health, down loaded from http://bmcpublichealth.biomedcentral.com/articles/10.1186/1471-2458-10-126

Faugier, J and Sargeant, M. (1997) Sampling Hard to Reach Populations. Journal of Advanced Nursing. Volume 26, pp $790-797$.

Ferrell. J. (2013) Cultural Criminology and the Politics of Meaning. Critical Criminology, Volume 21, pp 257-271.

Flynn, K and Hoffer, L. (2017) Transitioning Illicit Drug Preferences and Emerging User Identities in Ohio: The Proliferation of Methamphetamine Use among African Americans. Journal of Ethnicity and Substance Abuse. Published online 5 July 2017.

Finlinson, H, Colon, H, Robles, R and Soto-Lopez, M. (2006) An Exploratory Study of Polydrug Use Histories Among Recently Initiated Injection Drug Users in San Juan, Puerto Rico. Substance Use and Misuse, Volume 41 pp 915-935.

Foon, L, Wilkins, C, Thai, P, and Mueller, J. (2017) An exploratory wastewater analysis study of drug use in Auckland, New Zealand. Drug and Alcohol Review, September 2017, Vol. 36, pp 597-601

Frisher, M, and Beckett, H. (2006) Drug Use Desistance. Criminology and Criminal Justice Volume 6, Issue one pp127-145.

Garriot. W. (2011) Policing Methamphetamine: Narcopolitics in Rural America, New York: New York University Press.

Gergen. K. (1994) Realities and Relationships. Soundings in Social Construction. Harvard University Press.

Gergen, K, Josselson, R and Freeman, M. (2015) The Promise of Qualitative Inquiry. American Psychologist, pp 1-9.

Ginsberg. A (1969) A 19 Year-Old Girl and Poet Allen Ginsberg Talk About Speed, downloaded from http://www.doitnow.org/pages/ginsberg.html

Gonzales, R, Mooney, L and Rawson, R. (2010) The Methamphetamine Problem in the United States. The Annual Review of Public Health. Volume 31, pp $385-398$. 
Gorman, M, Clark, C, Nelson, K, Applegate, T, Amato, E and Scrol, A. (2003) A Community Social Work Study of Methamphetamine Use Among Women: Implications for Social Work Practice, Education and Research. Journal of Social Work Practice in the Addictions, Volume 3, Issue 3, pp $41-62$.

Green. J. (2008) Partying on? Life After BZP-Based Party Pills. The New Zealand Medical Journal, Volume 121, Number 1283, pp 35-42.

Green, R, and Moore, D. (2013) Meth Circles and Pipe Pirates: Crystal Methamphetamine Smoking and Identity Management Among a Social Network of Young Adults. Substance Use and Misuse, Volume 48, pp 691 -701.

Greenfield. T. (2002) Research Methods for Postgraduate Students. Second Edition. Arnold Publishing. London.

Greer, C, and Jewkes, Y. (2005) Extremes of Otherness: Media Images of Social Exclusion. Social Justice, Issue 32, Volume one, pp 20-31.

Guba, E, and Lincoln, Y. (2005) Paradigmatic Controversies, Contradictions, and Emerging Confluences, in Denzin, $\mathrm{N}$ and Lincoln, Y. (eds). The Sage Handbook of Qualitative Research Methods. Third Edition. Sage Publications, pp 191-212.

Hacking. I. (1999) The Social Construction of What? Harvard University Press.

Hallam, C, and Bewley-Taylor, D. (2010) Drug Use: Knowledge, Culture and Context. The Beckley Foundation Drug Policy Programme. Briefing paper 21.

Hamilton. S. (2017) Limitations to Qualitative Research, downloaded from http://classroom.synonym.com/info-8196860-limitations-qualitative-research.html

Hammersley. R. (2011) Pathways through Drugs and Crime: Desistance, Trauma and Resilience. Journal of Criminal Justice, Volume 39, pp 268-272.

Hansen, H, Bourgois, P and Drucker, P. (2014) Pathologising Poverty: New forms of Diagnosis, Disability, and Structural Stigma under Welfare Reform. Social Science and Medicine, Volume 103, pp $76-83$.

Harris. S. (2015) To be Free and Normal: Addiction, Governance and the Therapeutics of Buprenorphine. Medical Anthropology Quarterly, Volume 29, Issue 4, pp 512-530. 
Hassin. J. (1994) Living a Responsible Life: The Impact of Aids on the Social Identity of Intravenous Drug Users. Social Science Medicine, Volume 39, Number 3, pp 391-400. Hawaii Meth Use and Attitudes Survey. June 5, 2009, Roper Public Affairs and Media, downloaded from www.hawaiimethproject.org

Healy, D. (2014) Becoming a Desister: Exploring the Role of Agency, Coping and Imagination in the Construction of a New Self. British Journal of Criminology, Volume 54, pp873-891.

Heather, N, Best, D, Kawalek, A, Field, M, Lewis, M, Rotgers, F, Weirs, W, and Heim, D. (2017) Challenging the Brain Disease Model of Addiction: European Launch of the Addiction Theory Network. Addiction, Research and Theory, published online at http://www.tandfonline.com/doi/full/10.1080/16066359.2017.1399659

Henderson, N and Williams, D. (2017) Medical Disease or Moral Deficit? Stigma Attribution and Cultural Models of Addiction Causality in a University Population. Cultural Medical Psychiatry, Volume 41, pp 480-498.

Herbeck, D, Brecht, M, Christou, D and Lovinger, K. (2014) A Qualitative Study of Methamphetamine Users Perspectives on Barriers and Facilitators of Drug Abstinence. Journal of Psychoactive Drugs, Volume 43, Issue 3, pp 215-225.

Hilden. P. (2014) Talking About Drug Use: Positioning and Reflexivity in Drug Research. Interviews and Beyond. Forum: Qualitative Social Research, Volume 15, Number 3, pp $1-23$.

Hlkatis, P, Moeller, R, Siconolfi, D, Jerome, R, Rogers, M, and Schillinger, J. (2008) Methamphetamine and Poly-Substance Use Among Gym-Attending Men Who Have Sex with Men in New York City. Behavioural Medicine, Volume 35, pp 41-48.

Hobkirk, A, Watt, M, Myers, B, Skinner, D, Meade, C. (2016) A Qualitative Study of Methamphetamine Initiation in Cape Town. International Journal of Drug Policy, Volume 30, pp 99-106.

Hodgson, P, Parker, A, and Seddon, T. (2006) Doing Drugs Research in the Criminal Justice Field. Addiction Research and Theory, Volume 14, Issue 3, pp 253-264. 
Hser, Y, Longshore, D, M, Anglin. (2007) The Life Course Perspective on Drug Use. Evaluation Review. Vol 31, Number 6 pp 515-547.

Hunt, G, Evans, K and Kares, F. (2007) Drug Use and Meanings of Risk and Pleasure. Journal of Youth Studies, Volume 10, Number one, pp 73-96.

Hunt-Howard. K. (2017) An Exploration of the Factors Associated with Methamphetamine Injection among Street Involved Drug Users and Dealers in Los Angeles: An Ethnographic Study. Journal of Drug Issues, Volume 47, Number one, pp 424.

Hutton. F. (2004) Up for it, Mad for it? Women, Drug use and Participation in Club Scenes'. Health, Risk and Society. Volume 6, Number 3, pp 223-237.

Hutton. F. (2005) Risky Business: Gender Drug Dealing and Risk. Addiction Research and Theory, Volume 13, Number 6, pp $545-554$.

Hutton. F. (2010) Kiwis, Clubs and Drugs: Club Cultures in Wellington, New Zealand Australian \& New Zealand Journal of Criminology, 2010, Volume 43, Issue one, pp 91111.

Irving. A. (2011) Life Story Narratives of Recovery from Dependent Drug and Alcohol Use: A Tool for Identity Reconstruction within a Therapeutic Community. Therapeutic Communities, Vol 32, Number 3, pp 182-200.

Ivers. R. (2002) Tobacco Addiction and the Process of Colonisation. Australian and New Zealand Journal of Public Health. Volume 26, Issue 3, pp 280-281.

Iversen, L. (2006), Speed, Ecstasy, Ritalin: The Science of Amphetamines. Oxford University Press. Oxford.

Ivsins, A, Roth, E, Benoit, C, and Fischer, B. (2013) Crack Pipe Sharing in Context: How Socio-Structural Factors Shape Risk Practices among Non-Injection Drug Users. Contemporary Drug Problems, Volume 40, Issue 4, pp 481-503.

Jarvinen. M. (2000) The Biographical Illusion: Constructing Meaning in Qualitative Interviews. Qualitative Inquiry, Volume 6, pp 370-391. 
Jarvinen, M and Ravn, S. (2011) From Recreational to Regular Club Drug Use: Qualitative Interviews with Young Clubbers. Sociology of Health and Illness, Volume 33, Number 4, pp 554-569.

Jarvinen, M and Ravn, S. (2014) Cannabis Careers Revisited: Applying Howard Becker's Theory to Present-day Cannabis Use. Social Science and Medicine. Volume 100, pp 133140.

Jenkins. P. (1994) "The Ice Age": The Social Construction of a Drug panic. Justice Quarterly, Volume 11, Number one, March 1994.

Jenkins. P. (1999) Synthetic Panics: The Symbolic Politics of Designer Drugs. University Press. New York.

Jenkot. R. (2008) Cooks are like Gods: Hierarchies in Methamphetamine Producing Groups. Deviant Behaviour, Volume 29, Issue 8, pp 667-689.

Jessup, M, Ross, T, Jones, A, Satre, D, Weisner, P, Chi, F and Mertens, J. (2014) Significant Life Events and their Impact on Alcohol and Drug Use: A Qualitative Study. Journal of Psychoactive Drugs, Volume 46, Issue 5, pp 450-459.

Joe. K. (1995) Ice is Strong Enough for a Man but Made for a Woman. A Social Cultural Analysis of Crystal Methamphetamine Use Among Asian Pacific Americans. Crime, Law and Social Change, Volume 22, pp $269-289$.

Joe K. (1996) The Lives and Times of Asian-Pacific American Women Drug Users: An Ethnographic Study of Their Methamphetamine Use, Journal of Drug Issues. Winter 1996 Volume 26, Issue one, pp $199-218$.

Joe. K, and Morgan. P. (1996) Citizens and Outlaws: The Private Lives and Public Lifestyles of Women in the Illicit Drug Economy. Journal of Drug Issues. Winter 1996. Volume 26, Issue one, pp $125-142$.

Johnstone A, Brennan K, Schenk S, Kennedy M, Lea R, and Fitzmaurice P. (2007) Benzylpiperazine (BZP). A Recreational Substance or Drug of Abuse? Journal of Psychopharmacology, Volume 21, pp 888-894. 
Johnson. B, Dunlap, E, and Benoit, E. (2010) Organizing Mountains of Words for Data Analysis, Both Qualitative and Quantitative. Substance Use and Misuse. Volume 45, pp $648-670$.

Jones. A. (2012) Dangerous Liaisons: Pakeha, Kaupapa Māori, and Educational Research. New Zealand Journal of Education Studies, Volume 47, Number 2, pp 100-112.

Kaplan. C. (2010) Translating Qualitative Drug Research, in Unresolved issues in Qualitative Research Agar. M. (ed), Substance Use and Misuse, Volume 45. Issue 5, pp 777-794.

Karlson. P. (2011) Between a Rock and a Whirlpool? Measurement Problems in Assessing Risk Perceptions of Illicit Drug Use. Nordic Studies on Alcohol and Drugs. Volume 28, pp 149-157.

Keane. H. (2008) Pleasure and Discipline in the Uses of Ritalin. International Journal of Drug Policy. Volume 19, Issue 5, pp 384-392.

Keane. H. (2011) The politics of Visibility: Drug Users and the Spaces of Drug Use, International Journal of Drug Policy, Volume 22, pp 407-409.

Kelly. B. (2010) Sampling and Recruitment Issues in Qualitative Drugs Research: Reflections on the Study of Club Drug Use in Metro New York. Substance Use and Misuse. Volume 45. pp 671- 683.

Kemp. R. (2013) Rock Bottom as an Event of Truth. Existential Analysis, Vol 24, Issue one, pp 106-110.

Kerley, K, Leban, L, Copes, H, Taylor, L, and Agnone, C. (2014) Methamphetamine Using Careers of White and Black Women. Deviant Behaviour, Volume 35, Number 6, June pp 477-495.

Kim, R, and Jackson D. (2008) A Comparison of Adolescent Methamphetamine and Other Substance Users in Hawaii, Hawaii Medical Journal, November 2008, Volume 67, Number 11, pp 294-302.

King. S. (2012) Transformative Agency and Desistance from Crime. Criminology and Criminal Justice, Volume 13, Number 3, pp 317-335. 
King. S. (2013) Early Desistance Narratives: A Qualitative Analysis of Probationers' Transitions Towards Desistance. Punishment and Society, Volume 15, Number 2, pp 147165.

Kirn, W and Dawson, P. (1998) Crank. Time Magazine, June 22, Volume 151, Issue 24, pp $27-31$.

Kirst. M. (2009) Social Capital and Beyond: A Qualitative Analysis of Social Contextual and Structural Influences on Drug-Use Related Health Behaviours. Journal of Drug Issues. Summer, 2009, pp 653-676.

Kleinig. J. (2015) Ready for Retirement: The Gateway Drug Hypothesis. Substance Use and Misuse, Volume 50, Issue 8-9, pp 971-975.

Knox, S, Kippax, S, Crawford, J, Prestage, G, and Van de Ven, P. (1999) Non-prescription Drug Use by Gay Men in Sydney, Melbourne and Brisbane. Drug and Alcohol Review, Volume 18, Number 4, pp $425-433$.

Kosten, T, Newton, T, De lar Gaza, R and Haile, C. (2012) Cocaine and Methamphetamine Dependence. Advances in Treatment. American Psychiatric Publishing. Washington DC. Labianca. D. (1992) The Drug Scene's New Ice Age. USA Today, January 1992, Issue 120. 2560.

Lahman, M, Rodriguez, K, Moses, L, Griffin, K, Mendoza, B and Yacoub, W. (2015) A Rose by Any Other Name is Still a Rose? Problematizing Pseudonyms in Research. Qualitative Inquiry, Volume 21, Issue 5, pp 445-453.

Lai, F, Wilkins, C, Thai, P and Mueller, J. (2017) An Exploratory Wastewater Analysis of Drug Use in Auckland, New Zealand. Drug and Alcohol Review, September 2017, Volume 36, pp 597-601.

Lamonica, A and Boeri, M. (2015) Risk Behaviours Among Suburban Women Who Use Methamphetamine; Social Harms and Social Solutions. Journal of Applied Social Science, Volume 9, Number 2, pp 98-114.

Larsson, S, and Sjoblom, Y. (2010) Perspectives on Narrative Methods in Social Work Research. International Journal of Social Welfare, Volume 19, pp 272-280. 
Larsson, S, Lilja, J, von Braun, T and Sjoblom, Y. (2013) General Theoretical Perspectives of Narrative Analysis of Substance Use-Related Dependency. Substance Use and Misuse, Volume 48, pp 1294-1305.

Larsson, S, von Braun, T, Sjoblom, Y and Hamilton, D. (2013) a Self-theoretical Perspective on the Use-Misuse of Alcohol and Drugs Based on Qualitative and Narrative Data. Substance Use and Misuse. Vol 48, number 13, pp 1317-1335.

Lauderback, D and Waldorf. D. (1993) Whatever Happened to Ice? The Latest Drug Scare. Journal of Drug Issues, Volume 23, Number 4, pp 597-613.

Lende, D, Leonard, T, Sterk, C, Kirk. E. (2007) Functional Methamphetamine Use: The Insider's Perspective. Addiction Research and Theory, Volume 15, Number 5, pp 465477.

Levy, J, and Anderson, T. (2005) The Drug Career of the Older Injector. Addiction Research and Theory, Volume 13, Issue 3, pp 245-258.

Liebregts, N, van der Pol, P, de Graf, R, van Larr, M, van den Brink, W, and Korf, D. (2015) Persistence and Desistance in Heavy Cannabis Use: The Role of Identity, Agency, and Life Events. Journal of Youth Studies, Volume 18, Issue 5, pp 617-633.

Lilja. M. (2013) Narrative Stories and Discourses in an Interview with a Former Amphetamine User. Substance Use and Misuse, Volume 48, pp 1360-1368.

Lin, S and Zhang, Y. (2014) Risk Control and Rational Recreation: A Qualitative Analysis of Synthetic Drug Use Among Young Urbanites in China. International Journal of Drug Policy, Volume 25, Issue 4, pp 769-775.

Lomas. D. (2011) Peter Fulcher Interview - The Last Days of Mr Asia. The Listener, 20 August 2011.

Lorvick, J, Lutnick, A, Wenger, L, Bourgois, P, Cheng, H and Kral, A. (2014) Non-Partner Violence Against Women Who Use Drugs in San Francisco, Volume 20, Issue 11, pp 1285 $-1298$

Loxley. W (1998) Weed or Speed? Convicted Drug Dealers' Views of Substitutions in the Western Australian Illicit Drug Market to 1992. International Journal of Drug Policy, Volume 9, Issue 2, pp $109-118$. 
Lyng. S. (2005) (ed) Edgework. The Sociology of Risk-Taking. Routledge. New York MacLean, S, Hengsen, R and Stephens, R. (2017) Critical Considerations in Responding to Crystal Methamphetamine Use in Australian Aboriginal Communities. Drug and Alcohol Review, Volume 36, Issue 4, pp 502-508.

McCoy, K, McGuire, J, Curtis, R, and Spunt, B. (2005) White Chicks on Dope: Heroin and Identity Dynamics in New York in the 1990s. Journal of Drug Issues, Volume 35, Issue 4, pp 817-841.

McKenna. S. (2013) The Meth Factor: Group Membership, Information Management, and the Navigation of Stigma. Contemporary Drug Problems, Volume 40, Issue 3, pp 351385.

McKenna. S. (2014) Navigating the risk environment: Structural Vulnerability, sex and reciprocity among women who use methamphetamine. International Journal of Drug Policy. Volume 25, Issue one, pp 112-115.

McLean. K. (2016) There's Nothing Here: Deindustrialisation as Risk Environment for Overdose. International Journal of Drug Policy, March, Volume 29, pp 19-26.

McFadden. M. (2016). Research Report: The New Zealand Drug Harm Index 2016 (2nd edition). Wellington: Ministry of Health.

McPherson, S, Hall, H, and Yukudo, E. (2009) Methamphetamine Use. Clinical and Forensic Aspects. Second Edition. CRC Press. Florida.

Maher. L. (2002) Don't Leave Us This Way: Ethnography and Injecting Drug Use in the Age of AIDS. International Journal of Drug Policy, Volume 13, Issue 4, pp 311-325.

Manderson. D. (1995) Metamorphoses: Clashing Symbols in the Social Construction of Drugs. Journal of Drug Issues, Volume 25, Issue 4, pp 799-816.

Mars, S, Fessel, J, Bourgois, P, Montero, F, Karandinos, G and Ciccarone, D. (2015) Heroin-related Overdoes: The Unexplored Influences of Markets, Marketing and Sourcetypes in the United States. Social Science and Medicine, Volume 140, pp 44-53.

Marshall, B and Werb, D. (2010) Health Outcomes Associated with Methamphetamine Use Among Young People. Addiction, Volume 105, Issue 6 pp $991-1002$. 
Martin. A and Stenner, P. (2004) Talking about Drug Use: What Are We (and Our Participants) Doing in Qualitative Research? International Journal of Drug Policy, Volume 15, Issue 5, pp $395-405$.

Martin. F (2011) Deep Entanglements: The Complexities of Disengaging from Injecting Drug Use for Young Mothers. Contemporary Drug Problems, Volume 38, Issue 3, September, pp 335-366.

Maruna, S, and Roy, K. (2007) Amputation or Reconstruction? Notes on the Concept of Knifing Off and Desistance from Crime. Journal of Contemporary Criminal Justice, Volume 23, Number one, February, pp 104-124.

Matthews. P. (2001) New Zealand's Lost War on Drugs, in The New Zealand Listener. May 19.

Mazzei, L and Jackson, A. (2012) Complicating Voice in a Refusal to let Participants Speak for Themselves. Qualitative Inquiry, Volume 18, Issue 9, pp 745-751.

Mayock. P. (2002) Drug Pathways, Transitions, and Decisions: The Experiences of Young People in an Inner-city Dublin Community. Contemporary Drug Problems, Volume 29, Issue one, pp 117-156.

Mayock. P. (2005) Scripting Risk: Young People and the Construction of Drug Journeys. Drugs, Education, Prevention and Policy, Volume 12, Number 5, pp 349-368.

Mayock, P, Cronly, J and Clatts, M. (2015) The Risk Environment of Heroin Use Initiation: Young Women, Intimate Partners, and Drug Relationships. Substance Use and Misuse, Volume 50, Issue 6, pp 771-782.

Measham. F. (2004) The Decline of Ecstasy, the Rise of Binge Drinking and the Persistence of Pleasure. Probation Journal, Volume 51, Issue 4, pp $309-326$.

Measham. F. (2006) The New Policy Mix: Alcohol, Harm Minimisation, and Determined Drunkenness in Contemporary Society. International Journal of Drug Policy, Volume 17, Issue 4, pp 258-268.

Measham. F, and Shiner, M. (2009) The Legacy of Normalisation: The Role of Classical and Contemporary Criminological Theory in Understanding Young Peoples' Drug Use. International Journal of Drug Policy, Number 20, Volume 6, pp502 - 508. 
Mennis, J, and Stahler, G. (2016) Racial and Ethnic Disparities in Out Patient Substance Use Disorder Treatment Episode Completion for Different Substances. Journal of Substance Abuse Treatment, Volume 63, pp25-33.

Meredith, C, Jaffe, C, Ang-Lee, K, Saxon, J. (2005) Implications of Chronic Methamphetamine Use: A Literature Review. Harvard Review Psychiatry. Volume 13. Number 3, pp 141-154.

Ministerial Action Group on Drugs. (2003) Methamphetamine Action Plan. May 22.

Ministry of Health. (2010) Drug Use in New Zealand: Key results of the 2007/2008 New Zealand Alcohol and Drug Use Survey. Wellington. Ministry of Health.

Ministry of Health. (2016) Amphetamine Use 2015/2016 New Zealand. Wellington. Ministry of Health.

Ministry of Health. (2016) Preparing for the Commencement of the Substance Addiction (Compulsory Assessment and Treatment) Act 2017, downloaded from https://www.health.govt.nz/our-work/mental-health-and-addictions/preparingcommencement-substance-addiction-compulsory-assessment-and-treatment-act-2017 Ministry of Justice. (2017) Trends in Conviction and Sentencing. Court Statistics for Adults (aged 17 and over) in the Year Ended June 2017, downloaded from https://www.justice.govt.nz/justice-sector-policy/research-data/convictionsentencing-statistics/

Ministry of Health Alcohol and Drug Use Survey. (2008), downloaded from http://www.health.govt.nz/publication/drug-use-new-zealand-key-results-2007-08$\underline{\text { new-zealand-alcohol-and-drug-use-survey }}$

Mishler. E.G. (1986) Research Interviewing: Context and Narrative. Cambridge. MA. Harvard University Press.

Montange. M. (2002) Appreciating the User's Perspective: Listening to the “Methadonians". Substance Use and Misuse, Volume 37, Issue 4, pp 565 - 570.

Moore. D. (2004) Beyond Subculture in the Ethnography of Illicit Drug Use. Contemporary Drug Problems, Summer, Volume 31, Issue 2, pp 181-212. 
Moore, D, and Fraser, S. (2006) Putting at Risk what we Know: Reflecting on the Drug Using Subject in Harm-reduction and its Political Implications. Social Science and Medicine, Volume 62, Issue 12, pp 3035-3047.

Moore. D. (2008) Erasing Pleasure from the Public Discourse on Illicit Drugs; On the Creation and Reproduction of an Absence. International Journal of Drug Policy, Volume 19, Issue 5, pp 353-358.

Morgan, R, and Hough, M. (2008) The Politics of Doing Criminological Research, in King, R, and Wincup, E. (eds) (2008) Doing Research on Crime and Justice. Second Edition. Oxford University Press.

Morrison. E. (2015) Drug Policy and Criminalisation: More Harm Than Good. HIV Australia, Volume 13, Number one, pp 35-37.

Mullins. C. (2006) Holding Your Square: Masculinities, Street Life and Violence. Willan Publishing. Devon.

Mythen. G. (2014) Understanding the Risk Society. Crime, Security and Justice. Palgrave MacMillan.

Natarajan. M. (2010) Drugs of Abuse: The International Scene. Volume One. Ashgate Publishing, United Kingdom.

Neal, J, Allen, D, and Coombes, L. (2005) Qualitative Research Methods within the Addictions. Addiction, Vol 100, Issue 11, pp 1584-1593.

Neal, L, and O'Brien, P. (2011) The P Nightmare, downloaded from www.ppta.org.nz/index.../474-dance-year-11-the-p-nightmare

Newbold. G. (2004) The Control of Drugs in New Zealand, in Hill, R, and Tait, G. (2004) (eds), Hard Lessons: Reflections on Governance and Crime Control in Late Modernity. Ashgate Publishing.

Newton, B, Rothlingova, Z, Gutteridge, R, LeMarchand, K, and Raphael, J. (2011) No Room for Reflexivity? Critical Reflections Following a Systematic Review of Qualitative Research. Journal of Health Psychology, Volume, 17, Number one, pp 866-885. 
New Zealand Government. (2010) Organised Crime in New Zealand. Downloaded from www.ofcanz.govt.nz/publications/organised-crime-new-zealand-2010

Nice. M. (2007) Using an Outcome Based Framework to Analyse Drug Policies upon Methamphetamine Markets: A Comparison of New Zealand and the United States (Oregon). Ian Axford (New Zealand) Fellowships in Public Policy. Fullbright, New Zealand. Notley, C, Blythe, A, Maskrey, V, Pinto, H, and Holland, R. (2015) Exploring the Concepts of Abstinence and Recovery Through the Experiences of Long-Term Opiate Substitution Clients. Substance Abuse, Volume 36, pp 232- 239.

OFCANZ. (2010) Organised Crime in New Zealand. Downloaded from http://www.ofcanz.govt.nz/publications/organised-crime-new-zealand-2010

O’Brien, M. and Madden, A. (2007) Knowledge, Relationships and Identity in Research on Drug Use, in Researching the Margins: Strategies for Ethical and Rigorous Research with Marginalised Communities. M, Pitts, and A, Smith. (2007) (eds) Palgrave Macmillan. Basingstoke.

O'Brien, A, Brecht, M and Casey, C. (2008) Narratives of Methamphetamine Abuse: A Qualitative Exploration of Social, Psychological and Emotional Experiences. Journal of Social Work Practices in the Addictions, Volume 8, Number 3, pp 343-366.

O'Cathail, S, O'Connell, O, Long, N, Morgan, M, Euastance, J, Plant, B and Hourihane, J. (2011) Association of Cigarette Smoking with Drug Use and Risk Taking Behaviour in Irish Teenagers. Addictive Behaviours, Volume 36, Issue 5, pp 547-550.

O’Gorman. A. (2016) Chillin, Buzzin, Getting Mangled, and Coming Down: Doing Differentiated Normalisation in Risk Environments. Drugs: Education, Prevention and Policy. Volume 23, Number 3, pp 247-254.

O'Malley, P and Mungford, S. (1991) The Demand for Intoxicating Commodities: Implications for the War on Drugs. Social Justice, Volume 18, Number 4, pp 49-75.

Ochieng. P. (2009) An Analysis of the Strengths and Limitations of Qualitative and Quantitative Research Paradigms. Problems of Education in the $21^{\text {st }}$ Century. Volume 13, pp $13-18$. 
Office of the Chief Coroner of New Zealand. (2012) Case Study from Recommendations Recap. Volatile Substance Abuse, Butane-Based Substances, Issue 2.

Olszewski. D, Dagmar, H, and Montanari, L. (2012) Users Voices. Experiences and Perceptions of European Drug Users on Controlling their Drug Consumption. EMCDDA.

Omori. M. (2010) Investigating Influences and Dimensions of Methamphetamine Policy. MA Thesis. University of California. Irvine.

Ovation Pharmaceuticals Guide. (2007), downloaded from http://www.fda.gov/downloads/Drugs/DrugSafety/ucm088582.pdf

Owen F, (2007) No Speed Limit - The Highs and Lows of Meth, St Martin's Press, New York.

Page. B. (2010) Unresolved Issues in Research on Drugs: The Impact of Illegality on Health and Well-being, in Unresolved Issues in Qualitative Research, Agar. M. (2010) (ed) Substance Use and Misuse, Volume 45, Issue 5, pp 777-794.

Page, B, and Singer, M. (2010) Comprehending Drug Use. Ethnographic Research at the Social Margins. Rutgers University Press.

Parker. H. (2005) Normalisation as a Barometer: Recreational Drug Use and the Consumption of Leisure by Younger Britons. Addiction Research and Theory, June 2005, Volume 13, Number 3, pp $205-215$.

Paternoster, R and Bushway, S. (2009) Desistance and the Feared Self: Toward an Identity Theory of Criminal Desistance. Journal of Criminal Law and Criminology, Fall, Volume 99, Issue 4, pp 1103-1156.

Pearson. G. (2001) Normal Drug Use; Ethnographic Fieldwork Among an Adult Network of Recreational Drug Users in Inner City London. Substance Use and Misuse, Volume 36, Issue one, pp 167-200.

Pederson M, Norgaard, L, and Traulsen, J. (2015) Pursuing Pleasures of Productivity: University Students' Use of Prescription Stimulants for Enhancement and the Moral Uncertainty of Making Work Fun, in Culture, Medicine and Psychiatry (2015) Volume 39, Issue 4, pp 665-679 
Pennay, A, and Moore, D. (2005) Exploring the Micro-politics of Normalisation: Narratives of Pleasure, Self-control and Desire in a Sample of Young Australian 'PartyDrug' Users. Addiction Research and Theory, October 2010, Volume 18, Number 5, pp 557-571.

Pennay. A. (2012) Carnal Pleasures and Grotesque Bodies: Regulating the Body During a "Big Night Out" of Alcohol and Party Drug Use. Contemporary Drug Problems, Volume 39, Issue 3, pp 397-428.

Pereira. R. (2013) Using Critical Policy Analysis in Occupational Science Research: Exploring Bacchi's Methodology. Journal of Occupational Science, Issue 21, Volume 4, pp389 -402.

Pilkington. H. (2007) In Good Company: Risk, Security and Choice in Young People's Drug Decisions. The Sociological Review, Volume 55, Number 2, pp373-392.

Pine. J. (2007) Economy of Speed: The New Narco-capitalism. Public Culture, Volume 19, Issue 2, p357.

Plumridge, E, and Chetwynd, J. (1999) Identity and the Social Construction of Risk: Injecting Drug Use. Sociology of Health and Illness, Volume 21, Number 3, pp 329-343.

Polkinghorne. D. (2007) Validity Issues in Narrative Research. Qualitative Inquiry, Vol 13, Number 4, pp 471-486.

Presser. L. (2012) Collecting and Analysing the Stories of Offenders, in Copes. H. (ed) Advancing Qualitative Methods in Criminology and Criminal Justice. Routledge. Canada. Quintero, G. (2012) Problematizing "Drugs": A Cultural Assessment of Recreational Pharmaceutical Use Among Young Adults in the United States. Contemporary Drug Problems, Fall, Volume 39, Issue 3, pp 493-535.

Ransley, J, Mazerolle, L, Manning, M, McGuffog, I, Drew, M, and Webster, J. (2011) Reducing the Methamphetamine Problem in Australia: Evaluating Innovative Partnerships Between Police, Pharmacies and other Third Parties. National Drug Law Enforcement Research Fund (NDLERF). Canberra.

Rasmussen. N. (2008) On Speed: The Many Lives of Amphetamine. New York/London: New York University Press. 
Reinarman, C, and Levine, H. (2004) Crack in the Rear-view Mirror: Deconstructing Drug War Mythology. Social Justice, Volume 31, Issues One and Two, pp 182-199.

Reith. G. (2005) On the Edge: Drugs and the Consumption of Risk in Late Modernity, in Lyng, S. (2005) (ed) Edgework. The Sociology of Risk-Taking. Routledge. New York Reynolds, J, Lenton, S, Charlton, M, and Caporn, J. (1997) Shopping, Baking and Using: The Manufacture, Use, and Problems Associated with the Use of Heroin Made in the Home from Codeine Based Pharmaceuticals, pp 324-339, in Erickson, P, A, Riley, D, A, Cheung, Y,T, and O'Hare, P, A. (eds) Harm Reduction: A New Direction for Drug Policies and Programs. Canada. University of Toronto Press.

Rhodes. T. (1997) Risk Theory in Epidemic Times: Sex, Drugs and the Social Organisation of Risk Behaviour. Sociology of Health and Illness, Volume 19, Number 2, pp 208-227.

Rhodes, T, and Quirk, A. (1998) Drug User's Sexual Relationships and the Social Organisation of Risk: The Sexual Relationship as a Site of Risk Management. Social Science Medicine, Volume 46, Number 2, pp 157-169.

Rhodes. T. (2002) The 'Risk Environment': A Framework for Understanding and Reducing Drug-related Harm. International Journal of Drug Policy, Volume 13, Issue 2, pp 85-94.

Rhodes, T, Lilly, R, Fernndez, C, Giorgino, E, Kemmesis, E, Ossebaard, H, Lalam, N, Faasen, I, and Spannow, K. (2003) Risk Factors Associated with Drug Use: The Importance of Risk Environment. Drugs: Education, Prevention, and Policy, Volume 10, Number 4, pp303329.

Rhodes, T, and Simic, M. (2005) Transition and the HIV risk Environment. British Medical Journal, Volume 331, July 23, pp 220-223.

Rhodes, T, Singer, M, Bourgois, P, Friedman, S and Strathdee, S. (2005) The Social, Structural Production of HIV Risk Among Injecting Drug Users. Social Science and Medicine, Volume 61, Issue 5, pp 1026-1044.

Rhodes. T. (2009) Risk Environments and Drug Harms: A Social Science for Harm Reduction Approach. International Journal of Drug Policy, Volume 20, Issue 3, pp 193 201. 
Ritter. A. (2006) Studying Illicit Drug Markets: Disciplinary Contributions. International Journal of Drug Policy. Volume 17, Issue 6, pp $453-463$.

Rivaux, S, Sohn, S, Armour, M, and Bell, H. (2008) Women's Early Recovery: Managing the Dilemma of Substance Abuse and Intimate Partner Relationships. Journal of Drug Issues, Volume 38, Issue 4, pp 957-980.

Sager. M. (1990) The Ice Age: A New Drug Epidemic Threatens America. Rolling Stone Magazine, February 8, 1990.

Sanberg. S. (2012) What Can Lies Tell us about Life? Notes Towards a Framework of Narrative Criminology, in Copes. H. (2012) (ed) Advancing Qualitative Methods in Criminology and Criminal Justice. Routledge. Canada.

Sanberg, S, and Copes, H. (2012) Speaking with Ethnographers: The Challenges of Researching Drug Dealers and Offenders. Journal of Drug Issues, published online, 16 November 2012, pp 1 -22

Sampson, R, and Laub, J. (2005) A Life-Course View of the Development of Crime. The Annals of the American Academy of Political and Social Science, Volume 602, Issue one, pp 12-45.

Sampson, R, and Laub, J. (2016) Turning Points and the Future of Life-Course Criminology: Reflections on the 1986 Criminal Careers Report. Journal of Research in Crime and Delinquency, Volume 53, Issue 3, pp 321-335.

Sato. A. (2008) Methamphetamine Use in Japan after the Second World War: Transformation of Narratives, in Contemporary Drug Problems, Volume 35, Issue 4, Winter 2008, pp 717- 746.

Seddon. T. (2007) Coerced Drug Treatment in the Criminal Justice System: Conceptual, Ethical and Criminological Issues. Criminology and Criminal Justice, August, Volume 7, Issue 3, pp 269-286

Seddon. T. (2010) A History of Drugs. Drugs and Freedom in the Liberal Age. Routledge. New York. 
Sexton, R, Carlson, R, Leukefeld C, and Booth, B. (2008) Trajectories of Methamphetamine Use in the Rural South: A Longitudinal Qualitative Study. Human Organization, Summer, Volume 67, Issue 2, pp 181-193.

Sharples. P (2007) First Reading of Evidence Amendment Bill. New Zealand Parliament. 19 June 2007, downloaded from https://www.parliament.nz/en/pb/hansarddebates/rhr/document/48HansS 20070619 00001029/sharples-pita-evidenceamendment-bill-first-reading

Sheridan. J, Butler, B, and Wheeler, A. (2009) Initiation into Methamphetamine Use: Qualitative Findings from an Exploration of First Time Use Among a Group of New Zealand Users. Journal of Psychoactive Drugs, Volume 41, Issue one, pp 11-17.

Shernoff. M. (2005) Crystal's Sexual Persuasion. Effect of Methamphetamine on Gay Men. The Gay and Lesbian Review, Volume 12, Issue 4, pp 24-27.

Shiner. M. (2009) Drug Use and Social Change: The Distortion of History. Palgrave MacMillan. London.

Slavin S. (2004) Crystal Methamphetamine Use among Gay Men in Sydney, Contemporary Drug Problems. New York. Fall 2004 Volume 31, Issue 3, pp 425-465.

Smith, R, and Crim, D. The World of the Haight-Ashbury Speed Freak. Journal of Psychedelic Drugs. pp 165-171, Published on-line July 25, 2011, downloaded from https://doi.org/10.1080/02791072.2011.587714

Sommers, I, and Baskin, D. (2004) The Social Consequences of Methamphetamine Use. The Edwin Mellen Press. New York.

Speed Read. (2012) Everything You Need to Know about Methamphetamine. Published by www.needle.co.nz and www.hepc.co.nz

Stefanogiannis N, Mason K, and Yeh, L. (2007) Drug Use in New Zealand. Analysis of the 2003 New Zealand Health Behaviours Survey. Ministry of Health.

Stevens. A. (2011) Drugs, Crime and Public Health. The Political Economy of Drugs Policy. Routledge. New York. 
Stevens. A. (2011) Sociological Approaches to the Study of Drug Use and Drug Policy. International Journal of Drug Policy, Volume 22, Issue 6, pp 399-403.

Stevens. A. (2011) Are Drugs to Blame? Criminal Justice Matters, Volume 83, Issue one, pp 24-25.

Sterk-Elfison. C. (1996) Just for Fun? Cocaine Use Among Middle-Class Women. Journal of Drug Issues, Volume 26, Issue one, pp 63-75.

Sterk. C. (2002) Drug Research: Ethnographies or Qualitative Works. International Journal of Drug Policy. Volume 14, Issue one, pp 127-130.

Stone. R. (2015) Pregnant Women and Substance Use: Fear, Stigma, and Barriers to Care. Health and Justice, Vol 3, Issue one, pp 1-15.

Suarez-Ortega. M. (2012) Performance, Reflexivity and Learning Through BiographicalNarrative Research. Qualitative Inquiry, Volume 19, Issue 3, pp189-200.

Sweeney, J, and Payne, J. (2011) Poly-drug Use Among Police Detainees. Australian Institute of Criminology. Trends and Issues in Crime and Criminal Justice, Number 425, August 2011.

Taylor. T, and Covey, H. (2008) Helping People Addicted To Methamphetamine. Praeger Publishing. Westport. USA.

Taylor. S. (2016) Moving Beyond the Other. A Critique of the Reductionist Drugs Discourse. Volume six, Issue one, pp 100-118.

Taylor, S, Buchanan, J and Ayres, T. (2016) Prohibition, Privilege and the Drug Apartheid: The Failure of Drug Policy Reform to Address the Underlying Fallacies of Drug Prohibition. Criminology and Criminal Justice, Volume 16, Issue 4, pp 452-469.

The New Zealand Drug Foundation. (2014) Our Psycho Psychoactive Substances Legislation. Matters of Substance, November 2014, Volume, 25, Issue 4.

The New Zealand Herald (2001) February $1^{\text {st }}$. Poor Man's Cocaine Becoming Drug of Choice. NZPA.

The New Zealand Herald (2003) September $23^{\text {rd }}$. NZ Chasing US sized Habit. NZPA 
The New Zealand Herald (2017) September $15^{\text {th }}$. Synthetic Cannabis. A Fatal Addiction. The Short Life and Tragic Death of Calum Jones. NZPA.

Teruya, C, and Hser, Y. (2010) Turning Points in the Life Course: Current Findings and Future Directions in Drug Use Research. Current Drug Abuse Review, Volume 3, Issue 3, September, pp 189-195.

Toufexis, A and Cohen, A. (1996) There is No Safe Speed. Time Magazine, September one. Volume 47, Issue 2, p37.

Tulloch, J, and Lupton, D. (2003) Risk and Everyday Life. Sage Publications. London.

Tunnel. K. (2004) Cultural Constructions of the Hillbilly Heroin and Crime Problem, in Ferrell. J, Hayward, K, Morrison, W, and Presdee, M. (eds) Cultural Criminology Unleashed. Glasshouse Press. London.

United Nations Office on Drugs and Crime. (2011) World Drug Report. Vienna, Austria.

Valdez, A, and Sifaneck, S. (2010) Qualitative Methodological Issues in Drug User Research. Substance Use and Misuse, Volume 45, Issue 5, pp 645-647.

Valentine, K, and Fraser, S. (2008) Trauma, Damage and Pleasure: Rethinking Problematic Drug Use. International Journal of Drug Policy, Volume 19, Issue 5, pp 410416.

Van Roeyen, S, Anderson, S Vanderplasschen, W, Colman, C, and Vander Laenen, F. (2017) Desistance in Drug-using Offenders: A Narrative Review. European Journal of Criminology, Volume 14, Number 5, pp 606-625.

Vitellone. N. (2010) Just Another Night in the Shooting Gallery? The Syringe, Space, and Affect, in Environment and Planning: Society and Space 2010, Volume 28, pp $867-880$.

Vitellone. N. (2013) The Empirical War on Drugs. International Journal of Drug Policy, Volume 24, Issue 3, pp 182-188.

Wallace, C. (2006) Menace or Moral Panic? Methamphetamine and the New Zealand Press. MA Thesis. Auckland University of Technology.

Waters, J, and Biernacki, P. (1989) Targeted Sampling: Options for the Study of Hidden Populations, in Social Problems, Volume 36, Number 4, October 1989. 
Waters. J (2015) Snowball Sampling: A Cautionary Tale Involving a Study of Older Drug Users. International Journal of Social Research Methodology, Volume 18, Number 4, pp 367-380.

Webb, M, Deitzer, J and Copes, H. (2017) Methamphetamine, Symbolic Boundaries, and Using Status. Deviant Behaviour, Volume 38, Issue 12, pp 1393 -1405.

Wilkins, C, Pledger, M, Lee, A, Adams, R and Rose, E. (2004) A Local Pilot of the New Zealand Arrestee Drug Abuse Monitoring System. SHORE. Massey University.

Wilkins, C, Girling, M, Sweetsur, P, and Butler, R. (2005) Methamphetamine and Other Illicit Drug Trends in New Zealand, Centre for Social and Health Outcomes Research and Evaluation, Massey University.

Wilkins, C, and Sweetsur, P. (2008) Trends in Population Drug Use in New Zealand: Findings from National Household Surveying of Drug Use in 1998, 2001, 2003, and 2006, in The New Zealand Medical Journal, Volume 121, Issue 1274, pp 61-71.

Wilkins C, Griffiths R, Sweetsur P. (2009) Recent Trends in Illegal Drug Use, Centre for Social and Health Outcomes Research and Evaluation, Massey University.

Wilkins C, and Sweetsur P. (2009) Tracking the Availability of Drugs in New Zealand: Implications for Policy Response. Social Policy Journal of New Zealand. Issue 34, pp 163171.

Wilkins C, and Sweetsur P. (2010) The Association Between Spending on Methamphetamine/Amphetamine and Cannabis for Personal Use and Earnings from Acquisitive Crime Among Police Detainees in New Zealand. Addiction, Volume 106, Issue 4, pp 789-797.

Wilkins. C, Sweetsur. P, and Griffiths, R. (2011) Recent Trends in Pharmaceutical Drug Use Among Frequent Injecting Drug Users, Frequent Methamphetamine Users and Frequent Ecstasy Users in New Zealand, 2006 - 2009. Drug and Alcohol Review, May, Volume 30, Issue 3, pp 255-263.

Wilkins C, Griffiths R, Smart, B, and Sweetsur P. (2011) Recent Trends in Illegal Drug Use in New Zealand 2006 - 2010, Centre for Social and Health Outcomes Research and Evaluation, Massey University. 
Wilkins, C, Prasad, J, Wong, K, Rychert, M. (2015) Recent Trends in Illegal Drug Use in New Zealand, 2006 -2014, Social and Health Outcomes Research and Evaluation, Massey University.

Williams, L, and Parker, H. (2001) Alcohol, Cannabis, Ecstasy and Cocaine: Drugs of Reasoned Choice Amongst Young Adult Recreational Drug Users in England. International Journal of Drug Policy, Volume 12, number 5, pp 397-413.

Williams. L. (2013) Changing Lives, Changing Drug Journeys: Drug Taking Decisions from Adolescence to Adulthood. Routledge. London.

Women's Strategy (2017 - 2021), Department of Corrections, downloaded from https://www.corrections.govt.nz/resources/newsletters and brochures/corrections works/2017/corrections works sept 2018/wahine e rere ana ki te pae hou wom ens strategy 2017-2021.html

Woodall, D, and Boeri, M. (2014) When You Got Friends in Low Places You Stay Low: Social Networks and Access to Resources for Female Methamphetamine Users in LowIncome Suburban Communities. Journal of Drug Issues, Vol 44, Issue 3, pp 321-339.

Worley, R, Worley, B and Wood, B. (2016) There Were Ethical Dilemmas All Day Long! Harrowing Tales of Ethnographic Researchers in Criminology and Criminal Justice. Criminal Justice Studies, Volume 29, Issue 4, pp 289-308.

World Health Organisation. (2000) Guide to Drug Abuse Epidemiology. Department of Mental Health and Substance Abuse Dependence Non-communicable Diseases and Mental Health Cluster, WHO.

World Health Organisation. (2010) Report on the Meeting on Indicators for Monitoring Alcohol, Drugs and other Psychoactive Substance Use, Substance-attributable Harm and Societal Responses. WHO, Valencia Spain, 19-21 October 2009.

Young. J. (2004) Voodoo Criminology and the Numbers Game, downloaded from http://www.malcolmread.co.uk/JockYoung/

Zabransky. T. (2007) Methamphetamine in the Czech Republic. Journal of Drug Issues, Volume 37, Issue one, pp 155-180.

Zander. B. (2002) Speed Freaks. The New Zealand Listener. April 6 - 12. 
Zinberg. N. (1984) Drug, Set, and Setting. The Basis for Controlled Intoxicant Use. Yale University Press, downloaded from http://druglibrary.eu/library/books/zinberg2.pdf 
Appendix A.

TE WHARE WĀNANGA O TE ÜPOKO O TE IKA A MĀUI
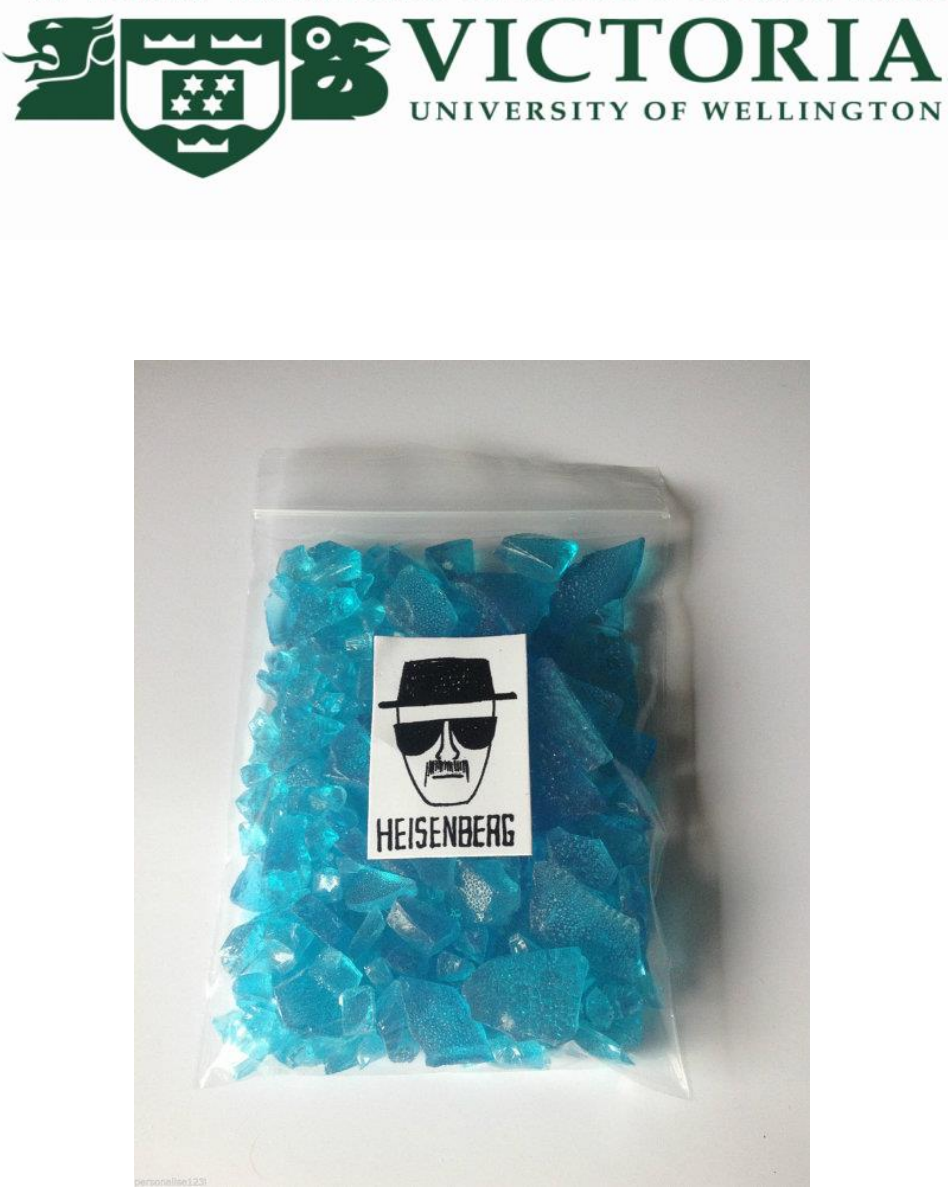

Are you interested in telling your story about using methamphetamine?

My name is John and I am a PhD student at Victoria University. I am researching drug use and would like to talk with current or recent methamphetamine users about using methamphetamine.

All research participants will receive a \$20 New World voucher. If you would like to tell me your story in confidence, please text Meth to 0225634704

John Dance, PhD Candidate. Supervisor, Dr Fiona Hutton, Senior Lecturer, Victoria University, Wellington. Ethics Approval Number 19235 


\section{Appendix B.}

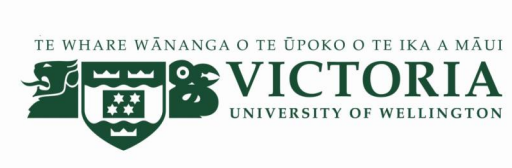

\section{Narratives of Methamphetamine Use Project: consent form}

I understand and have had explained to me the reasons for this research project and I have had a chance to raise any concerns I might have and to have my questions about the research answered clearly. I understand that

- With my permission, the researcher will record my interview using a digital audio recorder

- I can instruct the researcher not to record my interview

- That I do not have to answer any question I feel uncomfortable with

- Any information I give is held in the strictest confidence and that I will not be named in any publication or other use of this material.

- The researcher will publish the material from this research in reports to funding bodies and in academic journals

- The researcher may use information from this project to present papers at academic conferences

- That the researcher may use this material at a later date to inform further research

- That I can stop participating at any time in the interview for any reason, and that I can withdraw from the study up to two months after my interview or prior to data analysis

- That the researcher will provide access to my transcript and a summary of the study's results

- To withdraw from this research project please contact John Dance on 4636886 / 0275736886 or e-mail john.dance@vuw.ac.nz by xxx xxx xxx

I agree to participate in this research

Signed Date.

John Dance PhD Candidate. Supervisor: Dr Fiona Hutton, Senior Lecturer, Institute of Criminology, Victoria University, Wellington (04 463 7649) 


\section{Appendix C.}

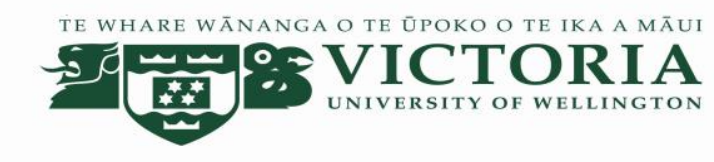

\section{'Narratives of Methamphetamine Use' Research Project}

Interview Participant Information Sheet

The aim of this project is to examine methamphetamine use among drug users by recording their drug using stories. Evaluations of these stories will be used to challenge methamphetamine and other drug using stereotypes, and to examine the discourse surrounding the use of methamphetamine and other forms of drug use in New Zealand.

This research will help with the production of more information in the future that aims to reduce the harms associated with methamphetamine and other forms of drug use.

By participating in an interview it is understood that you consent to take part in the research process. Interviews will be taped using a digital audio recorder. All participants have the right to instruct the researcher not to record their interview.

The information you give will be treated with the strictest confidence and you will not be named in any write up or report produced from these interviews. Under no circumstances will the information you provide will be shared with the police or any other government agency.

All written material will be kept in a locked file accessible only by the researcher in the researcher's office at Victoria University, Wellington. All electronic information will be kept in a password protected file accessible only by the researcher on the researcher's private office computer. All written and electronic information will be destroyed 2 years after the conclusion of this research. Any audio recordings or written transcripts will be returned to participants, or destroyed upon request.

The information that you give will be used to fulfil the requirements of a PhD thesis, and later, in academic conference papers, reports and journal articles.

This project was approved by the university ethics committee on 23 May 2012 (Ref. No 19235). If you have any questions about the interviews or the research in general please contact John Dance, PhD candidate in Criminology either by e-mail; john.dance@vuw.ac.nz or by phone W. 044636886 M. 027573 6886. 


\section{Appendix D. Research participants}

\begin{tabular}{|c|c|c|c|c|c|c|c|c|}
\hline No & Pseudonym & Age & Gender & Children & Ethnicity & Recruitment & $\begin{array}{c}\text { Gang } \\
\text { affiliations }\end{array}$ & $\begin{array}{c}\text { Drugs identified as } \\
\text { causing experiences of } \\
\text { harm }\end{array}$ \\
\hline 1 & Will & 21 & Male & No & European & Poster & No & $\begin{array}{c}\text { Cannabis, } \\
\text { Methamphetamine } \\
\text { and Benzodiazepines }\end{array}$ \\
\hline 2 & Tania & 21 & Female & No & Māori & Bridge & Yes & Methamphetamine \\
\hline 3 & Moana & 25 & Female & No & Māori & Poster & No & Methamphetamine \\
\hline 4 & Ben & 31 & Male & Yes & Māori & Bridge & No & $\begin{array}{c}\text { Cannabis and } \\
\text { Methamphetamine }\end{array}$ \\
\hline 5 & Charlie & 22 & Male & No & European & $\begin{array}{l}\text { Referred by } \\
\text { friend }\end{array}$ & No & $\begin{array}{c}\text { Datura, Cannabis BZP, } \\
\text { Morning glory seeds }\end{array}$ \\
\hline 6 & Steve & 33 & Male & No & European & Poster & No & $\begin{array}{c}\text { Cannabis and } \\
\text { Methamphetamine }\end{array}$ \\
\hline 7 & Angus & 33 & Male & Yes & European & Bridge & Yes & $\begin{array}{c}\text { Methamphetamine } \\
\text { and Alcohol }\end{array}$ \\
\hline 8 & Rayleen & 33 & Female & Yes & Māori & Poster & Yes & $\begin{array}{l}\text { Alcohol, } \\
\text { Methamphetamine, } \\
\text { and Benzodiazepines }\end{array}$ \\
\hline 9 & Amy & 33 & Female & Yes & Māori & Bridge & Yes & $\begin{array}{l}\text { Methamphetamine, } \\
\text { Cannabis and alcohol }\end{array}$ \\
\hline 10 & Rebecca & 23 & Female & Yes & European & Bridge & No & $\begin{array}{l}\text { Methamphetamine, } \\
\text { alcohol, Morphine, } \\
\text { Ritalin }\end{array}$ \\
\hline 11 & Sean & 33 & Male & Yes & European & Bridge & No & Methamphetamine \\
\hline 12 & Jess & 25 & Female & No & European & Poster & No & Cannabis \\
\hline 13 & John & 39 & Male & Yes & European & Poster & No & $\begin{array}{l}\text { IDU of Opiates and } \\
\text { Methamphetamine }\end{array}$ \\
\hline 14 & Terry & 40 & Male & Yes & Māori & Bridge & Yes & $\begin{array}{c}\text { Cannabis and } \\
\text { Methamphetamine }\end{array}$ \\
\hline 15 & Debbie & 26 & Female & & European & Bridge & Yes & Methamphetamine \\
\hline 16 & Mathew & 18 & Male & & Māori & Poster & No & $\begin{array}{l}\text { Cannabis, 'synthetic } \\
\text { Cannabis'. } \\
\text { Methamphetamine }\end{array}$ \\
\hline 17 & Kiri & 50 & Female & & European & Poster & Yes & Methamphetamine \\
\hline
\end{tabular}




\section{Appendix E.}

The substances participants identified as using. Each participant identified having used, or frequently using, five or more licit and illicit drug types, including methamphetamine in the course of their drug-using trajectories:

\begin{tabular}{|c|c|}
\hline Alcohol & Magic Mushrooms \\
\hline Amphetamine- Sulphate & Mephedrone \\
\hline Anti-depressants (no brand reference) & Mescaline (Cactus) \\
\hline Benzodiazepines (unspecified) & Methamphetamine \\
\hline BZP (definition page 11) & Methamphetamine - Hydrochloride (Ice) \\
\hline Cannabis (resin and plant) & Methylphenidate (Ritalin) \\
\hline Clonazepam & Morning Glory seeds \\
\hline Cocaine & Morphine \\
\hline Crack Cocaine & Nicotine \\
\hline Diazepam (Valium) & Nitrous Oxide (NOS) \\
\hline Datura (definition page 124) & Poppy Seed Tea \\
\hline Dextromethorphan & Salvia (definition page 116) \\
\hline Ecstasy-(3,4-methylenedioxy- & 'Synthetic' Cannabis (definition page 189) \\
\hline methamphetamine or MDMA) & TMFF (definition page 11) \\
\hline Heroin & Tramadol \\
\hline Lorazepam & Zopiclone \\
\hline LSD & \\
\hline
\end{tabular}


